Adrián R. Vila

Directores: Cordón García, José Antonio/ Gómez Díaz, Raquel
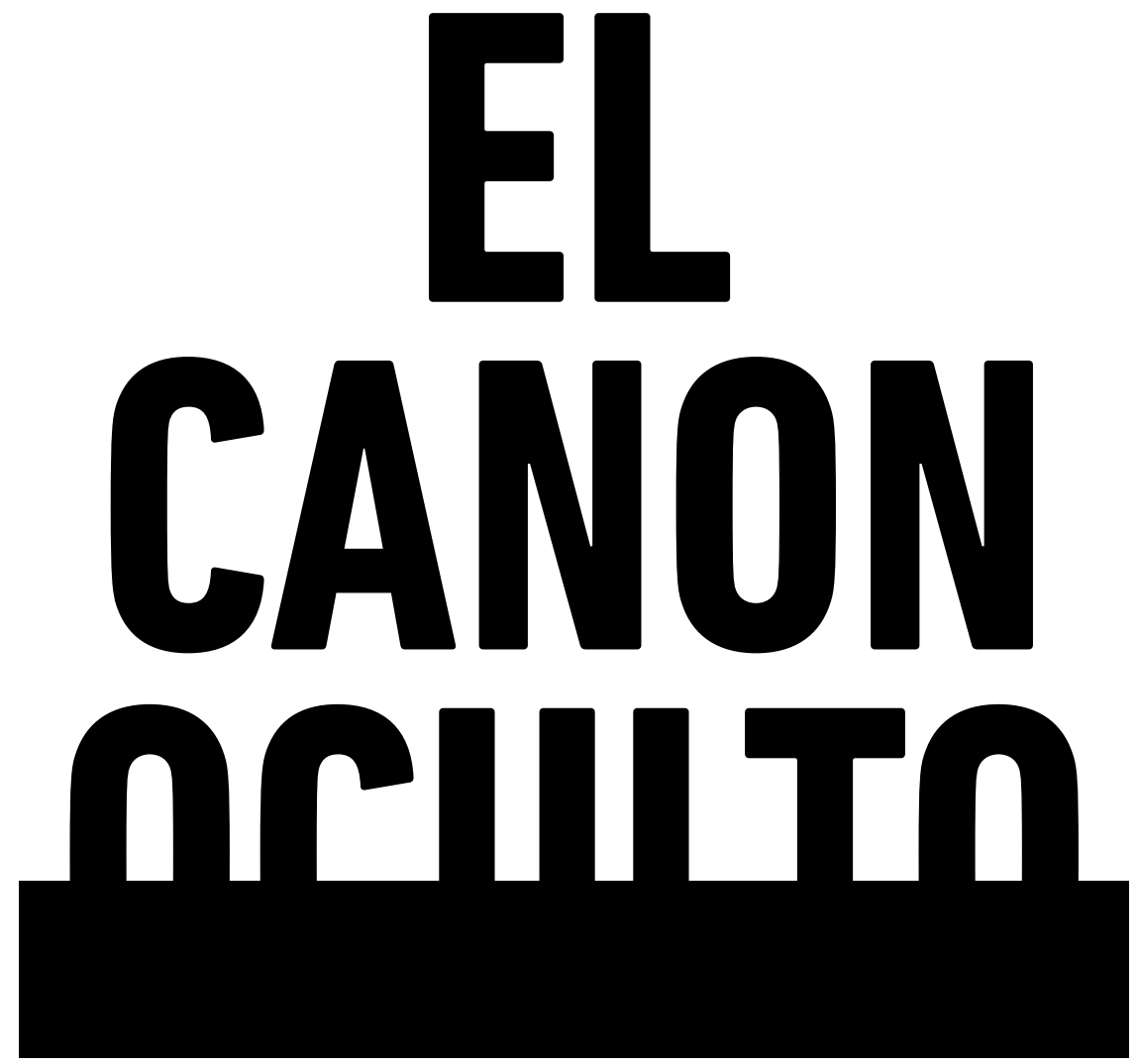

\title{
La literatura de América Latina y el Caribe en la transposición al ecosistema digital
}

Tesis doctoral

Salamanca, 2015 
Mi especial agradecimiento a los Dres. Raquel Gómez Díaz y José Antonio Cordón García por su sabia orientación, seguimiento y supervisión sincera en la realización de esta Tesis.

A la Magister Gloria Lynch de la Universidad Nacional de Luján (Argentina) por las recomendaciones metodológicas relacionadas con el aparato crítico de esta Tesis.

Destaco, asimismo, mi agradecimiento a los Dres. Isabel Huizi y Gianni Vattimo y a los profesores Ariel Schettini, Cristina Civale y Eugenia Corvalán por su aporte desinteresado y la utilización de sus horas académicas para la dilucidación de temas teóricos ligados a las nociones de gusto y arte latinoamericano de esta Tesis. A la Profesora Silvia Toloza por su aporte en relación con el canon literario educativo latinoamericano. Y al Lic. Julio Alonso Arévalo por sus aportes relativos a la relación entre bibliotecas y ecosistema digital.

Especial reconocimiento a los doctores Flavia Freidenberg, Fernando Pedrosa, Andrés Malamud, Diego Martínez y Guillermo Mira Delli-Zotti por su contribución relacionada con los temas ligados a los procesos estatales, identitarios, políticos y geopolíticos de las categorizaciones relativas a América Latina y el Caribe.

Mi gratitud con la Dra. Bibiana Andreucci de la Universidad de Luján y su equipo del Instituto Superior Docente $\mathrm{N}^{\circ} 6$ de Chivilcoy por su apoyo a las actividades relacionadas con esta investigación.

Al Lic. Nicolás Javaloyes (Universidad de Buenos Aires - Universidad del Museo Social Argentino) por sus observaciones y correcciones sobre el campo teórico de la actividad artística.

Al DG Juan Cruz Gonella (Universidad de Buenos Aires) por su colaboración en la construcción y diseño de esta Tesis.

$\mathrm{Al}$ analista de sistemas Nehuén Prados, de la Universidad Nacional de Luján (Argentina) por su aporte en términos de resolución de temas informáticos ligados a esta Tesis, y, asimismo, a Cristian Páez por su colaboración en la indagación de las bases de datos más importantes del campo cultural. 
A mis compañeros de militancia de los 80, aquellos de M.T. de Alvear y Uriburu. 


\section{Título}

El canon oculto. La literatura de América Latina y el Caribe en la transposición al ecosistema digital

\section{Autor}

Vila, Adrián R.

\section{Director / Tutor}

Cordón García, José Antonio / Gómez Díaz, Raquel

\section{Departamento}

Universidad de Salamanca (España). Programa de Doctorado en Formación en la Sociedad del Conocimiento. Fecha: 2015

\section{Palabras clave}

Canon literario, Harold Bloom, transposición de literatura, libros electrónicos, soportes tradicionales, literatura latinoamericana, plataformas de comercialización, bibliotecas digitales.

\section{Keywords}

Literary canon, Harold Bloom, transposition of literature, ebooks, paper work, Latin-American literature, sales platforms, digital libraries.

\section{Clasificación UNESCO 5701.06}

\section{Fecha}

2015-06-04 


\section{Resumen}

El presente trabajo tiene como objeto de estudio la acción de la industria editorial en digital en el marco de la transposición a formato digital de los títulos de un corpus literario latinoamericano y caribeño que incluye a los autores que Harold Bloom marca como segmento latinoamericano del canon occidental y los aportados por las teorías críticas feministas, queer, poscoloniales / decoloniales. Se analizan las principales plataformas de venta de ebooks y las principales bibliotecas digitales y se comparan en ellas las ofertas de dichos títulos y autores en soporte papel y en formato digital.

\section{Abstract}

This paper aims to study the action of the digital publishing industry in the context of the transposition into digital format of the titles of a Latin American and Caribbean literary corpus which includes authors such as Harold Bloom brand Latin American segment of the Western canon, and those provided by theories produced by feminist criticism, queer, postcolonial / decolonial in the context of the action of digital publishing industry. This study aims to analyze the main sales platforms of ebooks and the main digital libraries in order to compare the offers of these titles and authors on paper and digital formats. 
«Padre, no te espantes pues todavía estamos nepantla».

(Fray Diego Durán, Historia de las Indias de Nueva España,1581 
1. Justificación. Objetivos. Metodología. Estructura

1.1. Justificación

1.2. Objetivos

1.3. Metodología

1.4. Estructura

p. 77

2. La literatura latinoamericana y caribeña: canon y corpus propuesto

2.1. América Latina; América Latina y el Caribe; Literatura

latinoamericana y caribeña. Algunos conceptos

2.2. Canon y corpus

p. 95

3. De la galaxia Gutenberg al ecosistema digital

3.1. La galaxia Gutenberg

3.1.1. Las editoriales cartoneras: una dispositividad material latinoamericana 
3.2.2. La vía judicial: intervención de los Estados para

la regulación del ecosistema digital

p. 139

3.2.3. Edición digital: mercados de interés

3.2.4. Aspectos destacados del panorama internacional

de la edición digital ….................................................................... p. 160

3.2.5. Análisis de la transición de galaxia Gutenberg al

ecosistema digital

3.2.6. Autopublicación y lectura social

p. 171

3.2.7. Redes sociales temáticas

3.2.8. Plataformas de lectura en línea p. 179

3.3. Estrategias de la industria editorial para la transposición

a digital en el marco de la globalización

3.4. Bibliotecas y ecosistema digital p. 186

4. Transposición de impresos a digital de los títulos del corpus literario latinoamericano y caribeño construido. Tablas y análisis de resultados.

4.1. Análisis de tablas p. 194

4.1.1. Búsquedas en soporte impreso p. 197

4.1.2. Búsquedas en soporte digital p. 198

4.1.3. Los 50 títulos que más aparecen en impreso p. 200
4.1.4. Los 50 títulos que más aparecen en digital: el canon oculto

4.1.5. Los primeros 50 autores que aparecen en impreso

4.1.6. Un recorte más amplio. Un análisis de la disposición en soporte digital sobre los 193 títulos que más aparecen (de 7 a 11 veces sobre 13 plataformas) sobre los resultados en

las búsquedas en plataformas comerciales internacionales y servicios de intercambio de documentos

4.1.6.1. Un análisis de la disposición en soporte digital sobre los 19 títulos que más aparecen (de 4 a 5 veces sobre 8 bibliotecas) sobre los resultados

en las búsquedas en bibliotecas

\subsubsection{Los primeros 50 autores que aparecen} en digital

4.1.8. Los primeros 50 títulos que aparecen en plataformas latinoamericanas

(ambos soportes)

4.1.9. Los primeros 50 títulos que aparecen en bibliotecas latinoamericanas

(ambos soportes)

4.1.10. Resultados destacados de las búsquedas por segmento del corpus literario latinoamericano y caribeño

4.2. Algunos aspectos destacables de los resultados de las búsquedas 
5.1. Conclusiones relacionadas con el corpus literario

latinoamericano y caribeño propuesto para las búsquedas

en plataformas comerciales y bibliotecas

5.2. Conclusiones relacionadas con transposición a digital de literatura latinoamericana y caribeña en

plataformas comerciales y en bibliotecas

5.3. Conclusiones relacionadas con el ingreso de criterios

de gusto en la construcción de la oferta en digital

de literatura latinoamericana y caribeña

6. Líneas de trabajo a futuro

7. Bibliografía

7.1. Entrevistas

Primera entrevista: Dra. Flavia Freidenberg

Segunda entrevista: Lic. Ariel Schettini

p. 315

Tercera entrevista: Lic. Cristina Civale

Cuarta entrevista: Dr. Gianni Vattimo

Quinta entrevista: Dr. Andrés Malamud

p. 318

Sexta entrevista: Dra. Isabel Huizi Castillo

Séptima entrevista: Lic. Eugenia Corvalán

p. 320
8.1. Tabla general de comparación de ofertas en papel en plataformas comerciales y servicios de lectura en streaming y descarga de los títulos y autores del corpus literario latinoamericano diseñado. Amazon - Barnes \& Noble - Google Books - iBookstore I iTunes - Kobo - Free-Ebooks - Casa del Libro

- Gandhi - Librería Santa Fe - Livraria Cultura -

Perubookstore.com - Scribd - Nubico

8.2. Tabla general de comparación de ofertas en papel en bibliotecas globales de los títulos y autores del

corpus literario latinoamericano diseñado

Columbia University Libraries - Biblioteca del Instituto Latinoamericano de Berlín - Biblioteca Nacional de España - Public Library New York - Gallica (Biblioteca Nacional de Francia) - Europeana (Biblioteca digital de la Unión Europea) - Biblioteca Nacional de Perú Biblioteca de São Paulo

8.3. Tabla general de comparación de ofertas en digital en plataformas comerciales y servicios de lectura en streaming y descarga de los títulos y autores del

corpus literario latinoamericano diseñado

Amazon - Barnes \& Noble - Google Books - iBookstore /

iTunes - Kobo - Free-Ebooks - Casa del Libro - Gandhi -

Librería Santa Fe - Livraria Cultura - Perubookstore.com

- Scribd - Nubico

8.4. Tabla general de comparación de ofertas en digital en bibliotecas globales de los títulos y autores del corpus literario latinoamericano diseñado

Columbia University Libraries - Biblioteca del Instituto Latinoamericano de Berlín - Biblioteca Nacional de España - Public Library New York - Gallica (Biblioteca Nacional de Francia) - Europeana (Biblioteca digital de la Unión Europea) - Biblioteca Nacional de Perú -

Biblioteca de São Paulo 
9. Corpus literario latinoamericano y caribeño diseñado para esta Tesis,

en tomo 2 en tomo 3.
ÍNDICE DE FIGURAS

Figura 2. Esquema de la estructura del corpus literario

latinoamericano y caribeño elaborado

Figura 3. Campo general de la información y la comunicación p. 110

Figura 4. Cadena del libro tradicional p. 111

Figura 5. Cadena de las editoriales cartoneras latinoamericanas

Figura 6. Esquema del flujo de interacciones en torno a la

literatura latinoamericana y caribeña y los lectores. Industria editorial en digital, editoriales cartoneras, bibliotecas, redes sociales y crítica especializada

Figura 7. Estructura del ecosistema digital

Figura 8. Las 50 empresas más inteligentes en 2014 , según

MIT Technology Review

Figura 9. Interacción de contenidos, formas/dispositivos y distribución en el ecosistema digital con los correspondientes actores (marcas) predominantes

Figura 10. Infografía del modelo económico del libro impreso y del libro digital

Figura 11. Modelo editorial analógico y modelo editorial digital: agentes 
Figura 12. Mapa de las redes sociales: temáticas. Redes especializadas en literatura

Figura 14. Plataformas de lectura en línea

Figura 15. Estrategias decisionales combinadas de la industria editorial en digital en relación con la literatura latinoamericana

y caribeña para la construcción del catálogo en digital

Figura 16. Publicidad de Amazon para su plataforma Kindle y de iBooks para la tienda de contenidos iTunes de Apple

Figura 17. Proceso PDA (Patron Drivens Adquisitions) Genérico

Figura 18. Estrategias de adquisición de libros digitales en bibliotecas

Figura 19. Cadena del libro digital

Figura 20. Cartoneras en digital

Figura 21. Composición de la oferta en digital

Figura 22. Esquema de autores y categorías de formas literarias

latinoamericanas y caribeñas que componen el canon oculto

Figura 23. Estrategias relacionadas con el gusto en el marco de las estrategias de adquisición de libros digitales en bibliotecas y estrategias decisionales de la industria editorial

Figura 24. Del corpus impreso al corpus digital
Tabla 1. Síntesis de la composición del CLLyC: cantidad de títulos y autores por segmento

Tabla 2. Cuota de mercado estimada de venta de libros online y en Amazon y plataformas locales de impresos y ebooks en los cinco grandes grupos globales de la edición "tradicional"

Tabla 3. Los ingresos de los diez principales grupos editoriales en millones de euros, 2010-2013

Tabla 4. Cuota de mercado de ebooks (según varias fuentes)

en mercados seleccionados

Tabla 5. Cuota de mercado estimada de venta de libros en línea y en Amazon y en plataformas locales. Impresos y ebooks. en mercados elegidos

Tabla 6. Tamaño del mercado y producción de nuevos títulos en los 23 mayores mercados editoriales del mundo

Tabla 7. Mercado de libros EE.UU.: 2010-2011

Tabla 8. Mercado de libros China

Tabla 9. Mercado de libros Alemania

Tabla 10. Mercado de libros Reino Unido

Tabla 11. Mercado de libros Francia

Tabla 12. Mercado de libros España 
Tabla 14. Mercado de libros Suecia

Tabla 15. Mercado de libros Dinamarca

Tabla 20. Evolución de los títulos registrados en ISBAN, según soporte en América Latina 2005-2011

Tabla 21. Comparación de resultados de las ofertas en papel I digital de los títulos y autores del CLLyC por plataforma y biblioteca

Tabla 22. Síntesis de los resultados de las búsquedas de los títulos de los autores del CLLyC

Tabla 23. Los 50 títulos del corpus que más aparecen en soporte impreso

Tabla 24. Los 50 títulos del corpus que más aparecen en soporte digital
Tabla 26. Los 193 títulos que más aparecen en ofertas en digital en plataformas comerciales y servicios de lectura en streaming y descarga de los títulos y autores del CLLyC.

Amazon - Barnes \& Noble - Google Books - iBookstore / iTunes - Kobo - Free-Ebooks - Casa del Libro - Gandhi - Librería Santa Fe - Livraria Cultura - Perubookstore.com - Scribd Nubico

Tabla 27. Los 18 títulos que más aparecen en ofertas en digital en bibliotecas de los títulos y autores del CLLyC

Tabla 28. Los 50 autores del corpus que más aparecen en soporte digital

Tabla 29. Los primeros 50 títulos que aparecen en plataformas comerciales latinoamericanas (ambos soportes): Gandhi Librería Santa Fe - Livraria Cultura - Perubookstore.com

Tabla 30. Los primeros 50 títulos que aparecen en bibliotecas latinoamericanas (ambos soportes): Biblioteca Nacional de Perú Biblioteca de São Paulo 
INTRODUCCIÓN

Una parte importante de la discusión contemporánea sobre la existencia de un canon literario pasa por la reivindicación y, mayoritariamente, la crítica al ensayo de Harold Bloom El canon occidental (1995). Ese canon sería la expresión concreta de la necesidad de aplicar criterios de restricción en la construcción de un repertorio limitado, abarcable, a mano del individuo "que todavía desea leer en este momento de la historia" (1995: 25), ante la imposibilidad de leerlo todo. El lugar del canon literario es "el teatro de la memoria" y las grandes obras de la literatura son lugares en ese recinto (1995: 39). El canon, concebido de esa manera, es el arte de la memoria literaria que pretende limitar lo inconmensurable (1995: 50) y, a la vez, se constituye en caja de herramientas para un lector individual que lo necesita. Con esos criterios, Bloom se aboca a la tarea de seleccionar esa lista, compuesta por autores que responden a los principios de sublimidad estética y naturaleza representativa, que se destacan por su extrañeza original y que pasarán a formar parte del corpus restringido a los autores representantes de todo el canon occidental (1995: 21).

A más de 20 años de la publicación original (el trabajo de Bloom en inglés se publicó en 1994), la construcción del mencionado canon produjo sin solución de continuidad respuestas críticas a la empresa bloomiana desde las baterías propias teóricas de cada una de las escuelas y corrientes que el mencionado Bloom etiquetó como "Escuela del resentimiento".

Las primeras respuestas que podríamos denominar de orden moderno apuntaron a los propios componentes del canon: el juego de autores incluidos y excluidos, así como cuáles de sus obras ameritarían la composición canónica.

Luego, devinieron respuestas directas que apuntaron, más que a la composición, a las dimensiones ético-políticas de la propia existencia de un canon: ¿es necesario un canon? ¿no expresa la sola existencia de un canon un ocultamiento de las formas literarias y los autores que no lo componen?; el sesgo ideológico de la propia construcción canónica ¿no supone una concepción jerárquica de la literatura?

Así, el listado de objeciones que relevamos pasan desde la propuesta de alternativas como la detección de autores excluidos del seomento latinoamericano y caribeño del canon (compuesto por dieciocho autores y treinta y seis obras latinoamericanas y cinco autores y siete títulos caribeños) hasta a elaboración de definiciones del campo cultural centradas en el cuestionamiento a un canon uniforme (y construido por las élites culturales), promocionando formas culturales centradas en la diversidad y la diferencia que fueron descartadas para la elaboración de dicho segmento: 
a) La idea de este canon occidental fue rechazada por el predominio masculino ("patriarcal, machista") por parte de la crítica feminista. (Bolaño Sandoval, 2011: 25)

b) Una variación del rechazo mencionado anteriormente es la adjudicación al canon de Bloom de un criterio "heterocentrista" o, por lo menos, que no incluye "los libros más explícitamente relacionados con lo gay" (Woods, 2001: 21).

c) También fue rechazado por los críticos provenientes de los llamados cultural studies por la "jerarquización cultural" que deja de lado las prácticas socioculturales de las formaciones culturales subalternas. (Castañeda, 2009; Moraña, 2004; Beverley, 1996 y 2004; Schettini, 2014).

d) En una variación de los cultural studies, las críticas al canon realizado por Bloom de parte de teóricos de los estudios poscoloniales marcan que la jerarquización mencionada expresa criterios que consagran la producción cultural del llamado centro mundial (generalmente, europeos y norteamericanos) desplazando a los actores propios de las llamadas "culturas de la periferia o poscoloniales" (Serra: 124; Schettini, 2014; Corvalán, 2014; Mignolo, 1994-1995: 25).

El proceso colonial que tomó como objeto al Nuevo Mundo dejó de ser construido teóricamente "no como el descubrimiento de lo nuevo, sino como la integración operativa de lo disponible. La modernidad siempre supone inclusiones pragmáticas" (Antelo, 2009). América (Latina) se constituyó como un espacio de disputa por las formas de esa integración y los conceptos de esa disputa son "hispanoamericanismo", "iberoamericanismo", "panamericanismo" y "latinoamericanismo", en el marco de la ola globalizadora mundial. La noción de latinoamericanismo parece ser la perspectiva más acertada para un nuevo pensamiento sobre las culturas, las lenguas y las literaturas de esa entidad en construcción que es América Latina. Comprende al gigante de los emergentes latinoamericanos que es Brasil, así como desde mediados de la década del 80 se viene desarrollando un concepto de América Latina más amplio, el cual plantea la incorporación del Caribe a partir de la lenta incorporación de las literaturas de las zonas francohablantes. La inscripción de estas literatura sirvió como avanzada para la articulación entre la literatura latinoamericana y las literaturas del Caribe inglés y holandés, del papiamento, del papiamen (Surinam) en los términos en que se asumen en la literatura latinoamericana (Pizarro, 1987: 25).
Así, se desarrollaron dispositivos teóricos que relevan la historia común del Caribe insular articulada en rasgos económico-sociales similares como la "economía de plantación, trata de esclavos, historia de cimarronaje, cultura de resistencia, incomunicación entre las islas y luchas entre las metrópolis", entre otros rasgos (Pizarro, 1987: 25) y dispositivos teóricos que pesquisan las relaciones históricas comunes del Caribe con zonas de la región latinoamericana, las formas de desarrollo cultural similares y la literatura, por la evidencia de temas, problemas, y las formas estructurales de las literaturas caribeñas, antillanas y de las Guayanas. Los rasgos de similaridad en la organización de los sistemas literarios de América Latina y Caribe son expuestos por los trabajos de este tipo de dispositivos teóricos: existen sistemas literarios ligados a la metrópoli (Gran Bretaña, Holanda, Francia), otro sistema literario en creole, papiamento, papiamen, e inclusive, sistemas multilingües. Es decir que la estructura de los sistemas literarios del Caribe, Antillas y Guayanas se muestra organizada con la misma disociación de las estructuras lingüísticas heredadas de la metrópolis que en América Latina. Asimismo, la noción de identidad de América Latina ha ido incluyendo al Caribe a lo largo de las últimas décadas del siglo XX y de los años que corren en el siglo XXI, pertenencia expresada por otra parte, por "autorreconocimiento" de los países caribeños en diferentes organismos internacionales (Malamud, 2015).

Las acciones que parten de la crítica literaria abarcan desde la inclusión de autores, obras, géneros, perspectivas de abordaje a las obras hasta la exclusión de autores, obras, géneros y perspectivas de abordaje. Es decir, no podemos negar la influencia de la institución literaria en la imposición de criterios de "lo editable". Los editores intervienen en el campo intelectual conformando un campo que legitima lo escrito al publicarlo y distribuirlo socialmente; consagra autores al mismo tiempo que desecha a otros y habilita formas de lectura y niega otras (Bourdieu, 1999). Y es, en este punto, en el que la idea de un canon único ingresa en tensión con la acción de la industria editorial (en digital). Cuando hablamos de canon nos referimos tanto al catálogo de obras y autores que las instituciones literarias determinan como "literarios auténticamente" como al arte de la memoria literaria que pretende limitar lo inconmensurable (Bloom, 1995: 50) y, a su vez, caja de herramientas para el lector individual que lo necesita para ejercitar la lectura.

En el mencionado El canon occidental, Bloom introduce a dieciocho autores latinoamericanos y a cinco autores caribeños como parte de lo que llama "profecía canónica" de la "edad caótica" (siglo XX), "edad literaria" que destaca como etapa actual, conformada por aquellos autores que menciona como representantes de la modernidad. 
Autores y obras (en el orden que consta en El canon occidental):

- Rubén Darío (Antología poética)

- Jorge Luis Borges (El Aleph; El Hacedor, Ficciones; Ensayos completos; Antología personal)

- Alejo Carpentier (El siglo de las luces; Los pasos perdidos; El reino de este mundo; El recurso del método)

- Guillermo Cabrera Infante (Tres tristes tigres; La Habana para un infante difunto)

- Severo Sarduy (Maitreya)

- Reinaldo Arenas (El mundo alucinante)

- Pablo Neruda (Canto general; Residencia en la tierra; Veinte poemas de amor y una canción desesperada; Plenos poderes; Antología poética)

- Nicolás Guillén (Antología poética)

- Octavio Paz (Poesía completa; El laberinto de la soledad)

- César Vallejo (Antología poética; España, aparta de mi este cáliz)

- Miguel Ángel Asturias (Hombres de maíz)

- José Lezama Lima (Paradiso)

- José Donoso (El obsceno pájaro de la noche)

- Julio Cortázar (Rayuela; Todos los fuegos el fuego; Relatos escogidos

- Gabriel García Márquez (Cien años de soledad; El amor en los tiempos del cólera)

- Mario Vargas Llosa (La guerra del fin del mundo)

- Carlos Fuentes (Cambio de piel; Terra Nostra)

- Carlos Drummond de Andrade (Poemas)
Los autores (y obras) caribeños que incorpora Harold Bloom al canon occidental (Bloom los menciona como de Indias Occidentales, West Indians. Se coloca el título en el idioma original) son los siguientes:

- Cyril Lionel Robert (C.L.R.) James (The Black Facobins: Toussaint L'Ouverture and the San Domingo Revolution World Revolution 1917-1936; The Future In the Present)

- V. S. Naipaul (A Bend in the River; A House for Mr Biswas)

- Derek Walcott (Collected Poems)

- Michael Thelwell (The Harder They Come)

- Aimé Césaire (La Poésie)

$\mathrm{Al}$ destacar el recorte efectuado por el mencionado Bloom en el diseño de El canon occidental y atendiendo la perspectiva crítica a un canon uniforme (y construido por las élites culturales, se ha desarrollado un corpus de autores y obras (CLLyC) que ingresan desde otras "formas" de la literatura, desde otras perspectivas que se presentan como ampliación de la muestra de autores y títulos, y tomando como fuentes de autores y obras una heterogénea plataforma de repertorios, catálogos, enciclopedias, antologías, ensayos críticos, listas, que son disímiles y distantes entre sí como:

1. Los títulos y autores del mencionado El canon occidental, de Harold Bloom

\section{Del Diccionario de autores latinoamericanos realizado por César Aira}

\section{De La gran novela latinoamericana de Carlos Fuentes}

4. De Saraus. Movimiento - Literatura - Periferia - São Paulo. Antología, compilada por Lucía Tennina

5. De De la Tricolor a la Wiphala. Narrativa contemporánea de Bolivia, de Sergio Di Nucci, Nicolás Recoaro y Alfredo Grieco y Bavio (selección, edición y notas) 
6. De McOndo (una antología de nueva literatura hispanoamericana) de Alberto Fuguet y Alberto Gómez

7. De 1.000 millones: poesía en lengua española del siglo XXI, editada por Daniel Helder, Daiana Henderson y Bernardo Orge

8. De Bogotá39, una selección realizada por los escritores colombianos Piedad Bonnet, Héctor Abad Faciolince y Óscar Collazos

9. Del Manifiesto del Crack, de Pedro A. Palou; Eloy Urroz; Ignacio Padilla; Ricardo Chávez Castañeda y Jorge Volpi

10. De Los chongos de Roa Bastos. Narrativa contemporánea de Paraguay, selección y edición de Sergio Di Nucci, Nicolás Recoaro y Alfredo Grieco y Bavio

11. De Latin American Writers on Gay and Lesbian Themes: A BioCritical Sourcebook de David William Foster

12. Del catálogo de títulos de autores latinoamericanos y caribeños de la Base de datos de editoriales cartoneras de University of Wisconsin

13. De la sección del CLLyC conformada por títulos de escritores caribeños, antillanos y de las Guayanas

14. Del Diccionario de la literatura latinoamericana de Susana Cella

15. De una sección de literaturas precolombinas

16. De Encyclopedia of Latin American and Caribbean Literature 1900 $-2003$

17. De la sección del CLLyC conformada por títulos de escritoras relevado del repertorio Latin American Women Writers: An

Encyclopedia, editado por María André y Eva Bueno

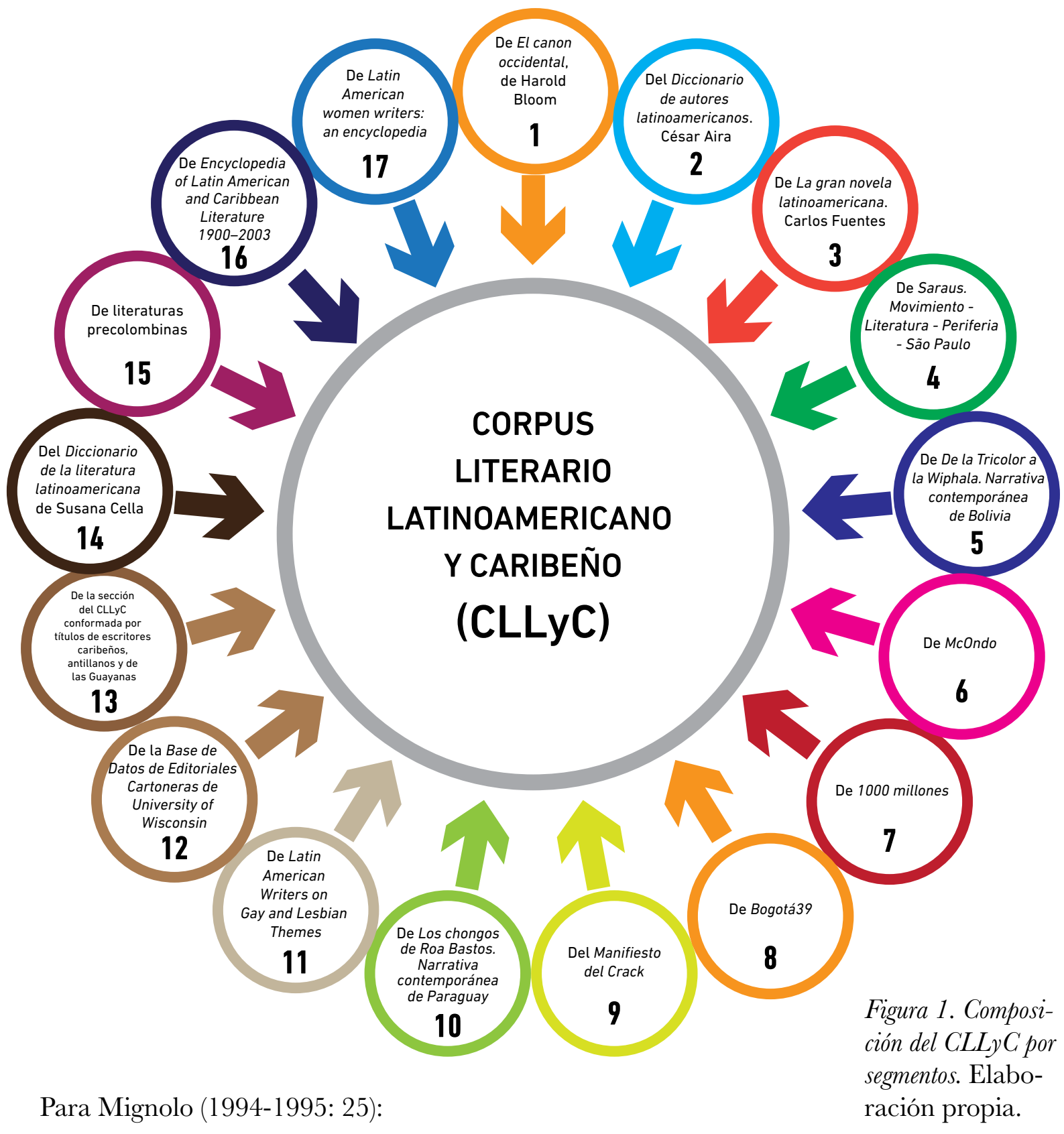

El campo de los estudios literarios se concibe más como un corpus heterogéneo de prácticas discursivas y artefactos culturales. El hecho de que alguna de ellas o de ellos adquiere estatuto canónico es parte de la complejidad de fuerzas sociales en conflicto pero de ninguna manera un fenómeno que naturalmente define el campo de estudio y determina lo que es necesario celebrar. Habría muchos otros aspectos que destacar, entre ellos la fuerte presencia de la escritura femenina, las tradiciones orales y los productos culturales híbridos de la colonia; todos los cuales ayudan a comprender la fuerza de un corpus que, en los estudios literarios, había quedado oculto por una noción de literatura que identificaba el canon con el campo de estudios y que tenía en las historias de la literatura la expresión de su autoridad. 
Siguiendo los "aspectos para destacar" que menciona Mignolo (19941995: 24), el corpus propuesto en este trabajo comprende tanto al segmento latinoamericano (y al segmento de West Indian) del canon de Bloom como a cánones alternativos o, más exactamente, a prácticas discursivas y culturales que incorporen la hibridez de la producción latinoamericana, la voces femeninas de su literatura, las voces de la producción precolonial, las literaturas periféricas y marginales, las heteroglosias que componen su campo cultural y literario, las formas bastardas de su literatura, las distintas maneras que tienen las voces subalternas de su literatura, las literaturas indígenas, las voces queer y feministas, las literaturas que se expresan en otras lenguas que no son el español y el portugués, las distintas formas de nepantlal o "estar en el medio". Con una estrategia de diseño general que exhiba la mayor cantidad posible de perspectivas sobre/desde la literatura latinoamericana y caribeña en el marco de procesos que reconocemos como ilimitados (las incorporaciones desde distintas perspectivas sobre la literatura latinoamericana y caribeña pueden tornarse infinitas).

Es decir que los criterios de incorporación al corpus elaborado cumplen (parcialmente) con la prescripción de los títulos del segmento latinoamericano del canon de Bloom (literatura del siglo XX), pero sumados a autore y obras propuestos por la crítica decolonial, corriente cuyo objeto teórico condiciona la selección al periodo precolonial y de "la Conquista" (siglos XVI y XVII), por las teorías queer, por el pensamiento feminista, por la dispositividad material de las ediciones cartoneras latinoamericanas, por las narrativas del boom, del postboom, de la "generación McOndo", por las narrativas de la marginalia paulista, por las narrativas de las hiperglosias de la región.

Si una acepción de la palabra "canon" hace centro en la deriva del árabe qanun (ley) para Said (2006: 44):

Este es solo un sentido bastante restrictivo. El otro es un sentido musical: el de canon entendido como una forma contrapuntística que se sirve de numerosas voces que se superponen según una pauta, por lo general, muy estricta. (...) Visto así, las humanidades canónicas, lejos de constituir tablas estrictas de norma y obras maestras inamovibles que nos intimidaran desde el pasado (...) estarán siempre abiertas a modificar sus combinaciones de sentido y significación

Said (1999) reformula la noción de canon al advertir sobre la concepción que la cultura occidental (anglófona) ha planteado en torno a otras cultura y sus mecanismos -siempre etnocéntricos- de construcción discursiva de identidades. Su lectura crítica y su apuesta metodológica recuperan una tradición que incluye lo occidental junto a otros archivos, a otras formas

"Nepantla" proviene del náhuatl hablada por olmecas, toltecas y nahuas, entre otros; significa 'en medio', estar entre dos mundos. Este vocablo fue utilizado por los indígenas al producirse la colonización española, al encontrarse entre esas dos culturas. narrativas y a otras temáticas, poéticas, autores. Así, el corpus diseñado para esta Tesis aporta 20.409 títulos diferentes de 2.932 autores diferentes. Lenguas de las obras: las distintas variedades del castellano y del portugués de América Latina, francés, inglés, neerlandés, guaraní, náhuatl, aymará, tomáraho, ashlushlay, ybytozo, toba quom, sanapaná, maká, axe-guayaki, ayoreo quiché, quiché, maya yucateca, chontal, cakchiquel, pokomchí, mam, zutuhil, patois, creole, jorapa, portuñol y heteroglosias entre las distintas lenguas.

Ahora bien, con el objetivo de relevar la transposición de estas obras a formato digital, se realizó la búsqueda de los mencionados títulos en dicho formato en las mayores plataformas multinacionales y en una serie de bibliotecas destacadas desde el punto de vista lingüístico y que sobresalen por prestaciones, arquitectura y disponibilidad digital. El proceso de expansión del libro digital es sostenido mundialmente, pero EE.UU. lidera el mercado por disponibilidad de títulos, por poseer un sistema de comercio electrónico desarrollado y por marcar la tendencia del negocio mundial. De ahí, la selección de las plataformas Amazon (representa el 70\% del mercado de libros electrónicos de EE.UU.) y sus competidoras Barnes \& Noble, Google Books, iBooks/Apple (Cordón García et al., 2011). La selección de FreeeBooks se debe a la necesidad de obtener muestras del estado de la oferta en digital de plataformas de descarga gratuitas. Asimismo, Scribd se presenta como un sistema novedoso de servicio de comercialización, intercambio de archivos y acceso a libros electrónicos por tarifa plana para suscriptores, al igual que Nubico. Livraria Cultura, Gandhi y Librería Santa Fe son plataformas destacadas en el comercio editorial latinoamericano. En el nivel de las bibliotecas, Public Library New York y Columbia University Libraries forman parte del grupo de las bibliotecas con mayor prestigio a nivel internacional por la calidad de los recursos que ofrecen. Disponen de múltiples recursos en soporte digital. La Biblioteca Nacional de España es la biblioteca más reconocida en el campo idiomático del castellano, asî como Gallica - Biblioteca Nacional de Francia es la biblioteca más reconocida internacionalmente en lengua francesa, ya que posee cerca de 900.000 libros, periódicos, manuscritos, mapas y dibujos digitalizados. Europeana es una biblioteca digital que posee casi cuatro millones de objetos digitales, incluidos libros impresos procedentes de más de 1.000 archivos en la Unión Europea. La Biblioteca del Instituto Latinoamericano de Berlín se seleccionó como biblioteca especializada en temas y autores y latinoamericanos. La Biblioteca Nacional de Perú y la Biblioteca de São Paulo forman parte del segmento de bibliotecas latinoamericanas con mayor reconocimiento, que disponen de colecciones en digital en oferta.

En síntesis, de un total de 20.409 títulos en el idioma original de las obras, propuestos por el corpus diseñado y buscados en las plataformas y bibliotecas mencionadas, se hallaron 15.032 títulos en algún soporte en alguna plataforma o biblioteca. En impreso, se encontraron 14.835 títulos y en digital 4.842. Es decir que de los títulos hallados del CLLyC elaborado 
se encuentran transpuestos a digital el 32,21\% de los títulos. Se destaca que 197 de los títulos hallados en digital solo están en ese formato, es decir que no aparecen como transpuestos de impreso a digital (pese a que en todos los casos son títulos no born-digital). En relación con los autores, se partió de un total de 2.932 autores que van desde la etapa precolombina hasta la actualidad, propuestos por el corpus literario latinoamericano y caribeño realizado para esta investigación. En cualquiera de los soportes se encontraron 2.491 autores en alguna plataforma o biblioteca, es decir, el 84,95\% de los autores propuestos por el CLLyC. En digital, se relevaron en las búsquedas 1.353 autores, el $46,14 \%$ del total. Solo aparecen en soporte digital catorce autores, el $0,47 \%$.

En digital, la plataforma que más títulos ofrece es la Web de intercambios Scribd. Esto ratifica que la participación del usuario en la oferta produce un incremento de las posibilidades de acceso: 1.718 títulos sobre 4.842 títulos hallados en digital, es decir, el 35,48\% de los títulos existentes en digital para las búsquedas efectuadas. Amazon ofrece 1.101 títulos, es decir, una oferta media en relación con el universo de búsquedas en digital (el $22,73 \%$ del total de los títulos en soporte digital hallados). Barnes \& Noble 600 títulos en digital $(12,39 \%)$. Se apunta que la oferta de literatura latinoamericana y caribeña en digital, en los idiomas originales de las obras, es muy baja por parte de la plataforma Kobo: 262 títulos (5,41\% de la oferta relevada). Casa del Libro y Nubico (ambas de España) forman parte de la "clase media" de la oferta de títulos de literatura latinoamericana y caribeña, en idiomas originales, en digital: 512 y 496 títulos, respectivamente, asi como los títulos disponibles en iBook Store de Apple: 368 títulos en digital. La oferta en digital de Google Books es baja: 143 títulos (menos del 3\%).

En relación con la oferta en bibliotecas, la que más títulos ofrece en soporte digital es la Biblioteca Nacional de España: 1.749 (el 36,12\% de la oferta disponible en digital). Luego la siguen la Biblioteca Europeana de la Unión Europea, con 582 títulos (12,01\%) y Columbia University Libraries con 572 títulos $(11,81 \%)$. La Biblioteca del Instituto Latinoamericano de Berlín dispone de 319 títulos (6,58\% del total). Se apunta la muy baja oferta en digital de la Public Library of New York y la Biblioteca Nacional de Francia-Gallica- con 23 y 21 títulos, respectivamente.

De las plataformas comerciales latinoamericanas, Livraria Cultura (Brasil) ofrece 1.035 títulos (21,37\% de los títulos hallados en el soporte), Gandhi (México) ofrece 617 títulos en digital (12,74\%) y LSF (Argentina) 336 títulos (6,93\%). Perubookstore ofrece 154 títulos en digital (3,18\%). De las bibliotecas latinoamericanas, la Biblioteca Nacional de Perú dispone de solo diez títulos en digital y la Biblioteca de São Paulo no ofrece ningún título del corpus diseñado a los efectos de esta investigación.

Destacamos que en el proceso de transposición/migración al formato digital, la industria actúa con criterios que escapan (o se oponen) a las es- trategias académicas de creación y sostenimiento de tradición en derredor de las obras canónicas. Quizá, las obras no deban tanto su presencia en los catálogos de las principales plataformas de ventas de libros digitales a los principios de circulación académica del orden tradicional como a las estrategias de lo que la industria considera "demanda real" de mercado (Cordón García, 2004: 23). La noción de una transposición automática de los títulos de la literatura latinoamericana a las distintas formas del digital se volvería inexacta, tanto en el contexto de nuevas formas de escritura, nuevas ideas de lo que es una obra y de lo que es autoría, así como de nuevos agentes y de nuevas formas de legitimación, ligadas también a la constitución de un "gusto global" en relación con la literatura latinoamericana que orienta la oferta bibliotecológica de autores y títulos pertenecientes al campo de esta literatura en el marco de un proceso transnacional de reconfiguración del negocio editorial. En este plano, hacemos extensivo al nivel de la oferta en soporte digital de los títulos del CLLyC diseñado el razonamiento de Pierre Bourdieu (1988: 228) sobre la relación entre campo de producción y gusto:

El campo de producción, que evidentemente no podría funcionar si no pudiera contar con unos gustos ya existentes, propensiones más o menos intensas para consumir unos bienes más o menos estrictamente definidos, es lo que permite al gusto realizarse, ofreciéndole, en cada momento, el universo de bienes culturales como sistema de posibles estilísticos entre los cuales puede seleccionar el sistema de los rasgos estilísticos constitutivos de un estilo de vida.

Si para el mencionado Bourdieu (1988: 228), "el universo de los productos ofrecidos por cada uno de los campos de producción tiende a limitar de hecho el universo de las formas de la experiencia (estética, ética, política, etc.) que son objetivamente posibles en un momento dado del tiempo", deberíamos destacar que en el desarrollo de esa limitación, aquellas propensiones resultantes constituyen también un recorte de la oferta que puede proyectarse tanto al nivel de la construcción del catálogo general de la literatura latinoamericana construido por transposición al digital de los títulos que circulan en soporte impreso. Esos "posibles estilísticos" también construyen parcialmente tanto la oferta de las plataformas comercializadoras como la oferta bibliotecológica en el marco de las estrategias adoptadas por los agentes implicados en ambos sectores. ${ }^{2}$

Terry Smith (2012: 327-328) destaca que una historia del arte contemporáneo no debería escatimar esfuerzos por establecer una línea cronológica, reconocer las herencias positivas y problemáticas del arte anterior, prestar atención al arte que se produce en todo el mundo, en su espacio local y en la circulación internacional y reconocer "tal vez por primera vez, que se trata del arte del mundo (es decir, no un arte universal con distintas manifestaciones locales, tampoco artes locales dependientes de la colonización o la globalización, sino artes generadas por la diversidad del 
mundo)". El arte actual, así, "está determinado de una forma más profunda por su situación dentro de la contemporaneidad" (2012: 21), es decir, un arte en y de la contemporaneidad, pero de una contemporaneidad global que también fue permeada por el llamado giro poscolonial que, de manera pedagógica, "generó la necesidad de relatos que funcionaran en el plano global, regional y local". En este nivel, también se subraya que la corriente ligada al boom de la literatura latinoamericana de la década del 60 se incorporó a la corriente principal de la literatura en castellano de manera anticipada a lo que describimos como inclusión al mainstream de las formas artísticas latinoamericanas y del Tercer Mundo con el llamado giro poscolonial.

Si cada campo posee formas de regular sus prácticas y representaciones que impone, también ofrece a los agentes que lo componen una "forma legítima de realización de sus deseos basada en una forma particular de illusio" (Bourdieu, 1995: 338). Esta illusio es una precondición y un resultado del juego social, es decir que "no es posible esquivarla por completo". Por ejemplo, el "crítico entra en el juego desde el preciso momento en que selecciona ciertas obras y las declara merecedoras de discusión pública” (Graw, 2013: 24). Acá también se nos presentan las figuras tanto del decisor en la estructura de las editoriales en relación con la transposición a obras a digital y la del bibliotecario encargado de construir su oferta de títulos en digital.

Para Roger Chartier (1995: 111), "los autores no escriben libros: escriben textos que luego se convierten en objetos impresos": el libro es el punto de convergencia de la batería de recursos que un sinnúmero de actores coloca a disposición del texto. En nuestro caso de estudio, podríamos hablar de la batería de recursos puestos a disposición de la industria de la edición digital en la transposición de las obras y autores de la literatura latinoamericana y caribeña. Todo esto, en el marco de tensiones entre, por un lado, gustos y concepciones globales que solamente podrían ser concebidos, pensados, "desde el centro" (Schettini, 2014) y, por el otro lado, formas de concebir la literatura de manera "antimoderna, antiglobal, provincial, subalterna" para las que "la literatura no es una ni es algo fijo ni algo que se pueda decidir, la literatura es un debate que está en la sociedad" y en la que ingresan formas literarias, de textualidad, de autoorganización que son propias de la periferia mundial latinoamericana y caribeña (Schettini, 2014; Mignolo, 1998). Destacaremos, entonces, que en la tensión entre el mantenimiento del corpu literario latinoamericano y caribeño que circula en impreso y la construcción del catálogo editorial digital, la transformación al nivel de los dispositivos materiales también ofrece recortes de la oferta literaria latinoamericana y caribeña y, a su vez, propone un canon oculto detrás de las estrategias de transposición a digital.

\section{JUSTIFICACIÓN. OBJETIVOS. METODOLOGÍA. ESTRUCTURA}

\subsection{Justificación}

El presente trabajo tiene como objeto de estudio la acción de la industria editorial en digital en el marco de la transposición a formato digital de los títulos de los autores que componen tanto el segmento latinoamericano y caribeño de El canon occidental de Harold Bloom como aquellos que son aportados por otras corrientes y teorías distantes/ en tensión con el mainstream literario (crítica feminista, estudios queer, cultural studies, cartonerismo editorial, y a los llamados estudios de la subalternidad y del giro poscolonial y decoloniales). Del colectivo de perspectivas críticas relevados, si bien se proponen diferentes lecturas a la lectura tradicional canónica bloomiana, no se concretan en un nuevo corpus exhaustivo sobre las mencionadas literaturas. O bien, cuando se los construye, el recorte para esa elaboración del corpus no incorpora segmentos que se constituyen en antagónicos, complementarios o aquellas prácticas discursivas y artefactos culturales que el propio recorte rechaza. Es decir que el proyecto de esta Tesis se articula alrededor de tres acciones:

1) La elaboración de un corpus literario latinoamericano y caribeño (GLLyC) que, además de recoger las perspectivas críticas acerca de la actividad canónica, se concrete como una propuesta que cubra las áreas de vacancia detectadas en las propuestas de los distintos segmentos literarios que lo componen o que los articule como segmentos complementarios.

2) El estudio de la localización de los autores y obras del propio CLLyC en plataformas y bibliotecas.

3) El estudio de la dilucidación de los mecanismos que construyen la transposición a digital de los títulos del CLLyC en el nivel de la oferta en plataformas y bibliotecas.

Asimismo, si Alonso Arévalo y Cordón García (2014: 19) destacan la necesidad de que "los datos estadísticos relativos al uso del libro electrónico en las bibliotecas deberían ser compartidos entre editores y bibliotecas para desarrollar un análisis común de sus usos", tenemos la expectativa de que este trabajo se articule con una relativa importancia práctica para la industria editorial, habida cuenta de que se presentan resultados de áreas de vacancia del catálogo general de la edición literaria latinoamericana y caribeña en digital tanto a escala internacional como a escala 
de los países de la región latinoamericana y caribeña. Además, proponemos los resultados de esta tesis como un relevamiento necesario para la oferta bibliotecológica en digital de aquellos títulos y autores que no están a disposición del público lector de los países y zonas comprendidas.

\subsection{Objetivos}

El presente trabajo tiene como objeto de estudio la acción de la industria editorial en digital en el marco de la transposición a formato digital de los títulos de los autores que componen un corpus de literatura latinoamericana y caribeña (CLLyC) diseñado para esta investigación. Comprende tanto al segmento de El canon occidental de Harold Bloom como aquellos autores y obras que son aportados por otras corrientes y teorías distantes/en tensión con el mainstream literario.

Las estrategias de la industria editorial ingresan en tensión con la idea central de Harold Bloom, quien destaca la configuración de un canon literario sin intervenciones ajenas a la acción de la crítica especializada. Es decir que en este plano de análisis la industria editorial en digital ofrece una batería de recursos que ingresan en tensión con esa "asepsia académica". Ofrece como resultado un recorte tanto del canon latinoamericano como del CLLyC construido con un criterio de amplitud que contenga expresiones de la literatura latinoamericana y caribeña no canónicas, en el marco de la transposición de sus títulos a formato digital.

Con la concreción de esta investigación se pretende como objetivo general describir el estado de la transposición a soporte digital de literatura editada en impreso y en las lenguas en las que se ofrece la literatura latinoamericana y caribeña, con especial atención a la oferta de las principales plataformas comercializadoras y bibliotecas digitales a nivel internacional y en bibliotecas y plataformas comercializadoras en digital de los países de la región. Además, se establecerán las diferencias de ofertas entre ellas al nivel de los títulos del CLLyC construido tomando como fundamento metodológico a los componentes del segmento latinoamericano del canon occidental de Bloom, sumados a aquellos autores y títulos relevados en distintos repertorios, catálogos y obras críticas, diccionarios, historias y antología de literatura latinoamericana y que pueden incorporarse al CLLyC desde una perspectiva teórica que comprende a la crítica feminista, los estudios queer, los cultural studies, a los llamados estudios de la subalternidad y del giro poscolonial.

Además, se detallarán las principales plataformas que comercializan libros en soporte digital y las principales bibliotecas que ofrecen títulos de literatura latinoamericana y caribeña, con la idea de establecer la diferencia de ofertas entre ellas de los títulos de autores latinoamericanos y caribeños del CLLyC construido. 


\subsection{Metodología}

La metodología del trabajo es la articulada con la guía y recomendación de los doctores José Antonio Cordón García y Raquel Gómez Díaz, desde el momento de inicio del trabajo hasta su concreción.

Tomando en cuenta los Objetivos (Ver 1.2. Objetivos) se recurrió a un diseño que combinara distintas estrategias de investigación: descriptiva, cuantitativa y cualitativa. Se recurrió a una técnica cuantitativa consistente en el desarrollo de búsquedas en plataformas comercializadoras y bibliotecas, y se apeló a una técnica cualitativa consistente en el relevamiento bibliográfico y teórico y la realización de entrevistas a informantes clave y bibliotecarios.

Para el desarrollo de la metodología se han seguido los pasos que se muestran en el siguiente esquema y que a continuación se explican:

\section{Fundamentación teórica}

- Revisión de autores y temas que han tratado el tema del canon de Bloom

- Revisión de autores y temas que han tratado la noción de corpus literario

- Delimitación conceptual de:

- América Latina

- Caribe

- América Latina y el Caribe

- Canon

- Corpus

- Galaxia Gutenberg

- Ecosistema digital

- Gusto 
- Entrevistas a especialistas para la definición y ampliación de conceptos

- Definición de plataformas comerciales y bibliotecas en donde se realizarán las búsquedas

\section{Diseño de un corpus literario latinoamericano y caribeño (CLLyC)}

\section{Búsqueda en soporte impreso y en digital de los títulos y autores} del corpus en las plataformas comerciales y bibliotecas definidas y

recolección de datos.

- Cruce de datos de las búsquedas en plataformas y en bibliotecas para la localización de coincidencias

- Identificación de las obras y autores pertenecientes al corpus que han sido traspuestas al entorno digital

- Creación de tablas con los datos recolectados

\section{Análisis de la información}

\section{Conclusiones}

\section{Fundamentación teórica}

Para desarrollar la investigación, se hacen imprescindibles las siguientes operaciones:

A) La dilucidación terminológica y conceptual que delimite definiciones y términos tales como:

- Canon / Corpus

- Hispanoamérica / Iberoamérica / América Latina / Panamérica / Indoamérica / Caribe / América Latina y el Caribe

- Literatura latinoamericana / Literatura latinoamericana y caribeña

- Galaxia Gutenberg / Ecosistema digital

- Gusto

B) La revisión bibliográfica que permita concretar lo expuesto en a) de esta fundamentación teórica:

Estudiar el canon de Bloom (1995) y la batería teórica que lo analiza:

- La noción de canon como catálogo de obras y autores que las instituciones literarias determinan como "literarios auténticamente" y como arte de la memoria literaria que pretende limitar lo inconmensurable fue trabajada desde Bloom (1995).

- El abordaje a los mecanismos de selección de las obras para la construcción del canon se realizó desde Pozuelo Yvancos y Aradra (2000); Mignolo (1994-1995, 1998); Lotman (1998); Serra (2012).

Relevar y estudiar las perspectivas críticas que ingresan en tensión con el mencionado canon de Bloom (1995).

- Desde perspectivas de género: de Mizraje (2003) se tomó la noción de teoría de género que permite "pensar todo" y "releer todo" y la recuperación de lo realizado por mujeres del pasado en los distintos corpus literarios internacionales; de André y Bueno (2008) se tomó el recorte de las obras de 170 escritoras latinoamericanas. 
- Desde los llamados gay \& lesbian studies: de Woods (2001) se tomó la idea de incorporación al CLLyC construido de títulos "explícitamente relacionados con lo gay" como respuesta a su ausencia en el canon bloomiano; de Foster (1991) se tomó el primer repertorio crítico sobre temas gay en la literatura latinoamericana con un análisi crítico de 26 títulos de 25 autores.

- Desde los estudios culturales: Beverley (1996, 2004), Castañeda (2009), Cornejo Polar (1987), Hall (1991, 2008), Moraña (2004); Schettini (2014).

- En el marco de los estudios poscoloniales: de Moraga (2013) tomamos la noción de predominio masculino ("patriarcal, machista") del canon bloomiano; de Serra (2012) se destaca la reivindicación de la realización de una lista concreta de autores y títulos por parte de Bloom Corvalán (2014) propone la descripción del estallado de los cánones y el esparcido de los fragmentos resultantes de Mignolo (1994-1995: 25; 1998) asumimos los aspecto "a destacar, entre ellos la fuerte presencia de la escritura femenina, las tradiciones orales y los productos culturales híbridos de la colonia" para incorporar en el corpus.

Relevar y estudiar el aparato teórico crítico restante, es decir aquellas visiones que funcionan como complementarias tanto con la versión bloomiana tradicional como con las perspectivas críticas a ella.

- La noción de corpus inclusivo del canon se toma de los trabajos de Pineda-Botero (2012), Grillo (2013) y - parcialmente- de Mignolo (1998), sobre todo, la definición de "canon como un subsistema dentro del sistema".

- La idea de incorporación de prácticas culturales diversas a las formas literarias propias de lo que llamamos "modernidad clásica" devienen de las investigaciones de Lotman-Uspenski (1971) sobre las maneras de autoorganización de la literatura y de Pizarro (1987), sobre todo, el énfasis colocado en la ampliación de la noción de literatura; asimismo de Hall (1991: 37) se tomó la noción de incorporación de formas "marginales" que reclaman "para sí mismas alguna de las formas posibles de representación". Tanto Lotman-Uspenski (1971) como Hall (1991) amplían las posibilidades metodológicas a la incorporación al CLLyC de formas literarias marginales "no modernas".
- La idea de conformación de un campo editorial como espacio de consagración de formas de escritura y de autores al distribuirlo socialmente se extrae de Bourdieu (1999).

Relevar y estudiar el aparato teórico-crítico que analiza y define la conceptualización geográfica, cultural, histórica, de las categorías Hispanoamérica, Iberoamérica, América Latina, Panamérica, Indoamérica, Caribe, América Latina y el Caribe.

- Fueron adoptados los conceptos de Rouquié (1989) sobre la evolución del término América Latina y su derivación histórica, geohistórica y cultural; de Malamud (2007; 2015) se tomaron el análisis sobre la conformación de los estados latinoamericanos, la noción de "herencia colonial" que compensó factores, que obstaculizaban los procesos de integración nacional y la idea de definición de la categoría "América Latina" por "autorreconocimiento"; de Oszlak (1982; 2007) se eligió la noción de elementos comunes en la construcción de los estados latinoamericanos en el marco de su heterogeneidad; de Huntington (1994) y Pedrosa (2013) se adquirieron las nociones acerca de la "tercera ola democrática" para ampliar la descripción de las características estatales comunes a las naciones latinoamericanas; de Freidenberg (2015) se trabaja con el análisis de la relación entre el concepto "América Latina" e "Hispanoamérica" en la actualidad; de Martínez (2012) se puntualiza la influencia de otros procesos de integración regional, como el de la Unión Europea.

Relevar y estudiar el aparato teórico crítico que analiza y define las nociones de literatura latinoamericana y literatura latinoamericana y caribeña.

- De Pizarro (1987) y Cornejo Polar (1987) se relevan las descripciones sobre el vínculo entre las literaturas de América Latina y del Caribe y la necesidad de establecer un objeto teórico común, y de Ramchand (1987), especialmente, la idea de propugnar y estimular una conciencia común entre América Latina y el Caribe, más allá de "los factores materiales" que los separan.

- De Glissant (1980; 2008) aceptamos la idea de relevar las poéticas de relación y pensamiento de archipiélago y la detección de la existencia de un lenguaje común por parte de los escritores del Caribe, en relación con el 
forzamiento de las lenguas occidentales por la necesidad de ganar expresividad.

- De Huizi Castillo (2015) consideramos la noción de la necesidad de amplitud en los enfoques teórico-críticos que permitan ir "más allá de una geohistoria de las artes".

- La idea de un nivel de integración, "supernumerario" con la incorporación de las letras americanas de otras lenguas autóctonas y de procedencia europea no latina es extraída de Ardao (1996).

Relevar y estudiar el aparato teórico crítico que describe y conceptualiza la etapa de transición / coexistencia entre Galaxia Gutenberg y el ecosistema digital.

- De McLuhan (1962) se utilizó la definición y descripción de la Galaxia Gutenberg; de Ong (1987), Sauerberg (2009) y Piscitelli (2010) la detección y descripción del "paréntesis Gutenberg" o intermezzo entre culturas de la oralidad.

- La idea de campo proviene de Bourdieu (1966) y la noción de campo editorial es la que el propio Bourdieu utiliza para el análisis del mercado de bienes simbólicos (1995)

- De Cordón García y Figuerola (2012) se releva la detección y descripción de un mercado por procesos de GILT (globalización, internacionalización, localización y traducción); de Alonso Arévalo y Cordón García (2010 se tomó la definición de acumulación vital de contenidos como la que define el estadio del libro digital.

- La idea de reemplazo del texto fijo y de lectura lineal, cartesiana, del texto impreso por formas de lectura en soporte digital que se presentan como fragmentarias y “nómades" se extrajo de Cordón García (2014).

- La descripción de las estrategias de compras de títulos digitales basadas en el modelo de adquisición impulsada por el usuario (Patron Driven Acquisition-PDA) fueron tomados de Vicente García (2013); Esposito et al. (2012); Gammon y O’Neill (2011); Walters (2012) y Alonso Arévalo (2015)
- El concepto de visibilidad es el propuesto por Cordón García (2004), sobre todo, la noción de "visibilidad consolidada" de obras que poseen un alto reconocimiento, entre otras razones porque son obras o que aparece en listas de más vendidos, o porque poseen un alto valor simbólico, entre otras cosas, por incorporación canónica.

- La idea de biblioteca digital como proceso caracterizado por el valor añadido por la propia biblioteca es de Tramullas Saz (2002).

Analizar y describir los problemas ligados a la formación del gusto (Bourdieu: 1988) en el marco de la etapa de transición / coexistencia entre Galaxia Gutenberg y el ecosistema digital.

- La idea de "sentido social del gusto" y de prácticas que regulan el sentido del arte se extrajeron de Bordieu (1988).

- La noción de pasaje de autonomía relativa del arte a heteronomía relativa es extraída de Graw (2013).

La descripción del circuito mainstream del arte mundial se obtuvo de Martel (2014), de Fleck (2014) y de Thompson (2015).

- La detección de la incorporación al mainstream del comercio de arte internacional de las estéticas del arte latinoamericano como sección de la corriente artística poscolonial se tomó de Smith (2012). De Martel (2014) se tomó la idea de la promoción de flujos de información y de cultura regionales, no solo globales, sino también transnacionales" (Martel, 2014: 416); y de Fleck (2014), en especial, la idea de incorporación de tradiciones modernas en el mainstream internacional de los desarrollos artísticos de América Latina del siglo XX en un proceso de "globalización del arte moderno" (Fleck, 2014: 17).

- Lipovetsky y Serroy (2015) proveyeron las nociones de "hiperestetización del mundo" y de "cuarta fase de estetización del mundo" y Thompson (2015) nos suministró un panorama de las cifras reales de ventas de arte contemporáneo de la periferia mundial en el concierto de las ventas de arte a nivel global.

- La relación entre producción artística y globalización se desarrolló desde el análisis del camino crítico global-local que despliega Groys (2014) y el análisis de García Canclini (2014) de las tensiones entre tradición y creencias locales, y la circulación y demanda de las audiencias de otros lugares. 
- La idea de concebir al gusto como "una automatización del mercado que indica qué es lo legítimo como arte" es relevada de Civale (2014). También se trabajó con la perspectiva de construir una nueva hipótesis interpretativa a partir de los resultados de esta investigación construida inductivamente y por analogía con la teoría incorporada en el marco teórico de esta tesis: los trabajos de Robert Fleck (2014), Frédéric Martel (2014), Terry Smith (2012), Giles Lipovetsky (2015), Don Thompson (2015) sobre el mundo del arte contemporáneo y de la recurrencia a los criterios relacionados con el gusto por parte de informantes clave entrevistados.

C) Efectuar entrevistas a especialistas para la definición y ampliación de conceptos. En este punto se destaca la necesidad de contrastar categoría y definiciones que en el relevamiento bibliográfico se presentan confusas o que se necesitan ampliar. Todas las entrevistas están incluidas en el apartado 7 , de esta Tesis.

En el desarrollo de las entrevistas se siguieron los siguientes pasos:

a) Definición de los especialistas a entrevistar:

- Lic. Ariel Schettini, especialista en literatura latinoamericana.

- Dr. Andrés Malamud, especialista en problemas políticos latinoamericanos.

- Dra. Flavia Freidenberg, especialista en problemas políticos latinoamericanos.

- Dra. Isabel Huizi Castillo, especialista en arte latinoamericano y caribeño.

- Dr. Gianni Vattimo, filósofo.

- Lic. Eugenia Corvalán, especialista en arte latinoamericano y caribeño.

- Lic. Julio Alonso-Arévalo, especialista en bibliotecología y ecosistema digital.

- Lic. Cristina Civale, especialista en arte y literatura latinoamericanos. b) Preparación del guion de la entrevista:

- Pregunta 1 - Para especialistas en literatura en arte y literatura latinoamericana (Schettini; Huizi Castillo; Corvalán; Civale; Vattimo):

Giro poscolonial mediante, ¿hay un gusto global (o concepción o criterios globales) sobre la literatura latinoamericana?

- Pregunta 1 - Para especialistas en políticas latinoamericanas (Freidenberg; Malamud):

¿Cómo se define el concepto "América Latina”?

- Pregunta 2 - Para especialistas en políticas latinoamericanas (Freidenberg; Malamud):

¿Qué tipo de demarcación permite acuñar la categoría «América latina y el Caribe»?

- Pregunta 1 - Para especialistas en biblioteconomía y ecosistema digital (Alonso-Arévalo):

¿Qué beneficios traen los Modelos de adquisición impulsada por el usuario (Patron Driven Acquisition-PDA)?

c) Ejecución de las entrevistas.

d) Análisis de las entrevistas.

D) Definición de plataformas comerciales y bibliotecas en donde se realizarán las búsquedas.

Se seleccionaron, en total, catorce plataformas comercializadoras en digital y servicios de lectura en streaming y descarga para realizar el estudio comparativo de las diferentes plataformas de comercialización de libros electrónicos y la disponibilidad de los títulos de los autores latinoamericanos y caribeños del CLLyC.

También se seleccionaron en total nueve bibliotecas digitales para realizar un estudio comparativo de su disponibilidad de los títulos de los autores latinoamericanos y caribeños destacados del CLLyC. 
La selección de plataformas comercializadoras y bibliotecas mencionadas anteriormente nos permite acceder a un estado actualizado de la oferta de los títulos y autores que componen el segmento latinoamericano del canon de Bloom, así como la oferta de los títulos y autores del CLLyC. Además, la lista de plataformas y bibliotecas nos permite analizar y compara en ellas las ofertas de los títulos de la literatura latinoamericana y caribeña del CLLyC para expresar una lista exhaustiva de obras y autores latinoamericanos. Asimismo, se comparan en ellas las ofertas de dichos títulos y autores en soporte papel y en formato digital.

\section{- Criterios destacados para la selección de las plataformas y} bibiotecas y características de ellas:

- Amazon destacó a principios de 2015 que dispone de 1.700.000 títulos de libros electrónicos en su catálogo, la gran mayoría están en inglés (Milliot, 2011; Wischenbart et al., 2013: 18). Además, posee una posición dominante en la venta de libros electrónicos, con más del 70\% de los compradores de EE.UU.,en mayo de 2011. Y, también, Amazon posee una posición dominante en el mercado de libros impresos de EE.UU. A fine de 2013, había ampliado su catálogo de ebooks en castellano de 22.000 a 48.000 títulos (Wischenbart et al., 2013: 38) y a 1.500 clásicos gratuitos en castellano. Su servicio de suscripción por tarifa plana Kindle Unlimited (ebooks y audiobooks) posee un catálogo de 700.000 títulos, 25.000 de ellos en español y una tarifa de $€ 9,99$ al mes. El servicio está disponible en Estados Unidos, Reino Unido, Alemania, Italia, España y Francia.

- Barnes \& Noble dispone casi tres millones de títulos de libros digitales con cerca del 27\% de los compradores de libro electrónicos (Milliot, 2011; B\&N, 2015).

- iBookstore y iTunes. En junio de 2011, Apple indicó que vendió 130 millones de libros electrónicos a través de iTunes. En octubre de 2012, vendió 400 millones. O sea que vendió más de 270 millones de libros electrónicos en dieciséis meses. La media de ventas mensuales es de cerca de diecisiete millones de unidades (Dedieu, 2013). Esta tienda iTunes Store está presente en 119 países desde fines de 2012. La aplicación iBooks (disponible en treinta idiomas) es la residente en las tabletas iPad y permite a los lectores descargar los libros digitales en formato *epub de iBookstore y está integrado con la plataforma iTunes de Apple para el intercambio y uso de otros formatos de archivo, como *pdf. Desde 2013, iBooks está disponible en más de cincuenta países.
- Google Books ofrece sus servicios de casi 350.000 títulos combinando sus ventas directas con el formato similar al de un distribuidor mayorista tradicional: permite a libreros independientes la venta de libros desde su propia plataforma, se ofrece como una plataforma de biblioteca y librería en línea (Cordón García y Arévalo, 2011). A su vez, el servicio Play Books ofrece más de cuatro millones de títulos que pueden ser adquiridos a través de Google Play.

- Kobo es una plataforma canadiense de libros electrónicos de estándares abiertos, que está presente en 190 países, alcanza a diez millones de usuarios y posee un catálogo de más de cuatro millones de libros, con títulos en 68 idiomas, entre los que está incluido el castellano (Araújo, 2013). Su lector electrónico ocupa actualmente el tercer lugar en la escena de la edición digital, detrás del Kindle de Amazon y del Nook de Barnes\&Noble.

- Casa del Libro ofrece un catálogo de alrededor de 1.000.000 títulos y uno de los mayores catálogos de libros electrónicos en español con cerca de 135.000 títulos, con aproximadamente un millón de usuarios registrados y 118 tiendas en España (Paredes, 2014). Posee una cuota del mercado español estimada en 15\% (Wischenbart et al., 2013: 38).

- Las búsquedas en Free-Ebooks se realizaron como forma de establecer también un estado del arte en plataformas de descargas gratuitas de libros digitales.

- Gandhi es la principal librería en fisico y en digital de México, así como una plataforma de auto-publicación. Aproximadamente un tercio de los pedidos realizados en Ghandi.com son pedidos mixtos (compuesto por dos libros impresos y un libro electrónico).

- Livraria Cultura es la principal librería en físico y digital de Brasil. Dispone de un catálogo de ocho millones de títulos en soporte papel y cerca de un millón de títulos en formato digital.

- Perubookstore.com es la principal librería online de Perú.

- Librería Santa Fe es la principal plataforma comercial de libros en digital (5.000 títulos) de la Argentina y una de las cadenas tradicionales más importantes. 
- También se efectuaron búsquedas en plataformas que representan los "nuevos modelos" de venta: Nubico y Scribd.

- Nubico es plataforma digital de venta por suscripción, resultado de una "joint venture" de Telefónica España y Círculo de Lectores al 50\% cada una. A su vez, dos multinacionales del sector editorial, Grupo Planeta y Bertelsmann España, participan en partes iguales del Círculo de Lectores. La plataforma cuenta con 100.000 clientes y dispone en la actualidad de 7.700 títulos de 83 editoriales, que ofrece en tarifa plana al mercado español con un costo para el cliente final de $€ 8,99 €$ al mes (IVA incluido) (Prieto, 2014).

- Scribd es una aplicación online en la que se pueden subir documentos y presentaciones para poder mostrarlas online con opciones de descarga en formato *pdf y *txt. Posee un catálogo de 500.000 libros a los que se puede acceder por una "tarifa plana" de U\$S nueve mensuales y ofrece 150.000 nuevos ebook de la editorial Harlequin. Incluye, además, más de 30.000 audiolibros en su base de datos, archivos disponibles bajo el sistema de suscripción. Scribd permite explorar, leer y compartir millones de obras escritas: guías de estudio, recetas, manuales prácticos, informes de analistas, presentaciones de negocios y hojas de cálculo, y publicaciones de las editoriales Random House, Workman, Chronicle Books, Wiley, O'Reilly, Harvard Press, University of Chicago y Duke Press, entre otros. Incluye: lector *epub y *pdf; documentos que pueden ser guardados para ser vistos sin conexión a Internet; periodización de recomendaciones editoriales; funciones para compartir lecturas, una gran selección de categorías (más de 1.800 categorías). A su vez, funciona como una red social en la cual se pueden seguir a otros usuarios de Scribd y ver la actividad de los amigos que seguimos (o nos siguen).

-Todas las búsquedas, asimismo, se efectuaron en aquellas bibliotecas más significativas desde el punto de vista lingüístico y que se destacan por prestaciones, arquitectura y disponibilidad digital (Chowdhury y Foo, 2012; Klimanski, 2006; Tramullas Saz, 2002; Turiel, 2010).

- Public Library New York forma parte del grupo de las bibliotecas con mayor prestigio a nivel internacional por la calidad de los recursos que ofrecen.

- La Biblioteca Nacional de España es la biblioteca más reconocida en el campo idiomático del castellano, así como Ga- llica - Biblioteca Nacional de Francia es la biblioteca más reconocida internacionalmente en lengua francesa y enlaza cerca de 900.000 libros, periódicos, manuscritos, mapas y dibujos digitalizados.

- Columbia University Libraries fue seleccionada por ser una de las bibliotecas con más reconocimiento en el campo académico.

- La Biblioteca Nacional de Perú y la Biblioteca de São Paulo se seleccionaron con el criterio de incorporar las más reconocidas bibliotecas latinoamericanas con colecciones en digital en oferta.

- Europeana es una biblioteca digital que posee casi cuatro millones de objetos digitales, incluidos libros impresos procedentes de más de 1.000 archivos en la Unión Europea.

- La Biblioteca del Instituto Latinoamericano de Berlín se seleccionó como biblioteca especializada en temas y autores y latinoamericanos.

\section{Diseño de un corpus literario latinoamericano y caribeño (CLLyC)}

El CLLyC propuesto y construido surge del relevamiento de fuentes documentales (repertorios, ensayos, antologías, artículos académicos, memorias, catálogos, diccionarios, historias, programas de estudio) literarias latinoamericanas heterogéneas, disímiles, distantes entre sí tanto en el tiempo como en las perspectivas y criterios de selección de autores y obras por las propias fuentes. Las listas de autores y obras fueron extraídas de fuentes que las aportan desde enfoques diversos y funcionan metodológicamente para las búsquedas como listados complementarios entre sí que ocupan las áreas de vacancia expuestas por las demás fuentes. 
Se apuntó al diseño un repertorio amplio de la literatura latinoamericana y caribeña, superando lo que Rafael Grillo (2013) analiza como "E canon (modelo único) que hace invisible el corpus (democrático conjunto)". Aunque, y asimismo, el CLLyC construido subsume el segmento latinoamericano del canon realizado por Bloom.

- Se construyó la lista de 18 autores y 36 obras que Harold Bloom introduce en el segmento latinoamericano de su canon y los cinco autores y siete obras que introduce en el segmento caribeño (West Indian) como parte de lo que llama "profecía canónica" de la "edad caótica" (siglo XX).

- El Diccionario de autores latinoamericanos realizado por César Aira aporta más de 1.300 autores y obras con un criterio de amplitud en la incorporación de autores: dramaturgos, poetas, novelistas, cuentistas, científicos, historiadores, cronistas, periodistas y ensayistas. Asimismo, nos provee de un segmento significativo de literatura brasileña (incorporación que no se realiza con frecuencia en los repertorios literarios latinoamericanos), pero no incorpora autores y obras precolombinos ni en otra lenguas que no sean castellano y portugués, así como no incluye autores surgidos a partir de 1985. Se transcribieron (el propio Diccionario no posee versión en digital) todos los autores y obras relevadas por Aira.

- El Diccionario de la literatura latinoamericana de Susana Cella contribuye con un listado de autores y obras que funciona de manera complementaria con el Diccionario de autores latinoamericanos de César Aira: incorpora textos precolombinos y en lenguas no hispánicas y a los escritores nacidos hasta 1940 o, en caso de que hayan nacido después del 40, que ya estuviesen fallecidos en 1998. La idea de "representatividad" de autores y obras prima sobre la "exhaustividad" (Cella, 1998: VII).

- La Encyclopedia of Latin American and Caribbean Literature 1900-2003, editada por Daniel Balderston y Mike Gonzalez, incorpora obras escritas entre esos años: 1900 y 2003, con lo cual también funciona como recorte temporal, además de geopolítico cultural.

- Saraus. Movimiento - Literatura - Periferia - São Paulo. Antología, de Lucía Tennina (compiladora) aporta autores y obras de poetas paulistas contemporáneos de la llamada "marginalia" y "estética marginal".
- De la Tricolor a la Wiphala. Narrativa contemporánea de Bolivia, de Sergio Di Nucci, Nicolás Recoaro y Alfredo Grieco y Bavio (selección, edición y notas) contribuye con cuentos de catorce autores bolivianos nacidos entre 1956 y mediados de los 80 , con la que articula una selección que expresa la emergencia de una nueva narrativa boliviana independiente, localizada tanto en la Ceja de El Alto pasando por la tropical selvática Santa Cruz de la Sierra y la geografía urbana de La Paz hasta el barrio de Liniers (Buenos Aires, Argentina), donde habita una de las concentraciones más grandes de bolivianos en el exterior.

- McOndo (una antología de nueva literatura hispanoamericana) editada por Alberto Fuguet y Alberto Gómez aporta a este CLLyC cuentos de aquellos autores incorporados a la antología por decisión programática nacidos desde 1959 "(que coincide con la siempre recurrida revolución cubana) a 1962 (que en Chile y en otros países, es el año en que llega la televisión)" (Fuguet, 1996: 9), además de autores "poco conocidos" hasta mediados de los 90 y cuya selección descarta, también por decisión programática, todo rastro de realismo mágico como poética. El mecanismo de selección "castigó" con rechazo cualquier atisbo de realismo mágico en los cuentos presentados para la Antología, en cuyos relatos priman las narrativas que ahonden en la pesquisa sobre la identidad personal del autor ("¿quién soy? ") más que en el "gran tema de la identidad latinoamericana" propia de la generación del boom (“iquiénes somos?”). A posteriori, Fuguet (Tsang, 2013) amplía las características poéticas de la generación literaria de esa antología a "lo híbrido, la mezcla". Pasada una década, Latinoamérica y su arte "han ido para allá": para McOndo. Y, en esa misma operación, incorpora al "gran autor $\mathrm{McOndo":} \mathrm{Roberto} \mathrm{Bolaño,} \mathrm{por} \mathrm{"ultrarrealista"} \mathrm{o}$ "posmoderno". En el caso de McOndo, al ser una antología de cuentos, se reemplazaron estos por los volúmenes de cuentos donde aparecían, o se incluyeron en las búsquedas los volúmenes de cuentos más cercanos temporalmente a la antología $\mathrm{McOndo}$ de esos autores. En el caso de Jaime Bayly, al no haber editado ningún volumen de cuentos, se incluyó su novela № se lo digas a nadie, que es la más cercana en el tiempo a la edición de la antología McOndo. En el caso de Roberto Bolaño se incorporó el volumen de cuentos Llamadas telefónicas y las dos novelas más cercanas temporalmente a la antología: Estrella distante y Los detectives salvajes. Ese listado de autores y de obras resultante de la antología McOndo es el aporte a la construcción de este CLLyC.

- El Manifiesto del Crack aporta una lista de seis autores mexicanos Jorge Volpi, Pedro Ángel Palou, Eloy Urroz, Ignacio Pa- 
dilla, Ricardo Chávez Castañeda y Vicente Herrasti), con un programa poético de una narrativa dislocada o desubicada de espacio y del tiempo de México, cuyas obras, todas posteriores a 1996, se caracterizan por una postura narrativa rupturista tanto del realismo mágico latinoamericano como de una cierta poética light representada por Ángeles Mastretta, Marcela Serrano, Laura Esquivel, Guadalupe Loaeza.

- 1.000 millones: poesía en lengua española del siglo XXI, editada por Daniel Helder, Daiana Henderson y Bernardo Orge aporta una lista que reúne a treinta y tres autores hispanoamericanos nacidos entre 1980 y 1995 y cuyas obras fueron editadas previamente en soporte digital o en soporte papel. La antología aporta una serie de propuestas poéticas desarrolladas en Latinoamérica, Europa y EE.UU. durante la última década.

- Bogotá39 es el resultado de una selección realizada por los escritores colombianos Piedad Bonnet, Héctor Abad Faciolince y Óscar Collazos. El listado de escritores elaborado se basó en la nominación de más de dos mil editores, críticos y lectores de todo el continente.

- La gran novela latinoamericana, de Carlos Fuentes, aporta un repertorio de autores y novelas desde la perspectiva de un autor del "boom".

- Latin American Women Writers: An Encyclopedia, editado por María André y Eva Bueno (2008), aporta un repertorio de 2.951 títulos de 303 escritoras desde la perspectiva de visibilización de la literatura escrita por mujeres.

- Una sección de títulos de escritores caribeños, antillanos y de las Guayanas diseñado sobre la base de la combinación de los títulos y escritores que componen la compilación West Indian Narrative: An Introductory Anthology (Ramchand); la antología They Came in Ships: An Anthology of Indo-Guyanese Writing (Benjamin Kallicharan, McDonald y Searwar); la selección The Routledge Reader in Caribbean Literature (Donnell y Lawson Welsh); The Companion to Anglophone Caribbean Literature (Donnel y Bucknor); la selección The Oxford Book of Caribbean Verse (Brown y McWatt) y los escritores caribeños, antillanos y de las Guayanas de la Encyclopedia of Latin American and Caribbean Literature 1900-2003, editada por Daniel Balderston y Mike Gonzalez.

Si el Diccionario elaborado por Aira propone autores y obras en español y portugués, Los chongos de Roa Bastos. Narrativa contemporánea de Paraguay y Saraus. Movimiento - Literatura - Periferia - São Paulo aportan en un caso obras en jorapa, guaraní y distintas formas de heteroglosia e hibridaciones entre guaraní, castellano y otras lenguas y hablas indígenas y, en otro caso, textos en el portugués de los jóvenes de la perifatividade paulista.

A su vez, si el Diccionario construido por Aira no aporta autores y obras precolombinos ni en otras lenguas que no sean castellano y portugués, así como no incluye autores surgidos a partir de 1985; el Diccionario elaborado por Susana Cella incorpora textos precolombinos y en lenguas no hispánicas y a los escritores nacidos hasta 1940 (o, en caso de que hayan nacido después del 40 que ya estuviesen fallecidos en 1998), asimismo, se elaboró un segmento específico para que la literatura precolombina esté representanda en el CLLyC. Latin American Women Writers: An Encyclopedia aporta obras de 258 escritoras nacidas entre los siglos XVI y fines del siglo XX. Los chongos de Roa Bastos. Narrativa contemporánea de Paraguay y Saraus. Movimiento Literatura - Periferia - São Paulo contribuyen con obras de autores nacidos en el periodo de 1965 y 1984 en el primer caso, De la Tricolor a la Wiphala. Narrativa contemporánea de Bolivia propone autores nacidos entre 1956 y mediados de los 80; en el caso de Saraus, aporta autores nacidos entre 1957 y mediados de los 80 que en su mayoría inician sus trabajos literarios en las décadas del 90 y principios de los 2000; así como McOndo (una antología de nueva literatura hispanoamericana) aporta escritores nacidos entre 1959 y que se destacan en su trabajo literarios a mediados de los 90. La antología 1.000 millones: poesía en lengua española del siglo XXI incluye treinta y tres autores hispanoamericanos nacidos entre 1980 y 1995 y el Manifiesto del Crack incorpora seis autores mexicanos nacidos entre 1961 y 1968 y cuyas obras son todas posteriores a 1996. Asimismo, la selección de Bogotá39 menciona treinta y nueve autores menores de 39 años en el año 2007.

Si el Manifiesto del Crack propone obras que "faciliten su traducción" (Santos, 2013: 288), Los chongos de Roa Bastos y Saraus aportan textos con complejidades textuales de difícil traducción habida cuenta de las distintas formas de utilización de heteroglosia y hablas coloquiales y registros y variedades dialectales tanto del castellano como del guaraní, del portugués y del jorapa, y otras lenguas y hablas indígenas y, por otro lado, las formas del habla del portugués de los jóvenes de los barrios periféricos de São Paulo. De la Tricolor a la Wiphala. Narrativa contemporánea de Bolivia contribuye con textos escritos mayoritariamente en las distintas variedades del castellano de Bolivia, excepto en el caso Alison Spedding, que escribe también en aymará. El ensayo de Latin American Writers on Gay and Lesbian Themes: A Bio-Critical Sourcebook de David Foster Wallace colabora con textos escritos en español y en portugués, aunque el autor trabaja con obras en español y portugués y obras traducidas al inglés. Y la selección de Bogotá39 incluye autores que escriben en español, portugués e inglés.

Si los cuentos elegidos para $\mathrm{McOndo}$ promulgan una postura narrativa rupturista con del realismo mágico latinoamericano, Carlos Fuentes en La gran novela latinoamericana nos brinda la perspectiva de abordaje de un es- 
critor del boom, que considera que en Cien años de soledad, de Gabriel García Márquez, se encuentra "la tensión entre Utopía, Epopeya y Mito" (2014: 262), cuyo tiempo es la simultaneidad, donde "los hombres se defienden con la imaginación del caos circundante, de las selvas y los ríos, del inmenso, devorador magna suramericano" (2014: 265).

Mientras la mayoría de las fuentes utilizadas no destaca una perspectiva de género (cosa que sí pueden realizar específicamente los autores mencionados al interior de sus textos), el repertorio Latin American Women Writers: An Encyclopedia, editado por María André y Eva Bueno (2008), nos aporta un registro de distintas formas narrativas escrito por 258 escritoras latinoamericanas, con una estrategia de abordaje teórico de literatura latinoamericana femenina. Otro tanto agrega el ensayo de Latin American Writers on Gay and Lesbian Themes: A Bio-Critical Sourcebook de David Foster Wallace: propone veintisiete títulos de veinticinco autores latinoamericanos en todos los géneros, con una estrategia que guía la incorporación de estos autores y obra que es la de incluir en el diseño del CLLyC la perspectiva que articula la relación entre homosexualidad y sociedad en la literatura latinoamericana.

Si McOndo y De la Tricolor a la Wiphala proponen cuentos, el Manifiesto del Crack propone novelas, al igual que la propuesta de Carlos Fuentes en la Gran novela latinoamericana; Saraus propone poesías, al igual que la antología 1.000 millones, aunque en este caso, algunos de los autores también escriben novelas, cuentos, cómics (que fueron incorporados al diseño del CLLyC). Algunos de los autores de De la Tricolor a la Wiphala escriben también novelas, poesías y cómics (y también fueron incorporados al diseño del CLLyC), así como los autores de la selección de Bogotá39.

El segmento de títulos de escritores caribeños, antillanos y de las Guayanas diseñado sobre la base de la combinación de los títulos y escritores que componen los trabajos mencionados previamente contribuye con 559 autores y más de 2.597 obras, con un criterio de amplitud en la incorporación de autores: dramaturgos, poetas, novelistas, cuentistas, científicos, historiadores, cronistas, periodistas y ensayistas. La radicalidad de esta incorporación se enmarca en una concepción de articulación de "lo caribeño" como unidad, que "siendo unidad, no es inseparable de América Latina" (Pizarro, 1987: 146). Si en el Caribe existen formas de estructuras sociales y percepciones del mundo comunes, expresadas en su literatura articulada en distintos sistemas literarios similares entre ellos, la incorporación de esto textos y autores nos habilitaría la descripción de sistemas literarios caribeños ligados a las distintas metrópolis coloniales (en castellano, portugués, francés, holandés), tanto como sistemas literarios en créole, patois, papiamento (papiamentu, papiamen), neerlandés y a los sistemas literarios multilingües en algunas de las expresiones literarias incorporadas.

En el caso del Catálogo de Editoriales Cartoneras latinoamericanas de la Universidad de Wisconsin, la incorporación en el CLLyC de sus títulos y autores introduce una perspectiva de inscripción vertical, es decir, su inscripción atraviesa todas las perspectivas poéticas y consideraciones que hemos descrito previamente. Asimismo, la incorporación de los títulos y autores de las editoriales cartoneras ${ }^{3}$ nos provee de títulos para la construcción de un CLLyC que contenga, asimismo, formas editoriales que integran la dispositividad material de la galaxia Gutenberg, pero que se constituyen como artefactos culturales propios de la oferta específica de las literaturas latinoamericanas.

En el diseño del segmento de las editoriales cartoneras del CLLyC propuesto se suprimieron los títulos de autores no latinoamericanos, dado que el objeto teórico de la presente investigación es el estado de la transposición de las literaturas latinoamericanas a soporte digital. Se destaca que las búsquedas en plataformas y bibliotecas de algunos de los títulos publicados por las editoriales cartoneras se dificultan, dado que se editaron cuentos sueltos, poemas separados de sus poemarios, así como pequeños ensayos de autor que forman parte de obras colectivas mayores que, o son de difícil rastreo y recomposición, o forman parte de obras mayores born-digital (sin transposición a impreso en ninguna de sus etapas).

En el caso de 17. De Encyclopedia of Latin American and Caribbean Literature 1900-2003, editado por Daniel Balderston y Mike Gonzalez (2004), se separaron los autores caribeños, antillanos y de las Guayanas y se los incorporó a la sección 13. de escritores caribeños, antillanos y de las Guayanas del CLLyC. Los restantes autores fueron incorporados como otra sección de las búsquedas.

Además, si el objeto de esta Tesis es el estudio de la transposición a digital de literatura en impreso, en el caso de la antología 1.000 millones se da el caso inverso: algunos escritores no publican en soporte papel y han sido transpuestos a impreso de digital (de webs, blogs, blogs de Tumblr).

- Lenguas de las obras: las distintas variedades del castellano y del portugués de América Latina, francés, inglés, neerlandés, guaraní, náhuatl, aymará, tomáraho, ashlushlay, ybytozo, toba quom, sanapaná, maká, axe-guayaki, ayoreo quiché, patois, creole, jorapa, portuñol y heteroglosias de la región.

- Se relevaron autores de cuarenta y tres nacionalidades. A saber:

${ }^{3}$ Las editoriales cartoneras se caracterizan tanto por emplear formatos artesanales como tapas y diseños coloreados libro por libro, como por la impresión de tapas en cartón y cartón corrugado e interiores mayoritariamente fotocopiados. Sus proveedores de insumos son recolectores de cartón y papel y nacieron como un fenómeno cultural propio del quiebre del neoliberalismo en las urbes latinoamericanas a fines de los 90. Ver 3.1.1. 
1. Argentina

2. Bolivia

3. Brasil

4. Chile

5. Colombia

6. Costa Rica

7. Cuba

8. Ecuador

9. El Salvador

10. Guatemala

11. Honduras

12. México

13. Nicaragua

14. Panamá

15. Paraguay

16. Perú

17. Puerto Rico

18. Republica Dominicana

19. Uruguay

20. Venezuela

21. Trinidad y Tobago

22. Islas Vírgenes

23. San Vicente y las Granadinas

24. Santa Lucía
25. Martinica

26. Jamaica

27. Surinam

28. Guyana

29. Dominica

30. Barbados

31. Saint Maarten

32. Haití

33. Bahamas

34. Grenada

35. Guadalupe

36. Belice

37. Montserrat

38. Antigua y Barbuda

39. Aruba

40. San Cristóbal y Nieves (Saint Kitts and Nevis)

41. España

42. Portugal

43. EE.UU

La presencia de autores de nacionalidad española se debe a dos tipos de inclusiones: por un lado, son autores (o directamente "conquistadores") de la etapa de la "Conquista" como Hernán Cortés (Medellín, Corona de Castilla, 1485); López de Gómara (Gómara, Soria, 1511); Bernal Díaz del Castillo (Medina del Campo, 1492); Pedro Cieza de León (Llerena, 1518); Alonso de Ercilla y Zúñiga (Madrid, 1533); Francisco Cervantes de Salazar (Toledo, 1514) y Fray Bartolomé de las Casas (Sevilla, 1474) y, por el otro, son autores incluidos en la antología 1.000 millones, poesía en lengua española del siglo XXI, que incorpora a Pablo Fi- 
dalgo Lareo (Vigo, España, 1984); Berta García Faet (Valencia, España, 1988) y Óscar García Sierra (León, España, 1994) y en La gran novela latinoamericana, de Carlos Fuentes, que incluye a Juan Goytisolo. Asimismo, el CLLyC incorpora autores nacidos en EE.UU. y que se radicaron en América Latina o poseen ciudadanía de alguno de los países de América Latina y el Caribe y autores nacidos en EE.UU. y que producen literatura latinoamericana y caribeña desde ese país, tal es el caso de Ana Carrete (San Diego, EE.UU., 1985), incluida en la Antología 1.000 millones, poesía en lengua española del siglo XXI.

La inclusión en el CLLyC de autores de nacionalidad portuguesa corresponde a la incorporación del cronista Pêro de Magalhães de Gãndavo y del historiador Gabriel Soares de Souza, ambos incorporados por César Aira en su Diccionario como escritores brasileños.

La inclusión en el GLLyC de autores de nacionalidad norteamericana corresponde mayoritariamente a la incorporación de múltiples especialistas en literatura latinoamericana y caribeña de la academia de EE.UU. que algunas de las fuentes incluye en sus listados, tal es el caso de Latin American Women Writers: An Encyclopedia, editado por María André y Eva Bueno y la Encyclopedia of Latin American and Caribbean Literature 1900-2003, editado por Daniel Balderston y Mike Gonzalez. En muchos casos, existen autores caribeños que poseen la ciudadanía de EE.UU. y autores nacidos en EE.UU. que viven y escriben en los países de la región.

Se destaca que constan de obras y autores que en el CLLyC se yuxtaponen por pertenecer a más de una fuente incorporada: en esos casos, se destaca la pertenencia de obra y autor a cada uno de ellos.

En algunos casos, se rastrearon títulos de los autores por fuera de los mencionados en esas fuentes y se incorporaron al CLLyC en función de que la muestra pudiese efectuarse por sus libros y no por poemas separados y cuentos, relatos y pequeños ensayos sueltos. Tal es el caso del Diccionario de autores latinoamericano de César Aira; de Saraus. Movimiento - Literatura - Periferia - São Paulo. Antología; De la Tricolor a la Wiphala; 1.000 millones, poesía en lengua española del siglo XXI; la compilación West Indian Narrative: An Introductory Anthology (Ramchand); la antología They Came in Ships: An Anthology of Indo-Guyanese Writing (Benjamin, Kallicharan, McDonald y Searwar); la selección The Routledge Reader in Caribbean Literature (Donnell y Lawson Welsh); The Companion to Anglophone Caribbean Literature (Donnel y Bucknor); la selección The Oxford Book of Caribbean Verse (Brown y McWatt) y en el Catálogo de Editoriales Cartoneras latinoamericanas y de Latin American Women Writes (André y Bueno). En algunos casos, se procedió a actualizar los títulos de las obras y a establecer una mayor precisión en sus títulos y subtítulos, también con el propósito de facilitar las búsquedas en plataformas y bibliotecas. En $\mathrm{McOndo}$, al presentarse como una antología de cuentos, se los reemplazaron por los volúmenes de cuentos donde aparecían y en el caso de que no estuviesen incluidos en volúmenes de cuentos, se introdujeron en las búsquedas los volúmenes de cuentos de los autores más cercanos temporalmente a la antología $M c$ Ondo o sus novelas. Tales son los casos de las obras de Jaime Bayly y del incorporado tardíamente a la generación literaria de $M c$ ondo Roberto Bolaño. Asimismo, se transcribieron los autores y obras relevadas por las distintas fuentes.

En los casos de escritores que no poseen libros editados (o que publicaron solo en antologías) o que no poseían libros editados en soporte impreso en el momento de elaboración de la fuente, se investigó la publicación en soporte impreso posterior a la edición de las antologías Saraus y 1.000 millones. Se trató de ampliar la muestra de títulos de los autores cuando la fuente no estaba actualizada.

En relación con el número de obras aportado por cada segmento del CLLyC se detalla:

- 43 títulos de 23 autores de El canon occidental de Harold Bloom.

- 11.102 títulos de 1.322 autores del Diccionario de autores latinoamericanos realizado por César Aira.

- 124 títulos de 65 autores de la Novela latinoamericana de Carlos Fuentes.

- 58 títulos de 38 autores de la antología Saraus. Movimiento - Literatura - Periferia - São Paulo. Antología, compilada por Lucía Tennina.

- 67 títulos de 14 autores de la antología De la Tricolor a la Wiphala. Narrativa contemporánea de Bolivia, de Sergio Di Nucci, Nicolás Recoaro y Alfredo Grieco y Bavio.

- 17 títulos de 15 autores de McOndo (una antología de nueva literatura hispanoamericana) de Alberto Fuguet y Alberto Gómez. ${ }^{4}$

- 95 títulos de 32 autores de 1.000 millones: poesía en lengua española del siglo XXI, editada por Daniel Helder, Daiana Henderson y Bernardo Orge.

${ }^{4}$ Alberto Fuguet amplía la lista de la antología McOndo en una entrevista de José Tsang en 2013. Se incorporó en el segmento del CLLyC al autor mencionado (Roberto Bolaño) en esa entrevista y algunas de sus obras contemporáneas con la antología McOndo. 
- 133 títulos de 36 autores de Bogotá39, una selección realizada por los escritores colombianos Piedad Bonnet, Héctor Abad Faciolince y Óscar Collazos.

- 22 títulos de seis autores del Manifiesto del Crack.

- 33 títulos de nueve autores de la antología Los chongos de Roa Bastos. Narrativa contemporánea de Paraguay, selección y edición de Sergio Di Nucci, Nicolás Recoaro y Alfredo Grieco y Bavio.

- 27 títulos de 25 autores de Latin American Writers on Gav and Lesbian Themes: A Bio-Critical Sourcebook de David William Foster.

- 469 títulos de 358 autores del catálogo de títulos de autores latinoamericanos y caribeños de la Base de Datos de Editoriales Cartoneras de University of Wisconsin.

- 2.597 títulos de 559 autores del seomento de escritores caribeños, antillanos y de las Guayanas diseñado sobre la base de la combinación de los títulos y escritores que componen la compilación West Indian Narrative: An Introductory Anthology (Ramchand); la antología They Came in Ships: An Anthology of Indo-Guyanese Writing (Benjamin, Kallicharan, McDonald y Searwar); la selección The Routledge Reader in Caribbean Literature (Donnell y Lawson Welsh); The Companion to Anglophone Caribbean Literature (Donnel y Bucknor); la selección The Oxford Book of Caribbean Verse (Brown y McWatt) y los autores caribeños, antillanos y de las Guayanas de la Encyclopedia of Latin American and Caribbean Literature 1900-2003 (Balderston y Gonzalez).

- 4.737 títulos de 595 autores del Diccionario de la literatura latinoamericana de Susana Cella.

- 2.951 títulos de 303 autoras de Latin American Women Writters: An Encyclopedia (André y Bueno, 2008).

- 50 títulos de literaturas precolombinas y ocho autores (muchas de las obras son anónimas o colectivas).

- 2.672 títulos de 651 autores latinoamericanos de la Encyclopedia of Latin American and Caribbean Literature 1900-2003 (Balderston y Gonzalez, 2004).
Se sintetiza: 20.409 títulos diferentes de 2.932 autores diferentes.

Finalmente, se destaca que el CLLyC se propone como una muestra complementaria de las formas literarias latinoamericanas y caribeñas, pese a que las estrategias de construcción de las fuentes utilizadas pueden resultar antagónicas entre sí. 
a. Sitios en los que se realizaron las búsquedas
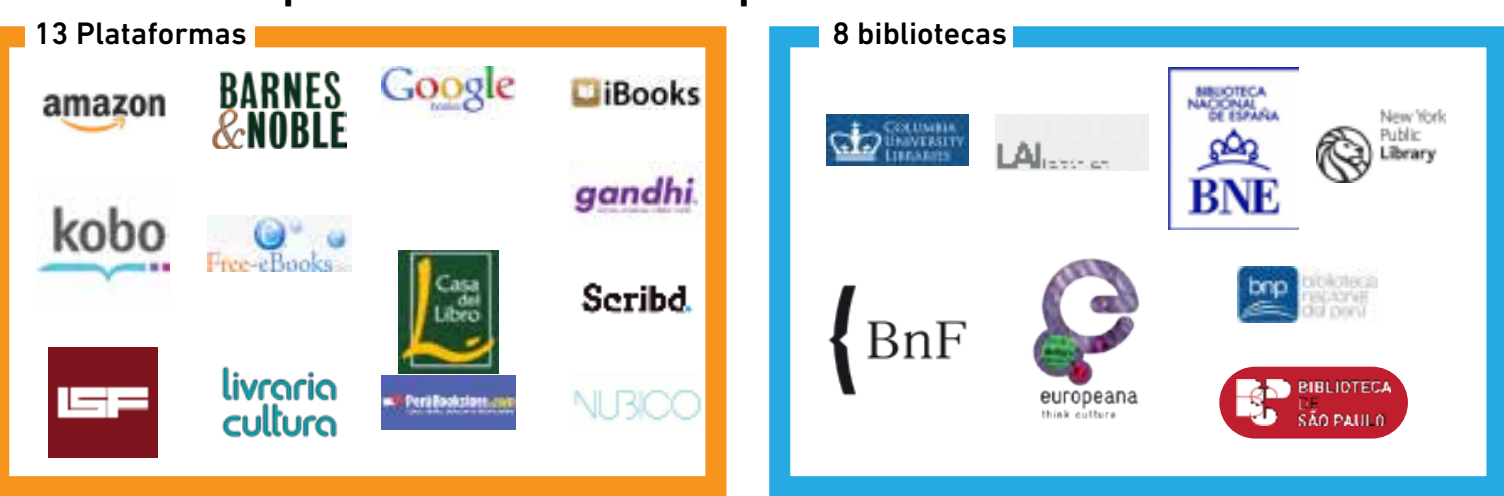

b. Corpus literario latinoamericano y caribeño

\subsection{9 títulos diferentes}

2.932 autores diferentes

\section{c. Obras aportadas por cada segmento del corpus diseñado:}

\begin{tabular}{|c|c|c|c|c|c|c|}
\hline $\begin{array}{c}\text { títulos } \\
23\end{array}$ & $\begin{array}{lr}\text { Canon } & \mathbf{1 1 . 1 5 5} \\
\text { occidental } & \text { títulos } \\
\text { de Harold } & \mathbf{1 3 2 7} \\
\text { Bloom } & \text { autores }\end{array}$ & $\begin{array}{l}\text { Diccionario de } \\
\text { autores } \\
\text { latinoamericanos } \\
\text { de César Aira }\end{array}$ & $\begin{array}{r}124 \\
\text { títulos } \\
65\end{array}$ & $\begin{array}{l}\text { Novela } \\
\text { latino- } \\
\text { americana } \\
\text { de Carlos } \\
\text { Fuentes }\end{array}$ & $\begin{array}{r}58 \\
\text { títulos } \\
38 \\
38\end{array}$ & $\begin{array}{l}\text { Antología } \\
\text { Saraus. Movimiento - } \\
\text { Literatura - Periferia } \\
\text { São Paulo. Antología, } \\
\text { compilada por } \\
\text { Lucía Tennina }\end{array}$ \\
\hline
\end{tabular}

67 Antología De la

títulos Narrativa contemporánea

14 de Bolivia, de Sergio

\begin{tabular}{l|l} 
autores & Di Nucci, Nicolás Recoaro \\
y Alfredo Grieco y Bavio
\end{tabular}

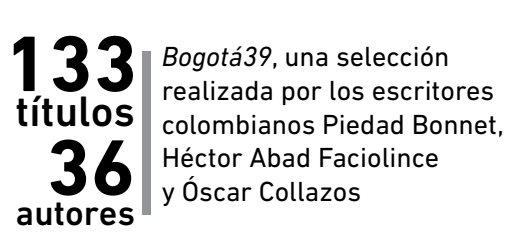

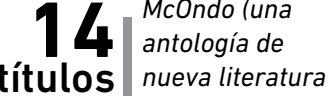
autores

(n)

36

14 hispanoamericana

14 de Alberto Fugue

33 Antología Los chongos atores

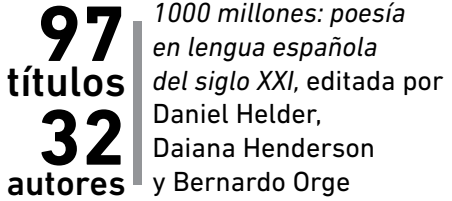

9 selección y edicicín de Sergio

\begin{abstract}
27 Latin American Writers títulos Themes: A Bio-Critical 25 William Foster 25
\end{abstract}

1822 del segmento de escritores caribeños, antillanos y de las

487 catálogo de títulos

títulos y caribeños de la Base de 377 Datos de Editoriales Cartone

822 del segmento de escritores caribeños, antillanos y de las títulos Guayanas disenado sobre la base de la combinación de los 384 Narrative: An Introductory Anthology editada por Kenneth autores Ramchand; la antologia They Came in Ships: An Anthology of Indo-Guyanese Writing diseñada por Joel Benjamin, Lakshmi 4757 Kallicharan, lan McDonald y Lloyd Searwar; la selección The
Routledge Reader in Caribbean Literature, editada por Alison $\begin{array}{ll}\text { títulos del Diccionario de la literatura } & \text { Doutledge Reader in Caribbean Literature, editada por Alison } \\ \text { Donell y Sarah Lawson Welsh; The Companion to Anglophone } & \text { Caribbean Literature editado por la mencionada Alison Donnel }\end{array}$ 597 latinoamericana de Susana Cella $\quad \begin{gathered}\text { Caribbean Literature editado por la mencionada Alison Do } \\ \text { y Michael A. Bucknor; y la selección The Oxford Book of }\end{gathered}$

\section{Tabla 1. Sintesis de} la composición del CLLyC: cantidad de títulos y autores por segmento.
53

\section{8}

atin American women

258
8 precolombinas
3) Búsqueda en soporte impreso y en digital de los títulos y autores del corpus en las plataformas comerciales y bibliotecas definidas y recolección de datos.

- Búsquedas efectuadas en trece plataformas: Amazon, Barnes \& Noble, Google Books, iBookstore / iTunes, Kobo, FreeEbooks, Casa del Libro (España), Gandhi (México), Librería Santa Fe (Argentina), Livraria Cultura (Brasil), Perubookstore. com (Perú), Scribd, Nubico (España).

- Búsquedas efectuadas en ocho bibliotecas: Columbia University Libraries, Biblioteca del Instituto Latinoamericano de Berlín, Biblioteca Nacional de España, Public Library New York (EE.UU.), Gallica (Biblioteca Nacional de Francia), Europeana (Biblioteca digital de la Unión Europea), Biblioteca Nacional de Perú, Biblioteca de São Paulo (Brasil).

El proceso de búsqueda y recolección de los datos en plataformas comerciales y bibliotecas

A) Se realizó la construcción de un "bot" para recolectar los resultados de la búsqueda de cada obra y autor del CLLyC en las diferentes plataformas. La forma de recolección varía de acuerdo con las características de cada plataforma y biblioteca.

B) Los datos que se recolectaron son: autor, título, soporte (papel/digital). Esta información fue almacenada en una base de datos para su posterior filtrado.

C) Mecanismo de búsqueda

1) Se cargaron los datos de autor + título + fuente en una base de datos. Aquellos títulos que pertenecen a más de un segmento del CLLyC, solo se buscaron una vez.

2) Se buscó solo el nombre de los autores del CLLyC en cada plataforma y biblioteca.

3) Se realizó una verificación de los resultados siguiendo tres criterios:

3.a) Coincidencia exacta: si el autor encontrado es exactamente el mismo que el que se buscaba, se lo considera válido.

3.b) Comparación flexible: si el autor encon- 
trado tiene las mismas palabras que el buscado ignorando los signos de puntuación, pero en otro orden, se lo considera válido. Por ejemplo: "Borges, Jorge Luis" es válido con "Jorge Luis Borges".

3.c) Similitud laxa: aquellos valores encontrados que contengan al menos una palabra de las buscadas, ignorando orden, puntuación, caracteres especiales (entiéndase caracteres con tilde, números, etc.) serán considerados válidos solo después de ser verificados manualmente en plataformas y bibliotecas. Este criterio de similitud laxa se aplicó en casos en los que las plataformas y bibliotecas no incorporan caracteres de los idiomas originales de las obras y autores (por ejemplo, el caso de las tildes en títulos y nombres de autores en Amazon).

De los resultados obtenidos, el 30\% de los títulos se incorporó a las búsquedas con el criterio 3.a (coincidencia exacta); el 20\% con el criterio 3.b (comparación flexible) y el 50\% restante con el criterio 3.c (similitud laxa) A su vez, de estos últimos, luego de la verificación manual, el 70\% fue considerado válido (porcentajes aproximados).

4) Luego se repitió el proceso, pero esta vez buscando autor + título en cada plataforma, solo de los autores que fueron verificados en el punto 3 .

5) Se realizó una verificación con el mismo método que en el punto 3, pero esta vez buscando coincidencia de autor + título.

De los resultados obtenidos en esta etapa, el 10\% validó con el criterio 3.a, el $30 \%$ con el criterio $3 . b$ y el $60 \%$ restante con el criterio 3.c. De estos últimos, luego de la verificación manual, solo el $20 \%$ fue considerado válido. (porcentajes aproximados).

6) Sobre la base de los resultados validados por el punto 5 , se realizaron una serie de tablas comparativas donde se organizaron los resultados.

D) Problemas que surgieron y soluciones halladas.

D.1. Problemas de contenido

\section{D.1.1. La calidad de los datos}

Los metadatos de cada plataforma sobre los que se realizaron las búsquedas son heterogéneos, imprecisos e inexactos, poseen errores ortográficos, palabras incompletas, los formatos varían según cada plataforma y biblioteca. Por ejemplo: el orden apellido-nombre, nombre-apellido en el caso de los autores. Solución: se optó por sumar dos criterios de búsqueda adicionales: comparación flexible y similitud laxa, descritos en los puntos 3.b y 3.c respectivamente, de esta forma el margen de error se redujo considerablemente.

\section{D.1. 2. La ubicación de los datos}

Las plataformas y bibliotecas no siempre ubican el título donde va el título y autor donde va el autor. Existen plataformas que no poseen siquiera en la misma página el conjunto de resultados. Esto es un error similar al problema 1 (calidad de los datos). Hay plataformas que ofrecen un resultado "Título: Jorge Luis Borges" y "Autor: El Aleph". Este resultado es considerado válido aunque los campos figuran invertidos. Solución: se optó por no dar relevancia a la ubicación si el valor buscado cumple con alguno de los criterios del punto 3 en cualquiera de los dos campos (título o autor) se consideró correcto, siempre y cuando el otro campo también cumpla con el mismo criterio para el otro valor.

\section{D.1. 3. La codificación de los datos}

No todas las plataformas (en especial, las bibliotecas) disponen de un buen soporte a UTF-8, esto es, caracteres especiales (tildes, caracteres $\mathrm{O}$, c, etc.) por lo que anulan en sus búsquedas aquellas palabras que contengan alguno de estos caracteres. Por ejemplo: si se busca "Antología poética" y se encuentra "Antologia poetica", el resultado es perfectamente válido, pero los buscadores de las plataformas no lo retornarán ya que no poseen soporte a estos caracteres. Este problema afecta las búsquedas de aquellas obras y autores en idioma portugués que utilizan caracteres especiales. Solución: en las plataformas donde se detectó el problema, se alteraron los términos de búsqueda antes de ser enviados, quitando los caracteres conflictivos y reemplazándolos por sus equivalentes. De esta forma, se amplía la obtención de resultados. También fue necesaria la implementación del criterio de búsqueda 3.c (similitud laxa) donde se ignora esto para no excluir posibles coincidencias en los resultados. 
D.1. 4. El tipo de formato digital

El formato digital o recurso electrónico es una categoría muy amplia: abarca desde los ebooks hasta software, videos, CDS y audio. Varias plataformas ofrecen recursos de varios tipos y no permiten un filtrado directo. Solución: se optó por recolecta solo los resultados que correspondan explícitamente a ebook, excluyendo cualquier otro tipo de recurso que pudiera aparecer.

\section{D.1. 5. Potencia de filtrado}

No todas las plataformas cuentan con un buscador avanzado. Varias solo permiten la búsqueda de un token uniforme (un texto donde autor y título deben ir juntos) por lo tanto, no es posible obtener gran precisión por parte de la plataforma en la lista de resultados obtenidos. Esto ocasiona que se deban analizar más resultados agregados para garantizar resultados confiables. Solución: se recolectaron todos los datos proporcionados por las plataformas y se agregó al bot un mecanismo para identificar y excluir aquellos que no correspondan con los patrones básicos. Por ejemplo: en el caso del problema 4, fueron excluidos mientras se recolectaban aquellos resultados cuyo formato era video.

D.1. 6. Volumen de resultados relevantes:

Varias plataformas, principalmente las comerciales, implementan lo que se conoce como "Paginador infinito", que consiste en mostrar en la primera y segunda páginas los resultados relevantes para la búsqueda, y a partir de las siguientes el resto de su catálogo, con lo cual una búsqueda puede generar varias decenas de miles de resultados, pero solo los primeros cincuenta son de importancia. Solución: solo se recolectaron los resultados correspondientes a las primeras tres páginas.

E) Creación de tablas

Todas las tablas poseen los siguientes campos:

- Plataforma/ Biblioteca: la dirección Web de la plataforma/ biblioteca para analizar.

- País de la plataforma/biblioteca: donde consta el país de sede de cada una.

- Autor y obra: se menciona el autor y se indica la presen- cia o ausencia en soporte digital de cada obra considerada del CLLyC. El orden de autores de las búsquedas se establece por ordenamiento alfabético de apellido de los autores. El orden de los títulos de las obras es el de inclusión en las fuentes utilizadas.

- Soporte de las obras: soporte papel/ formato digital.

- Cantidad de plataformas/bibliotecas en las que la obra está presente.

- Resultados sobre el total: sobre los títulos relevados, la cantidad de títulos obtenidos en la plataforma/biblioteca.

- Fuente: segmento del CLLyC que aporta la obra y autor (son quince fuentes)

Todas las búsquedas se hicieron en el idioma original de las obras. Se subraya, además, que en todas las tablas generales se marca la fuente de cada título y en el caso de yuxtaposición, se marca de qué fuentes provienen.

Se realizaron 61.551 búsquedas solo de autores y 207.570 búsquedas de autor + libro, todas efectuadas entre los meses de diciembre de 2014 y marzo de 2015.

En la base de datos construida existen 2.262.364 registros de resultados almacenados (cada uno corresponde a una tupla -lista ordenada de elementos o secuencia de ellos- compuesta por: sitio + libro buscado + autor buscado + título encontrado + soporte + autor encontrado).

Se realizaron 61.551 búsquedas solo de autores.

Se realizaron 207.570 búsquedas de autor + libro.

\section{Obras superpuestas:}

Obras que forman parte de un segmento del CLLyC: 16.515.

Obras que forman parte de dos segmentos del CLLyC: 3.095.

Obras que forman parte de tres segmentos del CLLyC: 714.

Obras que forman parte de cuatro segmentos del CLLyC: 70.

Obras que forman parte de cinco segmentos del CLLyG: 14 . 


\section{Autores y obras:}

- 746 autores con una obra en el CLLyC - 325 autores con dos obras en el CLLyC

- 241 autores con tres obras en el CLLyC

- 207 autores con cuatro obras en el CLLyC

- 185 autores con cinco obras en el CLLyC

- 157 autores con seis obras en el CLLyC

- 128 autores con siete obras en el CLLyC

- 95 autores con ocho obras en el CLLyC

- 84 autores con nueve obras en el CLLyC

- 82 autores con diez obras en el CLLyC

- 82 autores con once obras en el CLLyC

- 71 autores con doce obras en el CLLyC

- 54 autores con trece obras en el CLLyC

- 62 autores con catorce obras en el CLLyC

- 75 autores con quince obras en el CLLyC

- 36 autores con dieciséis obras en el CLLyC

- 31 autores con diecisiete obras en el CLLyC

- 22 autores con dieciocho obras en el CLLyC

- 23 autores con diecinueve obras en el CLLyC

- 31 autores con veinte obras en el CLLyC

- 23 autores con veintiúna obras en el CLLyC

- 25 autores con veintidós obras en el CLLyC

- 22 autores con veintitrés obras en el CLLyC

- 12 autores con veinticuatro obras en el CLLyC

- 17 autores con veinticinco obras en el CLLyC

- 9 autores con veintiséis obras en el CLLyC

- 9 autores con veintisiete obras en el CLLyC

- 8 autores con veintiocho obras en el CLLyC

- 12 autores con veintinueve obras en el CLLyC

- 8 autores con treinta obras en el CLLyC

- 5 autores con treinta y uno obras en el CLLyC

- 8 autores con treinta y dos obras en el CLLyC

- 4 autores con treinta y tres obras en el CLLyC

- 2 autores con treinta y cuatro obras en el CLLyC

- 7 autores con treinta y cinco obras en el CLLyC

- 3 autores con treinta y seis obras en el CLLyC
- 3 autores con treinta y siete obras en el CLLyC

- 2 autores con treinta y ocho obras en el GLLyC

- 1 autor con treinta y nueve obras en el CLLyC

- 1 autor con cuarenta obras en el CLLyC

- 4 autor con cuarenta y uno obras en el CLLyC

- 3 autor con cuarenta y tres obras en el CLLyC

- 1 autor con cuarenta y cuatro obras en el CLLyG

- 1 autor con cuarenta y seis obras en el CLLyC

- 1 autor con cuarenta y siete obras en el CLLyC

- 1 autor con cuarenta y ocho obras en el CLLyC

- 1 autor con cincuenta obras en el CLLyC

- 1 autor con cincuenta y ocho obras en el CLLyC

En resumen, la relación autor/obras en las búsquedas efectuadas: el $50 \%$ de los autores posee menos de cinco obras, el $75 \%$ menos de once títulos y un 25\% de los autores posee más de diez obras en el CLLyC.

Las Tablas generales realizadas con la transposición de impresos a digital de los títulos y autores del CLLyC construido en plataformas y bibliotecas constan en el punto 8 ("Anexos" de esta Tesis).

Tablas generales de comparación de ofertas en papel / digital en plataformas comerciales / bibliotecas de los títulos y autores CLLyC.

Amazon - Barnes \& Noble - Google Books - iBookstore / iTunes Kobo - Free-Ebooks - Casa del Libro - Gandhi - Librería Santa Fe Livraria Cultura - Perúbookstore.com - Scribd - Nubico / Columbia University Libraries - Biblioteca del Instituto Latinoamericano de Berlín - Biblioteca Nacional de España - Public Library New York - Gallica (Biblioteca Nacional de Francia) - Europeana (Biblioteca digital de la Unión Europea) - Biblioteca Nacional de Perú - Biblioteca de São Paulo 
8.2. Tabla general de comparación de ofertas en papel en bibliotecas globales de los títulos y autores del corpus literario latinoamericano diseñado

ColumbiaUniversityLibraries-Bibliotecadel InstitutoLatinoamericano de Berlín - Biblioteca Nacional de España - Public Library New York - Gallica (Biblioteca Nacional de Francia) - Europeana (Biblioteca digital de la Unión Europea) - Biblioteca Nacional de Perú - Biblioteca de São Paulo

\begin{tabular}{|l|l|l|c|}
\hline Autor & Obra & Fuentes & 言 \\
\hline Arguedas, José María & Los ríos profundos & 2,14 & 07 \\
\hline Borges, Jorge Luis & El Aleph & $1,2,3,14$ & 07 \\
\hline Borges, Jorge Luis & Obras completas & 2,14 & 07 \\
\hline Carpentier, Alejo & Concierto Barroco & $2,13,14$ & 07 \\
\hline Carpentier, Alejo & Los pasos perdidos & $1,2,3,13,14$ & 07 \\
\hline Abreu Gómez, Ermilo & Canek & 2 & 06 \\
\hline Abril, Xavier, & 2 & 06 \\
\hline Acevedo Díaz, Eduardo & Dos estudios & 2,14 & 06 \\
\hline Acevevedo Díaz. Fduardo & Ismael & 2.14 & 06 \\
\hline
\end{tabular}

8.3. Tabla general de comparación de ofertas en digital en plataformas comerciales y servicios de lectura en streaming y descarga de los títulos y autores del corpus literario latinoamericano diseñado

Amazon - Barnes \& Noble - Google Books - iBookstore / iTunes Kobo - Free-Ebooks - Casa del Libro - Gandhi - Librería Santa Fe -

Livraria Cultura - Perubookstore.com - Scribd - Nubico

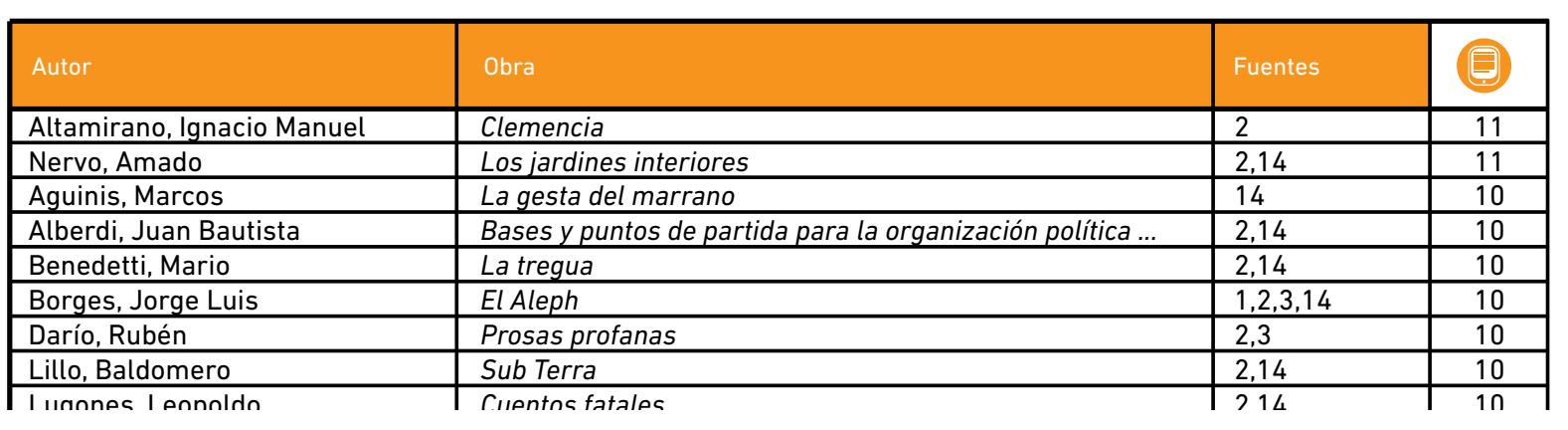

8.4. Tabla general de comparación de ofertas en digital en bibliotecas globales de los títulos y autores del corpus literario latinoamericano diseñado

Columbia University Libraries - Biblioteca del Instituto Latinoamericano de Berlín - Biblioteca Nacional de España Public Library New York - Gallica (Biblioteca Nacional de Francia) - Europeana (Biblioteca digital de la Unión Europea) - Biblioteca Nacional de Perú - Biblioteca de São Paulo

\begin{tabular}{|c|c|c|c|}
\hline Autor & Obra & Fuentes & e \\
\hline Cieza de León, Pedro & Crónica del Perú & 2 & 05 \\
\hline Ercilla y Zúñiga, Alonso de & La araucana & 2 & 05 \\
\hline Agustini, Delmira & Los cálices vacíos & & 04 \\
\hline Alberdi, Juan Bautista & El crimen de la guerra & 2,14 & 04 \\
\hline Alberdi, Juan Bautista & $\begin{array}{l}\text { Peregrinación de luz del día, o Viaje y aventuras } \\
\text { de la verdad en el Nuevo Mundo }\end{array}$ & 2 & 04 \\
\hline Altamirano, Ignacio Manuel & El Zarco & 2,14 & 04 \\
\hline Ascasubi, Hilario & Santos Vega & 2 & 04 \\
\hline $\begin{array}{l}\text { Ascasuol, Muldro } \\
\text { Bohadilla. Emilio }\end{array}$ & $\frac{3 \text { anlus vegd }}{\text { A fuean lento }}$ & $\frac{2}{2}$ & $\frac{04}{04}$ \\
\hline
\end{tabular}




\subsection{Estructura de la Tesis}

El cuerpo del trabajo se divide principalmente en cuatro apartados:

- La literatura latinoamericana y caribeña: canon y corpus propuesto.

- De la galaxia Gutenberg al ecosistema.

- Transposición de impresos a digital de la literatura latinoamericana y caribeña: plataformas digitales y bibliotecas digitales.

- Conclusiones.

Esta investigación se articula en la necesidad de dilucidar la relación entre literatura latinoamericana y caribeña e industria editorial en digital. Es decir, una nueva área de investigación a partir del impacto de la transposición a los distintos formatos en digital de los títulos de un CLLyC "no nativos digitales" (no producidos especialmente por medios digitales) (Strickland, 2009; Correa-Díaz, 2013), tomando como muestra el segmento latinoamericano del canon occidental construido por Harold Bloom y ampliado en un corpus de autores y títulos provistos por aquellas corrientes teóricas distantes en tensión con el mainstream literario.

Para eso, se lo desarrolla en un apartado dedicado a introducir el concepto de América Latina, de América Latina y el Caribe y de literatura latinoamericana y caribeña; la noción de canon; la idea de canon en Harold Bloom y distintas posturas que ingresan en contradicción con la propuesta de Bloom y que aportan a la construcción de un CLLyC.

El apartado dedicado a la "galaxia Gutenberg" y el "ecosistema del libro digital" nos permite ofrecer una visión que va desde la estructura del campo editorial dominado por el soporte papel (la cadena de agentes y acciones que conformaron el mencionado campo en el/los momento/s en que se editan los títulos del segmento latinoamericano y caribeño del canon occidental) hasta una descripción de la nueva estructura de agentes y acciones del nuevo campo editorial digital.

El tercer apartado estudia el traspaso de soporte impreso a formato digital de los títulos del CLLyC, con énfasis en el análisis de los datos obtenidos en las búsquedas en las distintas plataformas comercializadoras y bibliotecas. Es decir, es un apartado consagrado al análisis y comparación de los resultados obtenidos a partir de los indicadores que se elaboraron con el criterio metodológico descrito en el punto 1.3. de esta Tesis y cuya finalidad es la de dotarnos de un estudio comparativo que proporcione datos reales en relación con indicadores concretos. 
Finalmente, un apartado dedicado a la incorporación de las conclusiones obtenidas a partir de la exposición de los tres apartados anteriores.

En lo que hace a la dispositividad material de la Tesis, esta se presenta en tres tomos.

- En un primer tomo, se desarrolla el aparato crítico de los cuatro apartados de esta Tesis mencionados ut supra.

- En un segundo tomo, se edita el CLLyC realizado para esta Tesis con el listado de autores y obras por segmento que lo componen.

- En el tercer tomo, constan las 61.551 búsquedas solo de autores y 207.570 búsquedas búsquedas efectuadas con los resultados totales en soporte digital e impreso de los 20.409 títulos de los 2.932 autores del CLLyC diseñado.

\section{LA LITERATURA LATINOAMERICANA Y CARIBEÑA: CANON Y CORPUS PROPUESTO}

\subsection{América Latina, América Latina y el Caribe, literatura latinoamericana y caribeña. Algunos conceptos}

En el apartado 1 ("Objetivos") de esta Tesis, se mencionaba que el objeto de estudio de esta investigación es la acción de la industria editorial en digital en el marco de la transposición a formato digital de los títulos de los autores que componen el CLLyC diseñado para esta investigación. Pero, asimismo, la construcción del mencionado corpus literario torna necesaria la delimitación metodológica acerca de qué formas, autores y títulos se van a incorporar para la realización de las búsquedas en plataformas comerciales y bibliotecas. Es decir, la construcción del CLLyC deviene de precisar algunas de las consideraciones del debate terminológico en torno a las nociones de "América Latina" y "Caribe", y a las relaciones que entre ambas nociones puedan establecerse.

En principio, el adjetivo "latina" proviene del legado imperial francés como forma de incluir a Francia entre los países con influencia en América, excluyendo a las potencias anglosajonas. En 1836, el economista político Michel Chevalier publicaba en París las crónicas de sus viajes por América, continente en el que se replicaban a su entender las diferencias étnicas que se daban en Europa de la época:

Las dos ramas, latina y germana, se reproducen en el Nuevo Mundo. América del Sur es - como la Europa meridional-, católica y latina. La América del Norte pertenece a una población protestante y anglosajona (Chevalier, en Ardao, 1993: 55).

Esta primera idea, "creadora" del concepto, inicia la evolución del mismo por oposición a otros conceptos: latina por oposición a sajona.

España impulsó el término "Hispanoamérica" como marca de sus derechos por antigüedad, tradición, influencia, concepción geopolítica y continuidad de su presencia en la región desde 1492. A su vez, "Iberoamérica" fue la forma que encontraron España y Portugal en función de empalmar en una identidad común a las antiguas metrópolis de la península ibérica con sus viejas colonias (incorporando a Brasil) y, a su vez, excluir de la identificación, sobre todo, a Francia (y como respuesta a la operación de 
incorporación de la influencia imperial francesa a partir de la construcción de la categoría de "latinidad" impulsada por Francia desde la etapa de $\mathrm{Na}$ poleón III).

Asimismo, "Indoamérica" fue el término que propuso el intelectual y político peruano Víctor R. Haya de la Torre como forma de incorporar en la denominación de la región a los sectores descendientes de las sociedades precolombinas, a los pueblos originarios de América. A partir de la década de 1930 florecen en la región proyectos culturales y políticos indigenistas que reconocían la necesidad de incorporar la "trama indígena" en la configuración de las fisonomías nacionales de algunos de los países de la región. Esa América que integra latinidad e indigenismo fue calificada por el nicaragüense Augusto César Sandino como "indolatina” (Rouquié, 1989: 19).

Una primera aproximación de carácter geográfico a la categoría "América Latina" designa las partes del nuevo mundo que fueron colonizada por naciones de la Europa latina como España, Francia y Portugal. Sin embargo, un agrupamiento basado en regiones geográficas trae aparejadas inconsistencias de demarcación:

- Existen zonas del Caribe, Centro y Sudamérica que fueron dominadas por Inglaterra u Holanda (potencias coloniales no latinas): Antigua y Barbuda, Bahamas, Barbados, Belice, Dominica, Granada, Guayana, Jamaica, Saint Kitts y Nevis (San Cristóbal y Nieves), San Vicente y las Granadinas, Santa Lucía, Surinam, Trinidad y Tobago.

- Del mismo modo, hay zonas de Norteamérica en Canadá y Estados Unidos que fueron colonizadas por Francia y España, pero no se consideran latinoamericanas: Quebec, Luisiana, Florida, las regiones del Sur norteamericano anexionadas por EE.UU. y de antiguo dominio mexicano (Texas, Alta California, Nuevo México, Utah, Nevada, partes de Colorado, Oklahoma, Kansas, Arizona y Wyoming).

Pero, asimismo, para analistas como Rouquié (1989: 17), se trataría de un fallido "concepto cultural", que contendría a las naciones de cultura latina de América. Pero este tipo de encuadres traerían aparejadas otras inconsistencias:

- La inclusión de Canadá y su provincia francohablante de Quebec, "infinitamente más latina que Belice y tanto como Puerto Rico, estado libre asociado de Estados Unidos", pero a los que nunca nadie ha pensado incluirlos, "ni siquiera al nivel de su provincia francohablante, en su subconjunto latinoamericano" (Rouquié, 1989: 17)
- Según los censos oficiales elaborados entre 2000 y 2008, el total de población indígena identificada en América Latina es de 28.858.580 personas, mientras que en Latinoamérica habi$\tan 479.824 .248$ personas. Esto supone un porcentaje de población indígena identificada del 6,01\%. No obstante, Unicef (2009) destaca que la cifra de población indígena de América Latina se suele fijar en el 10\% del total de habitantes, según estimaciones elaboradas en 2004 por el Programa de Naciones Unidas para el Desarrollo (PNUD). Este universo demográfico difícilmente puede considerarse latino, y amplios sectores de la población quedarían excluidos del nombre otorgado a la región en donde viven.

- A su vez, las poblaciones no latinas que descienden de la inmigración no latina también quedarían fuera del agrupamiento: ¿son latinas "la Patagonia de los agricultores galeses, la Santa Catarina brasileña poblada de alemanes así como el sur chileno?" (Rouquié, 1989: 17).

- Tampoco es apropiado el nombre de "latinos" para la numerosa descendencia de africanos y asiáticos en el continente, quienes poseen una influencia cultural de envergadura en numerosos países. Al decir de Rouquié (1989: 17): "`son latinas esas Américas negras descritas por Roger Bastide?”.

Un agrupamiento de carácter idiomático, reducido a los países de América que havan adoptado el castellano, francés y portugués como lenguas heredadas de las potencias coloniales, también traería asociadas otras inconsistencias. En la región se habla una multitud de lenguas de origen precolombino, tanto con estatus oficial reconocido como no reconocido y que forman parte del patrimonio lingüístico de la región que denominamos "América Latina". Los pueblos indígenas de la región hablan 420 lenguas distintas, de las cuales 103 (el 24,5\%) son idiomas transfronterizos que se utilizan en dos o más países. Además, 108 pueblos indígenas son también transfronterizos (Unicef, 2009):

- El aimara posee 2,5 millones de hablantes.

- El guaraní posee de siete a doce millones de hablantes.

- Las lenguas caribes como el garifuna, el akawaio pemón, yukpa, eñepa, maquiritare o yecuaná, carïjona, chocó, kariña, waizwai, atroari, ingaricó, ikpeng, kuikuro, bacairí, apalai, hishkaryana, taulipang y macusí poseen 50 mil hablantes (Ethnologue).

- Las lenguas mavenses (huastaneca, yucatanecas, cholanas, kanjobalano-chujeanas, mameanas, quicheanas, poqom) po- 
seen cerca de seis millones de hablantes. Estos están distribuidos mayoritariamente en Guatemala (3,2 millones de hablantes) y México (2,2 millones de hablantes) y en menor medida en Belice (cinco mil hablantes), Honduras y El Salvador (Ethnologue).

- El mapundungun posee entre 100 mil y 200 mil hablantes en Chile y la Argentina (Zúñiga, 2006: 402).

- El náhuatl posee cerca de dos millones de hablantes, distribuidos mayoritariamente en México, con 1.700 .000 hablantes, Estados Unidos con 275.000 hablantes y El Salvador (náhuat) con 150-200 hablantes (Lemus, 2008: 1).

- El quechua, la lengua nativa con mayor número de hablantes, de nueve a catorce millones, se habla en siete países distintos: Argentina, Bolivia, Brasil, Colombia, Chile, Ecuador y Perú (Ethnologue).

Rouquié (1989) describe a América Latina como una América periférica que pertenece culturalmente a Occidente; sus Estados poseen un paralelismo en sus evoluciones históricas, y semejanzas de las obligaciones y las estructuras económicas y sociales; con una dependencia multiforme en relación con un centro único situado en el mismo continente: EE.UU. (Rouquié, 1989: 20). Para Oszlak (2007: 45, 46, 47, 48) pese a la heterogeneidad en la construcción de los estados latinoamericanos existen alguno elementos comunes, como las dificultades para alcanzar el desarrollo económico y social pleno y la persistente interrupción militar durante buena parte de la historia. Además de la coincidencia temporal de sus procesos de emancipación de las metrópolis coloniales.

Es decir, en la idea de Rouquié, una América Latina periférica es definida, también, en relación con los países centrales de la propia América (como EE.UU. y Canadá y algunas de las prósperas colonias británicas y holandesas). Esta acepción habilitaría la incorporación de algunas de la regiones con población anglohablante, como algunas de las Antillas y Guyana. A su vez, la idea de pertenencia al "mundo occidental" de América Latina definiría también un territorio que fue colonizado cuando las civilizaciones precolombinas se encontraban en crisis, lo que facilitó la imposición de lenguas, "valores y religión" (Rouquié, 1989: 22). Además de que tantos los pueblos originarios como los africanos esclavizados intervinieron sus formas religiosas creando formas sincréticas con la religión cristiana. Esta excepcionalidad dota a la región de un carácter de "Tercer Mundo de Occidente o el occidente del Tercer Mundo" (Rouquié, 1989: 22). Para Néstor García Canclini (1995: 149):
La cristianización de los indígenas, su alfabetización en español y portugués, el diseño colonial y luego moderno del espacio urbano, la uniformación de sistemas políticos y educacionales fueron consiguiendo uno de los procesos homogeneizadores más eficaces del planeta. Quizá con la excepción de los países árabes no existe otra zona en que un número tan grande de Estados independientes compartan un mismo idioma, una historia, una religión predominante, y que además hayan tenido una posición más o menos conjunta, durante cinco siglos, en relación con las metrópolis.

En esta descripción también priman las nociones de representación de la región en torno a los idiomas adoptados de las metrópolis. Pero también las maneras en que estas dejaron presentes durante mucho tiempo sus estructuras institucionales desarrolladas durante siglos y la recurrente idea del agrupamiento regional frente a las mismas metrópolis. A partir de la independencia, los estados del subcontinente recorrieron -con diferencias y retrasos- trayectorias paralelas en las cuales aparecen períodos claramente discernibles. Luego de una etapa de "larga espera" para una ruptura profunda con el régimen colonial (1825-1850) (Halperín Donghi, 1989: 145), se desarrolla (con excepciones centroamericanas y caribeñas) un periodo de orden neocolonial: integración en el mercado internacional de sus economías y élites; primarización de sus economías y exportaciones; ingreso a la división internacional del trabajo bajo supervisión de Gran Bretaña mediante especialización de producciones (mayoritariamente, primarias). Además, por un lado, la reconfiguración del Estado heredado de las metrópolis coloniales que, en lugares como Brasil, Perú y México, poseía un aparato institucional "lo suficientemente desarrollado en la época de la independencia como para resultar de utilidad a los nuevos gobernantes" (Malamud, 2007: 89). Este aparato institucional compensó factores físicos, étnicos, culturales que obstaculizaban los procesos de integración nacional. Por otro lado, la creación de condiciones de "estatidad" ("ser Estado") que les permitiera ser reconocidos por los demás estados del mundo, poseer el monopolio de la fuerza al interior de sus propias naciones, capacidad de crear una burocracia, capacidad de diferenciarse de la sociedad civil y crear y emitir símbolos con la idea de generar sentimientos de pertenencia (para el control ideológico como mecanismo de dominación) (Oszlak, 1982: 532).

Es de destacar que en este periodo, en algunos países de la región las corrientes inmigratorias alentadas desde los Estados nacionales en función de cubrir las necesidades de mano de obra para las economías primarias llegaron a ocupar porcentajes cercanos al 30\% de la población total. Tal es el caso de la Argentina entre 1910-1914 (siendo el 14,5\% de la población total en EE.UU.) (Sánchez Alonso, 2007: 400). La inmigración neta en la Argentina durante el período 1881-1930 alcanzó a 3,8 millones. En el periodo 1821-1932, la Argentina recibió un total de 6,4 millones y Brasil 4,4 millones (Whitaker, 1964: 54). Uruguay atrajo cerca de 600.000 inmigran- 
tes durante el mismo periodo. México acercó a 270.000 inmigrantes (para el periodo 1880-1900); más o menos el mismo número de inmigrantes permaneció en Cuba entre 1902 y 1930. En Chile ingresaron 200.000 inmigrantes. En Paraguay se recibieron menos de 18.000 inmigrantes. (Ferenczi y Willcox, 1929, citados por Sánchez Alonso, 2007: 400). Los salarios ofrecidos en algunas de las actividades económicas de la región superaban holgadamente a los salarios ofrecidos en los países de origen: hasta 1914 los salarios en la Argentina y Uruguay fueron de más de 200\% mayores en comparación con un promedio ponderado de los salarios de Italia, Portugal y España. Y alcanzaban los montos salariales ofrecidos por las mismas actividades económicas de los EE.UU. (Williamson, 1999, citado por Sánchez Alonso, 2007: 400). Demás está marcar que todo el desarrollo de la etapa se centraba en modelos agroexportadores, con utilización de mano de obra bajointensiva.

Así, entre 1880 y 1930, el orden neocolonial relacionado con la asociación de las élites locales a los intereses de Gran Bretaña llegó a su máximo desarrollo, quebrado por la crisis internacional de 1929. Esta crisis marcó el punto límite entre el mundo hegemonizado por el Imperio Británico y e nuevo mundo con preponderancia de EE.UU., que se erige como la nueva metrópolis de la región. Este periodo post 1930 está determinado por la relación de los países de la región con EE.UU. y en menor medida, con Canadá (Rouquié, 1989: 25). La relación entre ambos bloques entre 1933 y 1960 se caracteriza por un escaso nivel de intervención de los EE.UU. en América Latina (y buena vecindad). En lo económico, el modelo de desarrollo de la región estuvo centrado en la sustitución de importaciones y producción industrial destinada al mercado nacional con preeminencia de capitales nacionales. Más allá de esta periodización anclada en las relaciones internacionales, las fases económicas que atravesaron los distintos países son muy diferenciadas y no puede "discernirse un lazo causal evidente" (Rouquié, 1989: 25).

A este periodo lo seguirían relaciones más conflictivas con EE.UU. en un contexto de crisis de relaciones interamericanas como consecuencia de la Revolución cubana. La expansión de su influencia a gran parte de la región signó gran parte de las relaciones en el marco de la denominada "guerra fría" entre EE.UU. y sus aliados y el bloque hegemonizado por la antigua U.R.S.S. (y un rol secundario, pero partícipe, de China), además de los procesos de descolonización de Argelia y otras regiones de África y Asia (de manera destacada, Vietnam). En esta etapa, que se inicia en la década de 60, EE.UU. utiliza tácticas de bloqueo económico, ayuda económica (como la Alianza para el Progreso lanzada por Kennedy en 1961) y la intervención militar directa (Playa Girón -Cuba-, República Dominicana, Guatemala, Granada) y apoyo y subsidio a golpes militares en toda la región. El internacionalismo de los 60 articuló la estrategia cultural de la ya mencionada Alianza para el Progreso del presidente norteamericano John F. Kennedy para la región: una red de intereses comerciales, discursos geopolíticos y políticas de diplomacia cultural se desarrolló como uno de los vectores del campo cultural para el establecimiento de relaciones Norte-Sur en función de refundar una idea de identidad artística panamericana, acorde con la estrategia de internacionalismo mercantil que impulsaba David Rockefeller. Una retórica panamericanista intentó expresarse como la narrativa propia de la forma cultural de un mercado económico común que funcionara como vector contrahegemónico continental contra el internacionalismo socialista, cuya expresión latinoamericana más acabada (y novísima) era Cuba. Partes de algunas de las élites culturales de la región abrazaron el proyecto, como en los casos de Argentina y Brasil. Andrea Giunta $(1999,2001)$ destaca que desde la OEA (Organización de Estados Americanos)-organismo totalmente imbuido en la filosofía del panamericanismo-José Gómez Sicre (director de la sección de artes visuales de dicha organización) celebraba que América Latina hubiera comenzado a expresarse en el llamado lenguaje internacional desde fines de la década del 50. Este director de la sección de artes visuales de la OEA

proclamó reiteradas veces en el Boletín de Artes Visuales de la OEA que el mapa del poder cultural había cambiado y que ahora todas las ciudades de América (Nueva York, Buenos Aires, Río de Janeiro, Lima, Ciudad de México, San Pablo, Caracas, Washington) eran centros internacionales de arte (Giunta, 1999: 4).

Durante los primeros años de la década del 60 la asociación entre la crisis Este-Oeste desatada por Cuba y las políticas hemisféricas estadounidenses en el campo cultural intentando establecer sociedades culturales con parte de las élites latinoamericanas caracterizaron un segmento importante de la expresión artística de la región. Otros actores del campo institucional como Rafael Squirru, director del Departamento de Asuntos Culturales de la Unión Panamericana promovieron la integración de la forma internacionalista con las formas regionales y provincianas de expresión artística de la zona. La táctica consistía en fusionar expresionismo estético internacional (en realidad: elemento cultural nacional norteamericano, a la manera de Jackson Pollock, Mark Rothko, Philip Guston, Adolph Gottlieb, Willem de Kooning, Arshile Gorky, Robert Motherwell), con regionalismo artístico:

¿Es una versión latinoamericana de la abstracción, ya sea lírica o geométrica, la misma que la de Europa, Estados Unidos o Japón? ¡No! Las formas de expresión son internacionales pero el artista latinoamericano las maneja en una nueva, diferente, original manera propia (Squirru, citado por Giunta, 1999: 11)

El diseño del internacionalismo/panamericanismo suponía la sustracción de la tradición y formas del arte latinoamericano y su incorporación al arte internacional de manera que pudiera -el arte latinoamericano- incorporarse a la modernidad por su llegada tardía a la misma. Pero, a medida que fue avanzando la década, la realidad política latinoamericana fue mu- 
tando y recolocándose frente a otros (nuevos) problemas relacionados con su rumbo histórico-social y también lo hacía su campo cultural. La idea de aplicación del término "internacional" al arte latinoamericano comenzó a funcionar como descripción de mecanismos de subalternización desde ese momento.

Asimismo, y en lo económico en la etapa iniciada en 1960, ingresa en crisis el modelo de sustitución de importaciones y colapsa la capacidad financiera y tecnológica de muchos de los países de la región. Esto traería aparejado el desembarco de las empresas multinacionales en la industria de los países de la región en los años subsiguientes. El modelo de sustitución de importaciones propugnaba una intervención fuerte del Estado en la economía, a nivel de la producción y de la distribución e impulsaba controles de importación y exportación; otorgaba subsidios directos e indirectos a las empresas industriales; regulaba precios; subsidiaba tasas de interés en función de promover capitales productivos. Este modelo, llamado "desarrollismo" en países como la Argentina, Chile, Uruguay, Brasil y México fue quebrado por las sucesivas crisis económicas que atravesaron a nivel de las economías nacionales y las distintas fases de la economía internacional.

Gradualmente, los estados de América Latina fueron generando un nuevo tipo de Estado, del tipo autoritario, caracterizado por la intervención estatal sobre la sociedad con el fin de reestructurarla (Malamud, 2007: 90). Guillermo O'Donnell (1982) desarrolló el concepto de "Estado burocrático-autoritario" para describir estos regímenes. Y así lo fueron los Estado de la Argentina (1966-73 y 1976-83), Brasil (1964-84), Chile (1973-90) y Uruguay (1973-89). Para O’Donell (1982), el Estado burocrático-autoritario se desarrolla cuando el rol del Estado ingresa en una crisis completa de su rol, es decir, el Estado ingresa en una crisis de dominación social. En este caso, el Estado se vale de mecanismos de coacción en ausencia de mecanismos democráticos, desde una orientación tecnocrática eficientista de la gestión estatal. Esto combinaba mecanismos de represión a la escala de los problemas de autoridad estatal de cada país con programas de racionalización del sector público. América Latina alternó este tipo de regímenes con estrategias estatales ligadas al autoritarismo tradicional populista $(\mathrm{Ma}-$ lamud, 2007: 90). Martínez (2012: 48) marca la importancia del reconocimiento de las diferencias entre las distintas experiencias autoritarias en los países de la región, lo que desemboca en las diferentes características de la apertura democrática posterior. En los 80, la democracia fue adoptándose aleatoriamente en los países de la región: Ecuador, en 1978; Perú, en 1979; Bolivia y Honduras, en 1982; Argentina, en 1983; Uruguay, en 1984; Brasil y Paraguay en 1989; Panamá, en 1989 (a posteriori de una invasión de EE.UU.); Chile, en 1990; Nicaragua (posterior a la revolución sandinista) en 1990; El Salvador, en 1992; Guatemala, en 1990; Haití (luego de vario intentos fallidos: golpes de Estado e invasión de E.E.UU. con apoyo de la OEA y la ONU), en 1996, así como en República Dominicana (también después de varios intentos fallidos y sospechas de fraude electoral). Pedro- sa (2012; 2013: 211-213) destaca que aunque antes de la caída del Muro de Berlín "se habían producido importantes avances" en los procesos de transición democrática, lo que volvió anacrónicas las disputas armadas en los países de la región fue la "desaparición del socialismo real", lo que permitiría allanar el camino a la "tercera ola democrática" internacional a un conjunto de países de la región (Huntington, 1994; Pedrosa, 2013). Las transiciones, sobre todo

las que se realizaron en Centroamérica, donde los acuerdos de paz y el desarme de los grupos en conflicto, estuvieron fuertemente condicionados por la presión internacional. En estos casos, la presencia de actores externos en forma de mediadores, organizaciones internacionales, grupos de países amigos o, directamente, actores que interfirieron en la búsqueda de llevar el proceso a algún lugar que les conviniese geopolíticamente (como Cuba o EE.UU.), ocurrió en forma pública y notoria (Pedrosa, 2013: 211).

En ese contexto de salida de la guerra fría, a la influencia de actores externos directos que intervinieron en algunos de los procesos de transición democrática, es necesario destacar que en algunos de los países, sobre todo de la región sur de América Latina, existió una influencia marcada de la situación europea. Las transiciones española, portuguesa y griega funcionaron también como "referencias muy claras: una región que ha superado las experiencias autoritarias" y la noción de integración regional europea percibida "como un elemento central para la consolidación democrática" (Martínez, 2012: 49). En relación con las semejanzas de las obligaciones y las estructuras económicas y sociales en los distintos países de la región que subraya Rouquié (1989: 17) las tres más destacadas son: a) la concentración de la propiedad de la tierra; b) la antigüedad de la independencia y los modelos de desarrollo adoptados como determinantes de la singularidad de los procesos de modernización (industrialización tardía y escasamente autónoma con una urbanización fuerte, anterior al nacimiento de la industria) y c) la amplitud de los contrastes regionales resultantes de la urbanización concentrada, las estructuras agrarias particularizadas y la singularidad de cada proceso de industrialización.

A su vez, destacamos que el análisis previo nos permite señalar las imprecisiones y la ambigüedad de la etiqueta "América Latina", al dilucidar que este concepto no es "ni plenamente cultural ni solamente geográfico" (Rouquié, 1989: 17). La noción de existencia de América Latina definida por oposición y desde afuera es la que prima en este trabajo, es decir, la mayoría de las veces utilizamos esta categoría como forma de oponer a los países de la región con otros países. Esto es en oposición tanto con los países del continente que funcionan como nuevas metrópolis de la región, como los EE.UU. y Canadá, como en oposición con el resto de los países y regiones del mundo. Y, a la vez, como forma de identificación de producciones culturales de los artistas de la región en relación con las producciones de otras regiones. Aunque en el área cultural, 
"pese a la multiplicación de organismos integradores desde los años cincuenta (OEA, CEPAL, ALALC, etc.), ni siquiera hemos logrado establecer entre los países de América Latina formas de colaboración duradera y de conocimiento recíproco" (García Canclini, 1995: 149). La dificultad de acceder a producciones culturales entre los países de la región sigue siendo una característica de los mercados de bienes culturales de América Latina. En este plano, la dificultades para acceder a producción literaria de los escritores latinoamericanos siguen colocando a la región en una dependencia de los catálogos de la industria editorial española. La circulación intrarregional de bienes culturales sigue siendo deficiente, aunque el crecimiento de algunas producciones en el ecosistema digital indica una tendencia que puede facilitar la integración en algunas disciplinas.

Utilizaremos la categoría América Latina porque se ofrece como un término "cómodo", sin ignorar "sus límites y sus ambigüedades" (Rouquié, 1989: 20 y demarcando por oposición:

El término no alcanza a países ubicados en el continente como Belice, Surinam, Guyana, Guyana Francesa, Estados Unidos o Canadá. Tampoco a las islas caribeñas anglosajonas como Jamaica, Barbados, Antigua y Barbuda, Santa Lucía, San Kitts y Nevis, San Vicente y las Granadinas, Dominica (Varda, 2015).

Aunque, ya desde 1948 las Naciones Unidas con su proceso de regionalización fue dando lugar a la creación de organismo como CEPAL (Comisión Económica para América Latina y el Caribe), ILPES (Instituto Latinoamericano y del Caribe de Planificación Económica y Social), GELADE (Centro Latinoamericano de Desarrollo Empresarial), CLACSO (Consejo Latinoamericano de Ciencias Sociales) que fueron incorporando la idea de bloque regional compuesto por América Latina y el Caribe, a su vez, se fueron dando incorporaciones sucesivas a partir de la creación de organismos aglutinadores posteriores: la Comunidad de Estados Latinoamericanos y Caribeños (CELAC) creada en 2011 (además de la Unión de Naciones Suramericanas -UNASUR- que está formada por 12 países suramericanos soberanos independientes, en funciones desde 2011). Es, en este punto, en el que se plantea la pertenencia del Caribe a un concepto de América Latina de mayor amplitud, también ligado al crecimiento de relaciones diplomáticas y de asociación en organismos internacionales compartidos por los países del área, como es el caso de la Comunidad de Estados Latinoamericanos y Caribeños (CELAC). Sus Estados miembros son:
- Antigua y Barbuda

- República Argentina

- Mancomunidad de las Bahamas

- Barbados

- Belice

- Estado Plurinacional de Bolivia

- República Federal de Brasil

- República de Chile

- República de Colombia

- República de Costa Rica

- República de Cuba

- República Dominicana

- Mancomunidad de Dominica

- República del Ecuador

- República de El Salvador

- Grenada

- República de Guatemala

- República Cooperativa de Guyana

- República de Haití

- República de Honduras

- Jamaica

- Estados Unidos Mexicanos

- República de Nicaragua

- República de Panamá 
- República del Paraguay

- República del Perú

- Santa Lucía

- Federación de San Cristóbal y Nieves (Saint Kitts \& Nevis)

- San Vicente y las Granadinas

- República de Surinam

- República de Trinidad y Tobago

- República Oriental del Uruguay

- República Bolivariana de Venezuela

Si las organizaciones globales (ONU, UNESCO, Banco Mundial, Fondo Monetario Internacional) imponen la categoría "América Latina y el Caribe" con fines de simplificación estadística, la composición de la Comunidad de Estados Latinoamericanos y Caribeños (CELAC) demuestra que estos países la aceptan. Es decir, que el "autorreconocimiento de la etiqueta por los países implicados vía participación en la CELAC" (Malamud, 2015) funciona como uno de los criterios de demarcación. Para UNESCO (2015), América Latina y el Caribe es una región que "no siempre corresponde con la geografía, sino que tiene que ver con la ejecución de las actividades regionales de la Organización" y cuya "definición propia" tendría más que ver con esos criterios de actividades regionales que con otros criterios (no explícitos, por cierto, de parte de la Organización). ${ }^{5}$

A esta vinculación entre América Latina y el Caribe en términos de políticas gubernamentales y diplomáticas le es subsidiaria la incorporación de la literatura francohablante del Caribe desde mediados de los 60 al concepto de "literatura latinoamericana", que sirvió como avanzada para una vinculación entre la literatura latinoamericana y el resto de la literatura caribeña. Vinculación articulada, sobre todo por dos tipos de dispositivos teóricos: a) por un lado, la historia común del Caribe insular anclada en rasgos económico-sociales similares como lo son "economía de plantación,

${ }^{5}$ Los países que enumera UNESCO son: Antigua y Barbuda, Argentina, Bahamas, Barbados, Belice, Bolivia, Brasil, Chile, Colombia, Costa Rica, Cuba, Dominica, República Dominicana, Ecuador, El Salvador, Granada, Guatemala, Guyana, Haití, Honduras, Jamaica, México, Nicaragua, Panamá, Paraguay, Perú, Saint Kitts y Nevis, Santa Lucía, San Vicente y las Granadinas, Suriname, Trinidad y Tobago, Uruguay, República Bolivariana de Venezuela, Anguila*, Aruba*, Islas Vírgenes Británicas*, Islas Caimán*, Curaçao*, Sint Maarten* ${ }^{*}$ Estados asociados) trata de esclavos, historia de cimarronaje, cultura de resistencia, incomunicación entre las islas y luchas entre las metrópolis" entre otros rasgos (Pizarro, 1987: 25) y b) por otro lado, las relaciones históricas comunes del Caribe con zonas de la región latinoamericana, las formas de desarrollo cultural similares y la literatura, por la evidencia de temas y problemas, así como "articulaciones que son asumidas tanto en el caso de las literaturas del Caribe inglés y holandés como en el caso del francés y el español, tanto el papiamento o su equivalente de Surinam, en los términos en que se asumen en la literatura latinoamericana" (Pizarro, 1987: 25).

A su vez, estos rasgos de similitud en la organización de los sistemas literarios de América Latina y Caribe son expuestos por aquellos trabajos de este tipo de dispositivos teóricos del tipo b) que marcábamos previamente: existen en un primer nivel sistemas literarios ligados a la metrópoli (Gran Bretaña, Holanda, Francia); en un segundo nivel se dan otros sistemas literarios en creole, papiamento, papiamen; e inclusive, en un tercer nivel, sistemas multilingües. Es decir, que la estructura de los sistemas literarios del Caribe, Antillas y Guayanas se muestra organizada con la misma disociación de las estructuras lingüísticas heredadas de la metrópolis que en América Latina.

Para Cornejo Polar (1987: 131), el sistema literario latinoamericano se desarrolla en la tensión entre fuerzas que conducen a la integración y fuerzas que "tienden a desmembrarle". Pero, también, en el marco de las contradicciones propias al interior del sistema literario combinadas con "las fluctuaciones que dependen de la hegemonía que pueda adquirir en determinado momento una de esas dos fuerzas". Sin embargo, como destaca Pizarro (1987: 132-144), la constitución del sistema literario caribeño es resultado del desarrollo de un primer proceso "fundacional" en la cultura del Caribe que hizo que diferentes intelectuales hicieran un giro sobre el espacio antillano con el "movimiento de la negritud" en la década del 30: el poeta africano Léopold Sédar Senghor, al martiniqueño Aimé Césaire y el guyanés León Gontran Damas. Césaire utiliza el concepto négritude en la revista "L'Etudiant Noir" y lo reutiliza como categoría en su libro Cahier d'un retour au pays natal, en 1939. La idea de negritud funciona en Césaire como poética y como programa político de autoafirmación cultural en el marco de las luchas por los derechos civiles de la población negra. Glissant (1980) planteó la idea de détour (desvío) sobre la de retour (retorno) ante la imposibilidad de retorno a la tierra africana por parte de la población de origen africana trasplantada a Martinica. La noción de desvío a la tierra nativa del Caribe funciona como manera de ocultamiento de la dominación con la máscara de la asimilación. Para Glissant, las prácticas culturales del détour se perciben de manera destacada en la lengua créole: "primera geografia del Desvío, y que solamente en Haití escapó a esta finalidad original" (1980: 49). La criollidad no sería para Glissant el criollismo, sino la posibilidad de "generar un lenguaje que teja las poéticas, quizás opuestas, del créole y de la lengua francesa". En los países latinoamericanos el pensamiento criollo/mestizo tuvo un comportamiento diferente al del 
Caribe. Este pensamiento ha ido derivando desde una matriz eurocéntrica a formas filosóficas de la liberación y el pensamiento crítico, alejándose de esa tradición moderna desde la irrupción de trabajos como los de Juan Carlos Mariátegui. Esta deriva se constituye como renovación de la idea de criollidad/mestizaje en la construcción de lo que Mignolo (2003: 58) denomina "paradigma otro", es decir, el paradigma de ruptura construido por el pensamiento crítico y utopístico que se formula en todos los lugares en los cuales la expansión imperial/colonial "negó la posibilidad de razón, de pensamiento y de pensar el futuro" (Mignolo, 2003: 20).

Volviendo a Glissant (2008: 317):

Una definición del creóle es la de una lengua mezclada con elementos tomados de dos diferentes lenguas-madres. Esto significa que, en Martinica, Haití, Guadalupe, Santa Lucía o Dominica, el creóle está hecho a partir de un léxico francés. Para decirlo con más precisión, no es el idioma francés; sino la lengua de Normandía y de Bretaña, la lengua hablada por los marineros y otros inmigrantes. La sintaxis es una suerte de sintaxis de varias lenguas de la costa occidenta de África. El creóle, por tanto, es realmente una lengua de mezcla, así como una lengua de compromiso entre los antiguos esclavos y los antiguos amos.

Esta idea de criollidad sería el punto de partida desde el cual se percibe una identidad caribeña auténtica. Si Frantz Fanon y René Depestre introducen aquella primera categoría de negritud de Césaire en la corriente histórica, la idea de créolisation (acriollamiento) de Glissant marcaría una segunda etapa de construcción de una identidad de una región caribeña (ampliada) anclada en el sistema de plantación y balcanizada por los colonizadores occidentales. Una región "integrada por las Antillas y e Caribe, la costa caribeña de América Latina (parte costera de Venezuela y Colombia, que es diferente en muchos aspectos de los Andes sudamericanos), las Guayanas, la parte noreste de Brasil , y parte del sur de los Estados Unidos, se conecta a México y América Central, cuyo carácter de West Indian es evidente tanto en Panamá como en Belice. Las fronteras de Panamá y Belice definen una zona más extensa, entre América del Sur de los cuales estos países forman parte, y América del Norte" (Glissant, 2008: 81).

Según Glissant, existe un lenguaje común entre los diversos escritores del Caribe, independientemente de su lengua. Guillén, Walcott, Naipaul y el propio Glissant forzarían a las lenguas occidentales de acuerdo con sus necesidades expresivas, lo que podrían inscribirse en lo que llama poéticas de relación, pensamientos de archipiélago, aperturas a las complejidades de lo diverso frente a esa insularidad diversa y balcanizada. El crítico trinitense Kenneth Ramchand expresaba (1987: 145):

Cuando leo Pedro Páramo y la obra de un autor guyanés, me veo frente a una conciencia muy similar. Latinoamericanos y west indians compartimos una misma conciencia a pesar de las diferencias sociohistóricas. ¿Qué es más importante, esta conciencia común o los factores materiales que nos separan? Creo que una conciencia de América Latina que no excluya al Caribe no hispanoparlante puede ser propugnada y estimulada.

Las operaciones de integración literaria (y cultural) latinoamericana se iniciaron con un nivel inicial de integración de las letras en castellano, luego pasaron a un segundo nivel de integración de las letras americanas en castellano y portugués (que incorporó la literatura brasileña), para derivar en un tercer nivel de integración de las literaturas de todas las lenguas latinas con la inclusión de las literaturas francés (especialmente, de Haití). Ardao (1996: 33-34) propone un cuarto nivel de integración, "supernumerario" con la incorporación de "las letras americanas de otras lenguas correspondientes a su área: autóctonas hacia un extremo, de procedencia europea no latina hacia otro" en el contexto de un proceso no completado "a cabalidad". En este cuarto nivel de integración, tendríamos un sistema literario latinoamericano integrado por todas las literaturas en las distintas variedades del castellano y del portugués de América Latina, francés, inglés, holandés, papiamento, guaraní, náhuatl, aymará, quiché, patois, creole, jorapa, portuñol y las heteroglosias de todas las regiones de América Latina, Caribe, Antillas y Guayanas. En este cuarto nivel, ya disponemos de un campo literario común latinoamericano y caribeño.

La incorporación al premio anual de Casa de las Américas (Cuba) de la literatura caribeña de expresión inglesa (en 1975) y de la literatura caribeña francófona (en 1979) funcionó como puente articulador entre las literaturas de América Latina y el Caribe (además de la influencia de la Revolución cubana en toda la región). Asimismo, este premio prosiguió generando vínculos al generar los premios para la literatura brasileña (en 1980) y para la literatura indígena (en 1994). Además, existe consenso académico sobre la delimitación de los sistemas literarios latinoamericanos más allá de la localización geográfica y que tiene que ver con los llamados sistemas literarios populares, con los sistemas literarios en lenguas nativas y con las distintas formas heteroglósicas de las literaturas de la región. Para Ana Pizarro (1987: 190-191) la literatura

forma parte de la formalización estético-cultural de la misma manera que rasgos estético-culturales de otras formas ideológicas, como religión, derecho, filosofia, cultura en general. Esta interrelación permite ampliar la noción de la literatura hasta incluir en su ámbito discursos como la oratoria, los sermones, el discurso histórico, político, filosófico, etc.

Pero, frente al riesgo de una inclusión sin límites, la misma Pizarro propone la utilización del concepto de recepción "entendido como la percepción social que en el momento que este surge se tiene de lo literario. Es el lector social del texto en su situación histórica, pues, el que determina los límites de su literariedad. Esta percepción social tiene una dinámica histórica". 
Es decir, que a la delimitación del concepto de "América Latina" le es subsidiaria la delimitación del concepto "literatura latinoamericana". La historicidad de ambos conceptos parecen estar imbricados, y a una delimitación geográfica se le asocian las formas culturales que la expresan y que alejan de posturas esencialistas de "lo latinoamericano". La percepción social para la determinación del sujeto "América Latina y el Caribe" encaja con la dinámica propia del proceso de "autorreconocimiento de la etiqueta por los países implicados vía participación en la CELAC" como plantea Malamud (2015). Esta dinámica es la que tomamos para este trabajo, es decir, es nuestra estrategia de trabajar con la imbricación entre literatura latinoamericana y caribeña, en un corpus literario articulado.

Puntualizamos, también, que para la integración en la categoría "literatura latinoamericana y caribeña" es necesario recurrir a la asignación social del carácter de "literariedad" a textos y formas culturales que la concepción moderna europea quizá descarte del campo de la literatura. Eagleton (1988: 25, 26) define que existen obras que fueron construidas desde su inicio "como literatura, pero también es verdad que muchas no fueron construidas así". De la idea original del autor o de la institución legitimadora puede surgir que un escrito pueda "ser concebido como un relato de la historia, o un tratado filosófico" y más tarde pueda "ser denominado literatura, o viceversa. Algunos textos nacen literarios, a otros se les impone el carácter literario" (Eagleton, 1988, 25, 26). Así, las formas ligadas al folklore, las perspectivas relacionadas con manifestaciones culturales latinoamericanas y caribeñas como el bossa, el tango, el candombe, los diversos folklore nacionales y regionales, la murga rioplatense, el reggae y el ska (entre otros) pertenecen al campo de la literatura latinoamericana y caribeña. Asimismo, y como mecanismo de delimitación, también, es de utilidad operar con el "concepto de recepción, entendido como la percepción social que en el momento que este surge se tiene de lo literario" (Pizarro, 1987: 190), ante el riesgo de una inclusión indiscriminada.

\subsection{Canon y corpus}

Según el Diccionario de la Real Academia Española, la palabra canon se define así:

“(Del lat. canon, y este del gr. kavúv).

1. m. Regla o precepto.

2. m. Catálogo o lista.

3. m. Regla de las proporciones de la figura humana, conforme al tipo ideal aceptado por los escultores egipcios y griegos.

4. m. Modelo de características perfectas.

[...]

7. m. Decisión o regla establecida en algún concilio de la Iglesia católica sobre el dogma o la disciplina.

8. m. Catálogo de los libros tenidos por la Iglesia católica u otra confesión religiosa como auténticamente sagrados.

$[\ldots]$

17. m. pl. irón. Conjunto de normas o reglas establecidas por la costumbre como propias de cualquier actividad. [...]".

En la "Introducción" de esta Tesis se hizo referencia al El canon occidental, cuyo autor es Harold Bloom. A lo largo de su ensayo, el mencionado Bloom retoma la antigua idea de "catálogo de libros preceptivos", es decir, una lista de libros insustituibles en la biblioteca "necesaria".

La utilización de la categoría "canon", ligada al campo de la teología, le sirve al autor para designar un proceso de puja ("agón") entre las obras por perdurar en un campo solamente delimitado por su capacidad estética.

Pero la literatura no existe sin influencias: un concepto de análisis como la "angustia de las influencias" permite hacer una lectura de la tradición literaria en la que se privilegia la originalidad de escritores y obras en relación con autores y obras del pasado. En esa relación se evidencian "las sombrías verdades de la competencia y la contaminación", la contaminatio, forma de intertextualidad propia del Humanismo y de la cultura clásica grecolatina.

"El valor de una gran obra se encuentra en su extrañeza", es decir, en esa "forma de originalidad que o bien no puede ser asimilada o bien nos asimila de tal modo que dejamos de verla como extraña" (1995: 13) y que "condenaría" a los escritores vivos a la angustia de cargar con estas influencias para intentar superarlas. Y que se refleja en sus obras, las que deben arrastrar las influencias si se pretende originalidad significativa en la tradición literaria occidental. En este punto, el canon también se constituye en una interface entre tradición y ruptura, como puente a medida que se va reescribiendo a sí mismo. 
La crítica literaria no puede escapar a las preguntas liminares que constituyen el corazón de la disputa canónica: “¿Más que, menor que, igual a?”. Sin responder a esa triple cuestión no podría haber valor estético (Bloom, 1995: 34). En este punto, los textos perduran más allá de las fuerzas sociales e instituciones pedagógicas y religiosas. El valor estético de las obras es engendrado por una interacción entre los artistas (1995: 34) y Bloom reconoce la existencia en esa interacción e influencia recíprocas de elementos sociales, culturales, políticos, psicológicos. En este nivel, las fuerzas socio-históricas intervienen en la producción de las obras, pero de manera subalterna al valor estético aportado por el autor individual: "La energía social nunca ha escrito ni una sola escena" (1995: 47). Las diferencias cualitativas estéticas junto con la originalidad son las que tornarían en canónica a las obras: "Toda poderosa originalidad literaria se convierte en canónica" 1995 35). Esta originalidad de base estética constituye el gran escándalo al cual el resentimiento no puede acomodarse (1995: 35).

Para Bloom, aquellas corrientes teóricas que dejan de lado lo estético en la puja por legitimarse como corrientes se nuclean en "la escuela del resentimiento" (1995: 17, 26, 28, 35, 37, 45, 47, 48). En sus propias palabras: "Feministas, marxistas, lacanianos, nuevos historicistas -foucaultianos-, deconstruccionistas y semióticos" correrían a la estética del centro de la escena, dejando a la literatura en manos de la cultura de masas de los sectores de la alta cultura, bajo el dominio de los simples números de las ventas, constituyéndose el canon en una simple lista de mercancías, en un "fetiche" (1995: 48).

Siguiendo con Bloom, la imposibilidad de leerlo todo articula la empresa de aplicar criterios de restricción en la construcción de un repertorio limitado, abarcable, a mano del individuo "que todavía desea leer en este momento de la historia" (1995: 25). El lugar del canon literario es "el teatro de la memoria"; las grandes obras de la literatura son lugares en ese recinto (1995: 39). El canon es concebido como arte de la memoria literaria que pretende limitar lo inconmensurable (1995: 50) y, a la vez, se constituye en caja de herramientas para un lector individual que lo necesita.

Así, con los criterios antes expresados, Bloom se aboca a la tarea de seleccionar esa lista, incluyendo a aquellos escritores que pasarán a formar parte del corpus restringido a los autores representantes de todo el canon occidental (1995: 21).

En El canon occidental, Bloom estudia veintiséis autores. La lista de esos veintiséis autores "sublimes" estudiados está conformada por Chaucer, Shakespeare, Milton, Wordsworth y Dickens por parte de Inglaterra; Montaigne y Molière por Francia; Dante por Italia; Cervantes por España; Tolstoi por Rusia; Goethe por Alemania; Borges y Neruda por Hispanoamérica; Withman y Dickinson por Estados Unidos. También incluye a Samue Johnson, Jane Austen, George Eliot, Ibsen, Proust, Joyce, Virginia Wolf,
Kafka, Pessoa, Beckett y Freud; este último como ensayista. Destacando que Shakespeare se encuentra en el centro del canon occidental por su "agudeza cognitiva, energía lingüística y poder de invención” (1995: 55).

Debemos resaltar que en su estrategia conceptual, Bloom coloca al lector como implicado en la incorporación del texto a su sensibilidad personal. Esto le daría la posibilidad al texto de tornarse en un valor contemporáneo, resignificando a la obra. A esto lo llama "lectura fuerte", que se opone a una "lectura débil" dogmática que relativiza la verdad en su limitación historicista y que no permitiría el estímulo a nuevas literaturas (1995: 14, 22, 33; 2011). Es decir, Shakespeare como el indicador de emociones de millones de personas (no necesariamente europeas de etnia blanca y en todos los idiomas y circunstancias); el indicador de condiciones universales no históricas, sino fundamentales: las de poner en escenas las vidas y emociones de millones de seres humanos (1995: 49).

Al final del ensayo, Bloom coloca cuatro apéndices, correspondientes a las cuatro fases ("Edades") que toma de los Principios de una ciencia nueva de Giambatista Vico: Edad Teocrática, Edad Aristocrática, Edad Democrática y Edad Caótica (una profecía canónica). Estas cuatro edades se componen de una lista de unos 1.500 títulos canónicos de la historia literaria occidental que excluye expresamente la riqueza de la literatura china antigua, que constituye una esfera aparte (1995: 539). En el apéndice D, correspondiente a la cuarta Edad (Caótica), Bloom incorpora a los escritores latinoamericanos canonizados (y las obras seleccionadas) y a los escritores caribeños (como West Indian) canonizados (y sus correspondientes obras seleccionadas $)^{6}$. En este punto, la selección del canon de Bloom se sostiene por los méritos que Giorgio Serra (2012: 124) destaca:

El principal mérito de Harold Bloom consiste en su actitud práctica y explícita a la hora de hablar del canon literario. La mayoría de los críticos que abordan el tema lo hacen de manera excesivamente teórica: hacen un gran despliegue de retórica, pero en muchos casos no ofrecen más que palabrería vacía. Nunca se entiende qué es el canon para ellos, cuáles son los autores u obras canónicos, ni qué debería tener un autor o texto para ser considerado parte del canon. Bloom formula una lista concreta, de autores y títulos, y argumenta para defenderla.

Para nosotros, el listado formalizado de autores y títulos del segmento latinoamericano del mencionado canon funciona como primera muestra ordenada y criterio para la búsqueda de la trasposición a soporte digital de literatura latinoamericana y caribeña en impreso. Pero la construcción del canon por parte de Harold Bloom despertó polémicas en diferentes campos: cada una de las teorías y corrientes que el mencionado Bloom etiqueta como "Escuela del resentimiento" respondieron desde sus propias baterías teóricas. Sus impugnaciones al canon occidental van desde la detección de autores excluidos hasta la utilización de perspectivas que parten de de-

${ }^{6}$ Ver Autores y obras en la "Introducción" de la presente Tesis. 
finiciones del campo cultural que se centran en el cuestionamiento a un canon uniforme (y construido por las élites culturales), articulando formas culturales centradas en la diversidad y la diferencia que fueron descartadas para su elaboración.

- La idea de este Canon occidental fue rechazada por el predominio masculino ("patriarcal, machista") por parte de la crítica feminista (Bolaño Sandoval, 2011: 25; Moraga, 2013).

- Una variación del rechazo mencionado anteriormente es la adjudicación al canon de Bloom de un criterio "heterocentrista" o, por lo menos, que no incluye "los libros más explícitamente relacionados con lo gay" (Woods, 2001:21).

- También fue rechazado por los críticos provenientes de los llamados cultural studies por la "jerarquización cultural" que deja de lado las prácticas socioculturales de las formaciones culturales subalternas (Castañeda, 2009; Moraña, 2004; Beverley 1996 y 2004).

- En una variación de los cultural studies, las críticas al canon realizado por Bloom por parte de teóricos de los estudios poscoloniales marcan que la jerarquización mencionada expresa criterios que consagran la producción cultural del llamado centro mundial (generalmente, europeos y norteamericanos) desplazando a los actores propios de las llamadas "culturas de la periferia o poscoloniales" (Moraga: 2013; Serra: 124).

Pozuelo Yvancos y Aradra (2000: 20-21) relacionan la emergencia de la cuestión del canon "con la modificación del estatuto de la teoría que hace prevalecer, previa a la interpretación de las obras, qué obras han de ser objeto de interpretación y por qué esas y no otras". En este punto, el recorte que realiza Bloom como "límite a lo inconmensurable" (1995: 50) nos permite trabajar con una muestra reducida del catálogo general de la edición latinoamericana de literatura que está migrando a soporte digital. Como mencionábamos anteriormente, el recorte se desarrolla como un repertorio limitado, abarcable, de obras y títulos, facilitando las búsquedas articuladas sobre un listado reconocido académicamente. Para Foster (2005: 90), la existencia de un canon "es importante como un punto de referencia axial", aunque describe la multiplicidad de cánones literarios latinoamericanos: las universidades norteamericanas no trabajan con el mismo canon que los estudios latinoamericanos realizados desde los países o desde algunos de los países de la región. El mencionado Foster (2005: 90) detecta: "pocos se ocupan, por ejemplo, de Sor Juana fuera de EE.UU. y México".
$\mathrm{Al}$ existir un corpus potencial (la totalidad de lo producido por la cultura) y un corpus actual, en el marco de un corpus potencial inmenso, se trabaja con un corpus actual, pero con plena conciencia del "canon implícito" (Pineda-Botero, 1995: 28). En esta línea, se desarrolló un corpus de autores y obras de la literatura latinoamericana y caribeña (CLLyG) que amplía la lista de autores y de obras del segmento latinoamericano y caribeño de Bloom. Esta ampliación se concreta en la incorporación de obras y autores que tanto desde la propia Latinoamérica y el Caribe proponen teorías y corrientes que se posicionan desde una mirada crítica con el enfoque clásico de Harold Bloom. Igualmente, se han incluido autores y obras que provienen de repertorios y fuentes que no son producto de fuentes latinoamericanas y caribeñas, pero cuyos autores y obras que proveen coinciden con algunas de las perspectivas latinoamericanistas y caribeñas. Es decir, se han incorporado aquellos autores y títulos relevados en distintos repertorios críticos, diccionarios, historias y antología de literatura latinoamericana y caribeña y que pueden integrar el corpus desde una perspectiva teórica que comprende a la crítica feminista, los estudios queer, los cultural studies, y a los llamados estudios de la subalternidad y del giro poscolonial.

Si aceptamos la idea de literatura como "mecanismo autoorganizado" (Lotman, 1998: 28), Mignolo (1998) propone que esta forma de pensar la literatura como práctica discursiva regional y la formación y transformación del canon como un subsistema dentro del sistema. En esta diversidad, se incluirían "personas y comunidades que han interiorizado el concepto de literatura vocacionalmente en tanto que participaban en un sistema de interacciones que ellos mismos aceptan como literarias". Al subrayar "la necesidad de incluir la literatura no occidental, del tercer mundo, de mujeres, etc., en el canon refleja [...] la existencia de un grupo de investigadores que sienten, a nivel vocacional, que el canon debería transformarse para representar a una población plural como la americana" (1998: 261). La noción de descolonización de la literatura latinoamericana propone la puesta en escena de acciones de recuperación de los cánones literarios propios de las comunidades amerindias, que la acción de canonización basada en "la lengua y en los valores de las culturas colonizadoras más importantes (española y portuguesa)" logró silenciar, pero no suprimir (1998: 241). El ejemplo del Popol Vuh como un artefacto propio de una doble articulación canónica, por un lado, que representa una herramienta de la identidad cultural latinoamericana para el caso de intelectuales estudiosos de la problemática literaria regional; sin embargo, por otro lado, para los miembros de la comunidad quiché el Popol Vuh es "una forma de conservar sus propias tradiciones segregadas de las del mundo hispanohablante" (1998: 265). En esta instancia, la enseñanza del Popol Vuh se coloca en la acción descolonizadora de la literatura latinoamericana y funciona como un elemento propio desarrollado por el discurso académico de una cultura central. En el otro caso, para las culturas periféricas, el propio canon se constituye en un elemento "de cohesión y no de debate académico" 
(1998: 241). Además, la incorporación de las literaturas precolombinas al CLLyC expresa las distintas formas de la resistencia indígena ante la imposición española y una doble articulación frente a la lengua metropolitana: la recuperación de la propia historia de los pueblos originarios mediante la utilización del alfabeto latino (De la Garza, 1980). El canon hispanoamericano se fue construyendo sobre la base de un lenguaje estándar y de criterios estéticos imbricados en la propia noción de "poesía" y "literatura" del colonizador (Mignolo, 1998: 268), pero esto no inhibiría, a nuestro entender, la coexistencia de segmentos múltiples que reflejen la diversidad de formas, estéticas, dispositivos, poéticas que componen el campo de la literatura latinoamericana y caribeña, sino al interior de un corpus que funcione como espacio donde graviten esos múltiples segmentos, tales como el segmento latinoamericano y caribeño del canon de Bloom como los propios cánones propuestos por las llamadas "historias de la literatura latinoamericana". Estas historias latinoamericanas funcionaron como inicios de construcción de un canon literario latinoamericano, de manera precaria, en conjunto con la aparición recién a principios del siglo XX de las llamadas "bibliotecas americanas", como las de Rufino Blanco Fombona (Biblioteca Americana y una primera Biblioteca Ayacucho, entre los años 1910 y 1924) y Francisco García Calderón. Henríquez Ureña (en 1928) destacaba en la necesidad de "poner en circulación tabla de valores, nombres centrales y libros de lectura indispensable" (1978: 46, 47) y el dispositivo de autores centrales para una historia literaria de América española: "Bello Sarmiento, Montalvo, José Martí, Darío, Rodó”. Asimismo, en sus correspondencias con Alfonso Reyes, Henríquez Ureña proponía una lista de "clásicos" que deberían leer los alumnos escolares: El cazador, del mismo Alfonso Reyes; Los Caranchos de la Florida de Benito Lynch; Raza de bronce de Arguedas; Barranca Abajo de Florencio Sánchez; Fuvenilia de Miguel Cané; Mis montañas de Joaquín V. González. Posteriormente, la Biblioteca Americana del Fondo de Cultura Económica de México y la Biblioteca Ayacucho se constituyeron en organizadoras de un archivo exhaustivo de la literatura latinoamericana, ambos emprendimientos canónicos latinoamericanos que según Zanetti (1998: 87, 97) fueron iniciados y diseñados por Pedro Henríquez Ureña y Ángel Rama.

Mignolo (1994-1995: 29) entiende que el canon parece "implicar una relación de tipo sustancial entre prácticas y paradigmas culturales", pero "el corpus necesitaría solo de una manejable delimitación espacial y temporal”. Así, el canon implicaría cuestiones de identidad ("¿qué es lo latinoamericano?") y el corpus necesitaría "parámetros localitivos (¿dónde y cuándo se relacionaron las prácticas discursivas en cuestión?)" (Mignolo, 1994-1995: 29). Con la misma disposición, Zanetti (1998: 97) propone que los cánones latinoamericanos son "en verdad, nacionales, y las obras que los integran se proyectan de un modo fluctuante hacia ese otro mayor". Esa fluctuación se da en el marco de contextos estéticos, culturales y políticos que instalarían en el presente la preocupación por el canon latinoamerica- no (Zanetti, 1998: 105). Es decir, que existen determinantes que colocan y recolocan el tema del canon latinoamericano con una cierta frecuencia episódica.

Es, entonces, nuestra estrategia en la construcción de este CLLyC la de relevar la oferta literaria latinoamericana y caribeña en digital en las principales plataformas comercializadoras en digital y en las principales bibliotecas internacionales, con un énfasis marcado en la descripción de la transposición a digital de las obras y autores del CLLyC construido. Es decir, ahondar en la perspectiva de dilucidación de los criterios de construcción de la oferta en digital de los títulos del mencionado corpus.

El corpus propuesto y construido surge del relevamiento de fuentes literarias latinoamericanas y caribeñas heterogéneas, disímiles, distantes entre sí tanto en el tiempo como en las perspectivas y criterios de selección. La idea central es proponer el CLLyC como un repertorio amplio de la literatura latinoamericana y caribeña, superando lo que Rafael Grillo (2013) analiza como "El Canon (modelo único) que hace invisible el Corpus (democrático conjunto)" y, en la construcción del corpus, explorar las literaturas en lenguas hegemónicas y subalternas, en lenguas amerindias, la literatura latinoamericana escrita en francés, en créole, en papiamento, en inglés, en portugués, en portuñol, en cocoliche, es decir, las literaturas de los distintos sistemas multilingües que componen la literatura latinoamericana y caribeña, como marcábamos en el apartado 2.1. de esta Tesis (América Latina; América Latina y el Caribe; Literatura latinoamericana y caribeña. Algunos conceptos).

El Diccionario de autores latinoamericanos realizado por César Aira aporta más de 1.300 autores y obras con un criterio de amplitud en la incorporación de autores: dramaturgos, poetas, novelistas, cuentistas, científicos, historiadores, cronistas, periodistas y ensayistas. Asimismo, nos provee de un corpus importante de literatura brasileña (incorporación que no se realiza con frecuencia en los repertorios literarios latinoamericanos), pero no incorpora autores y obras precolombinos ni en otras lenguas que no sean castellano y portugués, así como no incluye autores surgidos a partir de 1985.

El Diccionario de la literatura latinoamericana de Susana Cella contribuye con un listado de autores y obras que funciona de manera complementaria con el Diccionario de autores latinoamericanos de César Aira: incorpora textos precolombinos y en lenguas no hispánicas y a los escritores nacidos hasta 1940, o, en caso de que hayan nacido después del 40 que ya estuviesen fallecidos en 1998. La idea de "representatividad" de autores y obras prima sobre la "exhaustividad" (Cella, 1998 VII).

Los chongos de Roa Bastos. Narrativa contemporánea de Paraguay, selección realizada por Sergio Di Nucci, Nicolás Recoaro y Alfredo Grieco y Bavio, 
contribuye con una lista de autores nacidos entre 1965 y 1984, cuyas obra se escriben en jorapa, portuñol, y otras maneras (heteroglosias) de hibridaciones con guaraní y otras lenguas y hablas indígenas, desde una "renuncia programada y convertida en principio o acaso la indiferencia a los estándares del español internacional" (Di Nucci et al., 2011: 7).

Saraus. Movimiento - Literatura - Periferia - São Paulo. Antología, de Lucía Tennina (compiladora). Los saraus son encuentros literarios que se desarrollan en bares de las periferias de San Pablo, a la manera de fiestas poéticas de las favelas y barrios pobres de la ciudad, donde se declaman o leen textos propios o ajenos frente a un micrófono durante dos horas. También llamado Perifatividade. Autores nacidos entre 1957 y mediados de los 80 inician sus trabajos literarios en los 90 y principios de los 2000. La ciudad de San Pablo es la ciudad más grande de Brasil, la ciudad más grande de Latinoamérica y una de las más grandes del mundo.

Latin American Writers on Gay and Lesbian Themes: A Bio-Critical Sourcebook de David William Foster propone un ensayo crítico de poemas, cuentos, novelas y ensayos de escritores latinoamericanos cuyo eje articulador son las temáticas relacionadas con la constitución de la identidad gay, es decir que desde perspectivas de estudios queer y los llamados gay \& lesbian studies, David William Foster desarrolla lo que constituye para nosotros una sección de estas narrativas para la construcción del CLLyC.

McOndo (una antología de nueva literatura hispanoamericana) editada por Alberto Fuguet y Alberto Gómez aporta a este corpus cuentos de aquellos autores incorporados a la antología por decisión programática nacidos desde 1959 a 1962, además de autores de escaso conocimiento hasta mediados de los 90 y cuya selección descarta, también, por decisión programática todo rastro de realismo mágico como poética. Los cuentos de $M c O n d o$ se centran en realidades individuales y privadas:

Los más ortodoxos creen que lo latinoamericano es lo indígena, lo folklórico, lo izquierdista [...]. Mercedes Sosa sería latinoamericana pero Pimpinela, no. ¿Y lo bastardo, lo híbrido? Para nosotros, el Chapulín Colorado, Ricky Martín, Selena, Julio Iglesias y las telenovelas (o culebrones) son tan latinoamericanos como el candombe o el vallenato. Hispanoamérica está lleno de material exótico. Temerle a la cultura bastarda es negar nuestro propio mestizaje (Fuguet, 1996: 15).

El mecanismo de selección de la antología McOndo "castigó" con rechazo cualquier atisbo de realismo mágico en los cuentos presentados para la Antología, en cuyos cuentos priman las narrativas que ahonden en la pesquisa sobre la identidad personal del autor (“¿quién soy? ”) más que en el "gran tema de la identidad latinoamericana" propia de la generación de boom (“¿quiénes somos?”). Tal es su aporte a la construcción de este corpus.
De la Tricolor a la Wiphala. Narrativa contemporánea de Bolivia, de Sergio Di Nucci, Nicolás Recoaro y Alfredo Grieco y Bavio (selección, edición y notas). Para Nicolás Recoaro (2014 c):

Son tangentes, los nuevos narradores bolivianos, a la generación de escritores McOndo, más interesada por los Simpson, el heavy metal gringo o Breaking Bad que por los prestigios, cuántas veces dudosos, de la 'América profunda'.

El Manifiesto del Crack aporta una lista de seis autores mexicanos (Jorge Volpi, Pedro Ángel Palou, Eloy Urroz, Ignacio Padilla, Ricardo Chávez Castañeda y Vicente Herrasti), con un programa poético de una narrativa dislocada o desubicada del espacio y del tiempo de México, cuyas obras, todas posteriores a 1996, se caracterizan por una postura narrativa rupturista tanto del realismo mágico latinoamericano como de una cierta poética light representada por Ángeles Mastretta, Marcela Serrano, Laura Esquivel, Guadalupe Loaeza. Es decir, propone una literatura compleja, que expone mayores pretensiones en lo formal-estructural y cultural que la literatura del llamado post-boom. Generalmente, se trata de tramas ubicadas en Europa y Estados Unidos, y escritas en "un registro patrón de la lengua, para facilitar así la traducción" (Santos, 2013: 288).

1.000 millones: poesía en lengua española del siglo XXI, editada por Daniel Helder, Daiana Henderson y Bernardo Orge aporta una lista que reúne a treinta y tres autores hispanoamericanos nacidos entre 1980 y 1995 y cuyas obras fueron editadas previamente en soporte digital o en soporte papel. La antología no incluye solamente autores latinoamericanos de habla hispana, también hay estadounidenses y españoles. Los autores incluidos nacieron en dieciséis países diferentes, pero publicaron sus obras (libros, posts, Webs) en cuarenta y seos ciudades distintas de Latinoamérica, EE.UU. y Europa. Algunos escritores no publican en soporte impreso y han sido transpuestos de digital (de Webs, blogs, blogs de Tumblr) a impreso (en el camino inverso del objeto de estudio de esta Tesis).

La gran novela latinoamericana, de Carlos Fuentes, aporta un repertorio de autores y novelas desde la perspectiva de un autor del "boom". Funciona como un ensayo del recorrido del progreso de la novela en América Latina desde el inicio de la Colonia hasta nuestros días.

Bogotá39 aporta treinta y nueve autores menores de 39 años en 2007, con el criterio predominante del descubrimiento de nuevos escritores con la perspectiva de anticipación de una posible futura literatura latinoamericana.

Una sección de títulos de escritores caribeños, antillanos y de las Guayanas diseñado sobre la base de la combinación de los títulos y escritores que componen la compilación West Indian Narrative: An Introductory Anthology edi- 
tada por Kenneth Ramchand; la antología They Came in Ships: An Anthology of Indo-Guyanese Writing diseñada por Joel Benjamin, Lakshmi Kallicharan, Ian McDonald y Lloyd Searwar; la selección The Routledge Reader in Caribbean Literature, editada por Alison Donnell y Sarah Lawson Welsh; The Companion to Anglophone Caribbean Literature editado por la mencionada Alison Donnel y Michael A. Bucknor; la selección The Oxford Book of Caribbean Verse, editado por Stewart Brown y Mark McWatt; y los autores caribeños, antillanos y de las Guayanas de la Encyclopedia of Latin American and Caribbean Literature 1900-2003 (Balderston y Gonzalez). Este segmento caribeño, antillano y de las Guayanas del CLLyC contribuye con más de 2.500 títulos de 384 autores con un criterio de amplitud en la incorporación de autores: dramaturgos, poetas, novelistas, cuentistas, científicos, historiadores, cronistas, periodistas y ensayistas.

El aporte de autores y obras de las llamadas editoriales cartoneras latinoamericanas permite rastrear un estado del arte de la imbricación de dos vectores fundamentales para el análisis: significaciones simbólicas y formas materiales (Chartier, 2006: 10). Por un lado, con una perspectiva literaria latinoamericana postcolonial y, por el otro, con el dispositivo material (también postcolonial) mediante el cual las literaturas latinoamericanas circulan.

De la sección del CLLyC conformada por títulos de escritoras relevado del ensayo Latin American Women Writers: An Encyclopedia, editado por María André y Eva Bueno (2008) adquirimos las obras de más de 300 mujeres escritoras de América Latina entre los siglos XVI y XX, con una orientación especial al relevamiento de obras dramáticas, poéticas y ficcionales de mujeres latinoamericanas.

De la sección de literatura precolombina se incorporan cincuenta y tres obras de los siglos XV y XVI que reconstruyen parte de la literatura precolombina que se constituyen como piezas literarias que contienen tanto textos míticos, (códices), historias tradicionales, libros proféticos recopilaciones de usos y costumbres; poesías (como en el caso de Nezahualcóyotl), libros de cantos. En lenguas que van desde el español, al quiché, maya yucateca, chontal, cakchiquel, pokomchí, mam y zutuhil. Se destaca que la mayoría de las obras son anónimas y que la noción de autoría en las sociedades precolombinas originarias no se asemejaba a la noción de moderna de "autor" (destacamos ocho autores precolombinos de los pueblos originarios en el CLLyC). Muchas de las obras eran considerados como parte del patrimonio sagrado colectivo, no como obras personales (De la Garza, 1980).

La Encyclopedia of Latin American and Caribbean Literature 1900-2003, editado por Balderston y Gonzalez (2004), nos permite incorporar obras de autores latinoamericanos escritas entre los años 1900 y 2003, anexando, además, formas literarias ligadas tanto al campo de la edición (obras de editores productores culturales) como de la producción relacionada con las literaturas ligadas al "mercado" o bestsellers que esta fuente nos proporciona (y que son de dificil detección en otras fuentes sobre literatura latinoamericana). Se destaca el alto nivel de actualización temporal de las obras incorporadas (tanto en el plano de las obras caribeñas, antillanas y de las Guayanas como de las obras desagregadas para la sección latinoamericana).

A modo de esquema, en la Figura 2, se muestran las fuentes elegidas y se resumen los principales criterios para la incorporación al CLLyC de cada uno de ellos. 


\begin{tabular}{|c|c|c|c|c|c|c|c|}
\hline Repertorio $_{\text {Criterios }}$ & $\begin{array}{l}\text { Particularidad } \\
\text { de la fuente }\end{array}$ & Géneros & \begin{tabular}{|l} 
Lenguas \\
\end{tabular} & Poéticas & \begin{tabular}{|l|l} 
Período \\
\end{tabular} & \begin{tabular}{|l|} 
Zona \\
geográfica
\end{tabular} & 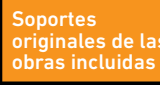 \\
\hline $\begin{array}{l}\text { Diccionario de } \\
\text { César Aira }\end{array}$ & 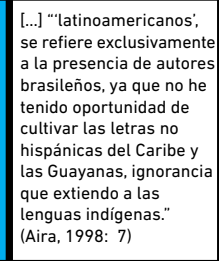 & Todos & \begin{tabular}{|l|} 
Español \\
Portuguús
\end{tabular} & 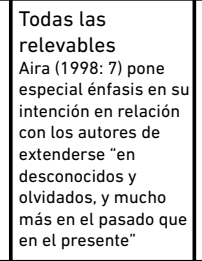 & \begin{tabular}{|l|} 
De la "Conquista" \\
a 1985
\end{tabular} & $\begin{array}{l}\text { América Latina } \\
\text { y el Caribe }\end{array}$ & Impreso \\
\hline $\begin{array}{l}\text { Diccionario de } \\
\text { Susana Cella }\end{array}$ & $\begin{array}{l}\text { El criterio que prima } \\
\text { es elde } \\
\text { "representativividad" }\end{array}$ & Todos & \begin{tabular}{|l|} 
Español \\
Portugués \\
Lenguas \\
indigenas
\end{tabular} & \begin{tabular}{|l|l|}
$\begin{array}{l}\text { Todas las } \\
\text { relevabbles }\end{array}$ \\
\end{tabular} & \begin{tabular}{|l|} 
Incorpora textos \\
precolombinos \\
hasta escritores \\
nacidos en 1940
\end{tabular} & \begin{tabular}{|l|} 
América Latina \\
y el Caribe
\end{tabular} & Impreso \\
\hline $\begin{array}{l}\text { Manifiesto del } \\
\text { Crack }\end{array}$ & \begin{tabular}{|l|} 
Los autores \\
caracterizan por una \\
postura narrativa \\
rupturista tanto del \\
realismo mágicol \\
como de eirrta \\
poética light
\end{tabular} & \begin{tabular}{|l|l|l|} 
Novela \\
\end{tabular} & 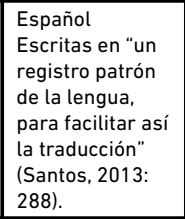 & \begin{tabular}{|l|l|}
$\begin{array}{l}\text { Proponen una } \\
\text { litereatura } \\
\text { compleja }\end{array}$ \\
\end{tabular} & \begin{tabular}{|l|l|}
$\begin{array}{l}\text { obras } \\
\text { posteriores } \\
\text { a } 1996\end{array}$ \\
\end{tabular} & México & Impreso \\
\hline $\begin{array}{l}\text { Los chongos de } \\
\text { Roa Bastos }\end{array}$ & \begin{tabular}{|l} 
Autores de la \\
periferia urbana
\end{tabular} & \begin{tabular}{|l|l|} 
Cuento \\
\end{tabular} & 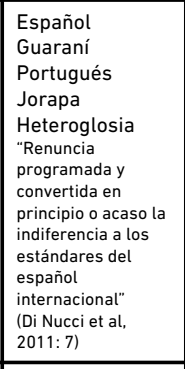 & & \begin{tabular}{|l|}
$\begin{array}{l}\text { Autores, nacidos } \\
\text { entre } \\
\text { y } 19865\end{array}$ \\
\end{tabular} & \begin{tabular}{|l|} 
Paraguayy \\
\end{tabular} & 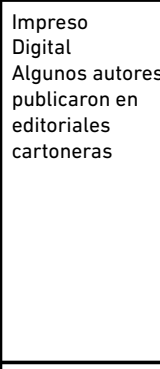 \\
\hline Saraus & 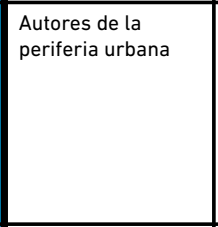 & \begin{tabular}{|l|l|} 
Poesía \\
\end{tabular} & \begin{tabular}{|l|} 
Portugués \\
Portugués \\
variedad \\
estándar paulista
\end{tabular} & \begin{tabular}{|l|} 
Literatura de la \\
periferia/ \\
marginalia
\end{tabular} & 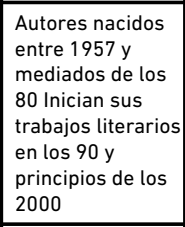 & \begin{tabular}{|l|l|l|} 
Săo Paulo \\
\end{tabular} & \begin{tabular}{|l|}
$\begin{array}{l}\text { Impresoso } \\
\text { Digital } \\
\text { Born-digital }\end{array}$ \\
\end{tabular} \\
\hline \multirow[t]{2}{*}{1000 millones } & \begin{tabular}{l|} 
Algunos escritores \\
no publican en \\
soporte papel: \\
transpuestos a \\
impresos de digitital \\
(de webs, bloss. \\
blogs de Tumblr).
\end{tabular} & \begin{tabular}{|l|}
$\begin{array}{l}\text { Poesiá Algunos } \\
\text { autores presentan } \\
\text { novelas, cuentos, } \\
\text { cómics. }\end{array}$ \\
\end{tabular} & \begin{tabular}{|l|l|} 
Español \\
\end{tabular} & & \begin{tabular}{|l|}
$\begin{array}{l}\text { Autores hispano- } \\
\text { americanos } \\
\text { nacidids entre } \\
\text { 1980 y y } 1995\end{array}$ \\
\end{tabular} & \begin{tabular}{|l|} 
Toda el área \\
idiomática en \\
español. \\
Los untores \\
nacieron en 16 \\
paises diferentes \\
pero publicaron \\
sus obras (libros. \\
posts, webs) en \\
46 ciudades \\
distintas de \\
Latinoamérica, \\
EE.UU. y Europa. \\
\end{tabular} & 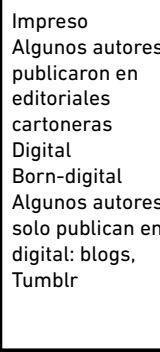 \\
\hline & Teorias de género & \begin{tabular}{|l|}
$\begin{array}{l}\text { Novelas, nouvelles, } \\
\text { cuentos. } \\
\text { non-fiction }\end{array}$ \\
\end{tabular} & \begin{tabular}{|l|l|} 
Español \\
\end{tabular} & & & \begin{tabular}{|l}
$\begin{array}{l}\text { América Latina } \\
\text { yel Caribe }\end{array}$ \\
\end{tabular} & Impreso \\
\hline Whipala & $\begin{array}{l}\text { En algunos casos, } \\
\text { la preoccupación, } \\
\text { literariaia de los } \\
\text { autores los halla } \\
\text { cercanos a los } \\
\text { escritores de } \\
\text { Mcondo. } \\
\end{array}$ & \begin{tabular}{|l|} 
Cuentos \\
Algunos autores \\
escriben novelas, \\
poesias y cómics \\
\end{tabular} & 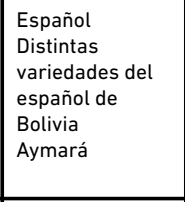 & \begin{tabular}{|l|} 
Exhibe un \\
catálogo hetero- \\
géneo de \\
escritores y \\
tónicos: urbanos, \\
rurales, villeros, \\
gay, tradicionales \\
\end{tabular} & \begin{tabular}{|l|}
$\begin{array}{l}\text { Autores nacidos } \\
\text { entrel } 956 \mathrm{y} \\
\text { mediados de } \\
\text { los } 80\end{array}$ \\
\end{tabular} & \begin{tabular}{|l|} 
Bolivia \\
Zonas \\
geográficas del \\
exterior de \\
Bolivia donde \\
habitan \\
bolivianos \\
\end{tabular} & 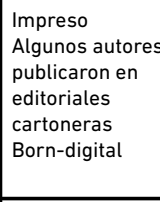 \\
\hline $\begin{array}{l}\text { Latiti American } \\
\text { Writires on Gay } \\
\text { and Lesbian } \\
\text { Themes de David } \\
\text { Foster }\end{array}$ & Teoría queer & \begin{tabular}{|l} 
Cuentos \\
Novelas \\
Poemas \\
Ensayos
\end{tabular} & \begin{tabular}{|l|l|} 
Español \\
Portugues \\
letautor trabajaj \\
con obras en \\
españoly \\
portuguésy \\
obras traducidas \\
al inglés)
\end{tabular} & \begin{tabular}{|l|l} 
Centradic on \\
temanticas y/o \\
poetcicas ueer \\
yestudios gay
\end{tabular} & & \begin{tabular}{|l}
$\begin{array}{l}\text { América Latina } \\
\text { y el Caribe }\end{array}$ \\
a
\end{tabular} & Impreso \\
\hline
\end{tabular}

\begin{tabular}{|c|c|c|c|c|c|c|c|}
\hline Repertorio & \begin{tabular}{|l} 
Particularidad \\
de la fuente
\end{tabular} & Géneros & Lenguas & Poéticas & Período & $\begin{array}{l}\text { Zona } \\
\text { geográficca }\end{array}$ & $\begin{array}{l}\text { Soportes } \\
\text { originales de las } \\
\text { obras incluidas }\end{array}$ \\
\hline $\begin{array}{l}\text { La gran novela } \\
\text { latinoamericana } \\
\text { de Carlos Fuentes }\end{array}$ & $\begin{array}{l}\text { Ensayo de un } \\
\text { escritor del "boom" }\end{array}$ & Novela & $\begin{array}{l}\text { Castellano } \\
\text { Lenguas } \\
\text { indigenas }\end{array}$ & & $\begin{array}{l}\text { Incorpora textos } \\
\text { precolombinos } \\
\text { hasta el presestte }\end{array}$ & 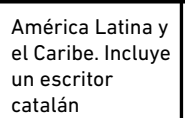 & Impreso \\
\hline Bogotá39 & 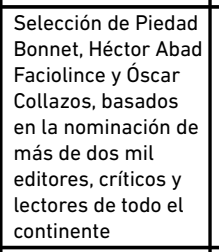 & \begin{tabular}{|l|l|l} 
Todos \\
\end{tabular} & $\begin{array}{l}\text { Espanolol } \\
\text { Portugués } \\
\text { Inglese }\end{array}$ & & \begin{tabular}{l|} 
Autores nacidos \\
después de 1968
\end{tabular} & \begin{tabular}{|l|} 
Selección de \\
autorers de 17 \\
paises latioume- \\
ricanos
\end{tabular} & $\begin{array}{l}\text { Impreso } \\
\text { Algunos autores } \\
\text { publicaron en } \\
\text { editoriales } \\
\text { cartoneras } \\
\text { Born-digital }\end{array}$ \\
\hline $\begin{array}{l}\text { Editoriales } \\
\text { cartoneras }\end{array}$ & 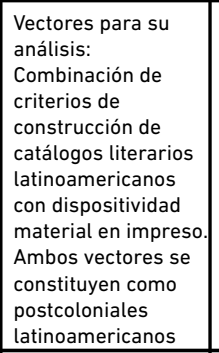 & Todos & $\begin{array}{l}\text { Distintas } \\
\text { variedades del } \\
\text { espanol del } \\
\text { Portugués } \\
\text { Lenguas } \\
\text { indigenas } \\
\text { Guaranai } \\
\text { Jorapa } \\
\text { Portuñol } \\
\text { lnglés } \\
\text { Aymará }\end{array}$ & $\begin{array}{l}\text { Todas las } \\
\text { relevables }\end{array}$ & \begin{tabular}{l|} 
Incorpora textos \\
precolombinos \\
hasta el presesnte
\end{tabular} & $\begin{array}{l}\text { América Latina y } \\
\text { el Caribe }\end{array}$ & $\begin{array}{l}\text { Impreso } \\
\text { Born-digital }\end{array}$ \\
\hline $\begin{array}{l}\text { Sección de } \\
\text { escritiones } \\
\text { caribeños, } \\
\text { antillanosy y de } \\
\text { las Guayanas }\end{array}$ & 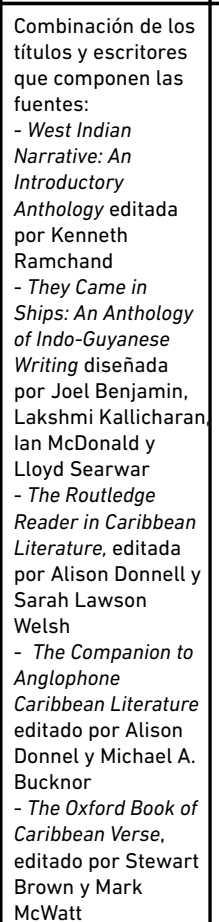 & \begin{tabular}{|l|l|} 
Todos \\
\end{tabular} & $\begin{array}{l}\text { Castellano } \\
\text { Portugués } \\
\text { Francés } \\
\text { Holondes } \\
\text { Créole } \\
\text { Patois } \\
\text { Papiamento } \\
\text { papiamentu, } \\
\text { papiamentu } \\
\text { Neerlandes } \\
\text { Heterogolosias }\end{array}$ & $\begin{array}{l}\text { Todas las } \\
\text { relevables }\end{array}$ & \begin{tabular}{l|} 
Autores desde \\
el siglo XIX hasta \\
el presente
\end{tabular} & $\begin{array}{l}\text { Auttores } \\
\text { carbibenss, } \\
\text { antilanosy de } \\
\text { las Guayanas. }\end{array}$ & Impreso \\
\hline
\end{tabular}




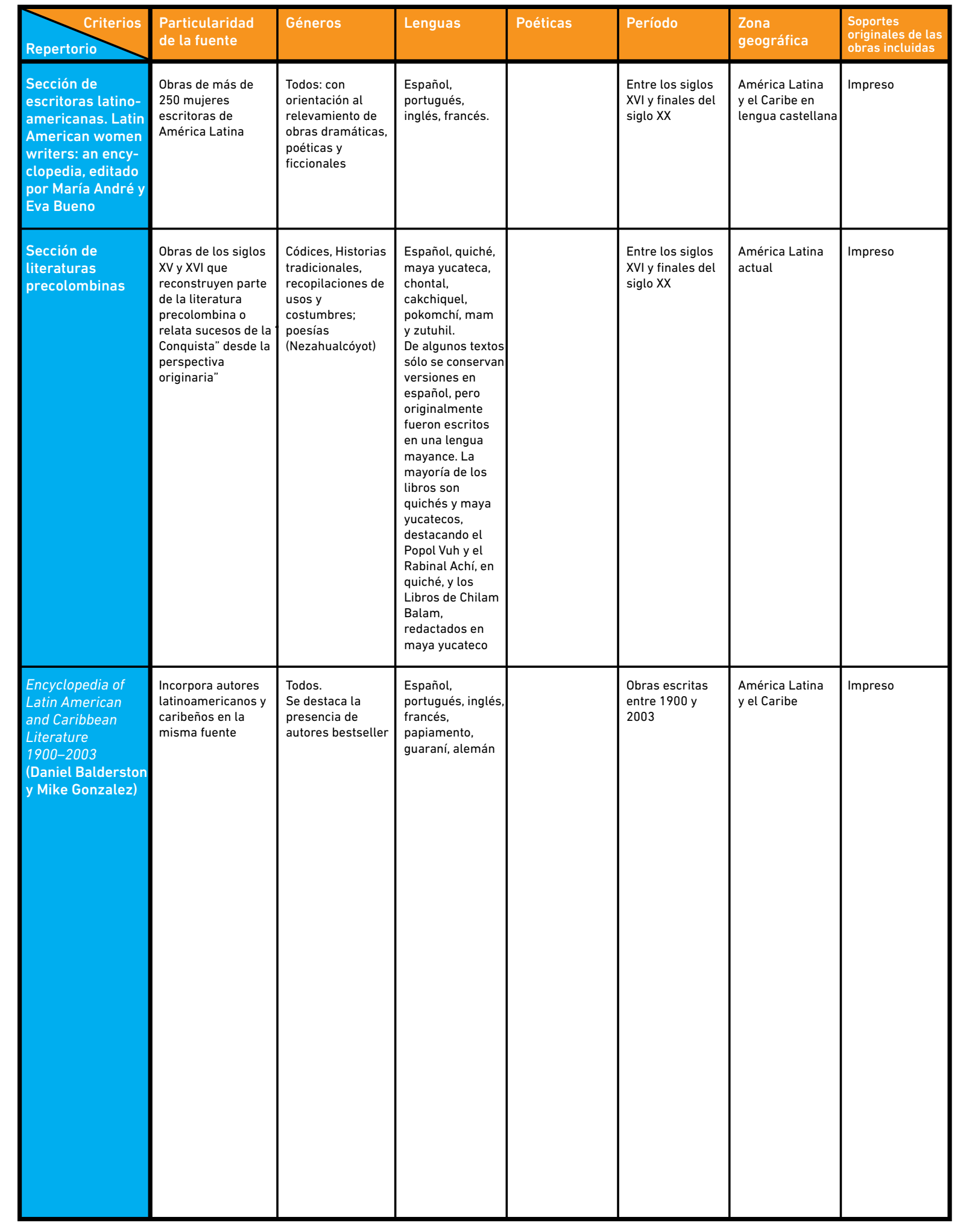

\section{DE LA GALAXIA GUTENBERG AL ECOSISTEMA DEL LIBRO DIGITAL}

\subsection{La galaxia Gutenberg}

Para McLuhan, quien acuñó la categoría "galaxia Gutenberg" (McLuhan,1962: 2), toda tecnología tiende a crear un nuevo mundo circundante para el hombre. Los distintos "medio ambientes tecnológicos" no funcionan como "meros receptáculos pasivos de las gentes", sino que se constituyen en procesos activos que darían forma tanto al hombre como a sus tecnologías coetáneas y futuras.

Para algunos autores, como Lars Ole Sauerberg, la era de la imprenta de tipos móviles, el periodo comprendido entre 1500 y 2000, no fue otra cosa que un "paréntesis Gutenberg" (Sauerberg, 2009: 2) entre el mundo oral de casi toda la historia previa a la invención de la imprenta y la oralidad secundaria que estaríamos viviendo a partir de la invención de Internet. Sauerberg (2009: 2) subraya:

The period from the late Renaissance to the beginning of the 21 st century will be seen as dominated and even defined by the cultural significance of print.

Piscitelli (2010) define esa idea del paréntesis como "post-Gutenberg es pre-Gutenberg", en el marco de la necesidad de elucidación de la duda estructural sobre si "efectivamente Gutenberg fue un eslabón indispensable en la marcha hegeliana de la historia, o si tal vez su aporte no fue muy distinto al añadadido de un nuevo epiciclo en el herrumbrado sistema Ptolomeico".

Walter J. Ong (1987: 20) también apuntaba que la etapa gutenberguiana de la cultura era un intermezzo entre culturas, o mejor, entre "culturas de la oralidad": entre una oralidad primaria para aquellas culturas que desconocen por completo la escritura (e impresión). Es decir, es“"primaria' por el contraste con la 'oralidad secundaria' de la actual cultura de la alta tecnología, en la cual se mantiene una nueva oralidad mediante el teléfono, la radio, la televisión y otros aparatos electrónicos que para su existencia y funcionamiento dependen de la escritura y la impresión".

El medio ambiente resultante de la acción de la imprenta de tipos móviles constituido por un conjunto simultáneo y recíproco de factores no directamente relacionados entre sí -y a los que McLuhan (1962: 2) describe metodológicamente como "mosaicos en perpetua interacción"constituyen la llamada galaxia Gutenberg. Hoy, funciona como categoría de descripción del sistema relacionado con las actividades editoriales, de imprenta, de base cultural, pero de "papel impreso". Desde la acción del autor, pasando por la imprenta hasta las formas de lectura asociadas al impacto de la letra impresa, sus agentes, sus acciones. 
Para Ros García (1994: 53), un sistema de información "se compone de múltiples procesos que son al mismo tiempo actores en otros subsistemas de la organización, y por que el sistema de información participa de toda actividad que se desarrolla en esa organización". En nuestra investigación destacamos que los sistemas generales de la información analógica y generales de la información digital poseen áreas de superposición, donde comparten elementos componentes. La galaxia Gutenberg pertenece al sistema general de la información analógica. El ecosistema del libro digital pertenece al sistema general de la información digital. Ambos subsistemas, galaxia Gutenberg y ecosistema del libro digital, poseen áreas de superposición, donde comparten elementos componentes. Ambos sistemas, sus subsistemas y componentes forman parte del campo general de la información la comunicación ${ }^{7}$.

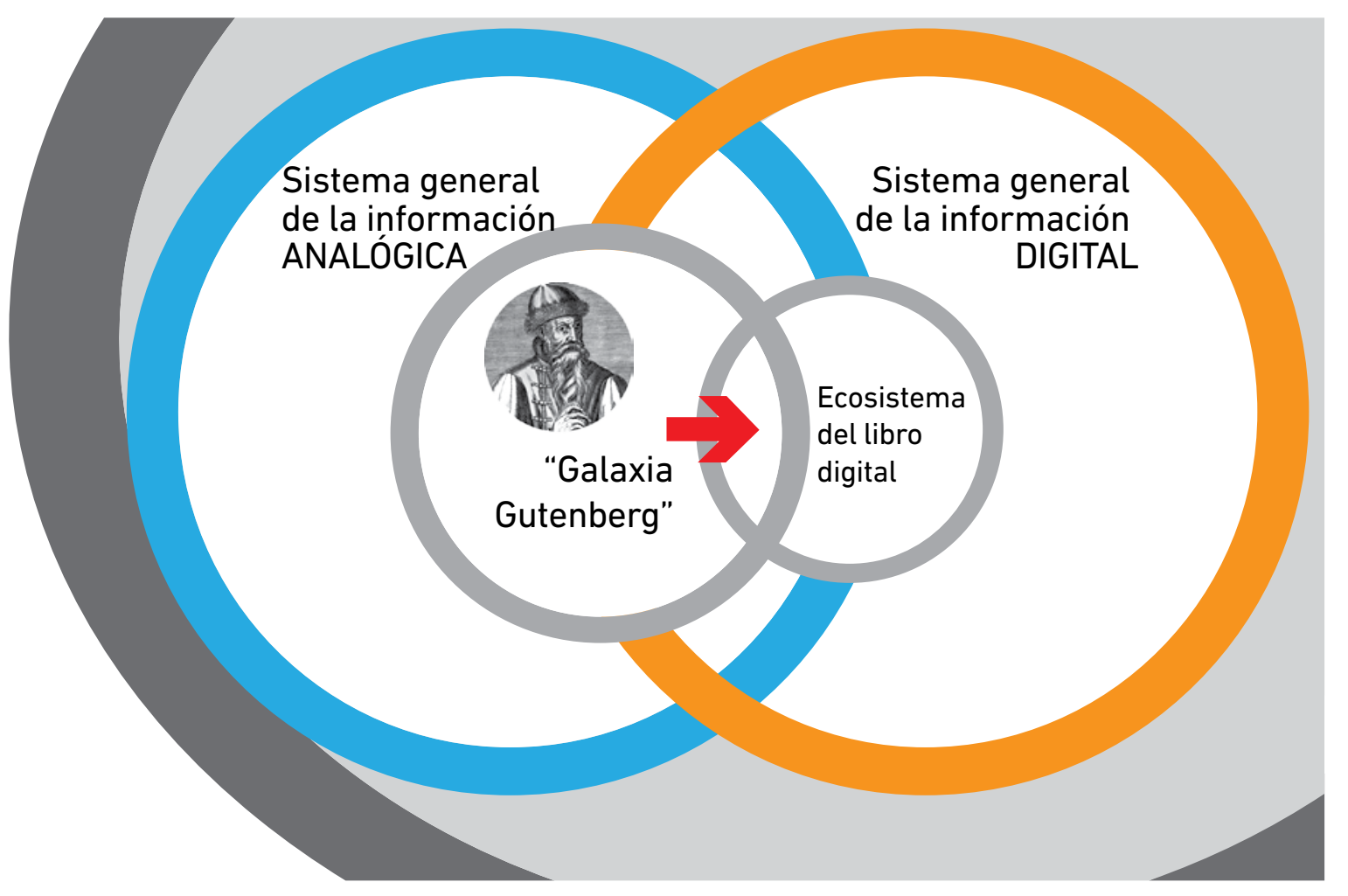

Figura 3. Campo general de la información y la comunicación. La flecha (en rojo) marca la transposición de parte de la "galaxia Gutenberg" al ecosistema de libro digital

Podríamos decir que lo que llamamos sistema del libro (en soporte impreso) involucra a agentes tan variados como escritores, traductores, dibujantes, diseñadores gráficos, fotógrafos, editores, libreros, distribuidores, imprenteros, importadores-exportadores, distribuidores, administrativos, correctores, lectores profesionales. Asimismo, está compuesto por la editorial, la distribuidora, las librerías (o la cadena de ellas), los escaparates de estas, el lugar que ocupa el libro físico en los mostradores y exhibidores, los stands en las ferias locales e internacionales, la publicidad en periódicos y secciones especializadas, los agentes literarios, las tiradas y cantidad de ediciones y reimpresiones, las estrategias de marketing alrededor del título y del autor, su ubicación en las listas de ventas, sus cifras de ventas, sus recensiones en publicaciones especializadas y suplementos, las estrategias de viralización de los títulos del catálogo en las redes sociales, las críticas en los medios de comunicación, sus adaptaciones conexas a otras artes no literarias (y literarias científicas y antologías). ${ }^{8}$ 
Ahora bien, los editores se desempeñan en contextos diferentes de acuerdo con el tipo de catálogo que construyen. Para Alejandro Katz (2003: 31) existen editores más cercanos al polo de la mercancía y editores más cercanos al polo del contenido (de acuerdo con el análisis de campos realizado por Pierre Bourdieu). Los primeros más "orientados a la valorización rápida de la mercancía, subordinados a la demanda preexistente, por una parte; y los editores del polo cultural, orientados a la valorización de los contenido y generadores de demanda futura, por la otra", aunque, agrega el citado Katz (2003: 31):

No existen los editores del 'campo comercial' puros del mismo modo que no existen los editores del 'campo cultural' puros: en toda editorial existe una mezcla de ambos, y es solo la predominancia de lo cultural o de lo comercial en esta mezcla lo que permite clasificar a las empresas en uno u otro de los campos.

En el plano del campo cultural, muchas veces son soslayadas las acciones tendientes a la construcción del catálogo, "de culto" o "de fondo editoria sostenido". En este nivel de análisis no es ajena la idea emparentada con el criterio de canonización de Bloom de una acción legitimadora propia de la crítica especializada que determine títulos y autores "auténticamente literarios". Las acciones desde la crítica especializada (sobre todo aquella que deviene de las universidades, departamentos y carreras de Letras/Filología programas de investigación abocados al estudio de la literatura) abarcan desde la inclusión de autores, obras, géneros, perspectivas de abordaje a las obras hasta la exclusión de autores y obras. Por lo tanto, no podemo negar la influencia de la institución literaria en la imposición de criterio de "lo editable". Los críticos literarios y académicos sostienen su influencia sobre las decisiones de qué libros y autores van a ser editados. Los editores intervienen en el campo intelectual conformando un campo editorial que legitima lo escrito al publicarlo y distribuirlo socialmente; consagra autore al mismo tiempo que desecha a otros y habilita formas de lectura y niega otras (Bourdieu, 1999), es decir, formas estilísticas, tópicos y autores de interés académico y con gran capacidad de penetración, también, a nivel de gerencias editoriales y boards de editores (esto también sucede en la edición general y en la "crítica cultural", no solamente en la literatura).

Pero, y asimismo, aquella tendencia se ve reforzada con el acceso de profesionales universitarios a las gerencias y consejos editoriales de las empresas, lo que permite acercar las posiciones académicas a la actividad comercial en el plano de la construcción de los catálogos y programas editoriales, es decir, la relación entre catálogo, mercado y crítica especializada se define en la concreción del catálogo literario (y literario "ampliado": ensayo, investigación en ciencias sociales, filosofía, etc.). En este punto, la crítica especializada funciona como puente de articulación entre mercado y literatura.
Además, y al mismo tiempo, también actúan otros vectores sobre la construcción general del catálogo. A saber: formas editoriales vinculadas al marketing que actúan en la concreción de un catálogo de alta rotación, que se caracterizan por poseer una concepción inmediatista de la cultura que concede predominio a las formas de utilización inmediata del libro ("sirve para..."; libros de autoayuda) o con la "farandulización" del catálogo (utilizando a figuras de la TV, del cine y de otros medios tradicionales). El fenómeno de bestsellerización logra incorporar nuevos públicos a la lectura y reorganiza el campo editorial. Se considera bestseller al libro que ha sido planificado para lograr un nivel muy alto de ventas, que logra situarse entre los más vendidos, y mantenerse en su puesto de éxito comercial durante un lapso relativamente corto (Arróspide, 2002). Aunque, asimismo, también un viejo bestseller puede convertirse en un título "de fondo", o sea de consumo sostenido en el tiempo. Pero, además, los costos de producción y publicidad de un bestseller son muy altos, lo que deja su operación de producción en pocas manos: grupos multimedia, especialmente (y que todo el programa editorial esté articulado en la meta estratégica de obtención de grandes ganancias).

Los procedimientos mercadotécnicos aplicados por los grandes grupos editoriales, también, logran la homogeneización de las prácticas de consumo cultural y de los contenidos en todos los sectores de las industrias culturales (Cordón García y García Figuerola, 2012: 22-23). Si los asociamos a otros vectores, como la fusión corporativa, nos encontramos con los riesgos que Schiffrin (2001: 172) marcaba como el peligro que corren las sociedades democráticas al desarrollarse en medios culturales en los que el número de ideas y de alternativas son reducidos al clausurarse el debate libre.

En otro plano de acción, encontramos actores académicos que participan o alientan pequeños emprendimientos editoriales. Por un lado, las multinacionales y grandes grupos no apuestan por la formación de catálogos anclados en lo "cultural" o que definen la edición de títulos "de fondo" y los editan para toda el área desde sus casas matrices. Pero hay casos en que sus catálogos sí están orientados en el polo de los contenidos: los casos de los sellos de este polo (en castellano) Taurus, Alfaguara, Tusquets, Paidós, Seix Barral, Emecé, por solo mencionar algunas, nos eximen de comentarios en este sentido.

A su vez, en el otro polo, existen editoriales "independientes" que se plantean como alternativas a la industria editorial mainstream, pero cuyos programas editoriales constan de títulos que son de difícil venta (en la mayoría de los casos). Si el mainstream es "lo contrario de la contracultura, de la subcultura de los nichos de mercado" y "para muchos es lo contrario del arte" (Martel, 2012: 22), estos sellos, orientados a la valorización de los contenidos, se encuentran en el dilema de editar títulos que cuentan con la dificultad de escapar a la subordinación de una demanda preexistente (propia del polo comercial, pero para un público altamente entrenado sim- 
bólicamente y escritos por escritores también altamente entrenados). Así, estos sellos boutique también funcionan como lectores de las grandes editoriales, cargando con el riesgo de que sus descubrimientos sean explotados por las grandes casas editoriales previas ofertas económicamente más rentables por parte de estas.

En algún punto, parte importante de la innovación literaria del catálogo general de la edición mundial está basada en la efectividad en el control del nicho de mercado propio y las estrategias de reputación virtual construidas en las redes sociales por las pequeñas editoriales (Cordón García y García Figuerola, 2012: 24-26). También hay que tomar en cuenta que mucho de esos sellos terminan siendo incorporados a los grupos empresarios en el momento en que disponen de un catálogo "de culto" desarrollado y son comprados con la intención manifiesta de incorporar sus títulos al grupo, como en los caso de Emecé al Grupo Planeta, de Anagrama al segundo grupo editorial de Italia: Feltrinelli, y de algunos de los sellos en castellano del Grupo Prisa adquiridos recientemente por Penguin Random House Bertelsmann AG: Aguilar, Alfaguara, Punto de Lectura, Suma de Letras y Taurus.

\subsubsection{Las editoriales cartoneras: una dispositividad material} latinoamericana

El fenómeno de las editoriales cartoneras fue iniciado por Eloísa Cartonera en la Argentina en 2001. Funciona como cooperativa editorial y de artes gráficas que produce libros hechos a mano. Se inició con la idea de ofrecer respuesta a la crisis política argentina y al colapso económico de 2001 y la salida postneoliberalismo de los primeros años de la década del año 2000, cuando el desempleo forzó a miles de personas a recolectar basura en las calles de las grandes ciudades. Muchos de esos sobrevivientes se dedicaron a seleccionar basura para el reciclaje por lo cual pasaron a ser conocidos como "cartoneros". En aquella situación de crisis social y económica, el sector cultural quedó muy afectado: los libros no se vendían, cerraban librerías y editoriales, los autores no podían publicar. Así, el escritor Washington Cucurto y los artistas visuales Javier Barilaro y Fernanda Laguna empezaron a confeccionar libros artísticos empleando cartón desechado. En solidaridad con los desocupados, cambiaron el objetivo que tenían de crear libros artísticos por el de poner la literatura al alcance de todos, vendiendo sus libros a precios asequibles y pagando a los cartoneros mejor que en los centros de reciclaje. Con la posterior incorporación de algunos cartoneros al equipo de producción, se creó la cooperativa Eloísa Cartonera. Esta, poco a poco, se fue constituyendo en un faro de atracción para escritores latinoamericanos que donaron sus obras para la construcción de un incipiente catálogo que se componía de relatos breves, cuentos sueltos, poemarios, novelas, obras de teatro, textos de vanguardia, literatura infantil y juvenil. La relevancia e impacto que tuvo el modelo cartonero que expandió Eloísa Cartonera ha trascendido las fronteras de la Argentina: más de sesenta editoriales cartoneras independientes operan en la actualidad en países de toda Latinoamérica y ya se han puesto en marcha editoriales cartoneras en España, Francia, Italia, Mozambique y Portugal. En España: Aída Cartonera, Cartonera Island, Cartonerita Niñabonita, Cartopiés Cartonera, Ediciones Karakartón, La Verónica Cartonera, Meninas Cartoneras, Paquita Cartonera, Pensaré Cartoneras, Ultramarina Cartonera; en Francia: Cephisa Cartonera, Babel Cartonnière, La Guêpe Cartonnière; en Italia: FernAnda Pappetrice; en Mozambique: Kutsemba Cartão y en Portugal: Bela Cartonera.

Así, las editoriales cartoneras se constituyen en plataformas de distribución cultural que reelaboran las formas tradicionales de edición en soporte impreso:

- Sus proveedores son algunos de los miles de trabajadores que colectan papeles y cartones en las bolsas y artefactos de recolección de basura de las ciudades latinoamericanas.

- Los títulos editados son donados por los autores (mayoritariamente, sin percibir contraprestación por derechos de autor). 
- Sin serialización estándar.

- Con un trabajo de arte y diseños artesanal (las cubiertas son coloreadas a mano con acuarela y témpera).

- Sin cadenas de distribución tradicional propias, la mayoría de sus títulos son distribuidos por los propios autores, vendidos en sus locales o en ferias (aunque algunos de sus títulos son distribuidos por empresas de distribución tradicional).

- Sin impresión profesional (la mayoría fotocopia o fotoduplica los textos).

- El pegado se realiza a mano y la encuadernados en cartón.

- Sin registro ISBN de las obras editadas.

En parte, la transposición a digital se realiza mediante la publicación en blogs de autor o de eventos tales como los distintos saráus y grupos de poesía de autores asociados. Asimismo, se detectan tanto la transposición a digital en páginas web, foros de Tumblr y blogs de algunos de los títulos publicados en ediciones cartoneras y, por otro lado, la acción en el sentido inverso: los materiales nacen en aquellas formas digitales y se transponen a impreso mediante la edición cartonera en papel. Finalmente, se destaca que algunos títulos de autores ligados a experiencias cartoneras no cruzan el límite autoimpuesto por sus autores de obras "born-digital" (sin transposición a papel en ninguna de sus maneras editoriales). Disponen de un catálogo colectivo que incluye autores bloomianos como Reinaldo Arenas, junto a escritores consagrados de la llamada generación del 72 (Nicholson y McClennen, 2013) como Tomás Eloy Martínez, Ricardo Piglia, Diamela Eltit, Luisa Valenzuela, César Aira; o escritores consagrados de distintas poéticas como Rdoolfo Walsh, Haroldo de Campos, José Emilio Pacheco, etc. Ksenija Bilbija (2010) resalta a los escritores bolivianos Adolfo Cárdenas y Christian Jiménez, al colombiano Andrés Caicedo, a los argentino Ricardo Piña y Viridiana Pistorio, a las colombianas Andrés Nieva y Adriana Martínez, a la paraguaya Maggie Torres y al mexicano Antonio Ramos Revilla:

No habían publicado anteriormente en las editoriales tradicionales y cuyas primeras publicaciones llegaron a las manos lectoras dentro de las tapas sacadas de algún basural, pintadas con témpera a través de un esténcil (Bilbija, 2010: 105).

Para la mencionada Bilbija (2010), el concepto de clandestinidad (de Certeau, 1996) recobraría "el valor literal". El trabajo de los cartonero es "semiclandestino" como también lo es la producción de los libros (los autores no reciben dinero alguno por sus derechos de autor, generalmente, los ceden a la editorial cartonera). A su vez, para el Estado, también, sería "semiclandestina", "ya que no se pagan impuestos por las ganancias (Bilbija, 2010: 112). Además, ninguna editorial cartonera registra los títulos en las correspondientes Agencias ISBN.

Son editoriales cartoneras cuyos catálogos fueron relevados de la Base de Datos de Editoriales Cartoneras de la Universidad de Wisconsin, las que detallamos:

- Argentina (Eloísa Cartonera, Editorial Retazos, Cartonera, Textos de Cartón)

- Bolivia (Yerba Mala Cartonera, Nicotina Cartonera, Rostro Asado Cartonera)

- Brasil (Dulcinéia Cartonera, Estação Catadora, La Katarina Kartonera, Severina Catadora, Sereia $\mathrm{Ca}(\mathrm{n})$ tadora)

- Chile (Animita Cartonera, Canita Cartonera, Helecho de Cartonera, Olga Cartonera)

- Colombia (Amapola Cartonera, Delahogado Elsombrero Cartonera, Patasola Cartonera)

- Costa Rica (Cartonera Tica)

- El Salvador (La Cabuda Cartonera, Pirata Cartonera)

- Ecuador (Dadaif Cartonera, Matapalo Cartonera)

- México (Cartonera La Cecilia, Cohuiná Cartonera, Cuxtitali Cartonera, Kodama Cartonera, La Cartonera, La Ratona Cartonera, La Rueda Cartonera, Regia Cartonera, Santa Muerte Cartonera)

- Panamá (Pelo Malo Cartonera)

- Paraguay (Mamacha Kartonera, MBurukujarami Kartonéra, Yiyi Jambó Cartonera)

- Perú (Sarita Cartonera, Casa Katatay, Qinti Qartunira)

- Puerto Rico (Atarraya Cartonera)

- Uruguay (La Propia Cartonera) 


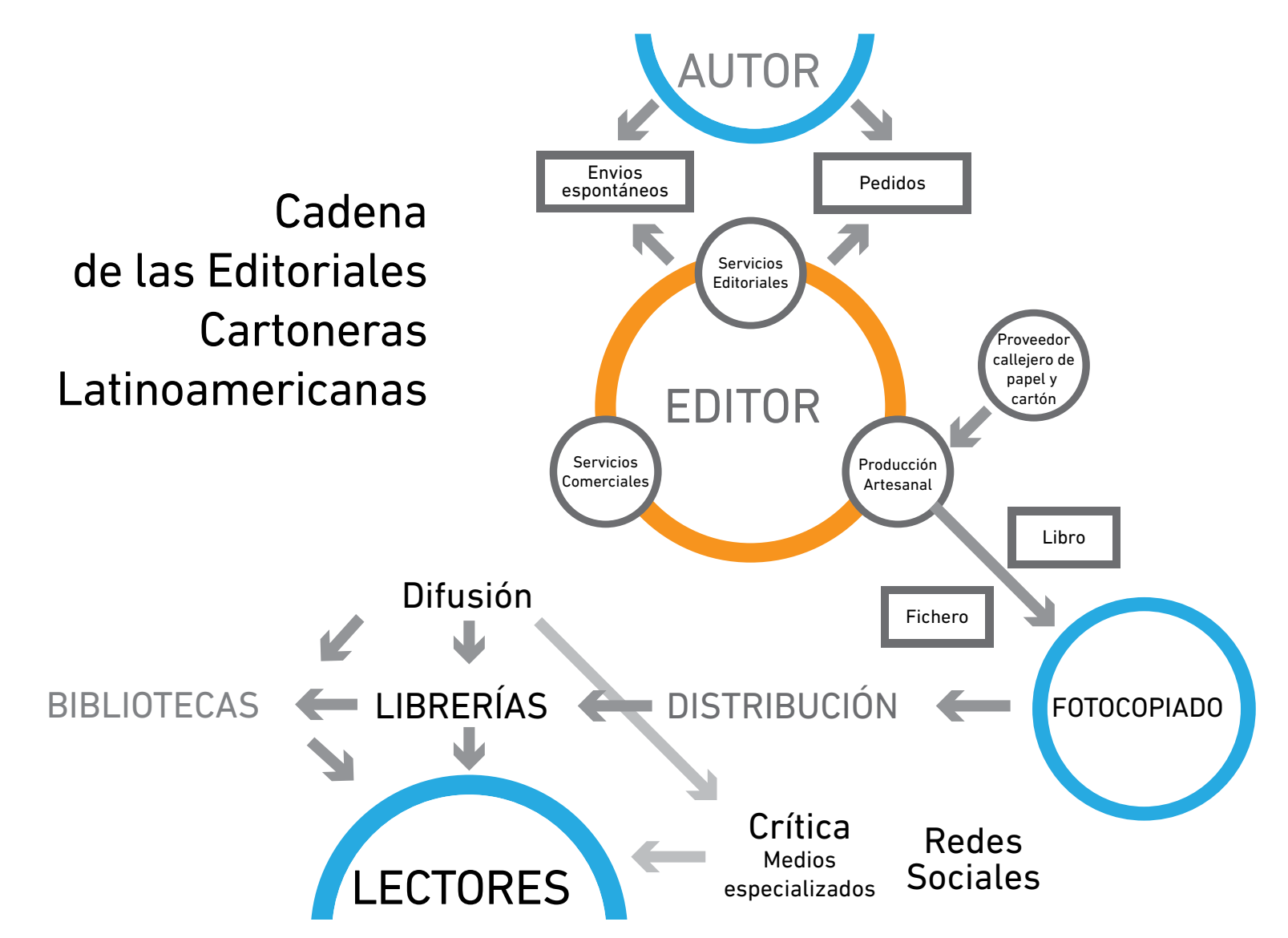

Figura 5. Cadena de las editoriales cartoneras latinoamericanas. Elaboración propia.

De Certeau (1996: 38) describía las formas de la apropiación cultural de los sectores populares, las formas del calificado "consumo" como dotada de "ardides, su desmoronamiento al capricho de las ocasiones, sus cacerías furtivas, su clandestinidad, su murmullo incansable, en suma una especie de invisibilidad pues no se distingue casi nada por productos propios, sino por el arte de utilizar los que le son impuestos", frente a una producción de la industria cultura "expansionista, centralizada". Como observamos en Figura 4, aunque las editoriales cartoneras parten de un nivel de producción artesanal, sus libros resultantes pueden pasar por venta directa a los lectores o, también, pueden formar parte de circuitos de distribución y venta de la industria editorial tradicional. En el nivel de la producción, las editoriales cartoneras latinoamericanas proponen una producción semiclandestina, revirtiendo, dentro de formas que siguen estando dentro de la dispositividad material del impreso, la noción de industrialización serializada y estándar. El fenómeno editorial cartonero puede ser descrito, asimismo, como una versión latinoamericana de la llamada "cultura trash", es decir, "la trivialización utilitaria, diseñada a la medida de la sociedad de la cultura de masas, de una serie de procesos culturales complejos y con cierto pasado a sus espaldas" (Costa, 2003:

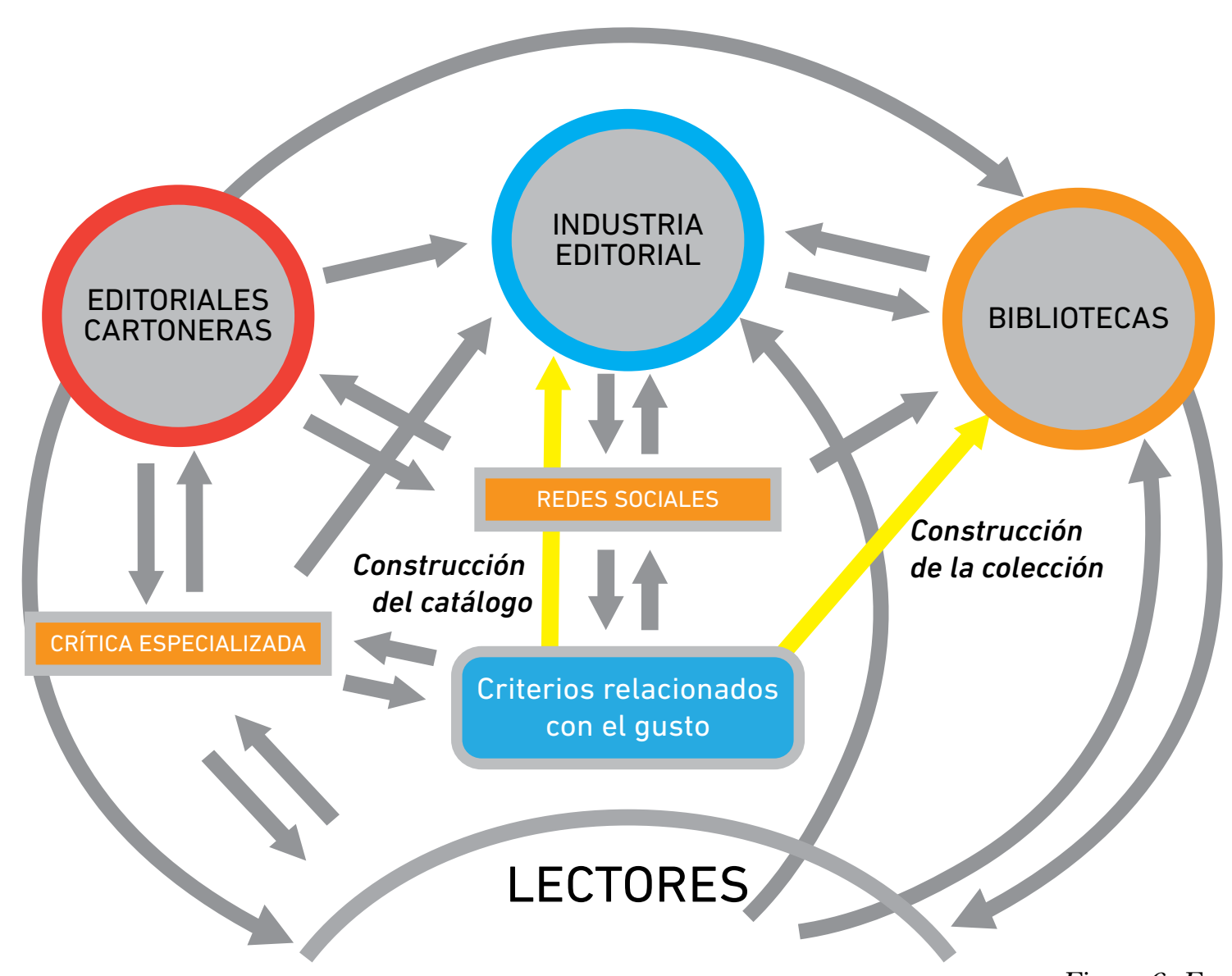

Figura 6. Esquema del flujo de interac-

149). En este punto, las ediciones cartoneras funcionarían, desde la apreciación de Costa (2003: 144) sobre el trash como "instrumentalización del mal gusto", como fenómeno estético "tan heterodoxo como cargado de potencial liberador", aunque, más que constituirse en una forma trivial de reutilización del "mal gusto", las ediciones cartoneras integran la dispositividad material de la galaxia Gutenberg, constituyéndose en artefactos culturales propios de la oferta específica de las literaturas latinoamericanas. Es decir que la dispositividad material mediante la cual circulan los textos de las literaturas latinoamericanas que publican las editoriales cartoneras se organiza como especificidad editorial mediante la cual circulan también formas literarias propias de Latinoamérica. Así, la incorporación de los títulos y autores de las editoriales cartoneras en el CLLyC nos permite rastrear formas editoriales que integran la dispositividad material de la galaxia Gutenberg, pero que se constituyen, además, como artefactos culturales propios de la oferta específica de las literaturas latinoamericanas como mencionábamos anteriormente. Es decir que la dispositividad material mediante la cual circulan los textos del segmento de las literaturas latinoamericanas que aporta dicho Catálogo constituye una de las fuentes de especificidad editorial mediante la ciones en torno a la literatura latinoamericana y caribeña y los lectores. Industria editorial en digital, editoriales cartoneras, bibliotecas, redes sociales $y$ crítica especializada. Elaboración propia. 
cual circulan las formas literarias propias de Latinoamérica. En este punto, se concretan, también, como una opción de edición decolonia que deconstruye las formas de edición tradicional moderna y amplía la dispositividad material mediante la cual se accede a los textos de la literatura latinoamericana.

\subsection{Ecosistema digital}

El ecosistema del libro digital es un subsistema constituido dentro del sistema general de la información digital que afecta a todo tipo de documentos electrónicos, sus estructuras empresariales y dinámicas de creación, producción, distribución y recepción. Todo ello se encuadra dentro del campo general de las tecnologías de la información y la comunicación, compartiendo las características entre unas esferas y otras, pero el libro digital posee un conjunto de características de tipo intelectivo, empresarial y sociológico que apuntan a la existencia de un conjunto de carácter más o menos autónomo, de ahí que hablemos de ecosistema. La idea de campo proviene de Pierre Bourdieu (1966: 2), con la intención metodológica de insertar una cierta autonomía relativa (del poder económico, religioso, político), en función de analizar un sistema regido por leyes propias (propio del estructuralismo).

El impacto del proceso globalizador posee diversos estamentos y diversas velocidades y escalas, García Canclini (1999: 49) la describe como "conjunto de procesos de homogeneización y, a la vez, de fraccionamiento articulado del mundo". La frontera tecnológica en la que se ha constituido la "nube" (cloud computing) repercute sobre las pautas de productividad de todo el sistema económico internacional en sus diferentes planos. En el plano de la industria manufacturera, en el plano de las finanzas y en los diversos planos subsidiarios o estamentos que componen la economía y la organización del trabajo, de los estados y de las subjetividades. El ecosistema digital funciona como un articulador o agente central que coordina y potencia acciones empresariales ligadas al entretenimiento, servicios de búsqueda, comercio, email, Web, servicios ligados a las actividades sociales (como las redes), servicios relacionados con el almacenamiento y transferencia de datos, herramientas (apps), servicios relacionados con la edición. Esas acciones y servicios, a su vez, se solapan y yuxtaponen en función de satisfacer las necesidades y gustos de los usuarios en términos de consumo de bienes tecnológicos y aplicaciones móviles, bibliotecas digitales, consumos de retail (minorista) y señales digitales y consumos articulados por ordenador (Ver Figura 7). 


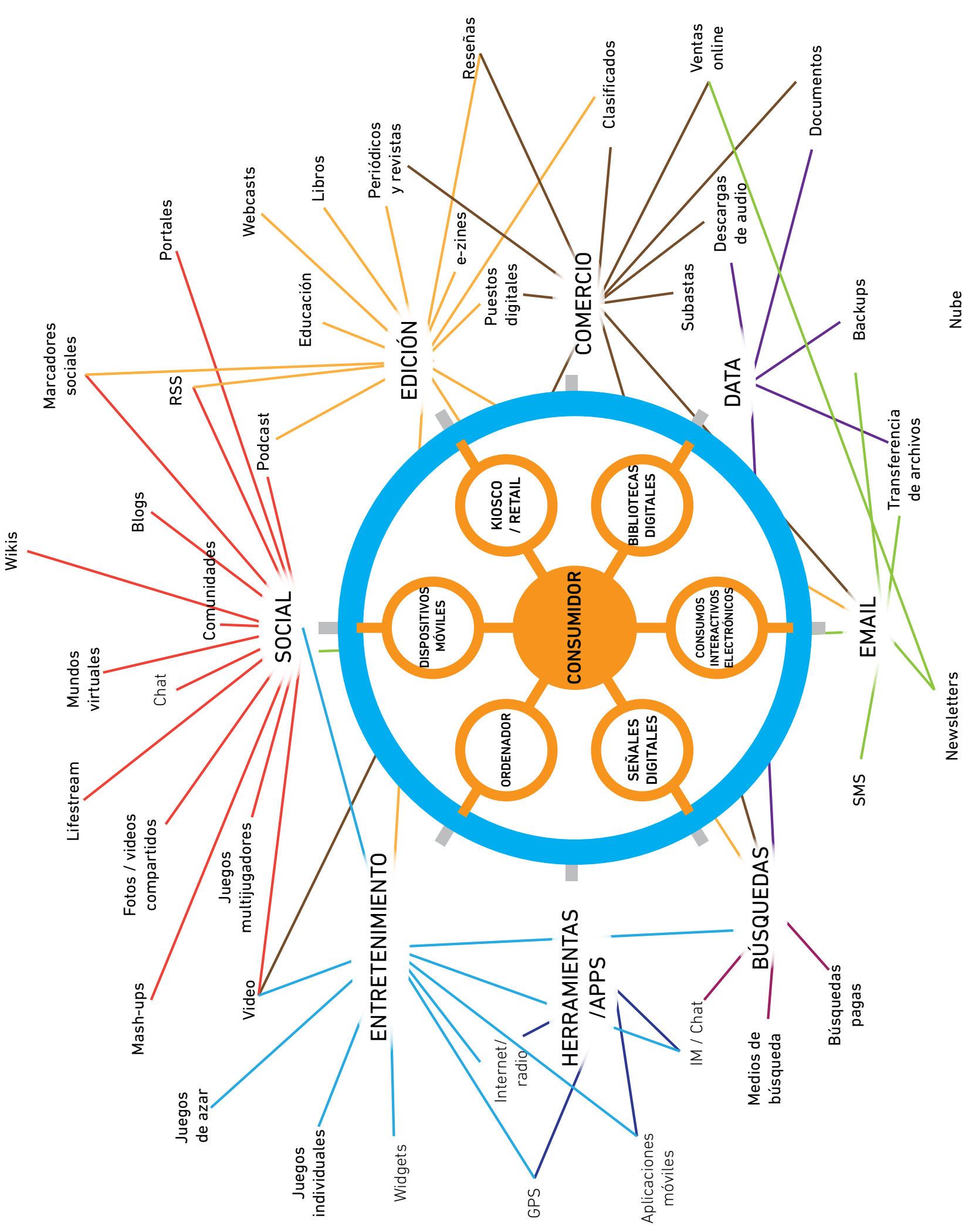

Ahora bien, en el espacio estratégico de la alta tecnología, la posición de las empresas norteamericanas es prácticamente monopólica: Amazon y Google poseen más del 70\% de la "nube" (Castro: 2014); siete de las diez principales empresas high tech globales son norteamericanas y las tres restantes chinas (Alibaba, Tescent, Baidú). En términos de valor, la primera es Google y Alibaba, la segunda. Google y Amazon son percibidas como dos de las diez empresas mejor calificadas como "inteligentes" en la lista de $M I T$ Technology Review (2014), un índice elaborado por editores de la revista para resaltar las empresas que han mostrado las innovaciones más importantes en el pasado año, no basadas en medidas cuantitativas, como patentes o gasto en I + D, ni en nombres conocidos como Apple y Facebook, que "no están en esta lista porque la reputación no importa. Estamos destacando aquellas empresas donde las innovaciones importantes están sucediendo en este momento", según Brian Bergstein, uno de sus editores (Ver Figura 8).

Figura 7. Estructura

del ecosistema digital.

Elaboración propia

basada en Infuz

Digital (2012). 


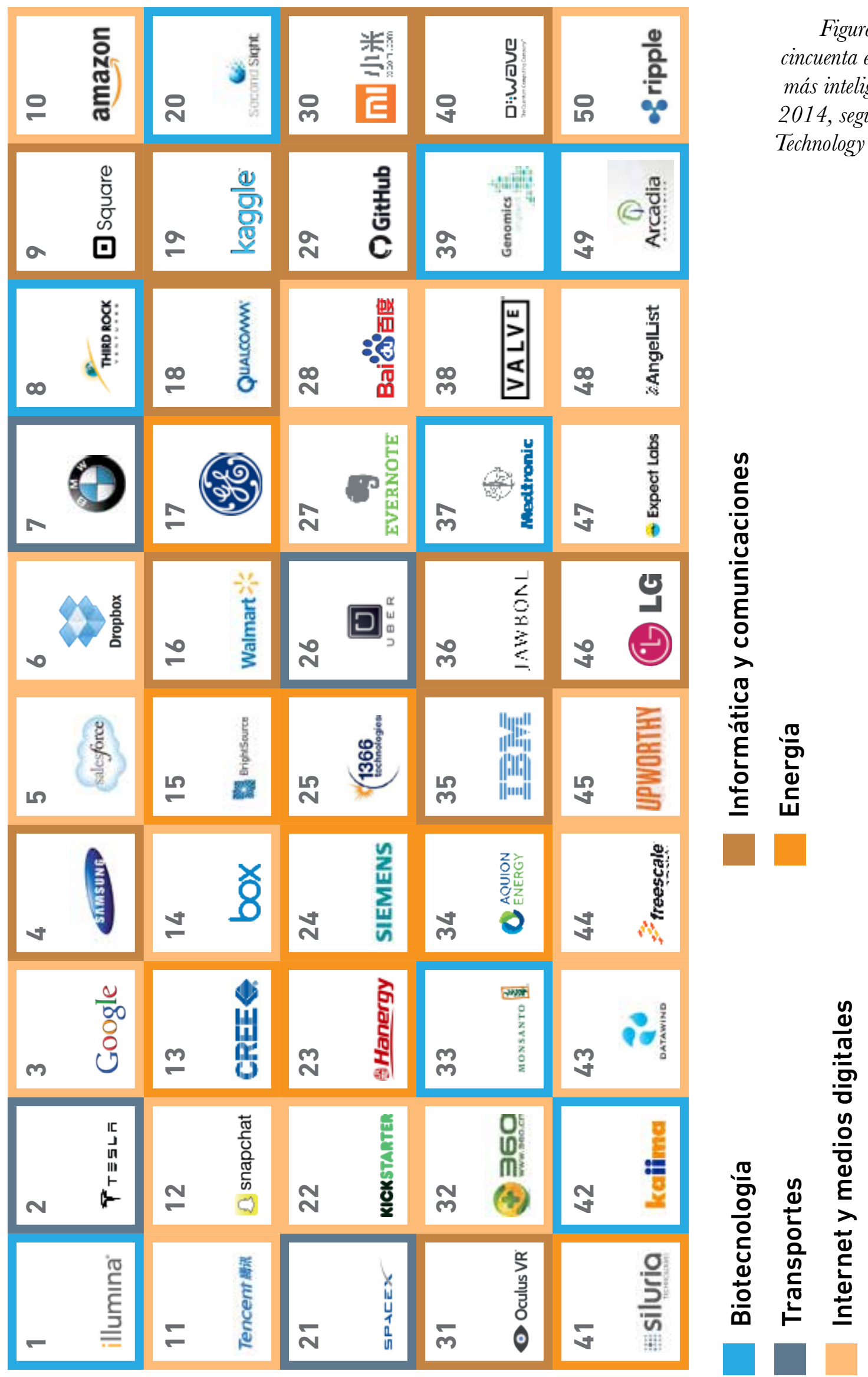

El libro es solo una parte del nuevo ecosistema de la escritura, de la edición, comunicación, búsquedas, entretenimiento, comercio, herramientas y la lectura en el marco de la globalización económica. ${ }^{9}$ Algunos especialistas identifican el momento de inicio de la globalización específica de la industria editorial cuando el grupo alemán Bertelsmann adquirió la mayor editorial del mundo: Random House y trasladó parte de sus oficinas de Münich a Nueva York, en 1998, en un proceso que se había iniciado en la década del 80 con la adquisición de Pantheon Books como parte del proceso de adquisición por parte de Bertelsmann AG de las compañías Doubleday-Dell y RCA Records (luego, BMG -Bertelsmann Music Group-) (Engelhardt, 1991; Schiffrin, 2001).

\subsubsection{El ecosistema digital: un sistema de marcas}

Amazon, y unas pocas otras empresas, sobre todo de los EE.UU., están desplegando sus servicios de libros electrónicos en una escala verdaderamente global. Con solo mirar los números de inversiones, flujos financieros e ingresos se introduce en el cambio de escala económico financiera que el nuevo ecosistema digital (y sus negocios conexos) ha producido:

- Pearson, el líder en la publicación de libros global, poseía ingresos anuales de $\$ 9,2$ mil millones en 2012

- NeresCorp ${ }^{10}$, uno de las principales empresas de medios globales y dueña de HarperCollins, tuvo en 2012 una facturación de $\mathrm{U} \$ \mathrm{~S} 34$ mil millones en 2012.

- Amazon U\$S74.450 millones en 2013 (un 22\% más que en 2012, tres veces los U\$S24.500 millones de 2009) (Cohen y Felitti, 2015)

- Apple cerró el trimestre de la temporada de compras navideñas de 2014 con un beneficio récord de U\$S18.000 millones (lo que representa un alza del 37,4\% respecto del mismo periodo de 2013). Además, registró ingresos por valor de U\$S74.600 millones, impulsados por la demanda en China y las ventas del iPhone 6. En solo tres meses ingresó U\$S51.100 millones por este producto, un $21 \%$ más que lo que ingresan de forma combinada sus rivales Google y Microsoft por todos sus negocios (Pozzi, 2015). A su vez, de acuerdo con su capitalización

\footnotetext{
${ }^{9}$ Ver Figura 7.

${ }^{10}$ Fundado en 1960 por el australiano Rupert Murdoch, News Corporation es considerado como uno de los mayores grupos de comunicación del mundo. Tiene el carácter de corporación multimedia con actividad en cuatro continentes: estudios cinematográficos, canales de televisión, medios impresos - periódicos y revistas-, radio, editoriales y distribución por satélite, que cubren Europa, América Latina, Asia y Australia.
} 
en bolsa (Wall Street), de más de U\$S700 mil millones, Apple posee un valor bursátil que sería el equivalente a dos empresas Googles; 2,5 Walmart, ocho McDonald's; 12 General Motors o 24 Twitters (Wakabayashi, 2015) y superior al PBI de un país como Suiza (Herbst-Bayliss y Forgione, 2015).

- Google tuvo ingresos de U\$S50 mil millones y un beneficio operativo de más de U\$S13 mil millones (Wischenbart et al., 2014).

- Alibaba, un gigante chino del comercio electrónico, inició a fines de octubre de 2014 una capitalización financiera de U\$S247.000 millones en los EE.UU. - una de las diez mayores capitalizaciones del mundo-, que la convirtió en la segunda en valor del sector de alta tecnología después de Google. La compañía china necesita una inversión cercana a los U\$S400.000 millones (Castro, 2014) para competir en condiciones parejas en el terreno de la "nube" (cloud computing) y lo cual la obliga a tomar créditos del sistema financiero internacional.

A su vez, y en el plano empresarial editorial "tradicional", debemos destacar que cinco grandes grupos poseen centenas de editoriales: Penguin Random House Bertelsmann AG, Hachette, MacMillan, News Corp. Verlagsgruppe von Holtzbrinck (HarperCollins) y Simon \& Schuster. Y todos, en menor o mayor medida, poseen sellos que editan en soporte digital y sellos tradicionales y en digital, a la vez. Asimismo, transponen títulos de soporte papel a digital y editan títulos nacidos en digital. ${ }^{11}$ Este panorama deviene de la política de concentración en el mercado mundial del libro tradicional que se inició en los años 80 con la compra de Bantam (1980), Double Day (1986) y Dell Publishing (1986) del mercado norteamericano por el grupo alemán Bertelsmann. Penguin Random House representa en la actualidad el 35\% del mercado editorial en inglés (Wylie, 2014).

${ }^{11}$ Penguin Random House Bertelsmann AG (Random House Group, Bantam Books, Caballo de Troya, Debate, DeBolsillo, Literatura Random House, Lumen, Plaza \& Janés, RHFlash, Sudamericana, Grijalbo Mondadori, Penguin, Viking, Prentice Hall, Longman, Addison-Wesley, New Raiders, Que, Sams, Merrian Webster, Scott Forestman acaba de comprar los sellos en español del Grupo Prisa: Aguilar, Alfaguara, Punto de Lectura, Suma de Letras y Taurus y los sellos en lengua portuguesa (Alfaguara, Foglio, Fontanar, Objetiva, Punto de Lectura y Suma de Letras, de Brasil); Time Warner (Time Inc., Advance Publications y DC Comics); Viacom (Simon \& Schuster); Newes Corp.; Verlagsgruppe von Holtzbrinck (Farrar, Straus \& Giroux y St. Martins Press) y Hearst (Black Books, Moto Books)

\begin{tabular}{|c|c|c|c|c|c|}
\hline & 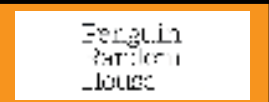 & [건 & WHarperCollins $P$ whilishers & samacmillan & SIMCNE SCHUSTER \\
\hline $\begin{array}{l}\text { Ingresosos del grupo } \\
\text { proveneientes } \\
\text { de pubicacicanes }\end{array}$ & E2655m (2013) & $€ 2066$ & E1189m (2012) & E1608m (2012) & $\varepsilon 809 m(2013)$ \\
\hline $\begin{array}{l}\text { Ingresos del grupo } \\
\text { provenientes } \\
\text { de ebooks }\end{array}$ & $20 \%$ & $10,4 \%$ & $39 \%$ & $27 \%$ & $n / d$ \\
\hline \multirow[t]{2}{*}{\begin{tabular}{|l|} 
Ingresos \\
de ebooks \\
(detalles, 2013) \\
\end{tabular}} & $\begin{array}{l}100 m \text { ebooks vendidos; } \\
-9 \% \text { en volumen } \\
2013 \text { - 2012 }\end{array}$ & $\begin{array}{l}\text { 30\% ing. en mercado } \\
\text { de USA; ;77\% en el } \\
\text { mercado adulto de UK }\end{array}$ & $28 \%$ ingresos por ebooks & $n / d$ & $2,6 \mathrm{~m}$ ebooks vendidos \\
\hline & $\begin{array}{l}\text { RH: } 10 \% \text { de los ingresos de } \\
\text { Alemanaia por ebooks; } \\
\text { Penguin: } 33 \% \text { de ingresos } \\
\text { por ebooks en USA (2011) }\end{array}$ & $\begin{array}{l}\text { Ing. de ebooks en Francia: } \\
\mathrm{n} / \mathrm{d}\end{array}$ & 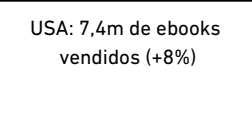 & & \\
\hline
\end{tabular}

Tabla 2. Cuota de mercado estimada de venta de libros online y en Amazon

El nivel de ingresos de los cinco grupos editoriales varía de €809 millones de Simon \& Schuster a los $€ 2.655$ millones de Penguin Random House. Los porcentuales de ingresos ligados a la venta de ebooks va del 39\% en el caso de HarperCollins al 10,4\% de Hachette (no se disponen cifras de Simon \& Schuster). En lo que hace a números de ebooks vendidos, la estimación de Wischenbart et al. (2014) tienen su punto máximo en Penguin Random House: 100 millones de ebooks vendidos en el periodo 2012-2013. Se destaca que Hachette vende en Reino Unido el 78\% de sus libros electrónicos a través de Amazon y un 60\% en Estados Unidos (Abrams a, 2014).

Pero, además, las grandes editoriales no están ganando cuota de mercado: en 2014 fue un año en que los cinco mayores editores mundiales tuvieron pocos éxitos de ventas. Las tres mayores: Penguin Random House, Harper Collins y Hachette tuvieron 43,9\% de cuota de mercado, su nivel más bajo desde que comenzaron los registros en 2001. El declive de los tres mayores mencionados pareciera estar realizándose con mayor velocidad que el declive del mercado de libros impresos, en general. Aunque Macmillan se presenta como el gran ganador de la etapa, con un 9,8\% de crecimiento (Jones, 2015). 


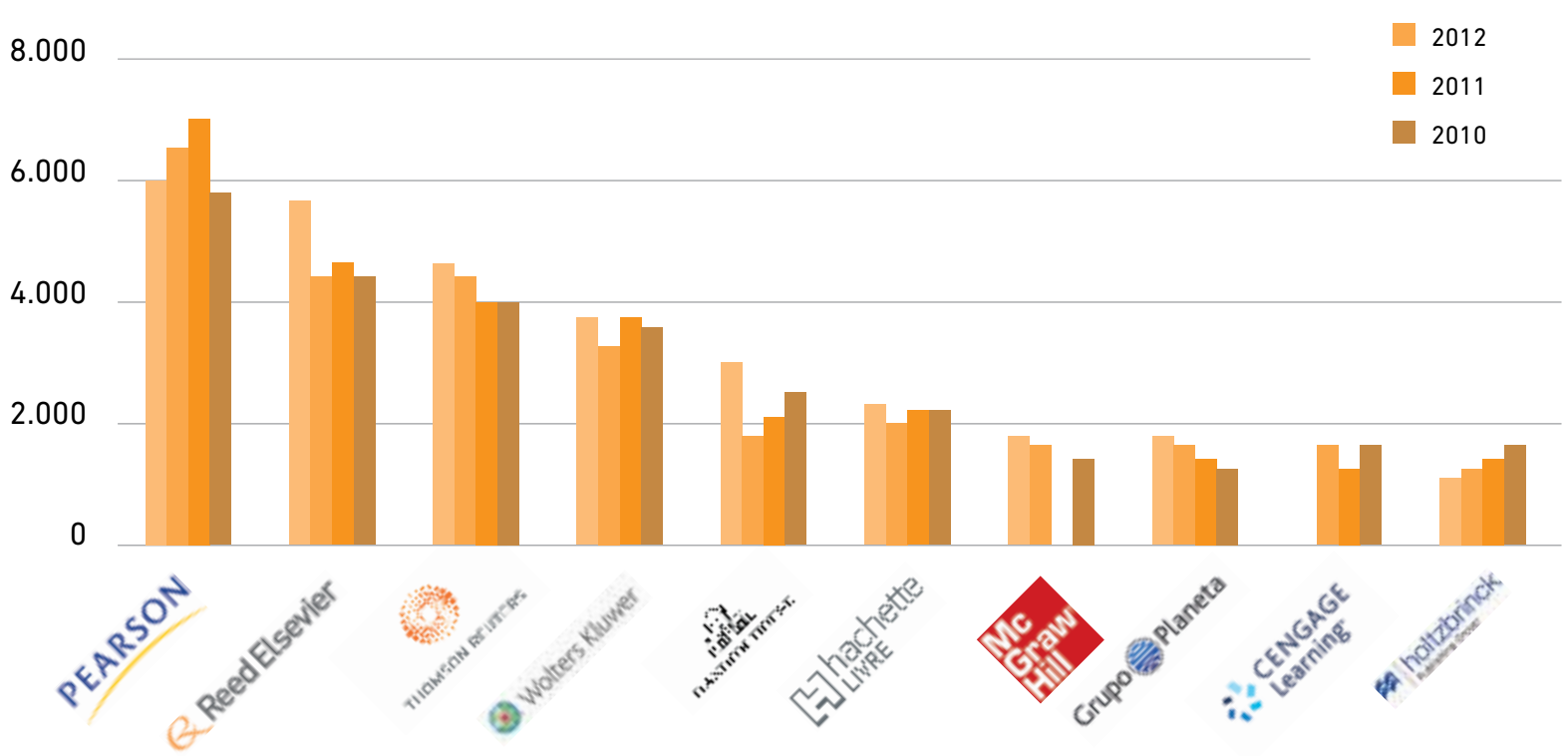

Tabla 3. Los

ingresos de los diez

principales grupos

editoriales en millo-

nes de euros. 2010-

A su vez, la frecuencia de ventas de ebooks en cada país seleccionado, en porcentajes sobre el mercado total de cada uno de ellos, va desde el 13\% 2013. Fuentes: en Reino Unido, $5 \%$ en Alemania, 4,7\% en Países Bajos y del 3 al $5 \%$ en

clasificación España (para la Agencia del ISBN es del 26,34\% del total de la producción global de la in- editorial en 2014) y 1,1\% en Francia. En la mayoría de los países selecciodustria editorial nados, el género predominante en digital es la ficción.

de 2014, Livres

Hebdo, buchre-

port, Publish-

News Brasil, $\mathrm{Pu}$

blishers Weekly y

The Bookseller.

Investigación

Wischenbart et

al. (2014).

\begin{tabular}{|c|c|c|c|c|c|c|}
\hline Mercado & $\begin{array}{l}\% \text { de ebooks en el } \\
\text { mercado total }\end{array}$ & Notas & $\begin{array}{l}\text { \% de ebooks en el } \\
\text { mercado comercial }\end{array}$ & Notas & $\begin{array}{c}\% \text { de ebooks en } \\
\text { segmentios } \\
\text { especificos }\end{array}$ & Notas \\
\hline 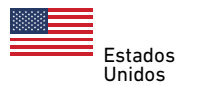 & $13 \%$ & 2012 (BISG) & $21 \%$ & 2012 (BISG) & Hasta 50\% & Ficción \\
\hline Ran & $11,5 \%$ & 2012 & $25 \%$ & & $40 \%$ & 2013, ficción \\
\hline Alemania & $5 \%$ & $2013(\mathrm{GFK})$ & $10,6 \%$ & Börsenverein & 15 a $20 \%$ & Nueva ficción, est. \\
\hline & $1,1 \%$ & 2013 (GFK) & $3 \%$ & $\begin{array}{l}\text { Est. (4,5\% incl. } \\
\text { todo lo digital, Xerfi) }\end{array}$ & 10 a $15 \%$ & Género: ficción, est. \\
\hline${ }_{\text {España }}$ & за $5 \%$ & 2013 (est.) & $8 \%$ & 2013, est. & $20-30 \%$ & $\begin{array}{l}\text { Ficción erótica } \\
\text { (est. Planeta) }\end{array}$ \\
\hline Ittalia & & & $4 \mathrm{a} 5 \%$ & Est. & Hasta $50 \%$ & Ficción de género, est. \\
\hline$\underbrace{}_{\substack{\text { Paises } \\
\text { Bajos }}}$ & $4.7 \%$ & NUV. & $10 \%$ & NUv & Hasta $40 \%$ & Ficción de género \\
\hline Suecia & $1 \%$ & Est. SVB & & & $\begin{array}{l}\text { Hasta } 70 \% \\
\text { del mercado librero }\end{array}$ & Est. \\
\hline
\end{tabular}

Tabla 4. Cuota de

Como marcan Cordón García y Figuerola (2012), la economía de la mercado de ebooks edición padece la implantación definitiva de un mercado regido por los (según varias procesos de GILT (globalización, internacionalización, localización y tra- fuentes) en mercados ducción). Las naves insignia del libro digital, las plataformas Amazon, Bar- seleccionados. nes \& Noble, Kobo, Apple y Google Books ejercen un monopolio marcado en la articulación del mercado y en la organización de la oferta editorial. Además de que los pocos actores globales líderes, Amazon, Apple, Google, Kobo, y un número creciente de líderes a escala regional y local, como la francesa FNAC, la alemana Tolino, China Mobile como así Telefónica española asociada al Grupo Planeta, o en Brasil Livraria Cultura con Kobo, todos están orientados a formar plataformas digitales para la venta de libros (y aplicaciones y productos y servicios asociados) (Ver Figura 10).

Google y Amazon comprendieron la importancia estratégica del "ecosistema de marcas" y han intentado replicar el éxito de Apple. Como resultado, el mercado actual está marcado por múltiples subsistemas emergentes, blindados unos de otro, en competencia para recoger y administrar tanto viejos como nuevos usuarios (y lealtad a sus marcas). La intersección de a) formas tecnológicas (dispositivos: lectores de libros electrónicos, tabletas, smartphones) con b) distribución (cómo compramos y pagamos) y c) contenidos (¿qué consumimos, qué leemos, qué miramos, qué jugamos?) está ocupada por los agentes centrales del ecosistema: iTunes, Instant Amazon, Google Play, Viewdini y Xfinit (estas dos últimas son portales de servicios de video y de televisión on demand). 


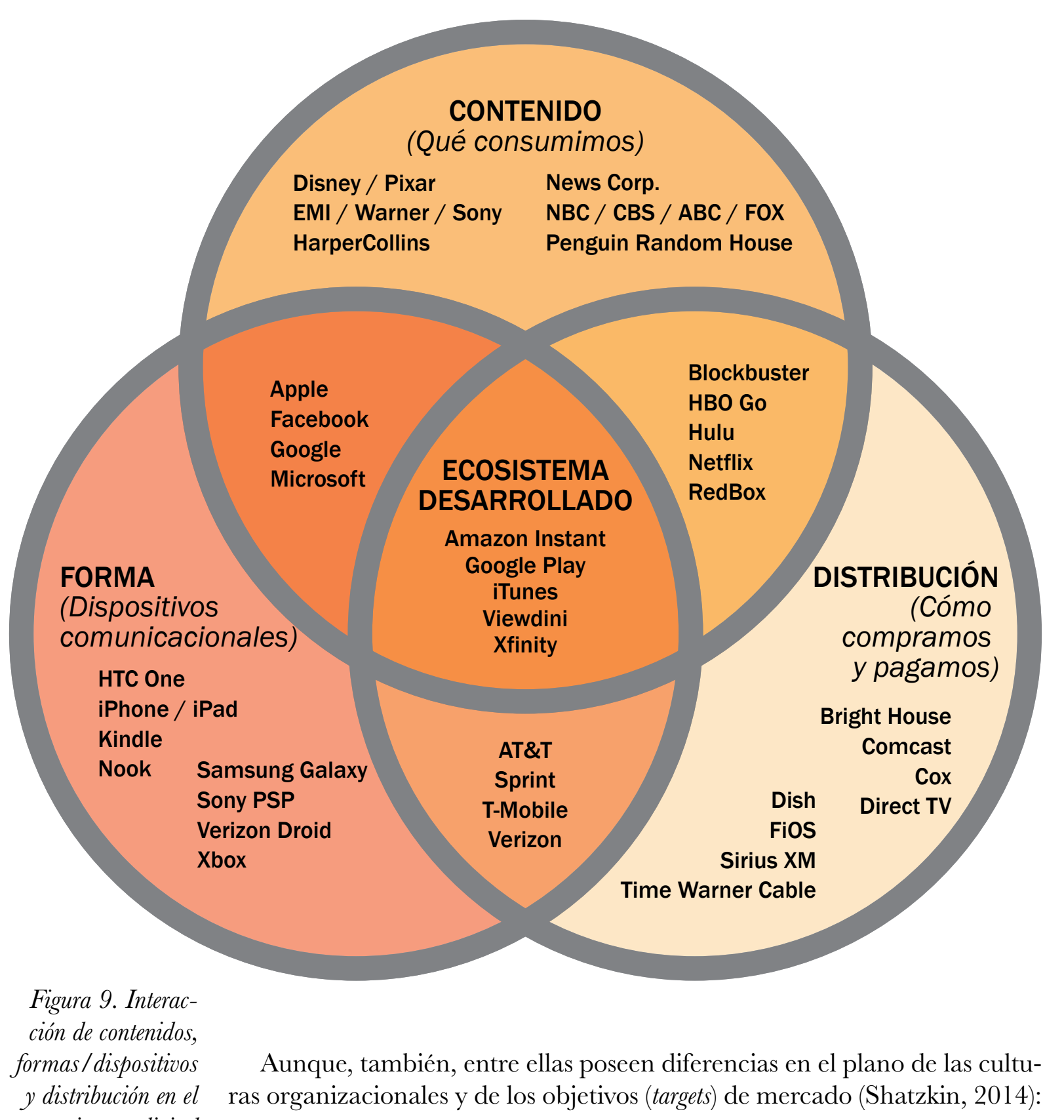

$y$ distribución en el ecosistema digital con los correspon dientes actores (mar cas) predominantes. Elaboración propia, basado en Keefe (2013).
- Para Amazon, la venta de libros es una estrategia de sostenimiento de identidad pública y de adquisición de clientes.

- Para empresas como Apple o Google, la transición digital y perspectiva global en la edición de libros será solo una parte de un panorama mucho más amplio, ya que distribuyen todo tipo de contenido de medios digitales, no solo libros.

- Para Apple, los libros son parte de otra estrategia: el in greso a un ecosistema que también promueve la venta de sus productos electrónicos/informáticos.
- Google, en cambio, también combina la venta de libros con las búsquedas en sus exploradores y la identidad en línea de cada usuario al interior de su propio ecosistema.

- A pesar de que los ingresos de los libros es un elemento central en Amazon, la venta al por menor de libros es una entre varias del conjunto de servicios que ofrece. Amazon, a su vez, vende libros en todos los formatos, Apple y Google no, lo que no permite avizorar estrategias de competencia directa entre los tres a mediano plazo.

- A su vez, Barnes \& Noble vende libros en soporte físico (700 librerías) y materiales en digital en formato *epub.

- En este punto, se destacan las diferencias de formatos electrónicos de la oferta de las diferentes plataformas. ${ }^{12}$ Simon $\&$ Schuster ha realizado una alianza con la Web de intercambio de documentos Scribd (y su librería online Scribd Store). Esta Web es visitada por sesenta millones de usuarios al mes, quienes vuelcan escritos de todo tipo de manera gratuita. Simon \& Schuster venderá ebooks de autores superventas como Stephen King y Dan Brown y posee un enlace directo a su propia Web en Scribd Store donde se pueden comprar, además de 5.000 títulos en formato digital, 7.000 títulos en papel que no tienen versión en digital. El formato anticopia de Adobe adoptado para este caso no permite lecturas en Kindle, lo que denota una estrategia ostensiblemente anti-Amazon.

- HarperCollins anunció que ha completado (en enero de 2015) el desarrollo de formato *epub3 para todas sus publicaciones: desarrolló con RSI Content Solutions para la aplicación de este formato y compartirá la tecnología DITA para editores (Darwin Information Typing Architecture), una norma de dibujo basado en *xml que facilita la creación y gestión de la información publicada (Dillworth, 2015).

- Una de las tendencia más fuertes en el mundo editorial actual (en enero de 2015) apunta hacia modelos de suscripción: Nubico, 24Symbols, Kindle Unlimited, Amazon Prime (libros + música + películas), Pelican Books, Scribd (Ver "Plataformas de lectura en línea"). Las posibilidades de rentabilización de producción cultural editada en formato digital en

${ }^{12}$ Con el programa Calibre se pueden convertir archivos originales en formatos: ePub, LRF, HTML, LIT, MOBI, TPZ, TXT, RTF, PDF, SNB, CBZ, CBR, CBC, ZIP, RAR, ODT, DOC, DOCX y pasarlos a: ePub, MOBI, AZW3, FB2, HTMLZ, LIT, LRF, PDB, PDF, PMLZ, RB, RTF, SNB, TCR, TXT, TXTZ, ZIP. 
entornos cerrados como los subsistemas del ecosistema digital blindado por las distintas marcas se tornan dificultosas. Solo se toman ganancias cuando las escalas del negocio son muy grandes (como en el sistema de la música digital). Pero, y en el sentido convergente de esta tendencia de modelos de suscripción, la aparición de los llamados sistemas de crowdfunding, también denominados micromecenazgo, financiación masiva, financiación en masa o por suscripción, permiten la recaudación de fondos a través de plataformas especializadas. Algunas plataformas importantes: la principal plataforma, Kickstarter finalizó 2014 con 22.252 proyectos financiados con un aporte de más de U\$S529 millones. Desde que fue lanzada en 2009 lleva financiadas a 7,7 millones de personas con sus proyectos; 2,3 millones de personas han financiado más de un proyecto; y 272 mil personas han financiado más de diez proyectos. Otra plataformas de crowdfunding: Lanzanos.com, Goteo.org, Fandyu.com Injoinet.com, My Major Company, Potlatch, SeedEClick, Crowdthinking, totSuma, Siamm, Fromlab, Kuabol, Fundedbyme, Get Your Case, Fundlike, StartVal, Uniempren, Verkami.com, Ulule.com, Libros.com, Pentian.com, Ilovescience, Vórticex.

Amazon

- Posee una posición dominante en la venta de libros electrónicos (y de libros impresos), con más del 70\% de la cuota de mercado de EE.UU. (Monge, 2014). La compañía Amazon comercializa, entre otros productos, ebooks y dispositivos de tinta electrónica. A su vez, ofrece de manera gratuita una aplicación multiplataforma desde la que se accede el catálogo de libros electrónicos que oferta. Kindle está disponible para iPad, iPhone, iPod touch, dispositivos con sistemas operativos Android, Windows Phone, BlackBerry, WebOS, además de ofrecer versiones para dispositivos específicos y los sistemas operativos de escritorio más tradicionales. Todas las versiones se pueden descargar desde la misma Web. La aplicación es compatible con varios formatos de ebooks, además de periódicos, revistas y documentos PDF Sus dispositivos lectores son los Kindle. Para la primera generación de Kindle, los formatos aceptados son Mobipocket (MOB , PRC), archivos de texto plano (TXT), libros Topaz ( TPZ ) y formato AZW de Amazon. En Kindle 2, añadió la capacidad de leer PDF y archivos HTML. Luego, KindleTouch, KindleTouch $3 G$ y Kindle Paperwhite pueden mostrarnos AZW, TXT, PDF, MOBI sin protección. Y los archivos en HTML, DOC, DOCX, JPEG, GIF, PNG y BMP a través de conversión. El Touch y Touch $3 C$ también pueden procesar Audible Enhanced (AA, AAX ) y archivos MP3.
- Las ventas de Kindle y tabletas se estiman en U $\$ S 4,5$ mil millones, un aumento del 26\% desde 2012, según Morgan Stanley. La expectativa de la compañía es que el "ecosistema Kindle" pueda dar cuenta de un $11 \%$ de los ingresos totales de la compañía para el resultado total de 2014 (el 23\% de su beneficio operativo) (Del Rey, 2013). La adquisición de la plataforma de lectura Goodreads (25 millones de miembros en la comunidad) también fortalece la influencia de Amazon en el campo editorial.

- Además, en junio de 2013 comenzó a vender sus dispositivos en China continental, con el Kindle Paperwhite a U\$S134 y su tableta Kindle Fire HD a U\$S200 (Sina, 2013).

- También en 2013, Amazon inició su venta de dispositivos Kindle en India, después de su lanzamiento de una tienda de Kindle en 2012 y presentó su Programa de Asociados Amazon (Shelf Awareness, 2013).

- En Francia, inició su estrategia específica con Jet City, especializada en novelas gráficas (edita tanto cómics físicos como versiones digitales) (Rueda, 2013).

- En España, Amazon factura a través de Luxemburgo, por lo que no es posible conocer sus números de ventas locales. Su filial española, encargada de la facturación de productos desde su centro logístico de San Fernando de Henares (Madrid), declaró que en 2013 aumentó un $65 \%$ la cifra de sus negocios (de $€ 10,56$ a $€ 17,46$ millones) con respecto al ejercicio anterior. Solo una pequeña parte de ese porcentaje corresponde a la venta de libros.

- En 2013 se vendieron unos 60.000 dispositivos Kindle en Brasil y la empresa tuvo una cuota de mercado del $30 \%$ del mercado, según el consenso general de la industria (Carrenho, 2014).

- Aun así, el hecho es que a partir de hoy es el vendedor de libros número uno de Brasil.

- En 2015 programa instalarse en México (anunció la compra de su primer centro de almacenamiento y distribución en Cuautitlán, Izcalli en el Estado de México). 


\begin{tabular}{|c|c|c|c|c|c|c|}
\hline Mercado & $\begin{array}{l}\text { Cuota de mercado } \\
\text { venta a por menor } \\
\text { online }\end{array}$ & $\begin{array}{l}\text { Amazon: cuota de } \\
\text { mercado en } \\
\text { minoristas online }\end{array}$ & $\begin{array}{l}\text { Amazon:cuota de } \\
\text { mercedo en ebooks }\end{array}$ & $\begin{array}{l}\text { Minorista local } \\
\text { no1 } 1 \text { en ventas }\end{array}$ & $\begin{array}{l}\text { Cuota de } \\
\text { mirecado del } \\
\text { minorista local }\end{array}$ & Notas \\
\hline 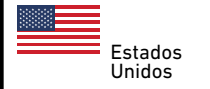 & 26 & & $67 \%$ & Barnes \& Noble & $12 \%$ & $\begin{array}{l}\text { "Más frecuentemente adquier } \\
\text { ebooks" para Kindle, Nook }\end{array}$ \\
\hline 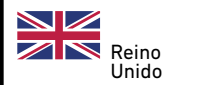 & & & $79 \%$ & Waterstones 3,3\% & & $\begin{array}{l}\text { Apple ca. 16\%, Kobo 10,4\% } \\
\text { (The Bookseller) }\end{array}$ \\
\hline Alemania & $16,5 \%$ (BöV), 26\% (Gfk) & $18 \%$ del mercado total & $43 \%$ & Tolino Alliance & $37 \%$ & Apple 15\% \\
\hline & $18 \%$ & & & & & \\
\hline España & & $35 \%$ & $40 \%$ & $\begin{array}{l}\text { Casa del libro, } \\
\text { El corte ingles, } \\
\text { FNAC, et al. }\end{array}$ & & Apple 40\% (est. DosDoce) \\
\hline Italia & 10 a $12 \%$ & 35 a $40 \%$ & & & & \\
\hline${ }_{\substack{\text { Paises } \\
\text { Bajos }}}$ & & & & BOL & 50 a $75 \%$ & BOL: Print + ebook \\
\hline Suecia & $30 \%$ & & & Adlibris & & $\begin{array}{c}\text { Amazon sólo desde } \\
\text { el extranjero }\end{array}$ \\
\hline
\end{tabular}

Tabla 5. Cuota de mercado estimada de venta de libros en línea en Amazon y en plataformas locales.

Impresos y ebooks,

en mercados elegidos

(Varias fuentes)

\section{Barnes \& Noble}

- Dispone de tres millones de títulos de libros digitales (B\&N: 2015) y una cuota de mercado de 20\% (Bosman, 2015). En Europa ha conseguido entre el $35 \%$ y el $45 \%$ de la comercialización de los libros electrónicos (Corroto a, 2014).

- Los negocios de la empresa incluyen la operación de aproximadamente 700 tiendas de especialidades y más de 600 librerías de universidad en los 50 estados de los EE.UU.; comercio minorista en línea a través de su sitio Web en BN.com y un liderazgo de mercado en la industria digital a través de su marca Nook de dispositivos de lectura, tabletas y contenidos digitales.

- La aplicación de Nook se encuentra disponible en todas las principales plataformas, incluyendo Android, iOS y Windows. Además, ha lanzado Nook HD, una tableta de 7 pulgadas de alta resolución y Nook HD + (una tableta tablet full HD ultraliviana).

- Para el primer trimestre del año fiscal 2014, Barnes \& Noble reportó una disminución de ingresos del 8,5\%, y una pérdida de U\$S8.9 millones (EBITDA), con la división Nook (que incluye los dispositivos, contenidos digitales y accesorios). Anunció U $\$$ S153 millones en ventas para el primer trimestre de 2014, con un descenso de 20,2\% de los U\$SS192 millones en ingresos reportados para el mismo periodo en el año fiscal 2013 (B \& N comunicado de prensa, 20 de agosto 2013).

- Barnes \& Noble fueron socios por dos años en el sistema de Nook: la versión de la aplicación Nook para Windows 8 está operativa en treinta y dos países diferentes.

- En diciembre de 2014, Barnes \& Noble compró a Microsoft su participación en Nook, que llegaba al 17\%. El negocio de Nook no termina de concretarse exitosamente: no representa más que el 3,8\% de sus ingresos en el trimestre que terminó el 1 de noviembre de 2014

\section{Google}

- Más de 50.000 editoriales tienen acuerdos de distribución de sus obras con Google Books.

- Google ha digitalizado más de 20 millones de libros. En algunas fuentes, la cifra se acerca a 30 millones de libros ( marzo de 2014) (Magán Walls y Tardón González, 2014: 10).

- Participa en el mercado del libro electrónico ofreciendo su aplicación disponible para $i O S$ y Android: Google Play Books. Desde esta aplicación se accede a una colección de millones de libros, probablemente la más grande de Internet. Google Play Books ofrece la posibilidad de resaltar textos y tomar notas en libros, incluso de páginas escaneadas y si los derechos de autor lo permiten, copiar texto seleccionado. La aplicación permite cargar archivos *epub y *pdf.

- Google Play Store (anteriormente Android Market) es una plataforma de distribución digital de aplicaciones móviles para los dispositivos con sistema operativo Android, así como una tienda en línea desarrollada y operada por Google. Permite a los usuarios navegar y descargar aplicaciones (desarrolladas mediante Android SDK), música, libros, revistas y películas. También se pueden adquirir dispositivos móviles como ordenadores Chromebook, teléfonos inteligentes Nexus, Google Chromecast, entre otros. 
- En marzo de 2012, con la fusión de Android Market con Google Music, el servicio fue renombrado a Google Play, como resultado de la nueva estrategia de distribución digital de Google.

- En julio de 2013, se anunció que Google Play había sobrepasado un millón de aplicaciones publicadas y se habían registrado más de 50 mil millones de descargas.

- Play Books ofrece más de cuatro millones de títulos que pueden ser adquiridos a través de Google Play. Los libros adquiridos son almacenados en la nube, logrando con esto estar disponibles para acceder a ellos directamente en esta aplicación o a través de la Web. Los usuarios pueden almacenar más de 1.000 archivos sin costo, mientras cada archivo no supere los 50 MB de espacio (Whitney, 2011)

- El 15 de mayo de 2013, se actualizó Play Books añadiendo la posibilidad de que los usuarios pudieran subir archivos en formato *pdf y *epub. Play Books se encuentra actualmente disponible en 44 países.

\section{iBookstore y iTunes}

- Sus tabletas iPad trabajan con *epub como formato por defecto. A su vez, el formato iBook es propio, creado por Apple, que únicamente se puede desarrollar (o adaptar) con el software iBooks Author. Solo para dispositivos iOS.

- Desde 2013, iBooks está disponible en más de 50 países.

- En la mayor parte de América Latina, iBookstore está funcionando desde mediados de 2012. En Brasil, posee una cuota estimada de mercado que va del 28,5\% (marzo de 2013) (Teixeira Stevens, 2013) al 30\% (Wischenbart et al., 2014: 62).

- Según Apple, el iPad registró unas ventas de 16.4 millones de unidades en el segundo trimestre de 2014. Apple vendió desde 2010, año en el que lanzó iPad casi 200 millones de unidades (mayo de 2014). Las ventas mundiales de Apple iPad de tercer trimestre de 2010 al cuarto trimestre de 2014 (en millones de unidades).

- El primer iPad de Apple fue lanzado en abril de 2010 (lleva seis versiones a diciembre de 2014). Sin embargo, a finales del verano de 2012, con el lanzamiento de la nueva genera- ción de lectores electrónicos de bajo costo así como tabletas, especialmente de Amazon, Barnes \& Noble y Kobo, ingresó en una puja importante por el mercado de dispositivos de lectura. A principios de 2012, la tableta iPad dominaba el mercado, dado que controlaba el $60 \%$ de los ventas mundiales de tabletas. Sin embargo, la compañía ha sufrido la disminución de su cuota de mercado a menos del $27 \%$ en el segundo trimestre de 2014, por la creciente competencia de Samsung $(17,2 \%)$ y Lenovo $(5 \%)$

- En junio de 2011, Apple indicó que vendió 130 millones de libros electrónicos a través de iTunes. En octubre de 2012 vendió 400 millones. Esto significa que más de 270 millones de libros electrónicos se vendieron en 16 meses. La media de ventas mensuales es de cerca de 17 millones de unidades (Dedieu, 2013).

- Para diciembre de 2012, la tienda iTunes Store se puso a disposición en 119 países, con grandes mercados como India y Indonesia, Rusia, Arabia Saudita y Turquía. Sin embargo, el universo de iTunes no es exactamente el mismo en todos los mercados.

- iBooks es una aplicación que se vienen equipados con iPads puesto que el dispositivo fue introducido por primera vez por Apple en enero de 2010. La aplicación permite a los lectores a descargar los libros digitales en formato *epub de iBookstore y está integrado con la plataforma iTunes de Apple para el intercambio y uso de otros formatos de archivo, como *pdf. La aplicación iBooks está en más de 30 idiomas.

- Kobo es una plataforma canadiense de libros electrónicos que ofrece un catálogo de libros gratuitos y de pago, una herramienta de autopublicación, varias aplicaciones para leer sus libros en casi cualquier dispositivo y una buena gama propia de dispositivos de lectura o tabletas. Su lector electrónico ocupa actualmente el tercer lugar en la escena de la edición digital, detrás del Kindle de Amazon y del Nook de Barnes\&Noble.

- Posee una plataforma propia de estándares abiertos, que está presente en 190 países y alcanza a diez millones de usuarios. 
- Dispone de tiendas en Alemania y Francia, y está asociada a Mondadori en Italia. En Reino Unido está asociada a WHS mith, editorial y distribuidora, creadora de los códigos SBN (Standard Book Number), que luego fueron adoptados internacionalmente como ISBN.

- Cuenta con un catálogo de más de cuatro millones de libros, con títulos en 68 idiomas, entre los que está incluido el castellano (Araújo, 2013)

- En lo que hace a lectura social, Reading Life es el nombre del sistema que recoge estadísticas sobre tus hábitos de lectura en Kobo, contabilizando número de páginas leídas, libros empezados y acabados, hora del día en las que se lee, entre otros. Los usuarios tienen la posibilidad de compartir o no esos datos con su comunidad.

- Kobo vende sus propios lectores electrónicos y tabletas: Kobo Touch, Kobo Glo, Kobo Mini, Kobo Arc. Los dispositivos de lectura pueden comprarse en Francia, Italia, Alemania Austria, Portugal, Reino Unido y en tiendas online como Redcoon.es en España. Además de sus propios dispositivos, cuentan con aplicaciones de lectura gratuitas para otros entornos, como iOS, Android, BlackBerry y Windows (Araújo, 2013).

- Kobo distribuye a través de su librería Kobo Books y también mediante su red de canales, asociado con proveedores locales o por país: Chapters/Indigo en Canadá, FNAC en Francia, WHSmith en Reino Unido, la Asociación de Librerías Independientes de EE.UU., Mondadori en Italia, Livraria Cultura en Brasil.

- Kobo recibió los clientes de Sony, cuando esta empresa decidió cerrar Reader Store, su propia tienda de libros electrónicos (Monroe, 2014).

- Siguiendo su estrategia probada en Europa, el modelo de negocio de Kobo para Brasil era asociarse con un fuerte proveedor local y encontraron una en Livraria Cultura, uno de los libreros más importantes de Brasil, con 16 tiendas en todo e país. Livraria Cultura también tiene un fondo muy fuerte de comercio electrónico, ya que fue pionera en la venta de libros en línea en Brasil a finales del decenio de 1990.

- Se estima que Kobo vende el 5\% del total de libros electrónicos en Brasil y se ubica tercero en ventas en Reino Unido con 10,4\%. (Wischenbart et al., 2014: 21, 62).
- En la India, desde octubre de 2013, Kobo está distribuyendo sus dispositivos de lectura a través de 100 puntos de venta en 14 ciudades. Sus ereaders están disponibles tanto en línea como fuera de línea en más de 200 puntos de venta en todo el país.

\subsubsection{La vía judicial: intervención de los Estados para la regulación}

\section{del ecosistema digital}

La distribución digital se transforma, también, en un campo para la intervención de distintos organismos nacionales, supranacionales y asociaciones sectoriales (tales como EE.UU., la Comisión Europea y gremios de editores y de autores) en función de regular la actividad comercial de actores globales como Amazon, Apple y Google, actores en plena disputa por la hegemonía de la economía digital presente y futura. Es así como casi todas ellas poseen demandas judiciales por actitudes comerciales monopólicas en relación con el tratamiento de los precios de los libros en formato digital y por cartelización de la oferta en diversos países. Los proyectos de digitalización de Google se han enfrentado por acciones legales coordinadas en varios países europeos, que ha tenido (especialmente, en Francia) un fuerte apoyo político de las instituciones gubernamentales para la creación, además, de formas de digitalización alternativas a Google (Wischenbart et al., 2014: 89). Algunos ejemplos son Gallica (Francia), Europeana (Unión Europea) y la plataforma de distribución Libreka y la Deutsche Digitale Bibliothek (estas dos últimas, de Alemania), sin mencionar los innumerables cargos legales contra Google. Asimismo, en la actualidad se percibe a Amazon como la amenaza principal (al menos para los representantes tradicionales del negocio editorial), sobre todo, en mercados modelados por empresas de tamaño mediano (o por pequeñas empresas familiares), como en la mayoría de los países emergentes y gran parte de los países europeos.

A su vez, durante 2014 se desarrolló una disputa entre Amazon y Hachette en la que participaron más de 900 autores estadounidenses, escritores del catálogo de Hachette (entre ellos, novelistas famosos como Paul Auster, Stephen King, Tobias Wolff o, la última ganadora del Premio Pulitzer, Donna Tartt), que publicaron en la prensa estadounidense una carta abierta en la que acusaron a Amazon de "tomar a los libros como rehenes" y le solicitaban poner un término al litigio. Durante todo el periodo de litigio, Amazon penalizó a los autores de Hachette, que dificultó el envío de los libros y subió sus precios. El conflicto se focalizaba no solo en relación con el precio de los libros, sino sobre todo en torno al porcentaje del precio de venta de cada libro electrónico que se reparten vendedor y editor (que es quien paga a los autores). Generalmente, se reparten $70 \%$ para el editor y $30 \%$ para el vendedor, pero Amazon exigía el 50\% del precio de venta al público o acceder a comprar los libros al menor precio posible, lo que produciría un descenso notable de los ingresos editoriales. El origen del conflicto se remontaba a unos años atrás, cuando HarperCollins, Pearson, 
Simon \& Schuster, Macmillan y la propia Hachette se aliaron entre ellas para hacer contratos de agencia o minoristas para comercializar libros electrónicos (coincidiendo con el lanzamiento de la tienda iBooks de Apple). En ese momento, Amazon había acordado reglas que le impusieron sus competidoras, lo que significó un aumento del precio que deseaban los editores y autores (alrededor del 20\% de aumento del precio de venta de los libros).

En Alemania también se dio un litigio de las mismas características con las filiales del grupo sueco Bonnier y las medidas contra los autores resultaron ser similares a las tomadas contra los escritores de Hachette: retraso en los envíos, supresión del botón para poder pedir un libro por adelantado, subida de los precios. Así, 1.188 escritores alemanes, austríacos, polacos y suecos (entre ellos, la austriaca Elfriede Jelinek, Premio Nobel de Literatura 2004, y Regula Venske, secretaria general de la sociedad de autores alemana) se consideraron "secuestradas" por Amazon, en una carta abierta publicada en la red en la que también denunciaron que sus libros eran distribuidos más lentamente, o se negaba su disponibilidad por ausencia de stock o directamente los autores no aparecían en las listas de autores recomendados por la plataforma Amazon. Así, la Asociación de Editores y Libreros de Alemania presentó una denuncia contra Amazon en el Bun deskartellamt, el organismo federal que lucha contra los monopolios (Ibañez Ridao, 2014). Acusaba a Amazon de violar las leyes de la competencia y solicitaba la intervención gubernamental.

El Parlamento francés aprobó en junio de 2014 una norma llamada "anti Amazon", que busca proteger las librerías tradicionales prohibiendo la acumulación de la gratuidad de los gastos de expedición y de un descuento de 5\% en los libros. La norma regula que los envíos de libros no pueden ser gratuitos dado que se considera esa estrategia como una rebaja encubierta que funciona contra el precio fijo(impuesto por ley en Francia). La respuesta de Amazon fue pasar a cobrar todos los envíos en territorio francés a un céntimo.

A su vez, en un juicio contra el gobierno norteamericano, diez corporaciones apoyaron a Microsoft en lo que hace a la protección de la privacidad de uno de sus clientes, dado que la Justicia de EE.UU. solicita acceso a email de uno de sus clientes (que está alojado en un servidor de Dublín). Microsoft cuenta entre otros con el apoyo de Apple, Amazon, AT\&T, Verizon, CNN,ABC, Fox News y Washington Post.

Ya en 2005, surgió una controversia entre Google y los autores, as como de asociaciones de editores y editores individuales de los EE.UU. y en el extranjero por la inclusión de "fragmentos" de obras con derechos de autor. Después de siete años de litigios y un establecimiento inicial de la causa rechazada en 2011 por un Tribunal de Nueva York, se llegó a un acuerdo entre Google y la Asociación Americana de Editores en octubre de 2012. El acuerdo ofrece a los editores la opción de retirar los títulos con sus derechos de autor escaneados por Google en las bibliotecas y la opción de que si Google desea mantenerlos en su programa, los editores deben recibir una copia digital de los títulos y otorgarle a Google el permiso de utilización comercial para su explotación comercial. Además, los usuarios pueden acceder hasta un $20 \%$ del título y, siempre que el editor otorgue el consentimiento, la opción de compra del título a través de la tienda Google Play. A su vez, los litigios judiciales entre Google y editores franceses como Hachette, Albin Michel, Flammarion Gallimard, y La Martiniere han sido resueltos en acuerdos extrajudiciales (Pfanner, 2011).

En los EE.UU., tras más de dos años de procesos judiciales por conspirar contra la libertad de precios en el mercado de los libros electrónicos, la Justicia declaró a Apple culpable de fijar los precios de los ebooks. El fallo determina que Apple es culpable de una "violación de la Sección 1 de la Ley Sherman" por conspirar con grandes editoriales "para trabajar juntos para eliminar la competencia en los precios de venta y aumentar los precios de libros electrónicos " (Jhonsa, 2013). Las editoriales implícitas son Simons \& Schuster, Hachette, HarperCollins, Penguin y Macmillan. Apple llegó a un acuerdo con las organizaciones de consumidores y los diferentes estados de los Estados Unidos y, finalmente, pagó una multa de U\$S 840 millones. El comienzo de esta historia se remonta al año 2012, cuando el Departamento de Justicia de los E.E.U.U. tomó de 33 estados de los Estados Unidos una denuncia contra Apple y cinco editoriales, concretamente Hachette, HarperCollins, Macmillan, Simon \& Schuster y Penguin, por no respetar la libertad de precios en el mercado de los libros electrónicos. En otras palabras, Apple y esas cinco editoriales pactaron en 2010 el precio de venta de los ebooks, aumentándolo y limitando así la competencia en el sector, haciendo frente a rivales como Amazon.

A su vez, en diciembre de 2012 la Comisión Europea adoptó "una decisión que hace que legalmente los compromisos vinculantes ofrecidos por Apple y cuatro editoriales internacionales" sean algo "simplemente inaceptable", para detener cualquier "connivencia para restringir o eliminar la competencia”. Además, Apple y las cuatro editores rescindirán los contratos de agencia actuales que son el resultado de la conducta colusoria; "durante un periodo de dos años, los editores no pueden, en ciertas condiciones, obstaculizar a los minoristas de libros electrónicos para establecer sus propios precios para los libros electrónicos o, de ofrecer descuentos y promociones"; "durante un periodo de cinco años, ni los cuatro editores ni Apple pueden celebrar acuerdos para sus ebooks con precio minorista con cláusulas de clientes "más favorecidos"' (Almunia, 2012: Comunicado de prensa de la Comisión Europea el 13 de diciembre de 2012). En enero de 2015, la Comisión Europea considera que las concesiones fiscales de Luxemburgo a Amazon son susceptibles de ser consideradas ayudas de Estado ilegales. Joaquín Almunia, ex-comisario de Competencia de la UE, solicitó en octubre de 2014 al Gobierno luxemburgués la información adicional sobre las prácticas impositivas de Amazon. En la misiva, Almunia avanza 
que, de confirmarse su evaluación preliminar del caso - que el pacto entre Luxemburgo y Amazon constituye una ayuda de Estado ilegal-, el brazo ejecutivo de la UE pedirá a la multinacional el reembolso de la cuantía afectada a las arcas luxemburguesas. Se cree que la Comisión Europea posee pistas firmes de que Amazon realizó transferencias entre filiales para pagar menos impuestos (Fariza, 2015)

\subsubsection{Edición digital: mercados de interés}

En 2014, Estados Unidos de América (26\%) sigue siendo el mercado más grande de libros del mundo, seguido por China (12\%), Alemania (8\%), Japón (75), Francia (4\%), Reino Unido (3\%) (Varias fuentes, compiladas po Wischenbart et al. para la Unión Internacional de Editores, IPA, 2013). Juntos, los seis mercados de libros más grandes, representan aproximadamente $60 \%$ del valor de la edición de libros global.

Tabla 6. Tamaño del mercado y producción de nuevos títulos en los 23 mayores mercados editoriales del mundo. El tamaño de cada círculo es proporcional al PBI per cápita en dólares. Fuente: Wischenbart et al., 2014
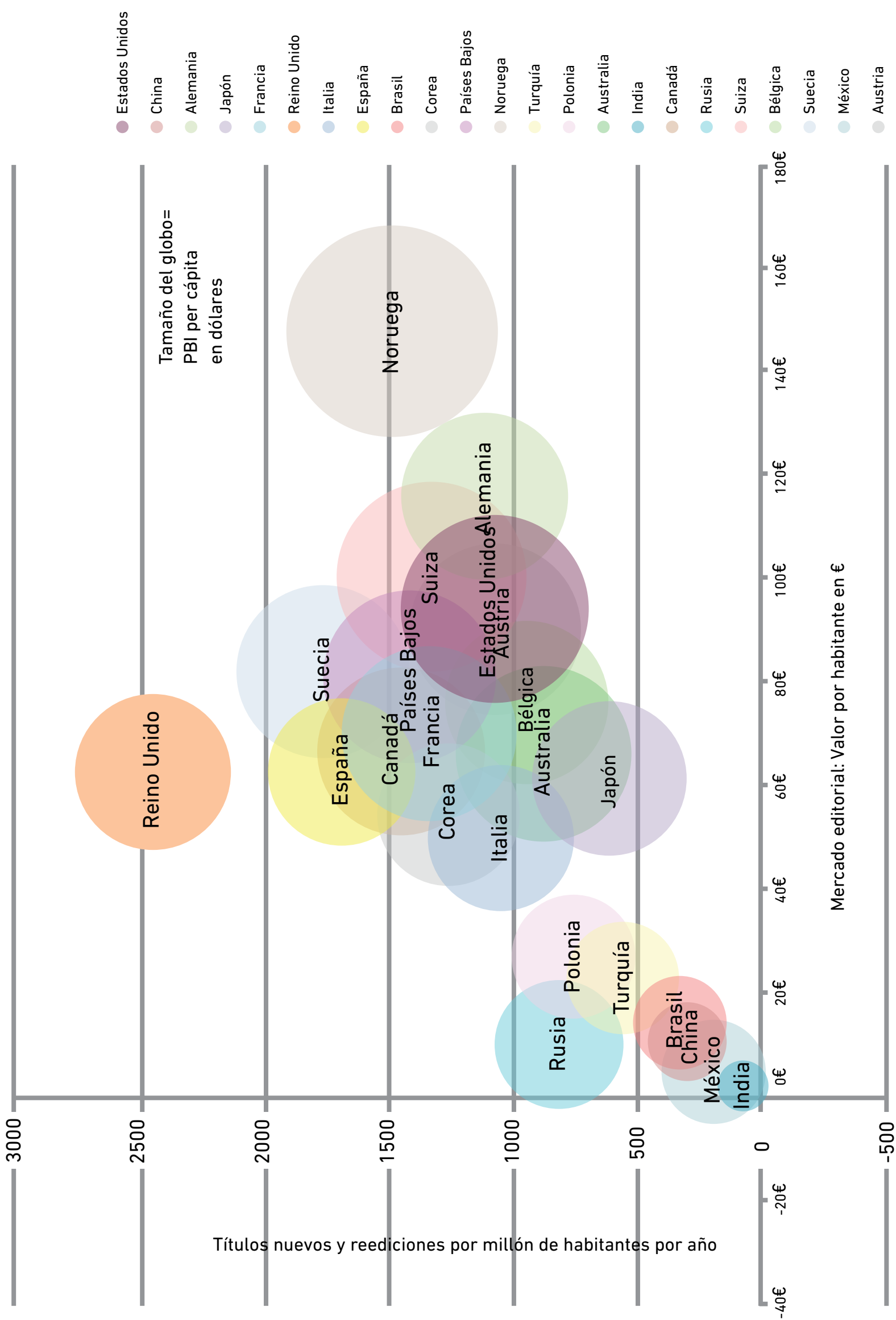
EE.UU.

- Los ingresos por ventas netas (2010-2011) fueron de U\$S27.124 millones, con un valor a precios del consumidor de U\$S38.700 millones.

- Se estima que el catálogo general en digital posee 1,7 millón de títulos (Wischenbart et al., 2014, sobre la base de diversas fuentes).

- Los ebooks representan el 23\% de las ventas totales de libro datos obtenidos de Nielsen, 2014; citado por Abrams b, 2014) y representaban cerca del $20 \%$ del mercado total de ventas en 2012, según BookStats (Hazard Owen, 2013; citado por Cordón García et al., 2014).

- El formato paperback siguió siendo el formato más popular con una participación de $42 \%$ de las ventas (en unidades). Los libros en tapa dura están por delante de las ventas de ebooks, con un $25 \%$ (en unidades).

- En la categoría (por géneros) de libros de ficción para adultos y jóvenes adultos, la ventas de ebooks (en unidades) es significativa, dado el éxito de ventas del formato de sagas del tipo Fuegos del hambre y Bajo la misma estrella (ambas para adultos jóvenes). En el último trimestre de 2014, la ficción para adultos representa el $45 \%$ de las ventas de libros electrónicos, muy por encima de los libros técnicos o no-ficción y, asimismo, los libros juveniles han ido creciendo del $24 \%$ en 2004 al $37 \%$ del total del mercado en 2014 (Informe Nielsen, citado por García, 2015).

- Ventas de libros impresos, género ficción: eran un 20\% desde 2004 hasta 2009 y se han reducido un 37\% desde entonces (como resultado del impulso tomado por los ebooks).

- Las ventas de libros de no ficción en impresos: eran un $18 \%$ desde 2004 hasta 2009 y se han reducido un $23 \%$ desde entonces. Las categorías más afectadas: viajes $(-50 \%)$ y libros de referencia $(-37 \%)$. Las categorías que más crecieron: religión/ biblias $(+43 \%)$, cocina/entretenimiento $(+11 \%)$, este último impulsado especialmente por libros publicados por celebridades (Friedman, 2015).

- El 24\% de los estadounidenses posee un lector electrónico y el $35 \%$ dispone de una tableta (Rainie y Smith, 2013; citado por Cordón García et al., 2014: 21). Además, los lectores de libros electrónicos también tienden a ser jóvenes y mujeres, según una investigación de "Internet Omnibus". Encuesta de PewResearch Center de más de 1.000 estadounidenses mayores de 18 años (Fottrell, 2014).

- Entre todos los adultos encuestados en enero de 2014 que leyeron un libro en el último año en EE.UU., el 28\% lee en digital (frente al 69\% que dijeron que leen libros impresos y $14 \%$ en audiolibros). Sin embargo, casi la mitad de los lectores de menos de 30 años leyeron un libro electrónico en enero de 2014 en comparación con el $31 \%$ en noviembre de 2012 y el $25 \%$ en diciembre de 2011.

- Entre 2011 y 2012 el porcentaje de ciudadanos hispanoamericanos en EE.UU. poseedores de una tablet o lector de ebooks se duplicó, pasando a ser uno de cada cinco. En el mismo segmento, entre 2012 y 2014, Amazon duplicó la oferta de títulos en formato digital en español en la tienda Kindle de EE.UU. (Merino, 2014).

\begin{tabular}{|c|c|c|}
\hline \multicolumn{3}{|c|}{ Estados Unidos (Mercado de libros 2010 - 2011) } \\
\hline Indicadores clave & Valores & Fuentes, comentarios \\
\hline $\begin{array}{l}\text { Tamaño del mercado de libros } \\
\text { (impresesos y electronicos [ }[\text { +ee] } \\
\text { a precios de consumidor) }\end{array}$ & $\begin{array}{l}\text { Ingresos por ventas netos: } \\
\text { U\$S } 27,124 \text { billones }\end{array}$ & $\begin{array}{l}\text { Debajo desde USS } 27,124 \text { billones. Fuente: AAP/BISG; } \\
\text { inofrmación de 2012.VValor delerercado a precios } \\
\text { del consumidor: est. USS } 38,700 \text { billones. }\end{array}$ \\
\hline $\begin{array}{l}\text { Títulos nuevos } \\
\text { por millón de habitantes }\end{array}$ & 1080 & \\
\hline $\begin{array}{l}\text { Titulos en eBook } \\
\text { (disponibles de las editoriales) }\end{array}$ & 1.700 .000 & $\begin{array}{l}\text { Amazon informa a principios de } 2013 \text { tener } 1.700 .000 \text { titulos } \\
\text { en su catálogo de ebooks, la gran mayoria de los cuales son } \\
\text { en inglés. }\end{array}$ \\
\hline Market share de ebooks & $\begin{array}{l}23 \% \text { de todas las } \\
\text { ventas comerciales }\end{array}$ & AAP/BISG \\
\hline Parámetros clave del mercado & Sin regulación de precios & \\
\hline
\end{tabular}

Tabla 7. Mercado de libros de EE.UU.: 20102011 (varias

fuentes). 


\section{China}

Los ingresos por ventas netas (2012) fueron de $€ 14.200$ millones (valor a precios del consumidor). Se estima (Wischenbart et al., 2014, sobre la base de diversas fuentes) que el catálogo general en digital posee 11.154 títulos en formato digital (sumados a seis millones de títulos de "literatura online"). En China, los títulos locales dominan el mercado aunque las ventas de libros impresos en línea aumentaron un 20\%. Las ventas de libros electrónicos crecieron un 50\% durante 2013, pero aún son menos del 5\% de todo el mercado, con dos jugadores principales: China Mobile y Kindle, de Amazon. Además, hay por lo menos tres detalles que conforman el entorno chino en la edición digital y la lectura: plataformas muy populares de lectura en línea, con 100 millones de usuarios de Internet chinos que han abierto cuentas; la prevalencia de dispositivos móviles para la lectura en pantalla y un alto porcentaje de usuarios de Internet móvil que leen "obras literarias a través de aplicaciones".

Por el lado de los contenidos, con mucho, el jugador individual más influyente, es Cloudary Corporation. De acuerdo con informes de iResearch y iRead, Cloudary controla el 72,1\% de los ingresos de este segmento de mercado de la literatura en línea en China (Lisa Zhang, en Wischenbart et al. 2014). Cloudary es una rama de Shanda Interactive Entertainment Ltd. (NASDAO: SNDA), que opera seis sitios web para usuarios de literatura en línea, principalmente www.qidian.com y tres empresas por fuera del sector editorial, así como revistas digitales y una plataforma de audiolibros. A par tir de marzo de 2012, Cloudary afirmó haber publicado en sus sitios web casi seis millones de títulos de más de 1,6 millones de los autores y contaba con más de 950.000 usuarios de pago en el cuarto trimestre de 2010 .

\section{Alemania}

Los ingresos por ventas netas (2012) fueron de €9.520 millones (valor a precios del consumidor). Se estima (Wischenbart et al., 2014, sobre la base de diversas fuentes) que el catálogo general en digital posee una cifra aproximada de 200.000 títulos en formato digital. En Alemania, los ebooks representan cerca del $5 \%$ del mercado editorial en 2013. Deutsche Telekom en asociación con las principales cadenas de librerías alemanas Thalia, Hugendubel, Weltbild y el Club Bertelsmann han creado Tolino, una plataforma de distribución de libros digitales con su propio dispositivo de lectura llamado Tolino Shine.

\begin{tabular}{|c|c|c|}
\hline \multicolumn{3}{|l|}{ Alemania } \\
\hline Indicadores clave & Valores & Fuentes, comentarios \\
\hline $\begin{array}{l}\text { Tamaño del mercado de libros } \\
\text { (impresosy y electronicos }[\text { [t+el } \\
\text { a precios de consumidorr }\end{array}$ & $€ 9.520$ millones & Börsenverein (Asociación de editores y libreros), 2012 \\
\hline $\begin{array}{l}\text { Títulos publicados por año } \\
\text { (nuevos y ediciones sucesivas) }\end{array}$ & 91.100 & Börsenverein (Asociación de editores y libreros), 2012 \\
\hline $\begin{array}{l}\text { Titulos nuevos } \\
\text { por millón de habitantes }\end{array}$ & 1.115 & \\
\hline $\begin{array}{l}\text { Titulos en eBook } \\
\text { (disponibles de las editoriales) }\end{array}$ & c. 200.000 EPUB & Estimado por Libreka y Bookwire \\
\hline Market share de ebooks & c. 10\% (del comercio, 2013) & (2012): 2,4\% del mercado total (Börsenverein) \\
\hline Parámetros clave del mercado & $\begin{array}{l}\text { Precios fijos para libros } \\
\text { impresos; VAT 7\% para } \\
\text { impresos, } 19 \% \text { para ebooks }\end{array}$ & $\begin{array}{l}\text { Börsenverein hace lobby para la extensión de precios } \\
\text { fijos a los ebooks. }\end{array}$ \\
\hline
\end{tabular}

Tabla 9. Mercado de libros de Alemania (varias fuentes) 


\section{Reino Unido}

En Reino Unido, la producción digital es cercana al 25\% del mercado global de libros. En este país, la mitad de los hogares poseía una tablet a mediados de 2013, sus niños tienen por segunda actividad a la lectura después de la utilización de redes sociales y se dispone de cerca de 1.750 .000 títulos en digital. El valor del mercado a precios de consumidor es de €4.540 millones. Los ebooks representan más de 20\% del género de ficción en el Reino Unido.

\begin{tabular}{|c|c|c|}
\hline \multicolumn{3}{|l|}{ VIJ Reino Unido } \\
\hline Indicadores clave & Valores & Fuentes, comentarios \\
\hline $\begin{array}{l}\text { Tamaño del mercado de libros } \\
\text { (impresos y electrónicos [p+e] } \\
\text { a precios de consumidor) }\end{array}$ & $£ 3,25$ billones & The Book Publishing Industry in Statistics 2013 \\
\hline $\begin{array}{l}\text { Titulos publicados por año } \\
\text { (nuevos y ediciones sucesivas) }\end{array}$ & 170.267 & PA Statistics Yearbook 2013 \\
\hline $\begin{array}{l}\text { Títulos nuevos } \\
\text { por millón de habitantes }\end{array}$ & 2.459 & \\
\hline $\begin{array}{l}\text { Títulos en eBook } \\
\text { (disponibles de las editoriales) }\end{array}$ & c. 1.750 .000 & $\begin{array}{l}\text { Títulos de ebooks disponibles en Amazon UK, a principios } \\
\text { de } 2013 \text {, de los que la vasta mayoría son en inglés. }\end{array}$ \\
\hline Market share de ebooks & $25 \%$ & de todo el comercio de libros \\
\hline Parámetros clave del mercado & $\begin{array}{l}\text { Sin regulación de precios; } \\
\text { VAT: } 0 \% \text { para impressos, } \\
20 \% \text { para ebooks }\end{array}$ & \\
\hline
\end{tabular}

Tabla 10. Mercado

de libros de Reino$$
\text { Unido (varias }
$$

fuentes).

\section{Francia}

Los ingresos por ventas netas (2012) fueron de U\$S 4.121 millones (valor a precios del consumidor; excluye las exportaciones). Se estima (Wischenbart et al., 2014, sobre la base de diversas fuentes) que el catálogo general en digital posee cerca de 126.000 títulos en formato digital. Los ebooks representan el 3\% de los ingresos de los editores, según el Sindicato Nacional de la Edición de Francia. En 2012 era del 2,4\%. En ese país, hay 6.000 .000 de tablets y 500.000 lectores dispositivos de lectura.

\begin{tabular}{|c|c|c|}
\hline \multicolumn{3}{|l|}{ Francia } \\
\hline Indicadores clave & Valores & Fuentes, comentarios \\
\hline \begin{tabular}{|l|} 
Tamaño del mercado de libros \\
(impresos y electrónicos [p+e] \\
a precios de consumidor)
\end{tabular} & $€ 4.121$ millones & $\begin{array}{l}2012 \text { excl. exportaciones; Syndicat National de l'Edition } \\
\text { (SNE). }\end{array}$ \\
\hline \begin{tabular}{|l} 
Titulos publicados por año \\
(nuevos y ediciones sucesivas)
\end{tabular} & 86.295 & SNE (datos de 2012) \\
\hline $\begin{array}{l}\text { Títulos nuevos } \\
\text { por millón de habitantes }\end{array}$ & 1.321 & Instituto Nacional de Estadísticas de Francia (INSEE) \\
\hline \begin{tabular}{|l} 
Titulos en eBook \\
(disponibles de las editoriales)
\end{tabular} & c. 126.000 & De los editores \\
\hline $\begin{array}{l}\text { Participación en los ingresos } \\
\text { de ebooks del editor }\end{array}$ & $\begin{array}{l}\text { c. 2,7\% del comercio (GfK) } \\
3 \% \text { (SNE) }\end{array}$ & Estimados GfK, SNE \\
\hline Parámetros clave del mercado & $\begin{array}{l}\text { Precios fijos para libros; } \\
\text { VAT 7\% para impresoss, } \\
\text { audiolibros y ebooks }\end{array}$ & \\
\hline
\end{tabular}

Tabla 11. Mercado de libros de Francia (varias fuentes). 


\section{España}

El tamaño del mercado editorial total era de €2.471 millones a 2012 con casi 80.000 títulos editados, de los cuales se estima una escala entre 30.000 y 50.000 títulos en formato digital, es decir, que el peso de los libros en formato digital en el mercado español varía de $3 \%$ a $5 \%$. Ahora bien, en España se publicaron 72.416 títulos en 2014, lo que supone un descenso de 2,5\% con respecto al año anterior (74.300), según el registro de la Agencia del ISBN (Sainz Borgo, 2015). El libro digital experimentó un retroceso de $6,2 \%$ con respecto a 2013. En 2014, con 19.077 títulos, las obras digitales representaron un $26,34 \%$ del total de la producción de las editoriales españolas.

Según el informe El sector del libro en España 2012-2014 del Observatorio de la Lectura y del Libro, con datos proporcionados por la Agencia Española ISBN y publicado por el Ministerio de Educación, Cultura y Deporte se registran 245 nuevos títulos, 57 de ellos digitales (ebooks) por día. El total de títulos publicados en España es de 768.000: el 74\% son en formato impreso y el $23 \%$ en formato electrónico. Y por cada $€ 100$ facturados, $€ 3$ proceden de libros digitales. Asimismo, Alonso Arévalo, Cordón García y Gómez-Díaz (2014, a: 9) concluyen que son las editoriales independientes las que hacen la apuesta más fuerte por el libro digital.

Según una encuesta del Centro de Investigaciones Sociológicas (CIS), solo un tercio de los españoles lee libros todos o casi todos los días de la semana y, principalmente, prefiere el género de la novela y los ejemplares en papel, frente a los ebooks. Un 15,2\% de quienes respondieron a la Encuesta sobre hábito de lectura se pueden considerar lectores habituales de libros digitales, frente al 66,3\% que reconoce no haber leído nunca en este formato y un $15,5 \%$ que no sabe lo que es ni ha oído hablar nunca de ello. Acerca de la "percepción" de los españoles sobre el futuro del formato digita aparece dividida: $42 \%$ cree que ambos formatos convivirán "en un futuro próximo", frente a $33 \%$ que piensa que la mayor parte serán electrónicos y habrá "muy pocos" en papel. Solo 16,5\% apuesta por el papel como lo más leído. Con independencia del formato, en los últimos doce meses (2014), los españoles leyeron una media de 8,69 libros y compraron 5,69 ejemplares; $50,5 \%$ compró algún libro en ese periodo, frente a 49,3\% que no compró ninguno, ni en papel ni en digital (El Mundo, 2015).

\begin{tabular}{|c|c|c|}
\hline \multicolumn{3}{|l|}{ España } \\
\hline Indicadores clave & Valores & Fuentes, comentarios \\
\hline $\begin{array}{l}\text { Tamaño del mercado de libros } \\
\text { (impresosy y electrónicos }[\text { [t+el } \\
\text { a precios de consumidolor) }\end{array}$ & €2.471 millones & 2012 (abajo 10,9\% de 2011, Asociación de Editores FGEE) \\
\hline $\begin{array}{l}\text { Títulos publicados por año } \\
\text { (nuevos y ediciones sucesivas) }\end{array}$ & 79.175 & 2012 (Asociación de Editores FGEE) \\
\hline $\begin{array}{l}\text { Titulos nuevos } \\
\text { por millón de habitantes }\end{array}$ & c. 1.872 & \\
\hline $\begin{array}{l}\text { Títulos en eBook } \\
\text { (disponibles de las editoriales) }\end{array}$ & $\begin{array}{l}\text { Entre } 30.000 \text { y } 50.000 \\
\text { (varios estimados) }\end{array}$ & \\
\hline Market share de ebooks & Por sobre 3 a $5 \%$ del comercio & 3\%: FGEE (mediados de 2013) \\
\hline Parámetros clave del mercado & $\begin{array}{l}\text { Ley de precios fijos para } \\
\text { ebooks; VAT del } 4 \% \text { en libros } \\
\text { impresos y } 21 \% \text { en ebooks }\end{array}$ & Tarifa reducida del VAT cancelada para ebooks en 2012 \\
\hline
\end{tabular}

Tabla 12. Mercado de libros de España (varias fuentes). 


\section{Italia}

El tamaño del mercado editorial total es de $€ 3.072$ millones (2012), con 63.800 títulos editados, de los cuales 71.283 son ebooks disponibles en las editoriales.

\begin{tabular}{|c|c|c|}
\hline \multicolumn{3}{|l|}{ Italia } \\
\hline Indicadores clave & Valores & Fuentes, comentarios \\
\hline $\begin{array}{l}\text { Tamaño del mercado de libros } \\
\text { (impresosy y electronicos }[\text { [t+e] } \\
\text { a precios de consumidor) }\end{array}$ & $€ 3.072$ millones & Asociación de editores \\
\hline $\begin{array}{l}\text { Titulos publicados por año } \\
\text { (nuevos y ediciones sucesivas) }\end{array}$ & 63.800 & 2012, AIE, Asociación de editores \\
\hline $\begin{array}{l}\text { Títulos nuevos } \\
\text { por millón de habitantes }\end{array}$ & 1.049 & \\
\hline $\begin{array}{l}\text { Titulos en eBook } \\
\text { (disponibles de las editoriales) }\end{array}$ & 71.283 & $\begin{array}{l}\text { Marzo de } 2013 \text { (hasta } 31.416 \text { en marzo de } 2012 ; \text { e-kitab / } \\
\text { Informazioni Editorialii y Asociación de editores AlE) }\end{array}$ \\
\hline Parámetros clave del mercado & $\begin{array}{l}\text { Libros con precios fijos, con } \\
\text { posibilidades de descuentos } \\
\text { en impresos de alrededor de } \\
\text { un } 15 \% \text {, sespecialmente a partir } \\
\text { de campanasdde relaciones } \\
\text { públicas, desse } 2012 \text {. VAT es } \\
\text { de } 4 \% \text { en impresos contra un } \\
20 \% \text { en ebooks. }\end{array}$ & \\
\hline
\end{tabular}

Tabla 13. Mercado

de libros de Italia

(varias fuentes).

El grupo Mondadori (Penguin Random House Bertelsmann AG) mantiene una posición central del mercado italiano. A su vez, RCS viene reduciendo su presencia en el mercado, sobre todo, la distribución de libros y revistas en quioscos. Tanto Mondadori como GeMS (Gruppo Editoriale Mauri Spagnol $)^{13}$ poseen desarrollos digitales, cada uno mediante la creación de plataformas de distribución: Mondadori para sus propios fines y GeMS formando un consorcio (eDigita) con Flammarion y Feltrinelli. A enero de 2015, el grupo Mondadori (que ya controla el sello Inaudi) estaría interesado en la parte de libros de RCS (RCS Libri, que controla las editoriales Rizzoli, Bompiani, Adelphi, Fabbri, Sonzogno y Marsilio) (Ponte Di Pino, 2015).

${ }^{13}$ GeMS (Gruppo Editoriale Mauri Spagnol): Bollati Boringhieri; Chiarelettere; Corbaccio;Duomo Ediciones; Garzanti; Guanda; La Coccinella; Longanesi; Editrice Nord; Ponte alle Grazie; Salani; Ape Junior, Magazzini Salani; Tea, Vallardi. En España, RCS

\section{Suecia}

El tamaño del mercado editorial total es de $€ 783$ millones (2012), con 10.648 títulos editados, de los cuales 4.800 son ebooks disponibles en las editoriales. La cuota de mercado de los libros digitales llega a $1 \%$, en un mercado en el que es más popular el préstamo que la compra.

\begin{tabular}{|c|c|c|}
\hline \multicolumn{3}{|l|}{\begin{tabular}{|l} 
Suecia \\
\end{tabular}} \\
\hline Indicadores clave & Valores & Fuentes, comentarios \\
\hline $\begin{array}{l}\text { Tamaño del mercado de libros } \\
\text { (impresosos yelectronicos [p+el } \\
\text { a precios de consumidor) }\end{array}$ & $€ 783$ millones & Asociación de editores \\
\hline $\begin{array}{l}\text { Títulos publicados por año } \\
\text { (nuevos y ediciones sucesivas) }\end{array}$ & 10.648 & De ellos 4965, comercial; Fuente: Asociación de editores \\
\hline $\begin{array}{l}\text { Titulos nuevos } \\
\text { por millón de habitantes }\end{array}$ & 528 & \\
\hline $\begin{array}{l}\text { Titulos en eBook } \\
\text { (disponibles de las editoriales) }\end{array}$ & 4800 & Estimado \\
\hline Market share de ebooks & $\begin{array}{l}\text { c. } 1 \% \text {; comienzan a aparecer } \\
\text { ebooksel préstamo es más } \\
\text { popular que la compra }\end{array}$ & \\
\hline Parámetros clave del mercado & $\begin{array}{l}\text { La mayor parte de los titulos } \\
\text { no poseen DRM. No hay } \\
\text { regulación de precios. VAT } 6 \% \\
\text { para impresosy } \\
25 \% \text { para ebooks }\end{array}$ & \\
\hline
\end{tabular}

Tabla 14. Mercado

de libros de Suecia

(varias fuentes). 


\section{Dinamarca}

El tamaño del mercado editorial total es de $€ 540$ millones (2011), con 9.619 títulos editados de promedio anual entre nuevas ediciones y reediciones. La cuota de mercado de los libros digitales varía de $1 \%$ a $2 \%$ según estimaciones de 2011 .

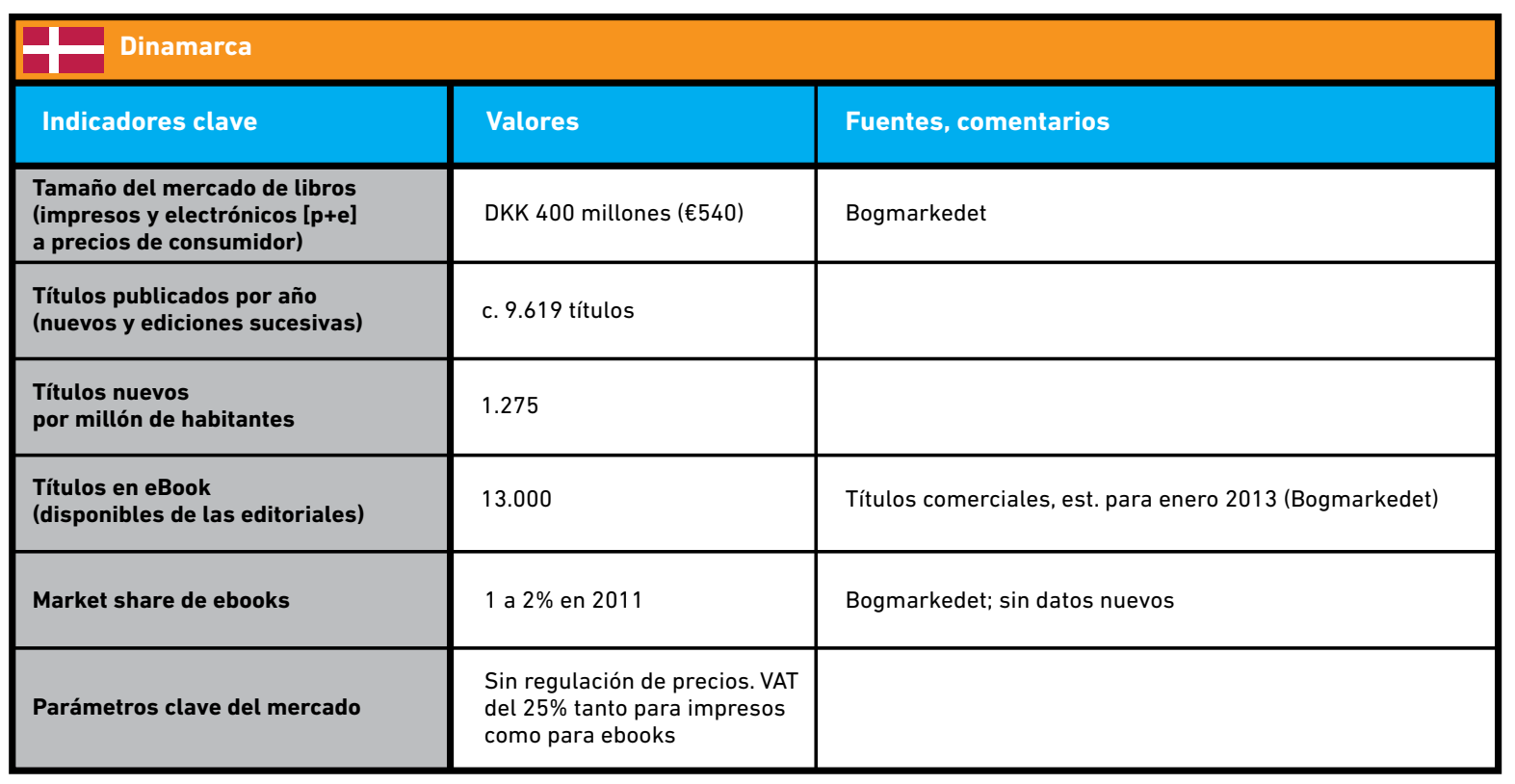

Tabla 15. Mer-

cado de libros de

Dinamarca (varias

fuentes).

\section{Países Bajos}

El tamaño del mercado editorial total es de $€ 1.363$ millones (2012), con 22.261 títulos editados. La cuota de mercado de los libros digitales llega a $4,7 \%$

\begin{tabular}{|c|c|c|}
\hline Indicadores clave & Valores & Fuentes, comentarios \\
\hline $\begin{array}{l}\text { Tamaño del mercado de libros } \\
\text { (impresos y electrónicos [p+e] } \\
\text { a precios de consumidor) }\end{array}$ & $\begin{array}{l}\text { €1.363 millones } \\
\text { (Comercial: } 557 \mathrm{~m} \text { ) }\end{array}$ & 2012, Asoociación de editores NUV \\
\hline $\begin{array}{l}\text { Titulos publicados por año } \\
\text { (nuevos y ediciones sucesivas) }\end{array}$ & 22.261 & 2012, Asoociación de editores NUV \\
\hline $\begin{array}{l}\text { Títulos nuevos } \\
\text { por millón de habitantes }\end{array}$ & 1.412 & \\
\hline $\begin{array}{l}\text { Títulos en eBook } \\
\text { (disponibles de las editoriales) }\end{array}$ & 30.000 & Est. Asociación de editores NUV \\
\hline Market share de ebooks & $4,7 \%$ & Est. Asociación de editores NUV \\
\hline Parámetros clave del mercado & $\begin{array}{l}\text { Precios fijos para libros para } \\
\text { 1 natoras la publicación } \\
\text { VAT de un } 6 \% \text { para impresos } \\
\text { contra un } 21 \% \text { (desdese octubre } \\
\text { de 2012) para ebooks }\end{array}$ & \\
\hline
\end{tabular}

Tabla 16. Mercado

de libros de Paí-

ses Bajos (varias

fuentes). 


\section{Rusia}

El tamaño del mercado ruso (a precios de consumidor, en 2012) es de $€ 1.200$ millones (a la cotización del $€$ de diciembre de 2012). Incorporadas las compras de libros por parte de los distintos niveles del Estado, el tamaño del mercado editorial ruso sería de cerca de $€ 1.500$ millones (cotización de rublo de diciembre de 2012). La plataforma LitRes (2015) estimaba la cantidad de títulos en digital para 2012 en una frecuencia de 80.000 a 100.000. En enero de 2015, la mencionada plataforma comercial ofrece más de 380.000 libros electrónicos y audiolibros en formatos para iPad, iPhone, Google Android, Windows Phone 7, Windows 8 y lectores de fabricación nacional rusa. En Rusia, los ingresos por ventas de libros electrónicos están en una cifra cercana a los ocho millones de dólares (en 2012, frente a la mitad de esa cifra en 2011). El 70\% de los rusos lee ebooks. La participación en el mercado de libros electrónicos en Europa alcanzó el 4,5\% del total. Price WaterHouse Cooper espera que los ingresos generados por la venta de libros electrónicos pasará de U\$S 2.310 millones en 2011 a U\$S 8.690 millones en 2018 (Forbes Statista, 2014; tomando como fuentes Books Stats y Association of American Publishers).

\begin{tabular}{|c|c|c|}
\hline \multicolumn{3}{|l|}{ Rusia } \\
\hline Indicadores clave & Valores & Fuentes, comentarios \\
\hline $\begin{array}{l}\text { Tamaño del mercado de libros } \\
\text { (impresosy y electronicos }[\text { [tee] } \\
\text { a precios de consumidolor) }\end{array}$ & 60.000 millones de rublos & 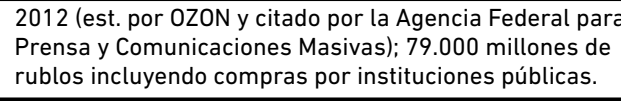 \\
\hline $\begin{array}{l}\text { Titulos publicados por año } \\
\text { (nuevos y ediciones sucesivas) }\end{array}$ & 116.888 & Cámara Rusa del Libro \\
\hline $\begin{array}{l}\text { Títulos nuevos } \\
\text { por millón de habitantes }\end{array}$ & 623 & \\
\hline $\begin{array}{l}\text { Titulos en eBook } \\
\text { (disponibles de las editoriales) }\end{array}$ & $\begin{array}{l}80.000 \text { a } 100.000 \text { (comerciales } \\
\text { y gratuitos, para fin de 2012) }\end{array}$ & LitRes \\
\hline Market share de ebooks & $>1 \%$ & \\
\hline Parámetros clave del mercado & $\begin{array}{l}\text { Unos pocos actores, compro- } \\
\text { metitos s y rofesionales tanto } \\
\text { en lo editorial coma en lato } \\
\text { venta por menorim muy alto } \\
\text { impacto de la pirateria. }\end{array}$ & \\
\hline
\end{tabular}

Tabla 17. Mercado

de libros de Rusia

(varias fuentes).

\section{Brasil}

El tamaño del mercado editorial total es de $€ 3.163$ millones (2013), con 57.473 títulos editados, de los cuales 25.000 son ebooks disponibles en las editoriales. Las ventas al Gobierno componen un 26,4\% de los ingresos editoriales totales. Distribuidora de Livros Digitais (DLD) es un consorcio de distribución de libros digitales que incluye Objetiva (parcialmente propiedad de Santillana), Record, Sextante, Rocco, Planeta, L \& PM y Novo Conceito. DLD vende alrededor del $30 \%$ del mercado de libros electrónicos del país.

\begin{tabular}{|c|c|c|}
\hline Indicadores clave & Valores & Fuentes, comentarios \\
\hline $\begin{array}{l}\text { Tamaño del mercadode de libros } \\
\text { (impresos y electronicos [ppe] } \\
\text { a precios de consumidor) }\end{array}$ & $\begin{array}{l}\text { USS } 3.176 \text { millones } \\
\text { (ingresos de los editores) }\end{array}$ & PublishNews \\
\hline $\begin{array}{l}\text { Titulos publicados por año } \\
\text { (nuevos y ediciones sucesivas) }\end{array}$ & 57.473 & PublishNews \\
\hline \begin{tabular}{|l} 
Títulos nuevos \\
por millón de habitantes
\end{tabular} & 109 & \\
\hline $\begin{array}{l}\text { Títulos en eBook } \\
\text { (disponibles de las editoriales) }\end{array}$ & 25.000 & Revolução eBook (comercial y gratis, mayo 2013) \\
\hline Parámetros clave del mercado & $\begin{array}{l}\text { Los libros estan excentos de } \\
\text { impuestos. Las ventas al } \\
\text { Gobiernosuman un } 26,4 \% \text { del } \\
\text { ingreso de los editores }\end{array}$ & \\
\hline
\end{tabular}

Tabla 18. Mercado de libros de Brasil (varias fuentes) 


\section{Argentina}

Según datos de la Cámara Argentina del Libro, en 2013 se registraron 27.757 títulos (entre digitales y papel) en la Agencia Argentina de ISBN, con un incremento del $5 \%$ frente a 2012 . El 83\% corresponde a soporte papel, el $16 \%$ a formato digital y el $1 \%$ restante a fascículos. Los registros de ciencias sociales presentan una concentración estadística mayor en formato digital que en papel: el 19\% del total de los libros editados en ciencias sociales es en formato digital frente al $12 \%$ de los editados en soporte impreso en esa temática. A su vez, cuatro de cada diez publicaciones registradas por las instituciones educativas y la universidad pública argentina son en formato digital. El libro digital presenta diferencias estadísticamente significativas respecto del libro en papel en el canal de ventas "distribución gratuita": el $26 \%$ de los libros digitales es accedido mediante ese canal, frente al 8\% de libro en soporte impreso (CAL, 2014). En el nivel de ventas, el papel sigue siendo hegemónico. Las principales editoriales del país editan en papel y en formato digital todas sus novedades mensuales de manera simultánea, pero se calcula que las ventas en formato digital no superan el $2 \%$ del total (Lafuente, 2014).

En relación con los índices de lectura en digital, ya en 2001 los lectores (definidos como quienes leen durante 15 minutos o más algún tipo de material) llegaban al 86\% y hacia 2011 (año de la última Encuesta Nacional sobre la lectura) ascendían al 90\%. También crecía la intensidad de lectura, en particular, las categorías superiores (lectores que leían entre 7 y 14 o más de 14 horas semanales). Por otra parte, en el periodo comprendido entre 2001 y 2011 comenzó a incidir en estas prácticas la lectura digital. De ser un fenómeno menor en 2001, con solo un $21 \%$ de personas que la practicaban, la lectura en la pantalla del ordenador, llegaba en 2011 al $48 \%$ y, entre los menores de 25 años, $75 \%$. Esto sin que descienda la lectura en los formatos tradicionales: la lectura de un libro al año creció alrededor de siete puntos (Moreno et al., 2014: 12, 13, 14). Ahora bien, el formato libro electrónico se comporta como un fenómeno marginal: solo un $7 \%$ lee en ambos formatos y solo un $1 \%$ dice leer solo libros electrónicos (Encuesta $\mathrm{Na}$ cional de Consumos Culturales, 2013).

\begin{tabular}{|l|l|l|}
\hline Argentina & & \\
\hline Indicadores clave & Valores & Fuentes, comentarios \\
\hline $\begin{array}{l}\text { Titulos publicados por año } \\
\text { (nuevos y ediciones sucesivas) }\end{array}$ & 27.757 & Agencia ISBN, Cámara Argentina del Libro (2013) \\
\hline Titulos en digital & 4.441 & \\
\hline Parámetros clave del mercado & $\begin{array}{l}\text { El 19\% de los libros editados } \\
\text { en Ciencias Sociales son en } \\
\text { digital/4 de cada 10 libros } \\
\text { editados por instituciones } \\
\text { educativasy universidad } \\
\text { publica son en digital }\end{array}$ & \\
\hline
\end{tabular}

Tabla 19. Mercado de libros de la Argentina (Fuentes: Agencia ISBN, Cámara Argentina del libro, Encuesta Nacional de Consumos Culturales y Ministerio de Cultura de la $\mathrm{Na}-$ ción y Moreno et al., 2014). 


\subsubsection{Aspectos destacados del panorama internacional de la edición} digital

- Las ventas de libros electrónicos parecen tener su propio ciclo. Las ventas de libros impresos tienden a alcanzar su punto máximo en el último trimestre del año, ya que los consumidores compran libros como regalos de Navidad, aunque esta tendencia puede estar declinando. Las ventas de libros electrónicos, sin embargo, poseen un pico en los dos primeros trimestres de cada año, dado que los usuarios cargarían contenidos en los dispositivos de lectura que recibieron como regalo en Navidad (en EE.UU.) (Tappuni, 2015).

- El segmento de alta tecnología norteamericano tuvo una expansión de $6,8 \%$ en el primer trimestre de 2014, con una previsión de $8,4 \%$ para 2015 , que sería el piso del resto de la década.

- El 46\% de los lectores a nivel mundial solo lee libros impresos; un 16\% lee más libros impresos que libros electrónicos; un $17 \%$ lee más o menos el mismo número de títulos en impreso y en digital; un 15\% lee más libros electrónicos que impreso y un 6\% lee exclusivamente en digital (Forbes Statista, 2014).

- En varios de los mayores mercados del libro de Europa continental (no siendo así en Reino Unido), la creación de una infraestructura digital ha dado lugar a la formación de consorcios, de los cuales varios han logrado ocupar una posición primaria o la de líder secundario en el entorno de servicio digital (tal es el caso de Francia, Alemania, España, Italia y Suecia). Pero, asimismo, en 2012 y 2013 se han puesto en funcionamiento innumerables emprendimientos digitales (especialmente, en Francia y Alemania). Wischenbart et al. (2014), en su investigación Global eBook: A report on market trends and developments, describe el proceso globalizador en digital para el caso de algunos países europeos cuyos mercados editoriales son de medianos a pequeños (como Eslovenia, Suecia y Dinamarca) como una combinación de dos movimientos: por un lado, las élites locales asocian la cultura tradicional de sus países como una singularidad cultural anclada en la cultura del libro (impreso) y a su literatura y, por el otro, esas mismas élites que se manifiestan como lectores de culto porque manejan lenguas extranjeras, especialmente el inglés, están abiertas a otras culturas y se desplazan y mueven por otros países, lo que las convierte en actores importantes en lectura digital.
- En los países desarrollados (EE.UU., Reino Unido, Francia, Alemania y Suecia), el 59\% de los consumidores de edades comprendidas entre 26 y 35 años y el 38\% de más de 35 años forman parte de la generación \#hashtag. De ellos entre un 11 y un $13 \%$, respectivamente, son caracterizados como "analógicos irreductibles" (Colombani, Sanderson, Videlaine, 2014; citado por Alonso-Arévalo y Cordón-García, 2015).

- En lo que hace a los BRIC'S (emergentes: Brasil, Rusia, India y China) también se observan movimientos comerciales de relaciones entre sí (Sur-Sur). Brasil es el segundo mercado de tecnología de la información (IT) del mundo emergente, detrás de China; y en él se han invertido U\$S134.200 millones en 2014, con un sistema de Internet móvil (smartphones) que se expande $28 \%$ anual (Castro, 2015). Además, en los BRIC'S más del 30\% de los consumidores mayores de 25 años ya han migrado a los medios digitales nativos (Colombani, Sanderson, Videlaine, 2014, citado por Alonso-Arévalo y Cordón-García, 2015).

- En la India, en el corredor Nueva Delhi/Bangalore se agrupan (clusters) las 600 grandes empresas trasnacionales de telecomunicaciones e información radicadas en el país. Allí también está ubicado el mayor número de institutos de formación tecnológica del mundo actual, que produce cerca de 80.000 graduados en IT al año (The Brooking Institution, 2013). El personal de la industria tecnológica crece $10.9 \%$ (226.000 profesionales) más por año. India se ha convertido en el tercer centro de alta tecnología del mundo detrás de EE.UU. e Israel, y en el primero de los países exportadores de la industria IT, fuera de la OCDE. El empleo indirecto de la industria de base tecnológica asciende a 8.000 .000 de personas $(30 \%$ son mujeres) y sus principales mercados para las exportaciones IT son EE.UU. (60\%) y Gran Bretaña (19\%). Para Castro (2009), "la industria IT de India es parte estructural del sistema de alta tecnología de EE.UU., y su eje de integración es Silicon Valley (California), donde la mitad o más de las nuevas empresas (start ups) son obra de ingenieros o científicos indios". Asimismo, al contar con la presencia comercial de Amazon Kindle y Kobo, el negocio minorista de libros electrónicos se está acelerando en la India. Aunque existe un retraso notable en la aparición de libros electrónicos en idioma hindi por limitaciones tecnológicas. Sin embargo, hay un crecimiento en ebooks en idioma hindi tanto en Kindle como en Flipkart. The National Trust libro (NBT), el órgano principal del Gobierno de la India, responsable de promoción de la cultura del libro y la lectura en el país, 
ha emprendido la digitalización de su fondo editorial. NBT ha publicado libros en inglés y en hindi desde su creación en 1957. NBT firmó un acuerdo con el proveedor de soluciones de contenidos digitales de Ninestars Technologies a principios de enero de 2014 para desarrollar libros electrónicos en inglés, hindi y las lenguas regionales indias. Los libros digitalizados estarán disponibles en una tienda electrónica que Ninestars desarrollará para las plataformas Android y iOS (Wischenbart et al., 2014).

- En China, las ventas de libros electrónicos crecieron un $50 \%$ durante 2013 , pero aún son menos del $5 \%$ de todo el mer cado, con dos jugadores principales: China Mobile y Kindle, de Amazon. Hay por lo menos tres detalles que conforman el entorno chino en la edición digital y la lectura: plataformas muy populares de lectura en línea, con 100 millones de usuarios de Internet chinos que han abierto cuentas; la prevalencia de dispositivos móviles para la lectura en pantalla y un alto porcentaje de usuarios de Internet móvil que leen "obras literarias a través de aplicaciones". Por el lado de los contenidos, con mucho, el actor individual más influyente, es Cloudary Corporation. De acuerdo con informes de iResearch y iRead, Cloudary controla el $72,1 \%$ de los ingresos de este segmento del mercado de la literatura en línea en China (Lisa Zhang, en Wischenbart et al., 2014). Cloudary es una rama de Shanda Interactive Entertainment Ltd. (NASDAQ, 2013), que opera una plataforma literaria impulsada por la comunidad en línea que incluye seis sitios web de literatura que comprenden Qidian.com, Readnovel.com, Hongxiu.com, Xs8.cn, Xxsy.net y Rongshuxia.com, cubriendo una gran variedad de géneros, como la fantasía, wuxia (artes marciales chinos), ciencia ficción, misterio y romance La plataforma literaria de la compañía también ofrece herramientas de comunidad, cuenta con sala de espacio personal, regalos virtuales, bar reseñas de libros y foro. A partir de marzo de 2012, Cloudary afirmó haber publicado en sus sitios web casi seis millones de títulos de más de 1,6 millones de autores y contaba con más de 950.000 usuarios de pago en el cuarto trimestre de 2010. Y poseía (en julio de 2013) 60 millones de títulos acumulados en su "biblioteca" (Linnemann, 2013).

- Asimismo, la industria de libros electrónicos en América Latina apenas comprende $1 \%$ de todas las ventas de libros en la región (Gilbert, 2014; Kan, 2015). La ausencia de acceso a Internet, la falta de lectores electrónicos y las bajas tasas de alfabetización de amplias zonas de la región hasta ahora han impedido un mayor crecimiento de la industria editorial digital: como en todas las economías emergentes, la inversión pública es crucial en la elaboración del sector educativo/cultural y en el fomento de las prácticas de lectura. Además, el acceso a Internet en los hogares de la región pasa de una frecuencia de escalas que va de $65 \%$ a 94\%. En Uruguay, Chile, Argentina y Brasil, el promedio es del $40 \%$ de la población. En El Salvador, Honduras, Dominicana, Nicaragua, Bolivia y Cuba son inferiores al 12\% de la población (Unión Internacional de Telecomunicaciones, 2012: 7, 9, 10, 11). De los 88.233 títulos registrados por las editoriales comerciales en América Latina en 2011, 58\% se encuentra en Brasil, 14\% en México y $6 \%$ en Colombia. Además, editaron el $15 \%$ de los títulos en digital, indicador que creció seis puntos con respecto a 2010 (9\%) (CERLAC, 2012: 18, 19). En América Latina, solo Brasil ha desarrollado de manera significativa la edición digital, con las editoriales globales con sede en el país que ya llevan digitalizados más del $50 \%$ de sus contenidos. La evolución de la edición (según estadísticas de las Agencias ISBN de los países latinoamericanos) nos muestra que en el periodo 2005-2011 el número de títulos registrados en la región en formato digital creció del 4\% al 13\%. En la Argentina, solo el 16\% de los libros publicados en 2013 se digitalizaron, por debajo del 17\% de 2012, según la Cámara Argentina del Libro (CAL, 2014). 


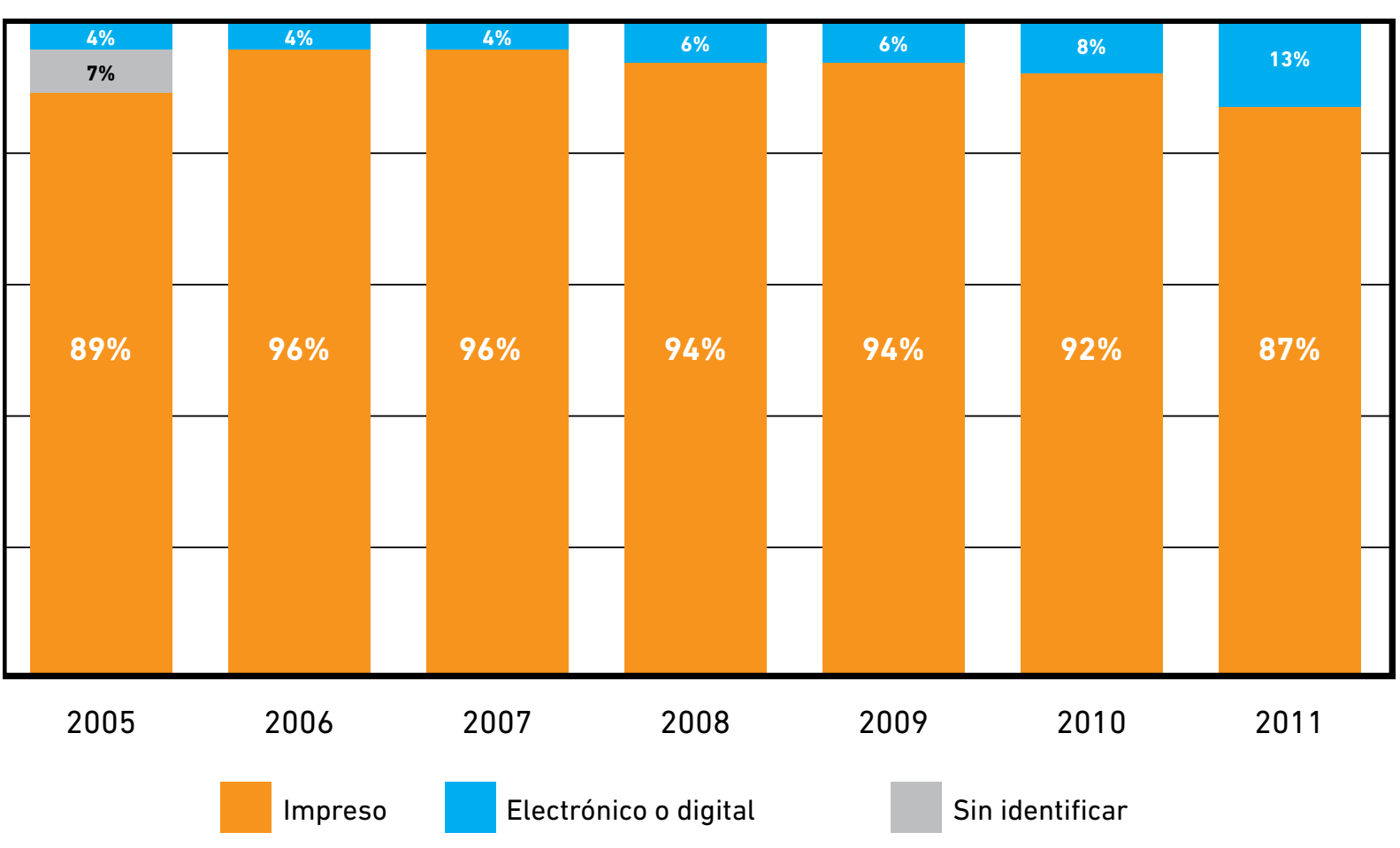

Tabla 20. Evolución de los títulos registrados en $I S$ $B A N$, según soporte en América Latina

2005-2011

Fuente: CER-

LAC (2012: 18)
- La transformación del ecosistema de autores, libros y la lectura que han generado los libros electrónicos les ha permitido ocupar un espacio en un número cada vez mayor en los mercados de libros y, en algunos, especialmente en los Estados Unidos y el Reino Unido, los ebooks son un motor del mercado de libros total. En Alemania, los libros digitales, al menos en el género ficción, comienzan a ser también un vector de crecimiento sectorial. Se detecta que a partir de 2013 los libros digitales funcionan como un nicho específico para sus lectores y nuevos lectores, desacoplándose el impulso inicial de crecimiento ligado al aumento de compra de dispositivos de lectura

- El 93\% de los niños de 2 a 13 años en EE.UU. lee un libro electrónico al menos una vez a la semana, según una nueva investigación de Digital Book World y PlayScience, cifra que se mantiene estable (frente al 92\%) desde el pasado año. El porcentaje de niños que leen libros electrónicos se ha mantenido igualmente consistente, con cerca de dos tercios de ellos (comparando enero de 2014 y enero de 2015). Para Kara Liebeskind, autora de la investigación Digital Book World y el próximo informe de PlayScience, The ABCs of Kids \& E-Reading: Volume 4, los niños no ven a los impresos y ebooks como mutuamente excluyentes. "Vemos esto con mayor claridad en el hallazgo de que los niños poseen el mismo libro en ambas versiones, así (Wischenbart et al., 2014: 152). como el hecho de que los niños prefieren digital, mientras que los padres prefieren co-leer con impresos" (Bellis, 2015).

- A su vez, en un estudio reciente de los niños y los hábitos de lectura de las familias (EE.UU.) de Scholastic, el grupo de edad más joven (6-8 años) informó la preferencia más fuerte para los libros físicos (66\%, seguido de los niños de 9-11 años con $56 \%)$. Scholastic encuentra que a pesar de que el porcentaje de niños de 6 a 17 que han leído un libro electrónico ha aumentado en los últimos cuatro años, durante los cuales los ebooks se han vuelto más frecuentes, la cantidad de jóvenes que prefieren imprimir sus ebooks se ha elevado, del $43 \%$ en 2012 al 55\% en 2014. Y lo ha hecho el porcentaje de niños que dicen que siempre querrán leer libros impresos aunque tengan ebooks disponibles (65\% el año 2013 frente al 60\% en 2012) (Bellis, 2015). 
Modelo económico estándar de la cadena del libro físico Fuente: SNE (Syndicat National des Éditeurs)

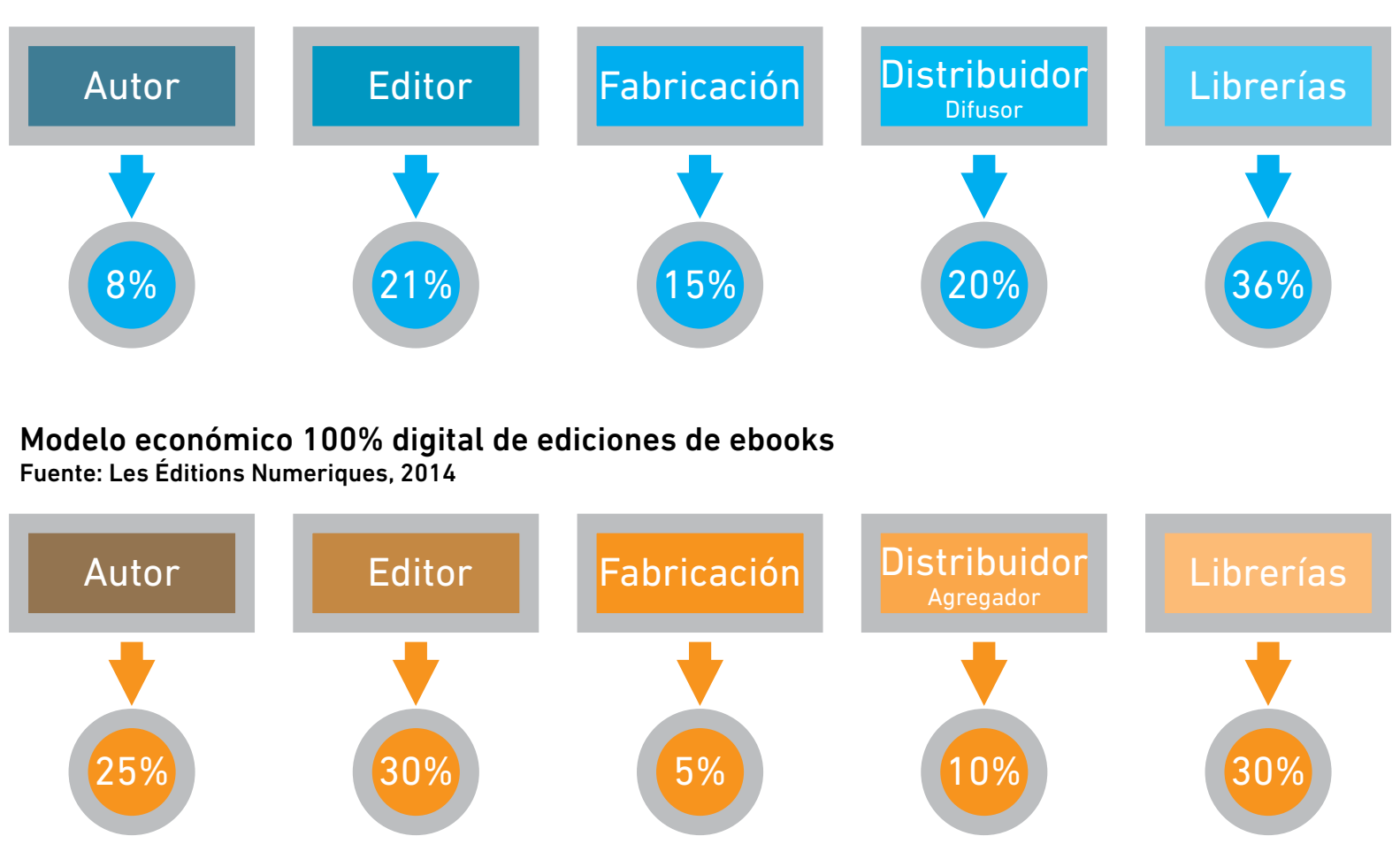

Figura 10 . Info-

grafia del modelo

económico del libro

\section{impreso y del libro 3.2.5. Análisis de la transición de galaxia Gutenberg a ecosistema} digital. Fuentes: digital

Les Editions

Numériques Los ebooks han comenzado a transformar el ecosistema de autores, li(2014) y Syndi- bros y lectura. A esto, ya en 1962 el propio McLuhan (1969: 415) anticipacat National des ba:

Éditeurs (2014)

La nueva galaxia eléctrica de acontecimientos ha entrado ya profundamente en la galaxia Gutenberg. Incluso sin colisión, tal coexistencia de tecnologías y consciencias causa trauma y tensión en toda persona viva.

La perspectiva macluhaniana se refuerza cuando en el presente aparecen mutaciones en el perfil profesional de eslabones enteros al interior de la estructura empresarial de las editoriales, relativas al diseño, programación, redes, aplicaciones y a lo que Vicente y Gozzer (2012: 97) llaman "sensibili- dad digital". Otro tanto deviene de los cambios en la relación entre autores y editores a partir de la posibilidad allanada por las nuevas tecnologías de establecimiento de relaciones directas entre productores y usuarios finales. Como vimos en el párrafo anterior, tanto a nivel de las funciones profesionales como en el nivel de las estructuras empresariales, atravesamos una época en la que galaxia Gutenberg y ecosistema digital se yuxtaponen, se solapan, comparten áreas y funciones y disponen de viejos y nuevos agentes así como otros son desplazados de la industria. Y, asimismo, también en el plano de la superestructura mundial de la edición se dan esas vicisitudes.

En esta etapa transicional, un $46 \%$ de los lectores a nivel mundial solo lee libros impresos; un 16\% lee más libros impresos que libros electrónicos; un $17 \%$ lee más o menos el mismo número de títulos en impreso y en digital; un 15\% lee más libros electrónicos que impresos y un 6\% lee exclusivamente en digital (Forbes Statista, 2014).

Tanto la galaxia Gutenberg como el campo general de las tecnologías de la información y la comunicación y sus subsistemas se han visto conmovidos por las transformaciones que devienen de las tecnologías. La escritura, la recuperación de información, las categorías prácticas de "autor", "lector", "librería", distribución, las formas del negocio, todos se han visto modificados por un nuevo paradigma: interactividad, información compartida, preeminencia de las redes sociales, una nueva autonomía del lector son acciones/virtudes/funciones en el marco del tránsito de parte de la cultura (de la galaxia Gutenbergo del paréntesis gutenberguiano, como se prefiera) al sistema general de la información digital y del nacimiento de productos culturales específicos creados para/en ese sistema general de la información digital.

En el presente, los contenidos de una editorial son digitales: los textos se escriben en un procesador de textos y son digitalizados en programas de arte y diseño en función de o bien ser impresos o bien colocarse en plataformas comercializadoras o digitales. A este segundo formato se le pueden agregar elementos multimediales como sonido o imágenes fijas o en movimiento. Y aunque el mercado de libros impresos sigue siendo preponderante, el mercado de libros digitales va ganando en escala año a año.

En este plano de análisis, algunos tipos de libros ya tienen una tradición construida en soporte digital, como las enciclopedias, las publicaciones jurídicas y de normas jurídicas y contables y las revistas científicas. En el caso de la ficción, tal es el caso de focalización de esta tesis, la transición se ha efectuado de manera más pausada. De todas maneras, en todos los casos, las posibilidades de separación de contenidos y continentes es un tema de análisis -y acción- para las editoriales. Separar texto y dispositivo formal (diría Chartier) en función de no limitar sus catálogos al formato-continente (Vicente y Gozzer, 2012: 96-97). Esta etapa de transición, inestabilidad y creación también es subsidiaria de los dispositivos de lectura, como Kindle 
de Amazon, Nook de Barnes \& Noble, iPad de Apple, Kobo y otras tablets, que han colaborado y son motores importantes de cambios al amplificar el campo de acceso por parte de los usuarios y al ampliar, asimismo, las posibilidades de descargas de contenidos.

El mundo editorial, cuyas bases se mantuvieron estables desde la invención de la imprenta -editor empresario que publica una obra de un autor a cambio de los derechos de explotación de ella en el marco de relaciones de fuerza y roles de los agentes definidos claramente-, ha ido siendo capilarizado por las nuevas tecnologías. Alonso Arévalo y Cordón García (2010: 67) nos dan una panorámica al nivel de la creación colectiva y variable en el nivel del libro digital cuando destacan que los documentos tienen un "crecimiento biológico", que lo transforman en "una especie de palimpsesto digital en el que la última versión acumula y refunde las anteriores". Si el libro impreso está definitivamente asociado a la idea de una intervención editorial, la idea de acumulación vital de contenidos es la que define el estadio del libro digital.

Alvin Toffler desarrollaba el término prosumers/prosumidores en 1980 (1981: 263) que combina el término consumidor con el término productor. E término había sido anticipado por McLuhan y Nevitt (1972: 4):

At electric speeds the consumer becomes producer as the public becomes participant role player.

En su inicio, el término prosumer designaba a aquellos consumidores que, tiempo mediante, llegarían a mejorar/diseñar servicios y bienes que consumía en el mercado. En 1990, el mismo Toffler (1990: 239) afirmaba:

El productor y el consumidor, divorciados por la revolución industrial, se reúnen en el ciclo de la creación de riqueza, con el cliente aportando no solo el dinero, sino el mercado y la información de diseño, de vital importancia para el proceso de producción. Comprador y proveedor comparten la información y el conocimiento. Algún día, los clientes también podrán presionar los botones que activan los procesos de producción remotos. Consumidor y productor se fusionan en un 'prosumer'.

Veinte años después, Enedina Ortega (2012: 120) propone que los nuevos actores sociales (jóvenes) han abandonaron el lugar de "consumidores pasivos" a través de la apropiación de la "Web 2.0, la convergencia tecnológica las redes sociales, la adquisición y apropiación de las diversas competencias digitales y de emprendimiento". Es decir, los jóvenes se transformaron en prosumidores porque utilizan toda la información que buscan constantemente para aplicarla“a sus proyectos creativos, mirar los problemas desde diferentes perspectivas, construir conocimientos a partir de una cultura participativa en red y desarrollar la capacidad de crear una cadena propia de suministro de información, de conocimiento y de diversos productos culturales, así como generar de sus propios públicos y consumidores".

Lessig (2008: 28) denomina a esta nueva convergencia como "cultura lectura/escritura" Esto es, como respuesta de modernización a una cultura de solo lectura ("read only culture" - $\mathrm{RO}-$ ), una cultura "menos versada en el desempeño o en la creatividad amateur y se siente más cómoda (pensar: sofá) con un consumo sencillo", es decir, pocos productores culturales lo hacen para que otros muchos los lean. En la "cultura lectura/escritura", aquellos que "leen" los recursos también desean "hacer su aportación [...] creando y recreando la cultura que los rodea [...] usando las mismas herramientas que los usuarios profesionales".

Los límites entre producción, distribución y consumo cultural se han ido difuminando en todos los planos. A nivel de la producción la idea de "autor" ha ido desdibujándose en el marco de procesos de multiplicación de discursos, fragmentación de contenidos, collages e intertextualidades hipertextuales, multimediales. Los textos y documentos crecen a partir de comentarios, añadidos, correcciones y modificaciones en la búsqueda del procomún. García Canclini se preguntaba (1990: 28):

¿Es posible democratizar no solo el acceso a los bienes, sino hibridarlos, de combinar los repertorios multiculturales que expande esta época multicultural? La respuesta depende, ante todo, de respuestas políticas y económicas.

Fernando González de Requena Redondo (2012: 229-251) desarrolla los argumentos de una etnografia de la escena cultural de saberes y prácticas ligados a la digitalización:

- La cultura hacker como forma de vida: carácter comunitario, la generación de capital económico a partir de la aplicación de pasión y diversión y un cierto emparentamiento con la figura del trendsetter: jóvenes que no se limitan a seguir modas, sino a crear tendencias. Pertenecen a "la franja más alta del nivel educativo y de la capacitación tecnológica" y que poseen recursos económicos y simbólicos para acceder a servicios digitales complejos (García Canclini; Cruces y Urteaga Castro Pozo, 2012: 8).

- Los cambios continuos en las formas de producción ligada a la creatividad, las formas de apropiación del conocimiento, su utilización con un cierto valor agregado y la recirculación de las formas culturales a partir de la reutilización. 
- La aparición de un "público recursivo", es decir, grupos de usuarios dotados de diferentes grados de conocimiento tecnológico e implicados activamente tanto en usar las tecnologías como en crear y mantener una infraestructura compartida y en sostener sus reglas de uso (Kelty, 2008: 5).

- La necesidad de recurrir a nuevas formas en el orden del "nombrar", utilizando conceptos nuevos, como el de "procomún" para dar cuenta de la promoción colectiva de un repositorio de elementos libremente disponibles para crear, el cual debe incluir tanto productos terminados como las herramientas para producirlos.

- La participación social y políticas del hacktivismo que cruza en simultáneo posiciones disímiles frente a los sucesos políticos (como la polarización "incluido"/ excluido").

La idea de procomún es como una de las respuestas a aquella pregunta de García Canclini (90: 28): destaca los compromisos sociales y negociaciones yuxtapuestas y coetáneas a la administración y funcionamiento de recursos compartidos. Es decir, procomún no solo sería el recurso (físico, material, "duro"), sino la forma de nombrar también a una comunidad, sus prácticas, su ideología acordada en esa administración y acción. Siempre en la dinámica de la acción (Bollier, 2013).

Otras formas del orden del "nombrar":

- Licencias copyleft: son aquellas licencias que permiten que cada persona que recibe una copia de una obra puede utilizarla, modificarla, redistribuirla y redistribuir las versiones derivadas de ellas. A veces se permite utilizarlas comercialmente, en otros casos, no (Fundación Copyleft).

- Peer production: se trata de un modelo productivo descentralizado, basado en el procomún, en el cual la tarea a realizar se divide en fragmentos de diverso tamaño (preferiblemente pequeños). Estos fragmentos se distribuyen entre muchas personas que aceptan libremente y luego se integran mediante un proceso lo más automatizado y rápido posible (Benkler, 2002: 36).

- Proyectos DIr (Do It Tourself: hágalo usted mismo) y movimiento maker: utilizando "átomos como bits", usando la poderosa herramienta del software y las industrias de la información para revolucionar la forma en la que fabricamos objetos materiales (MediaLab del MIT; citado por Gross, 201).
Es decir, serían nuevas formas de artesanato, que utilizan prototipos de prácticas, objetos, herramental, tecnologías, diseños, que incorpora tanto la reflexión sobre el propio proceso como la acción colectiva, compartida, colaborativa. Los objetos están abiertos a la copia y reutilización. La idea de "átomos como bits" proviene del razonamiento (profético) de Anderson (2010): "En la próxima revolución industrial, los átomos serán los nuevos bits".

\subsubsection{Autopublicación y lectura social}

Para Alonso Arévalo, Cordón García y Gómez Díaz (2014):

Se entiende por autopublicación la publicación de un libro o cualquier otro documento por parte del autor de la obra sin la intervención de un tercero o de un editor. Por tanto, el autor es responsable del control de todo el proceso, incluyendo el diseño (cubierta/interior), formatos, precio, distribución, marketing y relaciones públicas. Los autores pueden hacerlo todo o subcontratar la totalidad o parte del proceso con empresas que ofrecen estos servicios.

En la actualidad, la autopublicación permite el acceso directo a la edición a miles de autores. Para José Afonso Furtado (2014) la autopublicación, a partir de 2006, "con el resurgir de los dispositivos de lectura [...] ha producido un fenómeno de reconstrucción de la cadena de valor tradicional en la edición, que a su vez está provocando diversos fenómenos disruptivos.
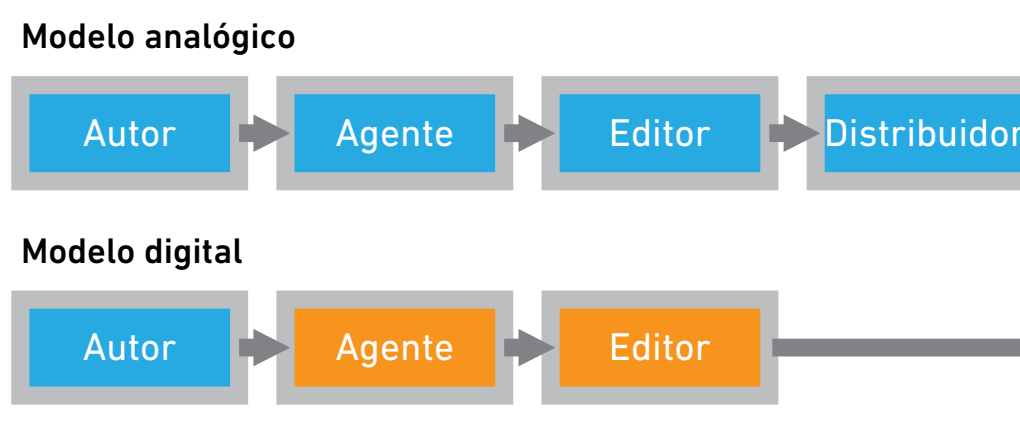

Librero

\section{Agentes necesarios}

Agentes posibles, pero NO necesarios

Figura 11. Modelo editorial analógico y modelo editorial digital: agentes. Fuente: Alonso Arévalo, Cordón García y Gómez Díaz (2014, b). 
De manera que el modelo digital produce un efecto de desintermediación en el cual solo los dos elementos extremos de la cadena de valor del libro son imprescindibles: el autor y el lector".

Como vemos en la Figura 11, en el modelo del libro digital desaparecen o se constituyen en innecesarios agentes centrales de la industria editoria tradicional, como editores, distribuidores y libreros.

En esta coyuntura de coexistencia de los modelos analógico y digital y de transposición de la galaxia Gutenberg al ecosistema digital no es necesaria la presencia de editores y agentes literarios en la actividad de mediación entre autor y lector en el modelo digital. La presencia en el esquema del modelo digital de libreros y distribuidores es de carácter prescindible: tanto los autores como los editores pueden llegar al lector directamente, utilizando solamente la plataforma digital disponible, como observamos en la Figura 11. Con la proliferación de la autopublicación, la cadena de costos se reduce y los precios de venta de los ebooks autoeditados tienden a la baja y son más accesibles que los libros en soporte impreso. Asimismo, pierden peso las formas tradicionales de recomendación de títulos y autores y, con ello, se da una pérdida de influencia de las formas de legitimación tradicional. Lectores y autores (y textos) se cruzan en las plataformas y en las redes sociales, en tanto las formas de lectura han ido rotando hacia formas nómadas, conectadas, colaborativas, sociales. La lectura lineal, cartesiana, del texto impreso también está siendo reemplazada por formas de lectura en soporte digital que se presentan como fragmentarias. Decía Amat (1992: 11):"Llega un punto en que el lector que utiliza los nuevos medios de escritura ya no sabe si lee o escribe". Así, el texto "estático", fijo, propio de la modernidad clásica ha empezado a ceder en manos de mecanismos de cocreación, donde los lectores intervienen con intervenciones, aportes, con formas actuales de la glosa, la tachadura y el subrayado. Las aplicaciones desarrolladas para la lectura social potencian la tendencia a compartir pareceres, a intervenir sobre las obras. El texto fijo, uniforme, se convierte en un texto inestable, caótico, que también impacta sobre sus formas de lectura. El libro de la galaxia Gutenberg posee una limitación material que impide la colaboración y participación y otras formas de intervención del lector que vayan más allá de las formas más clásicas de intervención escrita de la crítica especializada y los comentarios sociales del lector que corren en circuitos orales, sobre todo, porque no permite intervenciones en el propio texto.

En relación con las marcas del ecosistema digital relacionadas con la autopublicación, su principal actor, Amazon, no ofrece sus números reales de ventas, pero informa que un $48 \%$ de los 25 ebooks más vendidos en la Tienda Kindle en 2014 fueron obras autopublicadas a través de Kindle Direct Publishing (KDP, su plataforma de autopublicación). España es uno de los países donde opera Amazon con mavor número de autores registrados en su plataforma KDP (Corroto b, 2014). Según el informe Bowker (2013), en 2012 cerca de 235 mil títulos se autopublicaron en EE.UU. (alrededor del $37 \%$ de los ebooks de ese mercado).
Otros actores importantes en el modelo de autopublicación son:

- iBooks Author: de Apple, disponible en su Appstore, permite generar ebooks en formato ibooks, con una orientación marcada para la creación de contenidos para iPhone e iPad, para ofertarlo en su plataforma iBookstore.

- Author Solutions (adquirido por el gigante Penguin). En su catálogo había, en octubre de 2013, 150.000 autores, que han publicado 190.000 títulos la mayoría, en la red (Geli, 2013).

- Smashwords 40.608 títulos, casi el $47 \%$ del total de libros autopublicados en formato digital en EE.UU. (Alonso Arévalo, Cordón García y Gómez Díaz, 2014).

- Lulu (38.005 títulos) (Alonso Arévalo, Cordón García y Gómez Díaz, 2014).

- Literatura Nova: una red social de autopublicación de textos literarios en castellano (Alonso Arévalo, Cordón García y Gómez Díaz, 2014).

- Bubok: se encuentra disponible en España, Argentina, Colombia, México, Portugal, Suecia, Francia y Reino Unido. La publicación de la obra es gratuita y los autores suelen llevarse el $80 \%$ de los beneficios de sus libros. Además, permite un servicio de maquetación dentro de la misma web y la posibilidad de realizar impresiones bajo demanda.

- Blurb Books: una plataforma que permite la creación de cualquier tipo de libro. Se puede utilizar como espacio donde guardar ebooks de forma privada o compartirlos y venderlos.

- HarperCollins ofrece: Authonomy

- Blomsbury ofrece su guía y servicios editoriales (de pago) Writers Eै Artists.

- Holtzbrinck ofrece dos: Neobooks y Epubli.com.

- Barnes E Noble: ofrece Nook Press.

- Roca Editorial lo hace a través de RocaAutores.

En el sentido opuesto, la materialidad digital permite la socialización de la lectura como parte del proceso lector. En este nivel, las aplicaciones de lectura social y redes sociales dinamizan la práctica. Es decir, si se concibe 
que el aporte lector enriquece las obras podemos también definir que las aplicaciones empíricas de base tecnológica podrían permitir agregar valor a los textos (nada lejano de la idea de prosumición cultural que detallamos ut supra). Por ejemplo, la función de subrayado de Amazon, que identifica pasajes marcados por un número de lectores, es una forma de lectura social. También las lecturas de otros usuarios, sus valoraciones y sus lecturas preferidas, como en el caso de algunas redes sociales de lectura, como Goodreads (propiedad de Amazon), Anobii, Bookshout, Bookish, BookScout, Imaginaria, Shelfari, LibraryThing, Quiero Leer, Lecturalia, Entrelectores, Falsaria, Librofilia, Quelibroleo, Libros.com (ver Figura 12). En algunas plataformas, como SocialBook las formas de intervención por parte de otros lectores en los márgenes de los ebooks se constituyen en vectores de agregado de valor que la industria editorial por sí sola no puede proporcionar. La industria mejora el funcionamiento de las plataformas al permitir sumar imágenes y sonidos a los textos, pero la participación de otros lectores en los márgenes de los ebook agrega una idea de página y dispositividad material anclada en lo social. Así, lectura y pensamiento colaborativo convergen en la página.

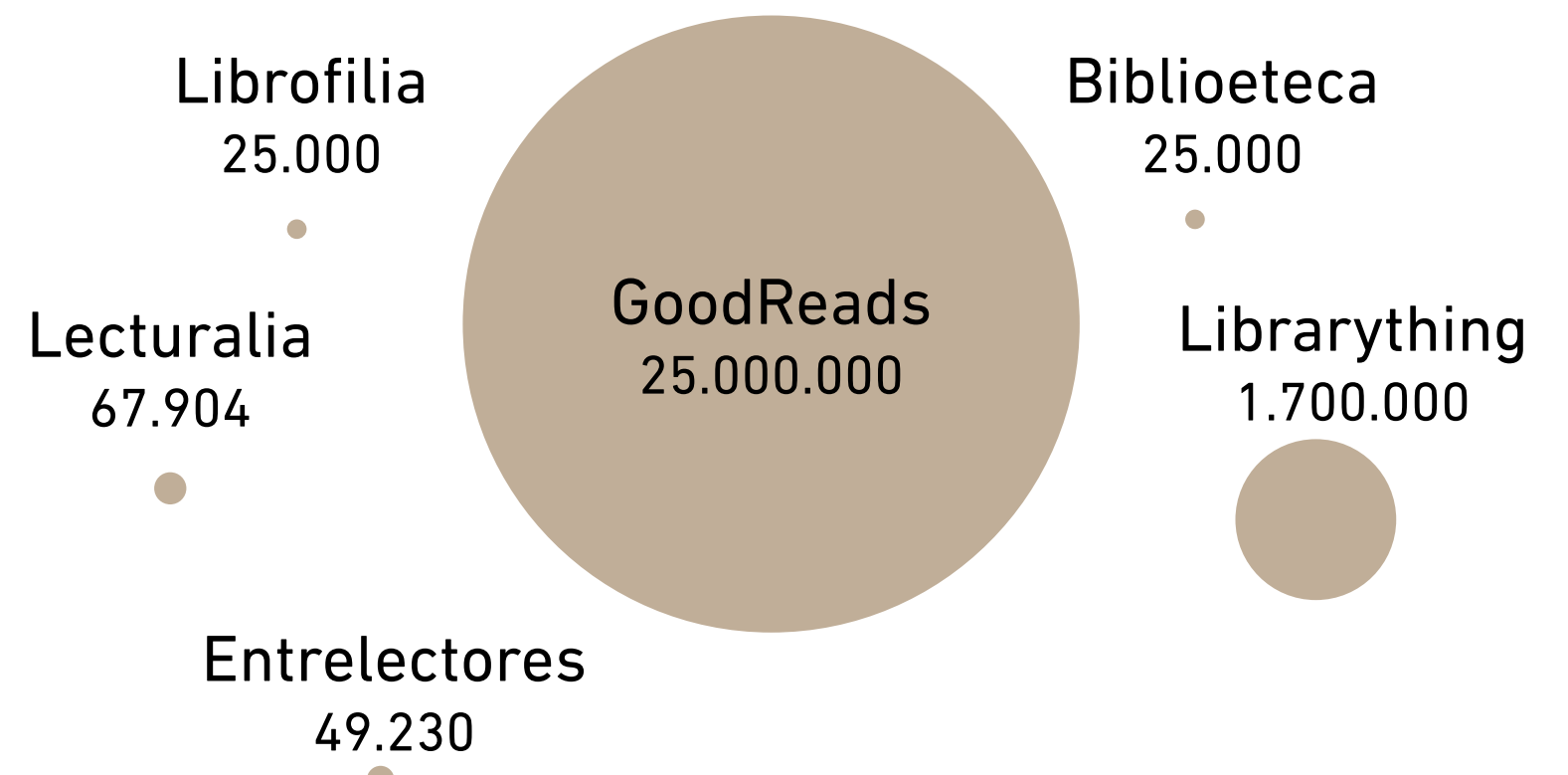

Figura 12. Mapa

de las redes sociales:

Temáticas. Redes

especializadas en

literatura. Fuen-

te: basado en

Esteban y Quirós

(2014).
GoodReads es la red social "literaria" hegemónica con 25 millones de usuarios registrados. Luego, Librarything posee 1,7 millón de seguidores (Esteban y Quirós, 2014).

Obsérvese en la Figura 3 que la galaxia Gutenberg forma parte del sistema de información analógica, pero solo es una porción de ella (en ese sistema general hay otros complejos, como el de la música analógica, el cine analógico, etc.). El ecosistema del libro digital también es solo una porción del sistema general de la información digital (compuesto también por audio digital, TV digital, vídeo digital, etc.). Asimismo, ambos sistemas son solo partes constitutivas del campo general de la información y comunicación. Schiffrin (2001: 172) consideraba que la fusión corporativa amenazaba "la manera de mantener la comunicación y el debate que solían considerarse una parte esencial de las sociedades democráticas... tenemos que confiar en que haya cada vez más personas que se den cuenta de lo peligroso que es vivir en un medio cultural en el que el número de ideas y de alternativas sea reducido, así como de lo importante que es mantener un debate abierto a todo el mundo".

Marcábamos previamente que en el marco del negocio "tradicional" del libro muchos editoriales pequeñas también funcionan como lectores de las grandes editoriales, cargando con el riesgo de que sus búsquedas y descubrimientos ligados al polo cultural sean explotados por las grandes casas. En este lugar, en la coexistencia de galaxia Gutenberg y ecosistema digital, algunos aspectos del mundo de los negocios se mantienen con pocas alteraciones: para Shatzkin (2014) pese a posiciones dominantes en algunos eslabones de la cadena "no habrá escasez de diversidad de la publicación de 'voces', pero muchos de ellas lo estarán haciendo como una función de soporte de otro negocio, no como una propuesta comercial independiente. Los editores y demás actores están construyendo comunidades verticales de interés de todo tipo, con muchos de aquellos propensos a convertirse en parte de la infraestructura de 'la edición de libros' del futuro, como creadores, editores y minoristas".

Podemos destacar, además, que la galaxia Gutenberg se discontinúa parcialmente en algunas porciones del ecosistema digital, pero continúa parcialmente en otras. Algunos elementos y funciones de la cadena tradicional del libro se mantienen en el nuevo ecosistema, otros se anulan, otros se resignifican. Si para Cordón García et al. (2011: 177) "la vinculación contractual y tecnológica propia del sistema impreso se diluye en una variedad de formas que amplían considerablemente el campo editorial", la perspectiva de abordaje del momento del arte empresarial descrito es la de rupturas y continuidades: ambos sistemas conviven tanto a nivel de algunas funciones profesionales, en el nivel de las estructuras empresarias y en la superestructura empresarial editorial mundial. Se desagregan en el nivel de las mismas funciones, estructuras y configuración de un mercado internacional concentrado, así como en la aparición de nociones que 
parten de una ruptura de una concepción cerrada gutenberguiana y que "redirigen su función en un sentido polimórfico, hasta extraerla en muchos casos del propio circuito editorial” (Cordón García et al., 2011: 177). Roger Chartier (2012) se preguntaba si el texto escrito propone ya una nueva forma de presencia de lo escrito capaz de favorecer y enriquecer el diálogo que cada texto entabla con cada uno de sus lectores. Y dice:"la respuesta está en los nativos digitales que ya identifican cultura escrita y textualidad electrónica”.

\subsubsection{Redes sociales temáticas}

La dinamización en el marco de redes sociales generales, como Facebook y Twitter, y redes especializadas, como Goodreads, permite ampliar el horizonte de participación del lector, enriquece los textos, genera obras nuevas constantemente, propone nuevas formas de apropiación y distribución cultural y sitúa a las bibliotecas como centros del ecosistema digital que estamos tratando. En este aspecto, si la función de la biblioteca como centro fuese adoptada por sus agentes, permitiría la intervención en la profundización de la lectura social de las obras en el marco de la oferta de la redes sociales. Este nuevo rol de las bibliotecas podría estabilizar su posición en el centro de la nueva escena del nuevo ecosistema. Y, en este mismo esquema, los lectores disponen del factor dinamizador que se les ofrece en redes sociales, que también se constituyen en un campo por la disputa por el sentido, por la significación en la sociedad, retomando la idea de desarrollo de un juicio crítico por parte del lector fundado en que sepa valora la calidad de las fuentes consultadas (Jenkins, 2009; Campal, 2012: 400).

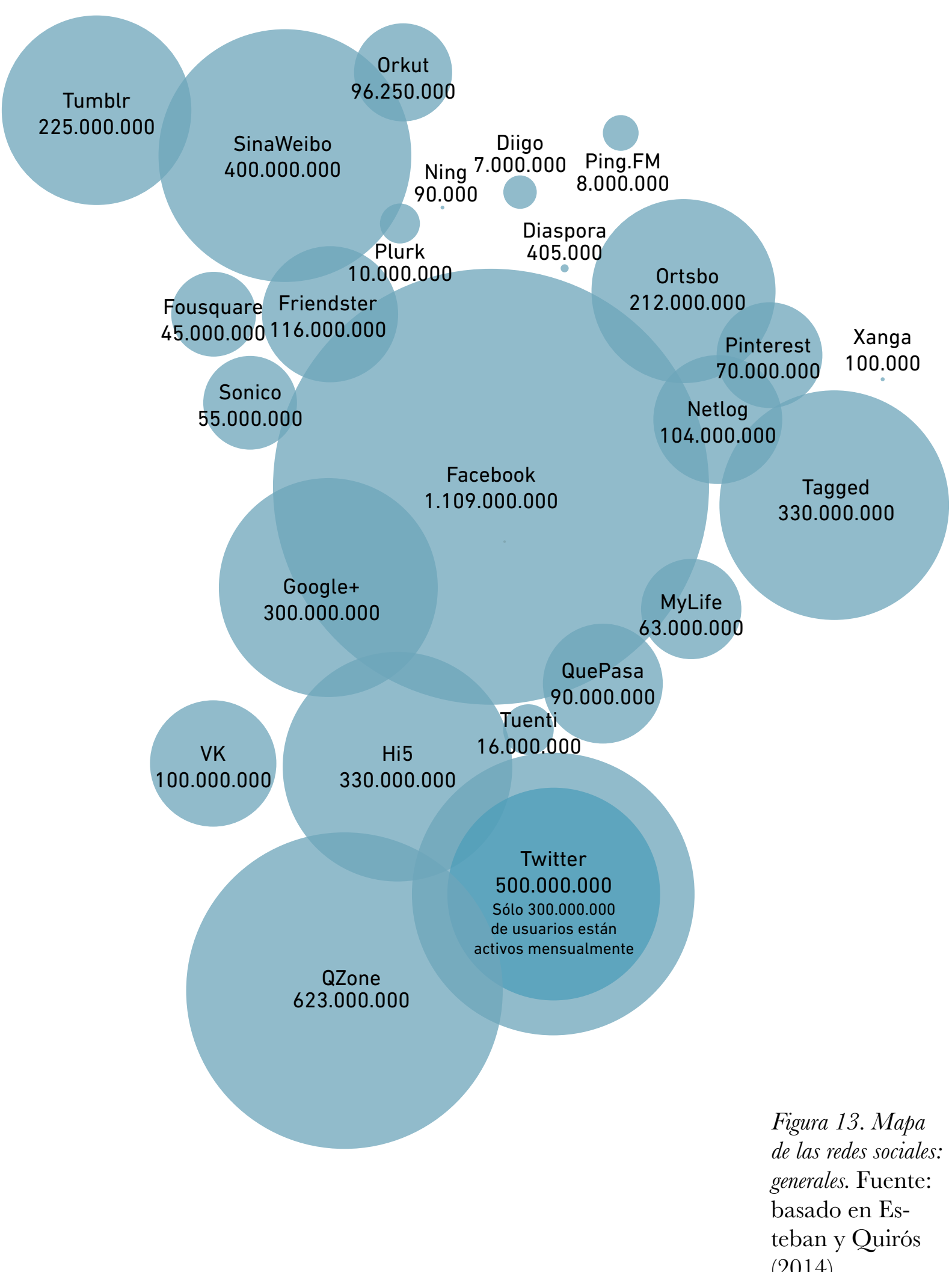

(2014). 
La investigación Nube de lágrimas, club de lectura en la nube. Lectores digitales y lectura social de la Fundación Germán Sánchez Ruipérez profundiza en el vector de la idea de intervención del lector como "colaboración originaria en la que es el valor por defecto, no la excepción" al concluir que "el libro no es lo importante sino la conversación sobre el libro" (Cordón García et al., 2014: 68). El objetivo principal de este proyecto era valorar el efecto de la formación para la lectura social y la dinamización de Lágrimas en la lluvia sobre la lectura. Para ello, trabajaron con dos grupos de lectores: alfabetizado y dinamizado. Ambos grupos pudieron compartir comentarios y subrayados en la plataforma de lectura social Readmill (una startup que fue cerrada por su comprador, Dropbox, en marzo de 2014) y pudieron conversar sobre la novela en un grupo de Facebook. Ambos grupos fueron formados para utilizar iPad, Readmill y Facebook; pero solo el grupo dinamizado fue guiado en la conversación en Facebook por una profesional del Centro de Desarrollo Sociocultural de Peñaranda de Bracamonte y contó además con la intervención de la propia autora (Rosa Montero). Dos tercios de los hilos abiertos por la dinamizadora contenían propuestas relacionadas directamente con la novela: los temas de fondo (en el $40 \%$ de las propuestas) los personajes $(37,80 \%)$, las posibles líneas de enriquecimiento $(35,50 \%)$ y la trama $(26,28 \%)$.

Las conclusiones del estudio aportan que: 1) los lectores dinamizados valoraron más tanto la novela como la experiencia completa de lectura acompañada; 2) con respecto a los datos obtenidos sobre la marcha (online), los lectores dinamizados participaron más en Facebook, hablaban de má personajes y de temas de fondo de la novela. Sin embargo, el porcentaje de intervenciones de los lectores dinamizados sobre cada personaje en particular y sobre cada tema de fondo concreto no era significativamente mayor que el que hacían los lectores alfabetizados

Por último, al analizar la calidad de lo dicho sobre los personajes y los temas el estudio releva que: 1) los lectores dinamizados describen con más frecuencia a los personajes (mientras que los alfabetizados solo los mencionan), pero esas descripciones son fundamentalmente unidimensionales; 2 no se releva una diferencia significativa entre lectores alfabetizados y dinamizados en relación con sus formas de pensar y cambios-revisiones sobre sus formas de pensar.

Estos resultados muestran, por lo tanto, que el impacto de la dinamización refleja el grado de satisfacción experimentado por los lectores: disfrutan más de la obra y de la experiencia de lectura compartida. El impacto sobre la lectura y la huella que de ella queda es, no obstante, más limitado.

\subsubsection{Plataformas de lectura en línea}

Las plataformas de lectura en línea y comunidades son plataformas basadas en Internet que reúnen lectores y libros, con finalidades comerciales y no comerciales, con participación de lectores y con promoción de productos por parte de los editores.

- 24symbols: una plataforma española diseñada para leer y compartir libros. El sitio trabaja con los editores para ofrecer sus ebooks en línea de forma gratuita a los usuarios, que pueden leerlos en su aplicación o navegador. La navegación entre títulos es libre. Guenta con aplicaciones para iOs, Android, Kindle Fire y BlackBerry. De los 161 libros más vendidos en 2014 (del ranking del diario El Periódico, enero-noviembre de 2014), 24symbols dispone de catorce títulos de ellos (Comunidad Baratz, 2015).

- Blendle: una startup holandesa que ofrece un servicio de suscripción para la lectura de artículos de revistas y noticias.

- Deutsche Digitale Bibliothek (DDB): proporciona acceso gratuito a libros, cuadros, esculturas, música y otras grabaciones sonoras, películas, información sobre la preservación de monumentos, exposiciones virtuales, inventarios de archivo. Ofrece links a los servicios digitales ofrecidos por todas las instituciones culturales y científicas alemanas.

- Legimi: esta plataforma polaca ofrece a sus suscriptores, por una cuota mensual de menos de $€ 5$, el acceso a una biblioteca de más de 2.000 libros electrónicos o, por el precio de compra del libro electrónico, sus usuarios pueden acceder a todos los títulos que deseen.

- La Librairie africaine numérique (Dakar, Senegal): plataforma ebook dedicada al libro de África y a la cultura africana. Se inició con un catálogo de 150 títulos.

- Libranova: una plataforma polaca de promoción de ebooks y lectura digital.

- Nubico: servicio de suscripción ebook español, co-propiedad de Planeta y Círculo de Lectores, proporciona acceso basado en suscripción a 8.500 títulos en ebooks de las principales editoriales españolas en castellano, inglés y catalán. De los 161 libros más vendidos en 2014 (del ranking del diario El Periódico, enero-noviembre de 2014), Nubico dispone de 49 títulos de ellos (Comunidad Baratz, 2015). 
- Pelican Books: Penguin Random House (aglutina el 25\% de las publicaciones a nivel mundial) y su sello Pelican Books de Reino Unido iniciaron una prueba en ese país de tal manera que los ebooks que se compren podrán disfrutarse en cualquier dispositivo tal como se puede efectuar con las plataformas de otros dispositivos como Amazon y Kobo. Se prevé que el resto del grupo ampliaría su oferta al resto de los sellos del grupo editorial si esta experiencia funciona a mediano plazo).

- Skoobe: un consorcio alemán liderado por Bertelsmann y Holtzbrinck que se especializa en préstamos de ebooks a la manera de una "biblioteca móvil" a través de una aplicación en la app de Apple o desde Google Play. Está prestando 50.000 títulos de libros electrónicos de más de 400 editores, con una cuota mensual $€ 9,99$. De los 161 libros más vendidos en 2014 (del ranking del diario El Periódico, enero-noviembre de 2014), Skoobe dispone de doce títulos de ellos (Comunidad Baratz, 2015).

- Yindo: un proveedor de ebooks holandés que amplió sus servicios para incluir su plan de suscripción. Por una cuota mensual, los usuarios pueden obtener préstamos de hasta un número limitado de ebooks a la vez.

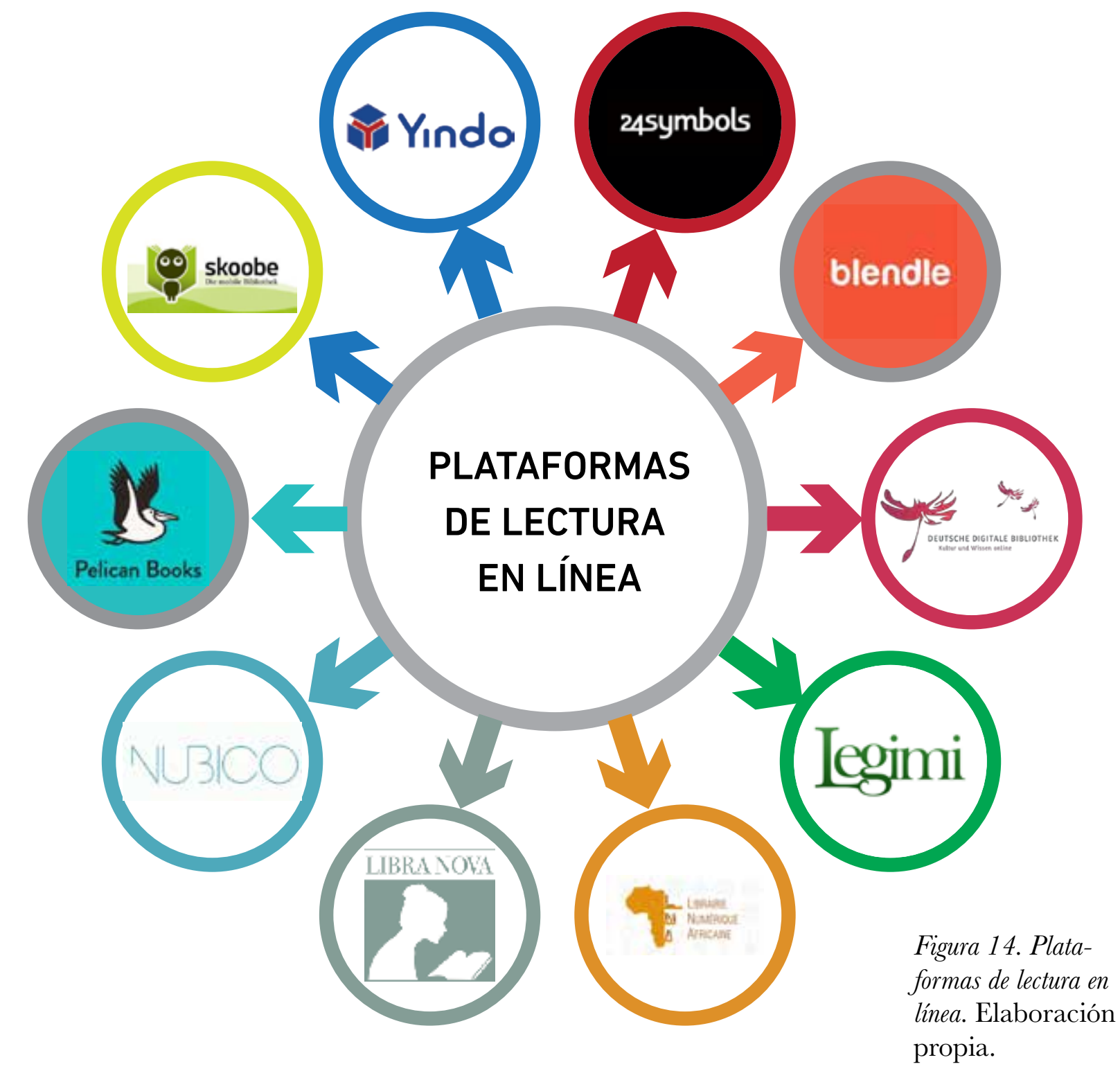




\subsection{Estrategias de la industria editorial para la transposición a digital en el marco de la globalización}

Para Néstor García Canclini (2013):

La autonomía del arte a 'la Bourdieu' correspondió a una etapa moderna en la que los artistas se desprendieron de los condicionamientos religiosos y políticos para generar formas independientes de cualquier instancia de poder exterior al acto creativo.

Asimismo, destaca que el "hecho que más fuertemente condiciona la práctica artística en la actualidad es la interrelación de textos, imágenes y procedimientos digitales" resultantes de la globalización. Si para Bourdieu existía autonomía relativa, se puede considerar que la acción de la industria editorial en digital produce una modificación en el campo editorial en la tensión preexistente entre el polo comercial y el polo de los contenidos. Esa autonomía relativa parece dejar paso a una heteronomía relativa (Graw, 2013) donde el acento no estaría colocado en el lugar de los contenidos, sino en el polo de la mercancía. $\mathrm{O}$, con mayor exactitud, aquello percibido en la tradición moderna clásica como "externo" al campo del arte, hoy poseería un poder que se acentúa, pero no como un absoluto, sino de manera limitada. Y, a su vez, el debilitamiento de la crítica especializada parece dar lugar a las estrategias ligadas a lo comercial y con otras decisiones relacionadas con el "gusto". Este puede ser uno de los vectores importantes de lo que Isabelle Graw (2013) define como pasaje de autonomía relativa a heteronomía relativa por preeminencia del polo comercial sobre el polo simbólico. Podemos tomar prestada por analogía esta hipótesis para el análisis del campo editorial.

Es decir, que los insumos y la circulación de la obra están globalizados, lo que habilitaría a pensar en las tensiones constantes entre "las tradiciones, creencias, iconografías locales y la circulación y las demandas o expectativas que se suponen en audiencias de otros lugares", lo que llevaría a pensar en el fin de una época en la que se creía y aspiraba a un arte global (García Canclini, 2013). Para Boris Groys (2014), hoy el artista se inicia en el sentido inverso que en el pasado. En la actualidad, ya no se pasaría de lo local a lo global. Primero se confronta con lo global coincidiendo con la idea de García Canclini: "subir textos e imágenes a Internet, abrirnos a todos, y recién después de eso ver si tu amigo te acepta". En ese nuevo camino crítico, "lo local es el último paso, y cada localidad tiene sus gustos, actitudes y prejuicios específicos y el artista habrá de considerar si quiere ser apreciado no solo por el mundo, sino también por su vecino" (Groys, 2014). La idea de Cristina Civale (2014) de concebir al gusto global como "una automatización del mercado que indica qué es lo legítimo como arte" nos permitiría, asimismo, articula dos planos de análisis de esta investigación: gusto y mercado. Es decir, la elucidación de un "gusto global" en relación con la literatura latinoamericana y caribeña que orienta la construcción del catálogo de autores y títulos pertenecientes al campo de esta literatura en el marco de un proceso transnacional de reconfiguración del negocio editorial. En este punto, la industria editorial figuraría yuxtaponiendo distintas estrategias para la decisión de la construcción del catálogo y que describimos en la Figura 23: a) aquellas relacionadas directamente con las estadísticas de ventas de los títulos en soporte impreso para asumir el riesgo empresario de transposición a digital de ellos y consideradas "demanda real de mercado" (Cordón García, 2004: 23); b) las estrategias ligadas a la necesidad de recuperación de financiera dadas las inversiones efectuadas en términos de compra de los derechos de autor y de adelantos a los autores o con decisiones de publicación por dominio público de las obras ${ }^{14}$; c) sumados a los costos de las estrategias de marketing relacionadas con esos mismos títulos y sus autores. Pero, asimismo, la acción estratégica general incluye: d) acciones que devienen también de la circulación de criterios que anclan en la elección de estilos, poéticas, estéticas, autores y obras de la literatura latinoamericana y caribeña. Las publicidades de Amazon para su plataforma Kindle y de iBooks para la tienda de contenidos iTunes que se incorpora en la Figura 16 resume en los títulos publicitarios algunas de las estrategias descritas previamente: "Ya en digital el realismo mágico de Gabriel García Márquez". Es decir: transposición a digital, desde decisiones poéticas, fundidas con decisiones ligadas a costos y ligadas a la promoción de autores, por un lado. Por el otro: "indies para descubrir", es decir, la promoción de productos editoriales mediante la reivindicación de formas editoriales "independientes". En este nivel, los decisores editoriales también definen el perfil de editorial en términos de propuestas estéticas, poéticas, autorales. Esto último, quizá, como resultado también de la influencia de las estéticas de la sección de arte latinoamericano de la corriente artística poscolonial incorporada al mainstream de comercialización de arte internacional (Smith, 2012: 22, 23).

${ }^{4}$ Por dominio público se entiende la situación en que quedan las obras literarias, artísticas o científicas al expirar el plazo de protección del derecho de autor.

Cada legislación nacional contempla un término de años contados desde la muerte del autor, para que estos derechos expiren. En España, por ejemplo, 80 años después de la muerte del autor sus obras pasan al dominio público (70 años para los autores fallecidos después del 7 de diciembre de 1987). En EE.UU., la Copyright Term Extension Act (CTEA) o Sonny Bono Copynight Term Extension de 1998 -también conocida peyorativamente como la Mickey Mouse Protection Act- extendió los plazos de copyright durante 20 años. Antes del Acta el copyright duraba toda la vida del autor más 50 años, o 75 años para una obra de autoría corporativa; el Acta extendió estos plazos durante la vida del autor más 70 años y para obras de autoría corporativa durante 120 años tras la creación o 95 años tras la publicación, independientemente de la anterioridad del punto final creativo. El Acta también afectó a los plazos de copyright para obras con copyright anteriores al 1 de enero de 1978, incrementando también su plazo de protección durante 20 años, hasta un total de 95 años desde la publicación. 


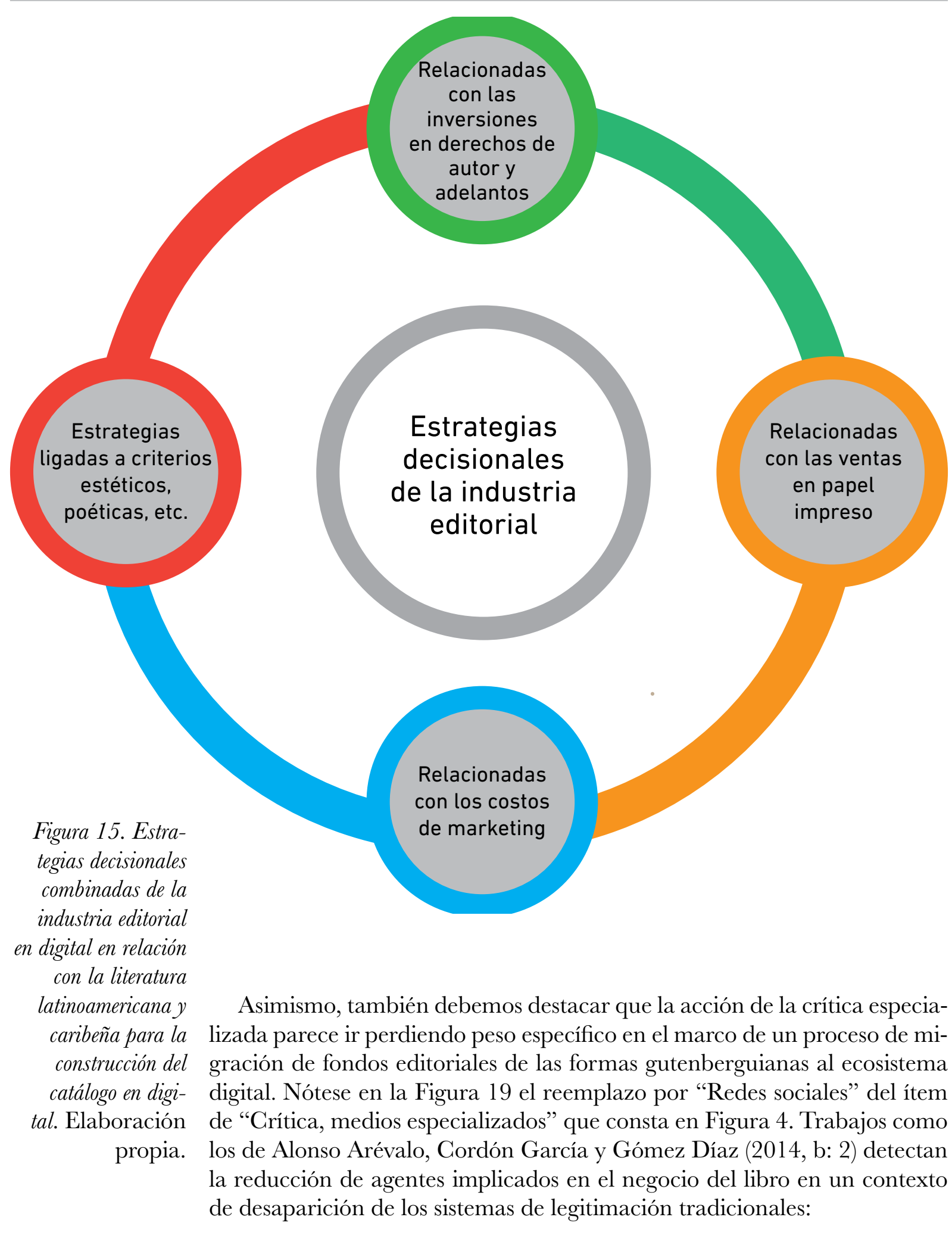

Los conceptos de autoría, crítica y recepción, profundamente asentados en el medio impreso, están cambiando sus competencias y significados al hilo de fenómenos únicamente imputables al contexto digital.
La idea de lo global como "interpretación o perspectiva desde donde se ven los hechos" (Schettini, 2014) está presente en la constitución de la mencionada oferta. En este plano, aportamos con una ampliación del campo de estudios de la "construcción del gusto" en los nuevos soportes digitales y como aporte al sostenimiento de una conciencia crítica de la relación entre "gusto" (Bourdieu, 1988) e industria, y como fuente de explicitación de formas que componen un gusto global (en el sentido de gusto concerniente a la globalización) que funcionaría como uno de los vectores de la elección de los títulos de la literatura latinoamericana al nivel de la oferta de bibliotecas y plataformas comercializadoras en digital.

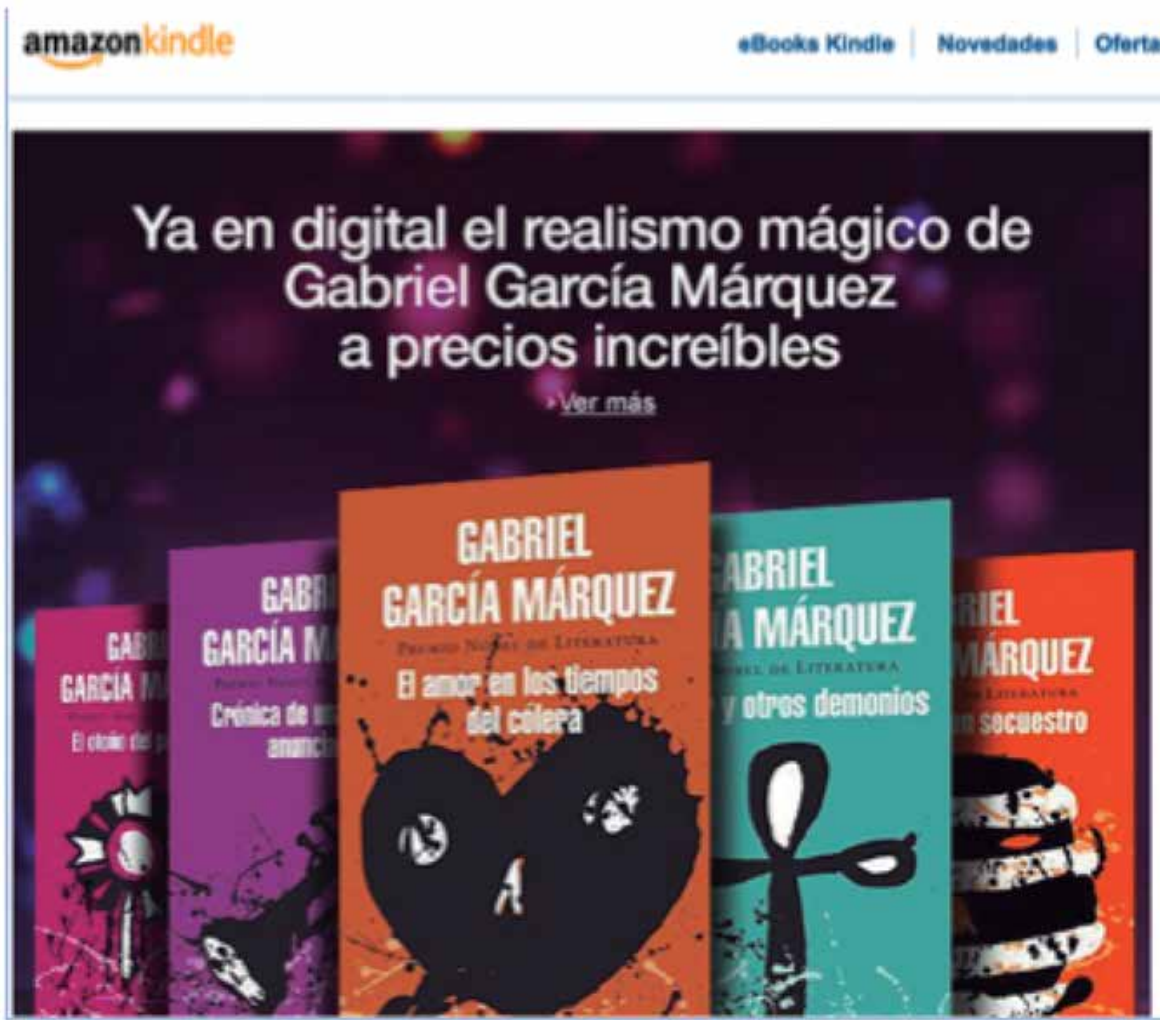

iBooks destacados

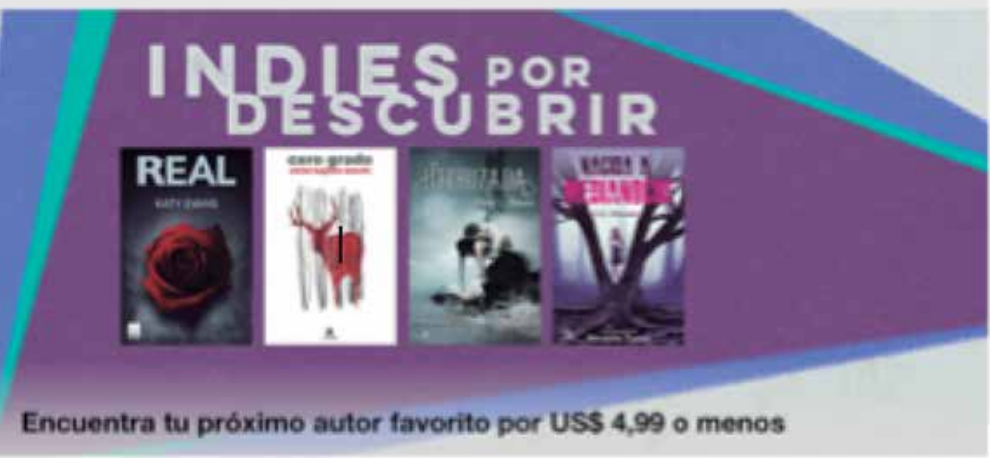

Figura 16. Publicidad de Amazon para su plataforma Kindle y de iBooks para la tienda de contenidos iTunes de Apple. Promoción de un estilo literario ("realismo mágico") y de formas editoriales indies (independientes), respectivamente. 


\subsection{Bibliotecas y ecosistema digital}

El propio carácter "híbrido" de las colecciones de las bibliotecas, es decir, la disposición de recursos físicos y digitales es lo que fundamenta el cambio de modelo de las bibliotecas (Orera Orera, 2011: 99). Para Tramullas Saz (2002: 6), la biblioteca digital es un proceso en el cual la información se transfiere desde una fuente a un usuario, pero, a su vez, este proceso "se caracteriza por su valor añadido" (por la biblioteca). Si la biblioteca digital debe ofrecerse como extensión/continuidad de los servicios de la biblioteca "tradicional", una de las funciones de la etapa que atravesamos es la de adaptar y reconvertir sus servicios a la modalidad digital. La biblioteca digital encuadra a la colección, las herramientas para gestionar esa colección, los expertos que actúan de intermediarios entre la información y el usuario. En este punto, debemos marcar que la formación de usuarios, es decir, la alfabetización digital, reinventa las funciones de las bibliotecas públicas, transparentando la utilización de dispositivos y aplicaciones "que sirven para mejorar los procesos de comprensión y asimilación lectora" (Cordón García et al., 2014: 7).

Asimismo, Rodrigues Dantas (2014: 534) considera que diferentes agentes pueden trabajar en la formación en herramientas de lectura social de una "mayoría de lectores comunes que apenas alcanzan el nivel de la tecnología digital". Esta formación, en manos de maestros, educadores y bibliotecarios puede aumentar las capacidades de lectura digital de las persona de la comunidad en la que están inmersas sus organizaciones. En esa reinvención, en ese cambio del perfil social y educativo de la biblioteca, el lector gana peso en la construcción de sus fondos bibliográficos. Laura Cohen (2006) propone en su Manifiesto del Bibliotecario 2.0:

Crearé sitios web abiertos que permitan a los usuarios hacer contribuciones conjuntas de contenidos con los bibliotecarios, a fin de mejorar su experiencia de aprendizaje.

\section{Y remata:}

Voy a formarme acerca de la cultura de la información de mis usuarios y buscaré formas de incorporar lo que aprendo en los servicios bibliotecarios.

Un ligero análisis de las formas de compra de títulos en digital más comunes por parte de las bibliotecas nos arroja:

a) Una de las estrategias habituales es la selección por paquetes. Esta estrategia supone ahorro en la inversión de la biblioteca, ya que generalmente se reducen los costos de los títulos. Aunque la selección de parte del bibliotecario es evadida y la composición del catálogo de la biblioteca de torna en desparejo, dada la disparidad en relación con la demanda de títulos por parte de los usuarios (el paquete cerrado se compone de una oferta de títulos con demanda y otros con demanda mediana o nula por parte de los usuarios).

b) Estrategia de adquisición "pick \& choose", es decir, elegir y escoger. Esta estrategia de selección de título a título es más costosa y permite asegurar un catálogo general (colección) de la biblioteca más dirigido a la demanda de los usuarios. Generalmente, es una estrategia que utilizan las bibliotecas públicas para la adquisición de ebooks (Gil, 2014).

c) Bolsa de descargas: esta estrategia de adquisición se realiza sobre el total de títulos del catálogo de la siguiente manera Vicente García, 2013):

Se establece un precio estimado por descarga y un número estimado mínimo de descargas sobre la totalidad del catálogo. En la compra individual de títulos aplicarían el precio por título adquirido, un precio por descarga y un número estimado mínimo de descargas por título.

d) La adquisición de archivos con carácter permanente también llamada compra "a perpetuidad" es otra estrategia de adquisición bibliográfica. Es la estrategia de adquisición clásica, a la manera de la galaxia Gutenberg: se adquiere un título "para siempre", sea cual fuere el soporte.

e) El acceso a través de licencias con un número de descargas o préstamos a determinar en convenio con la editorial. Por ejemplo, HarperCollins restringe por contrato a 26 el número de préstamos de cada uno de sus títulos y, una vez realizados, impone a las bibliotecas la renovación de la licencia (Vicente García, 2013).

f) Modelo de adquisición impulsada por el usuario (Patron Driven Acquisition-PDA), también llamado catalogación "just-incase" y adquisición "just-in-time". La mayoría de los agregadores ofrece acceso tanto a todos los títulos de libros electrónicos como a un grupo de títulos seleccionados por la biblioteca de acuerdo con el perfil o interés de la biblioteca. Esta estrategia de compras bibliotecarias permite ofrecer una colección de libros a usuarios autenticados de manera gratuita a la biblioteca o con un pequeño costo de alquiler de la obra. Una vez que un usuario traspasó el límite de páginas (de tiempo) establecido por contrato con un agregador, distribuidor o editorial, la biblioteca adquiere el título por un periodo establecido previamente en el contrato con el proveedor. Por ejemplo, diez vistas 
de páginas (excluyendo TOC e índice) o diez minutos de uso real dentro de un título o copiado o impresión (todo por sesión del usuario).

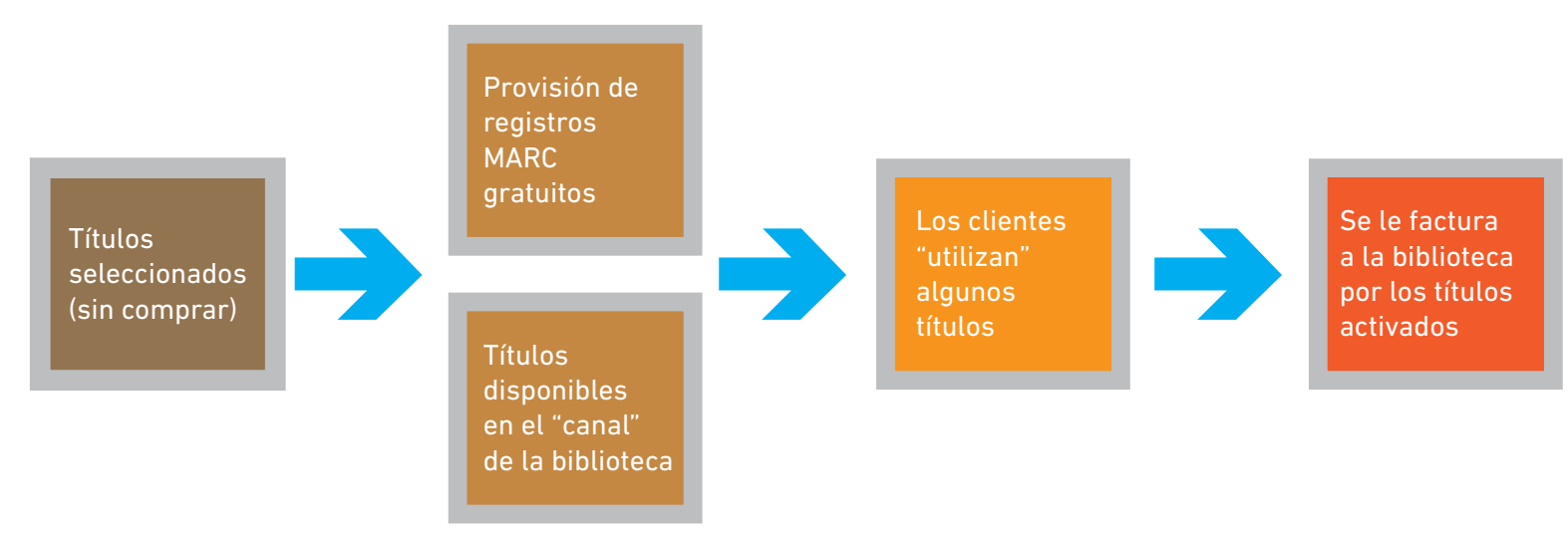

Figura 17. Proceso PDA (Patron Dri-

vens Adquisitions)

Genérico. Elaboración propia sobre "autoridad bibliotecaria" deja espacio a una participación directa del usuario la base de Alonso en la construcción de la colección: alrededor de 600 bibliotecas universitarias

Arévalo (2015) _ de todo el mundo articulan sus fondos bibliográficos desde esta estrategia (Esposito et al., 2012). Esta manera participativa es una de las apuestas que hacen posito et al., 2012). Esta manera participativa es una de las apuestas que hacen de contar con un primer lector para la compra reduce los riesgos de gastos superfluos en la adquisición. En este punto, sobresale un estudio realizado por Gammon y O'Neill (2011) sobre la contrastación de la regla “80/20" de Trueswell (1969, citado por Spindler, 2009: 2, 15; citado por Jackson, 1997), por la cual los bibliotecarios sostienen la creencia de que el $80 \%$ de la circulación de una biblioteca es impulsado por aproximadamente el 20\% de la colección. Esta investigación sobre el grupo Bibliotecas OhioLINK ${ }^{15}$ conformado por 16 universidades públicas de investigación, incluyendo cinco bibliotecas miembros de ARL (Association of Research Libraries), 23 comunidades y universidades técnicas, 50 colegios privados y la Biblioteca del Estado de Ohio, despliega un análisis de las estadísticas de circulación en todo el Estado de Ohio de un año. Este análisis define que el $80 \%$ de la circulación de las bibliotecas del Estado de Ohio es impulsado por solo el 6\% de la colección. ${ }^{16}$ Este tipo de contrastaciones es, asimismo, una demostración de las maneras en que la estrategia permite reducir la oferta de títulos sin circulación y se

${ }^{15}$ La colección combinada está compuesta por 50 millones de libros y otros materiales de la biblioteca. El tamaño de la colección combinada y el número de instituciones participantes hacen de este el mayor y más exhaustivo estudio de circulación en bibliotecas académicas jamás emprendido.

${ }^{16}$ Este estudio reveló, además, que las tasas de circulación varían ampliamente según el tema, el idioma, la institución y edad del material y que los límites a la duplicación innecesaria de títulos deben incluir lógicamente una diferenciación por disciplina. articula como una de las formas de la inserción en la colección de criterios que superan los propios del bibliotecario profesional a cargo. Esto no representaría que el primer uso por parte de un usuario se establezca en un índice apropiado sobre la utilización futura del libro electrónico ni sobre la pertinencia de ese título en el marco de la colección total de la biblioteca. Pero se articula como una zona de negociación entre los usuarios y los decisores bibliotecarios en función de la construcción de la colección de la biblioteca. Un estudio en bibliotecas universitarias de EE.UU. nos muestra que los bibliotecarios no han resignado a su responsabilidad en la construcción de las colecciones de las bibliotecas (Esposito et al., 2012: 12; Walters, 2012: 203, 209); a su vez, la mayoría de los bibliotecarios que respondieron los cuestionarios de la investigación apostaban por contemplar la estrategia PDA como una vía más de las utilizadas para el desarrollo de la colección sin apostar todo el presupuesto a la voluntad, o a la eventualidad del gusto de los lectores. Alonso Arévalo (2015) define que el modelo PDA significa, nada más y nada menos, que "la colección se adecua a la demanda de los usuarios". Es decir, la estrategia PDA es una de las ventanas por las cuales el gusto, el criterio sobre la literatura, sobre todo del usuario de las bibliotecas, puede ingresar a las formas de construcción del catálogo general de la biblioteca.

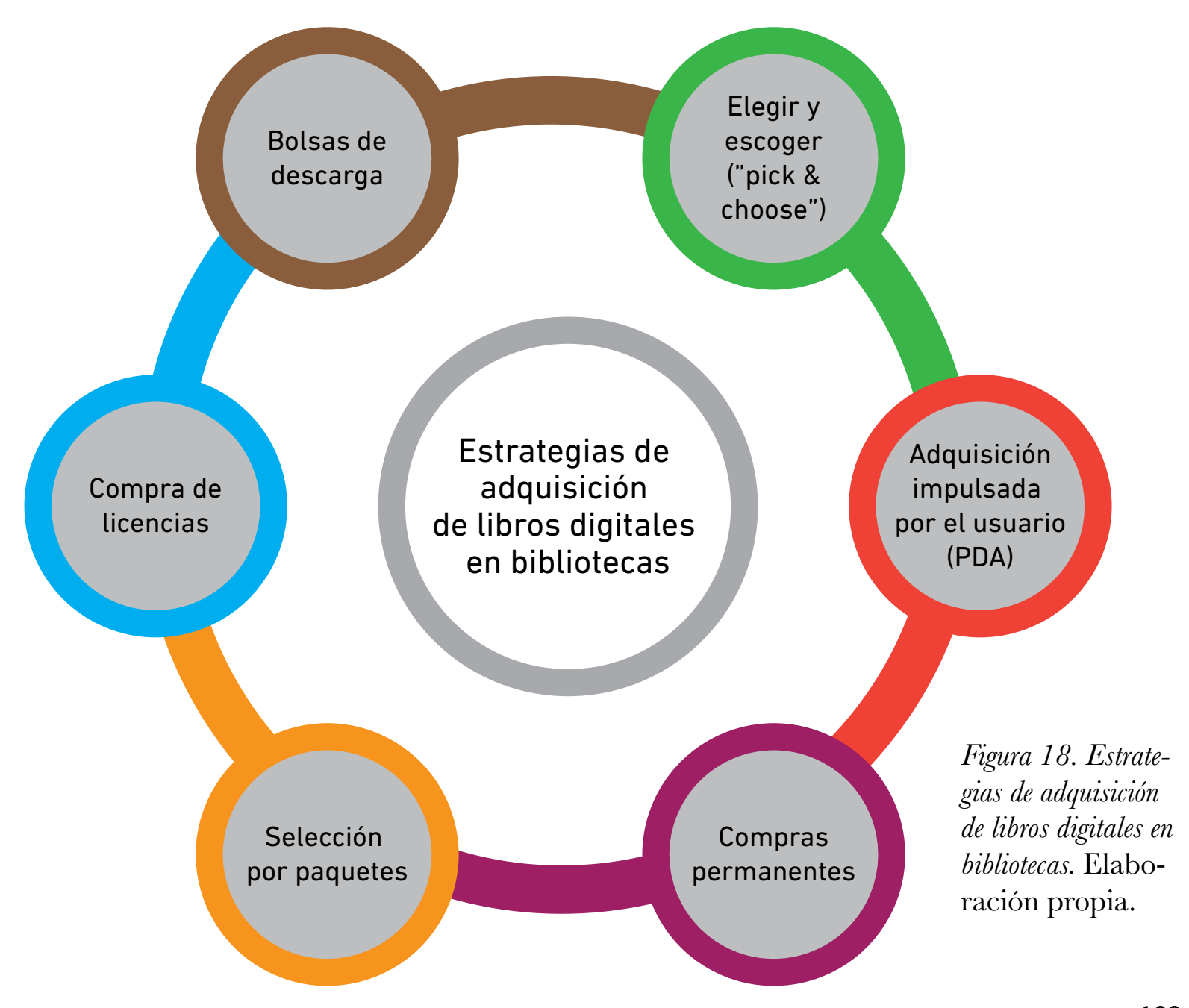


La formación de usuarios en el uso de nuevas tecnologías, aptitud que incluye los libros electrónicos, también redefine las competencias del lector y supone también una vuelta de tuerca en la formación de los propios bibliotecarios (formación de formadores). También una competencia muy importante para los efectos de esta investigación tiene que ver con el desarrollo y maduración de un juicio crítico por parte del lector, fundamentado en que sepa valorar la calidad de las fuentes consultadas (Jenkins, 2009, Campal, 2012: 400). La investigación Nube de lágrimas, club de lectura en la nube. Lectores digitales y lectura social realizada por un amplio equipo de la Fundación Germán Sánchez Ruipérez, en el marco del programa Territorio E-book (ya descrita en el apartado 3.2.7.) destaca: "el gran desafío de las bibliotecas que se instituyen en nodos de formación esenciales para la Formación y la Descubribilidad" es superar barreras,

gracias a la intervención de los profesionales. Barreras que se refieren no solo a los dispositivos y sus aplicaciones, sino fundamentalmente, al desarrollo de prácticas de lectura optimizada que favorezcan una comprensión más global y profunda de las obras, que faculten al lector al aprovechamiento de todas las herramientas que tiene a su disposición para conectar saberes y conocimientos vinculados con sus lecturas, que mejore sus competencias intelectivas en un universo conectado (Cordón García et al., 2014: 69).

Así, "la biblioteca cada vez será menos un lugar donde obtener información de una manera pasiva, para ser un lugar con un carácter premeditadamente proactivo capaz de involucrar a su comunidad" (Alonso-Arévalo y Cordón- García, 2015)

En este nivel, también la noción de "automatización de mercado" (Civale, 2014) nos permitiría articular dos planos de análisis de esta investigación: gust y mercado. Es decir, el ingreso del gusto de los lectores y profesionales bibliotecarios que orienta la oferta bibliotecológica de autores y títulos pertenecientes al campo de la literatura latinoamericana y caribeña en el marco de un proceso transnacional de reconfiguración del negocio editorial y de los componentes, acciones y paradigmas de lectura y escritura en el nuevo ecosistema.

Durante 2014, diez bibliotecas de EE.UU. y Canadá hicieron más de un millón de préstamos de libros digitales y dos de las bibliotecas superaron los dos millones de préstamos de libros electrónicos. En 2013, solo fueron seis las bibliotecas que efectuaron más de un millón de préstamos.

\section{Bibliotecas de EE.UU. y Canadá con más de un millón de préstamo} en 2014:

- New York Public Library (NY): (+ 42\%)

- Seattle Public Library (WA): (+ 35\%)

- Hennepin County Library $(\mathrm{MN}):(+33 \%)$

- Los Angeles Public Library (CA): (+ 56\%)

- Cleveland Public Library $(\mathrm{OH}):(+25 \%)$

- Calgary Public Library (AB): (+ 30\%)

- Cuyahoga County Public Library $(\mathrm{OH}):(+35 \%)$

- Public Library of Cincinnati and Hamilton County $(\mathrm{OH}):(+42 \%)$

Bibliotecas de EE.UU. y Canadá con más de dos millones de préstamos en 2014:

- Toronto Public Library $(\mathrm{ON}):(+49 \%)$

- King County Library System (WA): (+ 33\%)

Asimismo, la Asociación de Editores de Estados Unidos informó que las ventas de libros electrónicos crecieron más de un 210\% entre 2010 y 2011 Besen y Kirby, 2012). Al mismo tiempo, la disponibilidad de libros electrónicos a través de las bibliotecas públicas de EE.UU. también está creciendo: dos tercios de las bibliotecas públicas $(67,2 \%)$ ofrecían libros electrónicos en 2011 , frente al 55,4\% en 2009 y 38,3\% en 2007. 


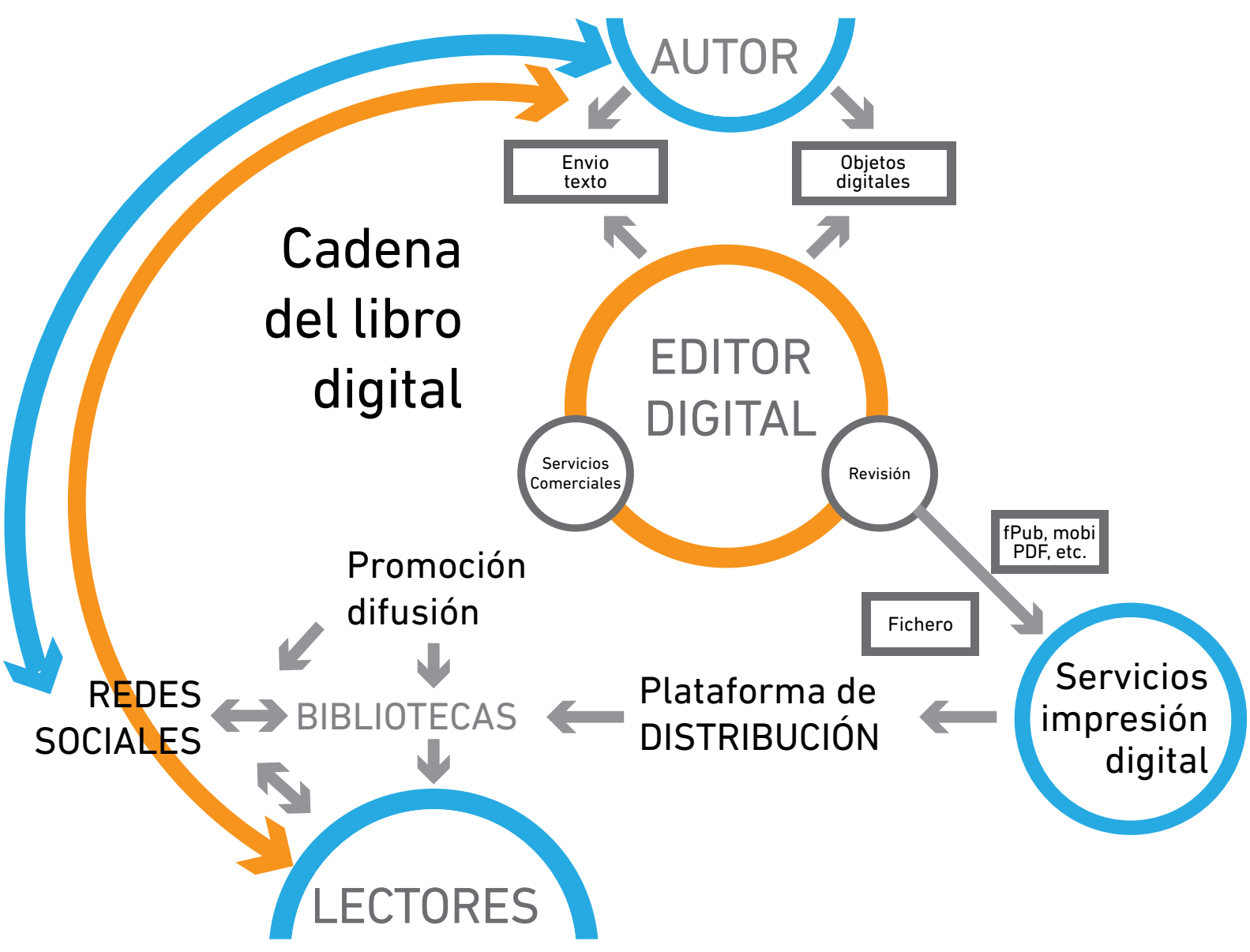

Figura 19. Cadena

del libro digital.

Fuente: Cordón

García (2014:

\section{TRANSPOSICIÓN DE IMPRESOS A DIGITAL DE LOS TÍTULOS DEL CORPUS LITERARIO LATINOAMERICANO Y CARIBEÑO CONSTRUIDO. TABLAS Y ANÁLISIS DE RESULTADOS ${ }^{17}$}

Por razones de espacio, se realizaron la siguientes figuras que funcionan como recortes de las Tablas completas que figuran en "Anexos" de esta Tesis:

- Tabla 23. Los 50 títulos del corpus que más aparecen en soporte impreso.

- Tabla 24. Los 50 títulos del corpus que más aparecen en soporte digital.

- Tabla 25. Los 50 autores que más aparecen en soporte impreso.

- Tabla 26. Los 193 títulos que más aparecen en ofertas en digital en plataformas comerciales y servicios de lectura en streaming y descarga de los títulos y autores del CLLyC.

- Amazon - Barnes \& Noble - Google Books - iBookstore / iTunes - Kobo - Free-Ebooks - Casa del Libro - Gandhi - Librería Santa Fe - Livraria Cultura - Perúbookstore.com Scribd - Nubico

- Tabla 27. Los 18 títulos que más aparecen en ofertas en digital en bibliotecas de los títulos y autores del CLLyC.

- Tabla 28. - Los 50 autores del corpus que más aparecen en soporte digital.

- Tabla 29. Los primeros 50 títulos que aparecen en plataformas comerciales latinoamericanas (ambos soportes): Gandhi

- Librería Santa Fe - Livraria Cultura - Perubookstore.com.

- Tabla 30. Los primeros 50 títulos que aparecen en bibliotecas latinoamericanas (ambos soportes): Biblioteca Nacional de Perú - Biblioteca de São Paulo. 


\subsection{Análisis de Tablas}

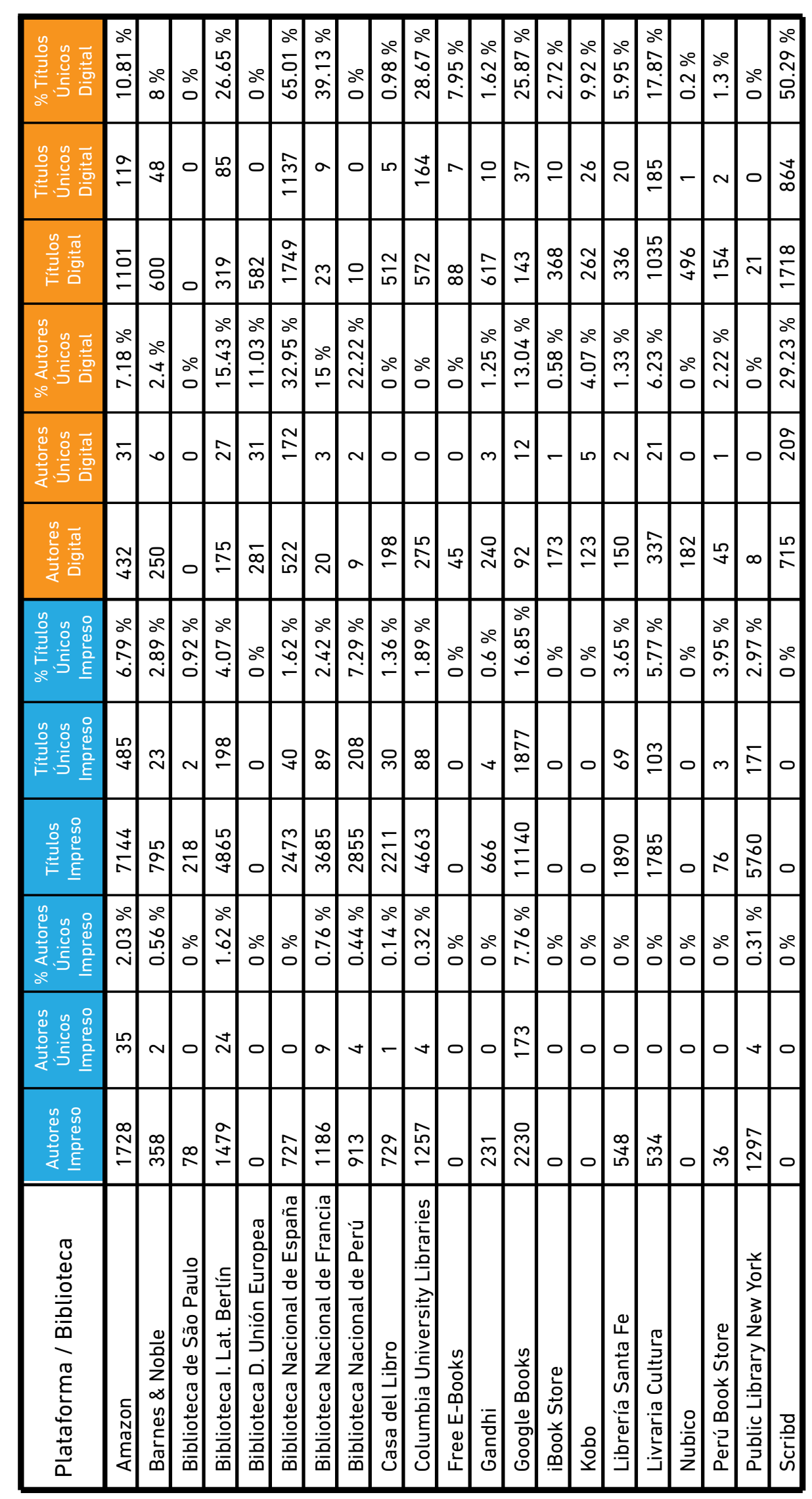

- Autores del CLLyC diseñado relevados en las búsquedas en soporte papel: 2.477

- Autores del CLLyC diseñado hallados en las búsquedas solo en soporte papel: 1.138

- Autores del CLLyC diseñado relevados en las búsquedas en digital: 1.353

- Autores del CLLyC diseñado hallados en las búsquedas solo en soporte digital: 14 


\section{Resultados obtenidos}

$14.83572,69 \%$

títulos hallados en algún soporte en alguna plataforma

o biblioteca

\subsection{7}

títulos hallado

en digital

$39,61 \%$

de los hallados en

algún soporte en algun

plataforma o biblioteca

$197 \mid 0,96 \%$

títulos hallados solo en digital

\section{$5,22 \%$}

de los hallados en

algún soporte en alguna

$249184.98 \%$

autores hallados en algún soporte

en alguna plataforma

o biblioteca
$50,62 \%$

\section{$4.842 \mid 23,72 \%$}

títulos no hallados del corpus buscado

en ningún soporte en

ninguna plataforma

o biblioteca

\section{$12.07174,17 \%$ \\ títulos hallados \\ en impreso \\ $\mathbf{9 4 , 7 7 \%}$ \\ de los hallados en algún soporte en alguna plataforma o biblioteca}

\section{$10.190 \mid 49,92 \%$}

títulos hallados del corpus buscado

solo en p

\section{$49,37 \%$}

\section{de los hallados en}

algún soporte en algun

taforma o biblioteca

\section{$5.37626,34 \%$}

del corpus buscado

en ningún soporte

en ninguna plataforma

o biblioteca

\begin{tabular}{|c|c|c|c|}
\hline $\begin{array}{r}1.353 \\
\text { autores hallados } \\
\text { en digital }\end{array}$ & $\begin{array}{l}46,16 \% \\
\text { del corpus buscado } \\
64,56 \% \\
\text { de los hallados en } \\
\text { algún soporte en alguna } \\
\text { plataforma o biblioteca }\end{array}$ & $\begin{array}{r}2477 \\
\text { autores hallados } \\
\text { en impreso }\end{array}$ & $\begin{array}{l}\mathbf{8 4 , 5 1 \%} \\
\text { del corpus buscado } \\
98,69 \% \\
\text { de los hallados en } \\
\text { algún soporte en alguna } \\
\text { plataforma o biblioteca }\end{array}$ \\
\hline $\begin{array}{r}14 \\
\text { autores hallados } \\
\text { solo en digital }\end{array}$ & $\begin{array}{l}0,47 \% \\
\text { del corpus buscado } \\
1,30 \% \\
\text { de los hallados en } \\
\text { algún soporte en alguna } \\
\text { plataforma o biblioteca }\end{array}$ & $\begin{array}{r}1.138 \\
\text { autores hallados } \\
\text { solo en papel }\end{array}$ & $\begin{array}{l}38,82 \% \\
\text { del corpus buscado } \\
\mathbf{3 5 , 4 3 \%} \\
\text { de los hallados en } \\
\text { algún soporte en alguna } \\
\text { plataforma o biblioteca }\end{array}$ \\
\hline
\end{tabular}

del CLIJC Elabosion poptor
4.1.1. Búsquedas en soporte impreso ${ }^{18}$

- La plataforma que más títulos dispone en soporte impreso es Google Books: 11.140 títulos sobre una búsqueda total de 14.835 (el 75,09\% de los títulos de literatura latinoamericana y caribeña disponibles en soporte impreso). Luego siguen Amazon, con 7.144 títulos (el 48,15\% de la oferta existente en impreso). De las plataformas de los países emergentes, la que más títulos impresos dispone es LSF (Argentina), con 1.890 títulos $(12,74 \%$ de la oferta existente), Livraria Cultura, de São Paulo, con 1.785 (12,03\%), Gandhi (México) ofrece 666 títulos en soporte impreso (4,48\%). Perubookstore ofrece 76 títulos en impreso (solo el $0,51 \%$ del total).

- En soporte impreso, la biblioteca que más títulos dispone es la Public Library of New York, con 5.760 (el 38,82\% de la oferta en soporte papel). Luego la siguen la Biblioteca del Instituto Latinoamericano de Berlín con 4.865 títulos (32,79\% del total de los títulos de la búsqueda) y Columbia University Libraries con 4.663 títulos en soporte papel $(31,43 \%)$. De las demás bibliotecas analizadas, se destaca, además, la oferta en soporte impreso de la Biblioteca Nacional de Francia: 3.685 títulos $(24,83 \%)$ y de la Biblioteca Nacional de Perú: 2.855 títulos $(19,24 \%)$

- La plataforma Google Books dispone de 2.230 autores en soporte impreso (el 90,02\% del total de autores relevados en soporte papel)

- La Biblioteca del Instituto Latinoamericano de Berlín dispone de 1.479 autores en soporte impreso (el 59,70\% de los autores disponibles en impreso); Public Library New York dispone de 1.297 autores en soporte impreso (el 52,36\% de los autores latinoamericanos y caribeños disponibles en impreso); Columbia University Libraries dispone de 1.257 autores en soporte impreso, seguido por la Biblioteca Nacional de Francia-Gallica- 1.186 autores.

- La Biblioteca Nacional de Perú se destaca entre las latinoamericanas: ofrece Livraria Cultura (Brasil) ofrece 913 autores en soporte impreso (el 36,85\% de los disponibles en impreso) 
- En relación con los títulos únicos en soporte impreso por plataforma y biblioteca (títulos en soporte papel que solo están disponibles en esa plataforma o biblioteca) destacamos una oferta mediana en Google Books y Amazon: ofrecen 1.877 títulos únicos sobre 11.140 títulos y 485 títulos únicos sobre 7.144 títulos, respectivamente. El resto de la oferta de títulos únicos en impreso es baja: Biblioteca Nacional de Perú ofrece 208 títulos únicos sobre 2.855 títulos en total y la Biblioteca del Instituto Latinoamericano de Berlín dispone 198 títulos únicos en impreso sobre una oferta total en ese soporte de 4.865 títulos. La Biblioteca Nacional de España también posee una oferta baja de títulos únicos en impreso: 40 títulos sobre una oferta total de 2.473 títulos en impreso.

- En relación con los autores únicos en soporte impreso por plataforma y biblioteca (autores cuyos títulos en soporte papel que solo están disponibles en esa plataforma o biblioteca) marcamos que Google Books dispone de 173 autores únicos (sobre 2.230 autores en total en soporte papel). El resto de la oferta de autores únicos relevados en las búsquedas es soporte impreso es muy baja.

\subsubsection{Búsquedas en soporte digital}

- La plataforma que más títulos ofrece en soporte digital es la Web de intercambios Scribd (esto ratifica que la participación del usuario en la oferta, produce un incremento de las posibilidades de acceso): 1.718 títulos sobre 4.842 título hallados en digital, es decir, el 35,48\% de los títulos existentes en digital para las búsquedas efectuadas. Amazon ofrece 1.101 títulos, es decir, una oferta media en relación con el universo de búsquedas en digital (el 22,73\% del total de los títulos en soporte digital hallados). Livraria Cultura ofrece 1.035 (21,37\% de los títulos disponibles en digital); Barnes \& Noble, 600 títulos en digital (12,39\%). Se apunta que la oferta de literatura latinoamericana y caribeña en digital, en los idiomas originales de las obras, es muy baja por parte de la plataforma Kobo: 262 títulos (el 5,41\% de la oferta relevada). Casa del Libro y Nubico (ambas de España) forman parte de la "clase media" de la oferta de títulos de literatura latinoamericana y caribeña, en idiomas originales, en digital: 512 $(10,57 \%)$ y $496(10,24 \%)$ títulos, respectivamente, así como los títulos disponibles en iBook Store de Apple: 368 títulos en digital $(7,60 \%)$.
- De las plataformas comerciales latinoamericanas, además de la destacada oferta de 1.035 títulos por parte de Livraria Cultura (Brasil), Gandhi (México) ofrece 617 títulos en digital (12,74\%) y LSF (Argentina) 336 títulos (6,93\%). Perubookstore ofrece 154 títulos en digital $(3,18 \%)$.

- Oferta en digital en bibliotecas: la biblioteca que más títulos ofrece es la Biblioteca Nacional de España: 1.749 (el $36,12 \%$ de la oferta disponible en digital). Este dato es muy destacable, dado que la Biblioteca Nacional de España ofrece en digital más títulos que las demás plataformas y bibliotecas en las que se efectuaron las búsquedas (incluida la Web de intercambio Scribd y la plataforma Amazon). Luego la siguen la Biblioteca Europeana de la Unión Europea, con 582 títulos $(12,01 \%)$ y Columbia University Libraries con 572 títulos $(11,81 \%)$. La Biblioteca del Instituto Latinoamericano de Berlín dispone de 319 títulos $(6,58 \%$ del total). Se apunta la muy baja oferta en digital de la Public Library of New York, la Biblioteca Nacional de Francia -Gallica-con 23 y 21 títulos respectivamente y la Biblioteca Nacional de Perú con diez títulos en digital y la Biblioteca de São Paulo con ningún título en digital.

- En relación con los títulos únicos en digital por plataforma y biblioteca (títulos en digital que solo están disponibles en esa plataforma o biblioteca) la oferta de Biblioteca Nacional de España es muy destacada: dispone de 1.137 títulos únicos sobre 1.749 títulos que ofrece en total en soporte digital. Luego, la Web de intercambio Scribd dispone de 864 títulos únicos sobre 1.718 títulos que ofrece en digital. Livraria Cultura ofrece 185 títulos únicos sobre 1.035 títulos del total en digital y Columbia University Libraries posee 164 títulos únicos sobre 572 títulos que ofrece en total en digital. La disposición de títulos únicos en digital por parte de Amazon es muy baja: 119 títulos sobre 1.101 del total de su oferta.

- En relación con los autores únicos en soporte digital por plataforma y biblioteca (autores cuyos títulos en digital que solo están disponibles en esa plataforma o biblioteca) marcamos que Scrib dispone de 209 autores únicos (sobre $705 \mathrm{au}-$ tores que dispone en total en soporte digital) y la Biblioteca Nacional de España 172 autores únicos relevados en digital (sobre 522 autores que posee en total en digital). El resto de la oferta de autores únicos relevados en las búsquedas en digital es muy baja. 


\subsubsection{Los 50 títulos que más aparecen en soporte impreso}

\begin{tabular}{|c|c|c|c|}
\hline Autor & Obra & Fuentes & Veces \\
\hline Carpentier, Alejo & Concierto Barroco & $2,13,14$ & 14 \\
\hline Carpentier, Alejo & Los pasos perdidos & $1,2,3,13,14$ & 14 \\
\hline Vargas Llosa, Mario & Los cachorros & $2,3,14$ & 14 \\
\hline Allende, Isabel & La casa de los espiritus & & 13 \\
\hline Arlt, Roberto & El juguete rabioso & & 13 \\
\hline Azuela, Mariano & Los de abajo & $2,3,14$ & 13 \\
\hline Benedetti, Mario & $\frac{10 s \text { centario }}{\text { Inver }}$ & $\frac{2,3,14}{2,14}$ & $\frac{13}{13}$ \\
\hline Bolaño, Roberto & Los detectives salvajes & 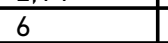 & 13 \\
\hline Borges, Jorge Luis & El Aleph & $1,2,3,14$ & 13 \\
\hline Cambaceres, Eugenio & Sin rumbo & 2,14 & 13 \\
\hline Carpentier, Alejo & El reino de este mundo & $1,2,3,13,14$ & 13 \\
\hline Neruda, Pablo & Veinte poemas de amor y una canción desesperada & $1,2,14$ & 13 \\
\hline Roncagliolo, Santiago & Abril rojo & & 13 \\
\hline Rulfo, Juan & Pedro Páramo & $2,3,14$ & 13 \\
\hline Alegría, Ciro & El mundo es ancho y ajeno & 2,14 & 12 \\
\hline Altamirano, Ignacio Manuel & Clemencia & & 12 \\
\hline Altamirano, Ignacio Manuel & El Zarco & 2,14 & 12 \\
\hline Amado, Jorge & Gabriela, cravo e canela & 2,14 & 12 \\
\hline Amado, Jorge & Sudor & & 12 \\
\hline 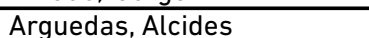 & Raza de bronce & 2,14 & 12 \\
\hline Arguedas, José María & Los ríos profundos & 2,14 & 12 \\
\hline Arguedas, José María & Yanar fiesta & 2 & \begin{tabular}{|c|}
12 \\
\end{tabular} \\
\hline Arlt, Roberto & Aguafuertes porteñas & 2 & 12 \\
\hline Arlt, Roberto & Los lanzallamas & 2 & 12 \\
\hline Arlt, Roberto & Los siete locos & 2 & 12 \\
\hline Asturias, Miguel Angel & El señor Presidente & 2,14 & 12 \\
\hline Asturias, Miguel Angel & Hombres de maíz & $1,2,14$ & 12 \\
\hline Asturias, Miguel Angel & Leyendas de Guatemala & 2,14 & 12 \\
\hline Benedetti, Mario & La borra del café & 14 & 12 \\
\hline Benedetti, Mario & La muerte y otras sorpresas & 2,14 & 12 \\
\hline Benedetti, Mario & La tregua & 2,14 & 12 \\
\hline Benedetti, Mario & Pedro y el capitán & 14 & 12 \\
\hline Benedetti, Mario & Primavera con una esquina rota & 2 & 12 \\
\hline Bioy Casares, Adolfo & Historias de amor & 2 & 12 \\
\hline Borges, Jorge Luis & Ficciones & $1,2,3,14$ & \begin{tabular}{|l|}
12 \\
\end{tabular} \\
\hline Borges, Jorge Luis & Inquisiciones & 2,14 & 12 \\
\hline Borges, Jorge Luis & Obras completas & 2,14 & 12 \\
\hline Cambaceres, Eugenio & En la sangre & 2,14 & 12 \\
\hline Cané, Miguel & Juvenilia & 2,14 & 12 \\
\hline Carpentier, Alejo & El acoso & $2,13,14$ & 12 \\
\hline Carpentier, Alejo & El recurso del método & $1,2,3,13,14$ & 12 \\
\hline Castellanos, Rosario & Oficio de tinieblas & 2,14 & $\frac{12}{12}$ \\
\hline Conti, Haroldo & Sudeste & 2,14 & 12 \\
\hline Cortázar, Julio & Bestiario & 2,3 & 12 \\
\hline Cortázar, Julio & Las armas secretas & 2,14 & 12 \\
\hline Cortázar, Julio & Octaedro & 2,14 & 12 \\
\hline Donoso, José & El Mocho & 2,14 & 12 \\
\hline Filloy, Juan & Op Oloop & 2,14 & 12 \\
\hline Neruda, Pablo & Canto general & $1,2,14$ & 12 \\
\hline Neruda, Pablo & Residencia en la tierra & $1,2,14$ & 12 \\
\hline
\end{tabular}

Tabla 23. Los 50 títulos del corpus que más aparecen en soporte impreso. (Esta figura es un recorte de las tablas 8.1. Tabla general de comparación de ofertas en papel en plataformas comerciales y servicios de lectura en streaming y descarga de los títulos y autores del corpus literario latinoamericano y caribeño diseñado; y 8.2. Tabla general de comparación de ofertas en papel en bibliotecas globales de los títulos y autores del corpus literario latinoamericano y caribeño diseñado). Elaboración propia.
En el nivel de la oferta de títulos en impreso, de 14.835 títulos relevados en las búsquedas en 14 plataformas y bibliotecas que disponen de títulos en impreso, solo tres títulos son ofrecidos en todas las plataformas y bibliotecas: dos títulos del escritor cubano Alejo Carpentier (Los pasos perdidos; Concierto barroco) y un título de Mario Vargas Llosa(Los cachorros). De los tre títulos, Concierto barroco, de Carpentier, es un título de El canon occidental, de Harold Bloom. Los dos autores son autores canónicos. De los títulos que los siguen, once obras fueron relevadas en trece plataformas y bibliotecas, de los cuales cuatro títulos pertenecen al canon bloomiano: El Aleph, de Jorge Luis Borges; Pedro Páramo, de Juan Rulfo; El reino de este mundo, de Alejo Carpentier y 20 poemas de amor y una canción desesperada, de Pablo Neruda. En este alto segmento marcamos que se encuentra la obra de Roberto Bolaño, Los detectives salvajes. Culminan la élite de la oferta en títulos las obras de autores canónicos Miguel Ángel Asturias (Leyendas de Guatemala y Hombres de maíz) y de obras tradicionales o relacionadas al folklore de algunos países latinoamericanos, en dominio público, de Miguel Arguedas (Los ríos profundos); Mariano Azuela (Los de abajo); Eugenio Cambaceres (Sin rumbo) y Ricardo Palma (Tradiciones), y el clásico de Roberto Arlt El juguete rabioso, en dominio público. Finalmente, se destacan Inventario, de Mario Benedetti y el bestseller de Isabel Allende, La casa de los espiritus. Se destaca la presencia de Abril rojo, de Santiago Roncagliolo (un autor de la matriz de la Generación McOndo y autor de ediciones cartoneras) en el segmento más presente en la oferta en soporte impreso en plataformas y bibliotecas. Entonces, se detectan las secciones mediante las cuales se articula la oferta del CLLyC en soporte impreso y se detallan a continuación.

\section{Sección de obras y autores bloomianos}

Jorge L. Borges (1899-1986)

El Aleph

Ficciones

Inquisiciones

Obras completas

Pablo Neruda (1904-1973)

20 poemas de amor y una canción desesperada

Alejo Carpentier (1904-1980)

Los pasos perdidos

Concierto barroco

El acoso 


\section{El recurso del método}

$\begin{array}{ll}\text { Julio Cortázar (1914-1984) } & \text { Bestiario } \\ & \text { Las armas secretas } \\ & \text { Octaedro } \\ \text { Juan Rulfo (1917-1986) } & \text { Pedro Páramo } \\ \text { Miguel Ángel Asturias (1899-1974) } & \text { Leyendas de Guatemala } \\ & \text { Hombres de maíz } \\ & \text { Weekend en Guatemala } \\ \text { Mario Vargas Llosa (1936) } & \text { Los cachorros } \\ \text { Reinaldo Arenas (1943-1990) } & \text { El asalto } \\ \text { José Donoso (1924-1996) } & \text { El Mocho }\end{array}$

\section{Sección de obras del canon escolar y folklore latinoamericano}

$\begin{array}{ll}\text { Ricardo Palma (1833-1919) } & \text { Tradiciones } \\ \text { Ignacio Altamirano (1834-1893) } & \text { Clemencia } \\ & \text { El Zarco } \\ \text { Eugenio Cambaceres (1843-1888) } & \text { Sin rumbo } \\ \text { Miguel Cané (1851-1905) } & \text { En la sangre } \\ \text { Mariano Azuela (1873-1952) } & \text { Fuvenilia } \\ \text { Martín Adán (1908-1985) } & \text { La casajo de cartón } \\ \text { Miguel Arguedas (1911-1969) } & \text { Los ríos profundos } \\ & \text { Relatos completos }\end{array}$

\section{Yanar fiesta}

Jorge Amado (1912-2001)

Gabriela, cravo e canela

$$
\text { Sudor }
$$

Adolfo Bioy Casares (1914-1999) Historias de amor

\section{Sección de narrativas de crítica social y "realismo"} latinoamericano

$$
\text { Mario Benedetti (1920-2009) Inventario }
$$$$
\text { La tregua }
$$

Primavera con una esquina rota

La muerte y otras sorpresas

Ciro Alegría (1909-1967)

El mundo es ancho y ajeno

Evaristo Carriego (1883-1912)

Misas herejes

Haroldo Conti (1925-? $\left.{ }^{19}\right)$

Sudeste

\section{Sección de títulos de autores que recién ingresan en dominio} público

$$
\begin{array}{ll}
\text { Roberto Arlt (1900-1942) } & \text { El juguete rabioso } \\
& \text { Los lanzallamas } \\
& \text { Los siete locos }
\end{array}
$$

\section{Sección de escritura de mujeres}

$\begin{array}{ll}\text { Isabel Allende (1942) } & \text { La casa de los espiritus } \\ \text { Rosario Castellanos (1925-1974) } & \text { Oficio de tinieblas }\end{array}$

Rosario Castellanos (1925-1974) Oficio de tinieblas 
Sección de títulos de escritores de la generación McOndo y de las ediciones cartoneras latinoamericanas

Santiago Roncagliolo (1975)

$$
\text { Abril rojo }
$$

Roberto Bolaño (1953-2003)

Los detectives salvajes

Se destaca que los títulos canónicos y de autores canónicos componen el segmento más presente en los resultados de las búsquedas en soporte impreso, así como un lote de autores ligados tanto a la generación McOndo como Roberto Bolaño y Santiago Roncagliolo, como autores ligados a éxito de ventas como Isabel Allende y pertenecientes a la sección de crítica social latinoamericana, como los títulos de Mario Benedetti. Asimismo, los títulos de autores en dominio público no tienen demasiado peso en la composición de la élite de títulos más encontrados en las búsquedas en plataformas y bibliotecas en soporte impreso. Además, no se encuentran títulos pertenecientes a la sección caribeña del CLLyC construido.

\subsubsection{Los 50 títulos que más aparecen en digital: el canon} oculto

\begin{tabular}{|c|c|c|c|c|}
\hline Autor & Obra & Fuentes & (-) & 司 \\
\hline Cieza de León, Pedro & Crónica del Perú & 2 & 14 & \\
\hline Mármol, José & Amalia & 2 & 14 & 10 \\
\hline Alberdi, Juan Bautista & Bases y puntos de partida para la organización política.. & 2,14 & 13 & 09 \\
\hline Alberdi, Juan Bautista & El crimen de la guerra & 2,14 & 13 & 11 \\
\hline Altamirano, Ignacio Manuel & Clemencia & & 13 & 12 \\
\hline & & 2,14 & 13 & \\
\hline Darío, Rubén & Prosas profanas & 2,3 & 13 & \\
\hline Lillo, Baldomero & Sub Terra & 2,14 & 13 & 08 \\
\hline Villaverde, Cirilo & Cecilia Valdés & 2,14 & 13 & 12 \\
\hline Acevedo Díaz, Eduardo & Brenda & & 12 & \\
\hline Barros Arana, Diego & Historia general de Chile & 2,14 & 12 & \\
\hline Blest Gana, Alberto & Martín Rivas & & 12 & \\
\hline Borges, Jorge Luis & El Aleph & $1,2,3,14$ & 12 & 13 \\
\hline Cruz, Sor Juana Inés de la & & & 12 & \\
\hline Darío, Rubén & Cantos de vida y de esperanza & $2,3,14$ & 12 & 10 \\
\hline Ercilla y Zúñiga, Alonso de & La araucana & 2 & 12 & \\
\hline Garcilaso de la Vega & Comentarios reales & 2 & 12 & 10 \\
\hline Ingenieros, José & El hombre mediocre & 2,14 & 12 & 10 \\
\hline Lillo, Baldomero & Sub sole & 2 & 12 & 08 \\
\hline López de Gómara, Francisco & Historia general de las Indias & & 12 & $\frac{10}{10}$ \\
\hline Rodó, José Enrique & Ariel & 2,14 & 12 & 10 \\
\hline Aguinis, Marcos & el marrano & & 11 & \\
\hline Asturias, Miguel Ángel & El señor Presidente & 2,14 & 11 & \\
\hline Borges, Jorge Luis & Ficciones & $1,2,3,14$ & 11 & \\
\hline Borges, Jorge Luis & Historia universal de la infamia & $2,3,14$ & 11 & 11 \\
\hline Cané, Miguel & Juvenilia & 2,14 & 11 & 12 \\
\hline Cieza de León, Pedro & Señorío de los Incas & & 11 & \\
\hline Darío, Rubén & Canto errante & 2 & 11 & 06 \\
\hline Darío, Rubén & Tierras solares & 2,14 & 11 & 07 \\
\hline $\begin{array}{l}\text { Díaz del Castillo, Bernal } \\
\end{array}$ & erdadera de la conquista de la Nueva España & & 11 & \\
\hline 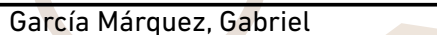 & Lah & 2.14 & 11 & \\
\hline 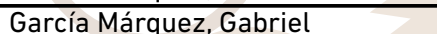 & LaM & 2.14 & 11 & \\
\hline Güiraldes, Ricardo & do Sombra & 2,14 & 11 & \\
\hline Las Casas, Bartolomé de & Historia de las Indias & 2 & 11 & 06 \\
\hline Lugones, Leopoldo & Las fuerzas extrañas & 2,14 & 11 & 09 \\
\hline Montenegro, Carlos & Hombres sin mujer & 2,13 & 11 & 05 \\
\hline Neruda, Pablo & Canto general & $1,2,14$ & 11 & 12 \\
\hline Nervo, Amado & Los jardines interiores & 2,14 & 11 & 06 \\
\hline Nervo, Amado & Misticas & 2 & 11 & 07 \\
\hline Palma, Ricardo & Tradiciones & 2 & 11 & 12 \\
\hline Palma, Ricardo & Tradiciones peruanas & 2,14 & 11 & 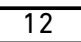 \\
\hline Rabasa, Emilio & La bola & 2 & 11 & \\
\hline Ignacio Manuel & $E l Z a$ & 2,14 & & \\
\hline Ignacio Manuel & 15 montañas & 2,14 & 10 & \\
\hline Arlt, $\mathrm{F}$ & rabioso & & 10 & 13 \\
\hline Borges, Jorge Luis & El Hacedor & $1,2,14$ & 10 & 10 \\
\hline Cané, Miguel & El viaje & 2 & 10 & 11 \\
\hline Carriego, Evaristo & Misas herejes & 2,14 & 10 & 10 \\
\hline Cervantes de Salazar, Francisco & Crónica de Nueva España & 2 & 10 & $\overline{08}$ \\
\hline Cortázar, Julio & Final del juego & & & \\
\hline
\end{tabular}

Tabla 24. Los 50 títulos del corpus que más aparecen en soporte digital. (Esta figura es un recorte de las tablas 8.3. Tabla general de comparación de ofertas en digital en plataformas comerciales y servicios de lectura en streaming y descarga de los títulos y autores del corpus literario latinoamericano y caribeño diseñado; y 8.4. Tabla general de comparación de ofertas en digital en bibliotecas globales de los titulos y autores del corpus literario latinoamericano y caribeño diseñado). Elaboración propia. 
En el nivel de la oferta de títulos en digital se destaca que, de los primeros 50 títulos más presentes en digital, el 82\% de los mismos están en dominio público. Sobre 4.842 títulos, solo dos títulos están presentes en 14 plataformas y bibliotecas: Crónica del Perú, de Pedro Cieza de León y Amalia, de José Mármol (dos obras que pertenecen al dominio público, en términos de derechos de autor).

Luego, ocho títulos están presentes en trece plataformas y bibliotecas. De ellos, seis títulos pertenecen al dominio público y solo uno es un título del canon de Bloom: El Aleph, de Jorge Luis Borges. El restante es la novela La tregua, del escritor uruguayo Mario Benedetti. El resto de los 50 títulos relevados está presente en 10, 11 y 12 plataformas y bibliotecas.

A su vez, de los primeros 50 títulos que más aparecen en digital cuatro son títulos bloomianos: tres son los volúmenes de cuentos de Jorge Luis Borges: El Aleph; Ficciones y El hacedor, además de Canto General de Pablo Neruda. Y, de esos 50 títulos, 20 son títulos de autores canónicos. A los ya mencionados se agregan títulos de los mismos Borges y Neruda y de los escritores bloomianos Gabriel García Márquez, Julio Cortázar Miguel Ángel Asturias y Rubén Darío. De estos títulos de autores bloomianos solo están en dominio público los seis títulos pertenecientes a Rubén Darío. Asimismo, doce títulos, con 10, 11 y 12 presencias en plataformas y bibliotecas son obras en dominio público de José Mármol, Rubén Darío, José E. Rodó, Cirilo Villaverde, López de Gómara, Alonso Ercilla, José Ingenieros, Inca Garcilaso de la Vega, Francisco Cervantes de Salazar, Baldomero Lillo. Entonces, se detectan las secciones mediante las cuales se articula la oferta del CLLyC en soporte digital y se detallan a continuación.

\section{Sección de obras y autores bloomianos}

Jorge L. Borges (1899-1986)

El Aleph

Ficciones

El hacedor

Historia Universal de la infamia

Pablo Neruda (1904-1973)

Canto general

Julio Cortázar (1914-1984)

Historias de cronopios y de famas

Las armas secretas

Libro de Manuel

Final de juego

Los premios

Gabriel García Márquez (1927-2014) La hojarasca

La mala hora

Miguel Ángel Asturias (1899-1974)

El señor Presidente

Son obras de autores canónicos bloomianos (y del boom de literatura latinoamericana de los 60). Todos son autores consagrados, ganadores de Premio Nobel (Asturias, Neruda y García Márquez) o ganadores del Premio Cervantes (Borges)

Rubén Darío (1867-1916)

Prosas profanas

Cantos de vida y esperanza

Tierras solares

Azul

Canto a la Argentina

Canto errante 
Estos títulos del escritor nicaragüense pertenecen al dominio público (además de ser obras de un autor canónico bloomiano).

\section{Sección de obras del canon escolar, folklore latinoamericano y} "obras morales"

Juan B. Alberdi (1810-1884) organización política de la República de Argentina

\section{El crimen de la guerra}

Estos títulos del historiador y abogado argentino pertenecen al dominio público, y, asimismo, forman parte tanto del canon escolar como de las lecturas sobre la historia de la Argentina: las Bases... constituye una lectura sobre la creación de un orden institucional argentino en el siglo XIX. El crimen de la guerra forma parte de los textos de lectura para la corriente historiográfica revisionista, que lo interpreta como texto en repudio a la Guerra del Paraguay o Guerra de la Triple Alianza (1865-1870). Otros, lo leen en clave de la Guerra Franco-Prusiana (1870-1871).

Diego Barros Arana (1830-1907)

$$
\begin{aligned}
& \text { Historia General de Chile } \\
& \text { (originalmente Historia } \\
& \text { Jeneral de Chile) }
\end{aligned}
$$

Es considerada la máxima obra historiográfica chilena del siglo XIX.

En esta sección se encontraría, Ariel, de José Enrique Rodó (1871-1917). Un ensayo de 1900 y considerado, como las obras de Juan B. Alberdi, como uno de los trabajos de mayor influencia en el campo de la cultura y de la política latinoamericanas.

El ensayo El hombre mediocre de José Ingenieros (1877-1925), si bien no forma parte del canon escolar, funciona como un ensayo de "interés filosófico" y de promover un hombre más pleno, menos individualista, con un cierto tono moral que lo emparenta con el Ariel de José E. Rodó.

Baldomero Lillo Figueroa (1867-1923) Sub Terra

Sub Sole

Miguel Cané (1851-1905) Juvenilia

El viaje

José Mármol (1817 -1871)
Amalia
Ignacio Altamirano (1834-1893)

Ricardo Palma (1833-1919)

Cirilo Villaverde (1812-1894)

Ricardo Güiraldes (1886-1927)
Clemencia

Tradiciones

Tradiciones peruanas

Cecilia Valdés o la loma del Ángel

Don Segundo Sombra

Forman parte de la llamada "literatura escolar": textos que constituyen os programas de estudio en el nivel educativo secundario de algunos países latinoamericanos (Argentina: Mármol, Güiraldes y Cané; Chile: Lillo; Cuba: Villaverde; México: Altamirano; Perú: Palma). Formaría parte de esta sección Cecilia Valdés o la loma del Ángel, de Cirilo Villaverde. Es considerada, quizá, la novela más representativa de la cubanía (identidad cultural cubana) tanto por sus temas como por su argumento; asimismo, se puede considerar la primera novela cubana. Es una novela en dos tomos, y el primero fue publicado en 1839 y su versión definitiva se publicaría en Nueva York en 1882. Algunos de estos autores, como Cané, ya eran propuestos en 1930 por parte de Henríquez Ureña en una carta a Alfonso Reyes para la lectura en el canon escolar (1983: 276).

\section{Sección de Crónicas de Indias, primeras historias de los futuros} países latinoamericanos y primeros escritos de mujeres y de costumbres

$$
\begin{array}{ll}
\text { Bernal Díaz del Castillo (1496-1584) } & \begin{array}{l}
\text { Historia verdadera de la } \\
\text { Conquista de la Nueva España. }
\end{array}
\end{array}
$$

Tuvo su primera edición impresa (póstuma) en 1632.

Hernán Cortés (1504-1547) Cartas de relación

Son cinco cartas al Rey, escritas entre 1519 y 1526 . La primera, fechada en julio de 1519, nunca se ha encontrado. La segunda y la tercera se publicaron en Sevilla (en 1522 y 1523) y la cuarta en Toledo (1525). La quinta carta quedó inédita hasta 1842.

Francisco López de Gómara (1511-1566) Historia Gral. de las Indias

Relata los acontecimientos sucedidos durante la conquista de México. Su primera impresión se realizó en diciembre 1552 en Zaragoza.

Francisco Cervantes de Salazar (1518-1575) Crónica de Nueva España. 
Escrita entre 1555 y 1565 (fue encontrada en 1914 en la Biblioteca Nacional de España, con lo que todas las ediciones son posteriores a esa fecha).

Pedro Cieza de León (1518-1554)

Crónica de Perú; Señoríos de los incas. Segunda parte de la Crónica del Perú.

Crónica de Perú: escrita en tres partes, de las que solo la primera se publicó en vida de su autor en 1553 y las otras dos partes quedaron inéditas hasta los siglos XIX y XX respectivamente.

Señorios de los incas. Segunda parte de la Crónica del Perú, que trata del señorío de los incas yupanquis y de sus grandes hechos y gobernación: Escrita, como su nombre lo indica, como la segunda parte de su Crónica, publicada por Jiménez de la Espada recién en 1881, después de sufrir distintas peripecias, como las de ser atribuida a otros autores.

Alonso Ercilla y Zúñiga (1533-1594)

La araucana

Es un poema épico culto editado en tres partes (1569, 1578 y 1589) y que relata la primera parte de la "Guerra de Arauco" entre españoles y mapuches o araucanos en el actual territorio de Chile.

Inca Garcilaso de la Vega (1539-1616)

Comentarios reales

Es un libro histórico-literario escrito por el primer escritor mestizo peruano, publicado en Lisboa en 1609.

$$
\begin{array}{ll}
\text { Sor Juana Inés de la Cruz (1651-1695) } & \text { Obras; Los empeños de } \\
\text { una casa }
\end{array}
$$

Los empeños de una casa es un drama tardobarroco en verso, aceptada como una de las obras cumbre de la literatura novohispana. Fue publicada por primera vez en 1693 (pero fue representada en teatro en 1683). La Obras proponen tanto un acercamiento a su trabajo en lírica del tardobarroco español, como a su obra dramática que va de los autos sacramentales religiosos a lo profano. Habilita lecturas desde perspectivas feministas de gran parte de su obra: Franco (1989); Sayers Peden (1982); Torras (2003); Urbano (1990). Parte de la obra de Sor Juana Inés de la Cruz también forma parte del canon escolar de algunos países latinoamericanos y de los programas de estudios de género de algunas universidades latinoamericanas, caribeñas y de EE.UU. Zanetti (1998: 92) adjudica el "olvido" canónico de dos siglos sobre la obra de Sor Juana Inés de la Cruz al rechazo académico a la estética barroca.

\section{Sección de títulos de autores que recién ingresan en dominio público}

Roberto Arlt (1900-1942)

El juguete rabioso

La inclusión de la obra más famosa de Roberto Arlt en el segmento de resultados más encontrados en formato digital puede adjudicarse a dos causas relevadas: la obra de este escritor se incorporó al dominio público el $1^{\circ}$ de enero de 2013, con lo cual su transposición a digital podría explicarse por su liberación de pagos de derechos. Asimismo, ha pasado a formar parte de los programas de enseñanza de literatura en la educación formal en la Argentina (la inclusión del autor al canon literario argentino es reciente).

\section{Leopoldo Lugones (1874-1938) \\ Las fuerzas extrañas}

Es considerado uno de los primeros libros del género de ciencia ficción y la fantasía en la Argentina. Su pertenencia al segmento de resultados más encontrados en formato digital puede adjudicarse, como en el caso de la obra de Arlt mencionada previamente, a que la obra de Lugones se incorporó al dominio público el $1^{\circ}$ de enero de 2009 , con lo cual su transposición a digital podría explicarse por su liberación de pagos de derechos en una fecha reciente, para lo cual la industria lo incorpora a sus catálogos en digital a posteriori de la liberación de derechos.

\section{Sección de narrativas de crítica social y "realismo" latinoamericano}

Carlos Montenegro (1900-1981)

Hombres sin mujer

Una novela que literaturiza relaciones homosexuales marcadas por la violencia en el marco de la vida presidiaria de Cuba, en la década del 20.

\section{Mario Benedetti (1920-2009) L L L tregua}

Retrata las costumbres y la concepción acerca de las relaciones amorosas y la sexualidad a mediados del siglo XX en una ciudad moderna latinoamericana. Es una novela de alta popularidad en el Río de la Plata: su versión cinematográfica fue la primera película argentina en competir por un Premio Oscar en 1975 en la categoría "Mejor película de habla no inglesa". La articulación entre literatura latinoamericana post-boom "ha creado nuevos públicos y nuevas posibilidades de éxito literario” (Giorgi, 2004: 174). 


\section{Sección de escritura de mujeres}

Isabel Allende (1942)

La casa de los espiritus

La escritora chilena, ligada por la crítica académica (Mizraje, 2007; Arróspide, 2002) a la literatura de mercado y a la industria bestseller, incorporada al CLLyC diseñado para esta investigación por el segmento de $L a$ gran novela latinoamericana, de Carlos Fuentes y de Latin American Women Writers: An Encyclopedia compone la élite de la oferta en digital en las plataformas y bibliotecas requeridas. La novela es un ejemplo del "realismo mágico" latinoamericano y su adaptación cinematográfica fue un éxito en taquillas, así como resultó merecedora de múltiples premios: en festival de cine de Baviera; en el festival de cine de Alemania y el Golden Screen de Alemania; y en el Festival Internacional del Nuevo Cine Latinoamericano de La Habana, entre otros. Como marcamos anteriormente, la combinación de literatura y cine en el marco de la fórmula del "realismo mágico" permite la ampliación de públicos y "nuevas posibilidades de éxito literario" (Giorgi, 2004: 124). Isabel Allende es reconocida como la primera mujer latinoamericana que accede al éxito internacional en la "escena de la gran literatura" a gran escala (García Pinto, 2004: 54). Esta novela es, además, la única escrita y editada en la etapa post dictaduras de la región. Isabel Allende, asimismo, es la escritora más joven de este segmento con más presencias en los resultados de las búsquedas: nació en 1942, además de ser la única escritora viva de los treinta escritores de la élite.

En esta sección también se incorporarían los títulos de Sor Juana Inés de la Cruz descritos previamente

\section{Sintetizando la búsqueda por secciones}

Los títulos que componen este segmento de la literatura latinoamericana y caribeña en digital son textos que exhiben una actitud fundacional (historias de la Conquista y de las etapas fundacionales de algunos de los países o del orden jurídico). El 56\% de ellos pertenecen al dominio público.

No hay presencia entre los títulos más relevados en digital de obras vinculadas a la narrativa post dictaduras, atravesada por distintos géneros y formatos vinculados con el documental/documento, lo autobiográfico, el nonfiction y la narrativa testimonial, la fragmentación como procedimiento o la parodia. Tampoco hallamos obras de escritores caribeños y de las Guayanas.

Hay presencias de voces silenciadas, como es el caso de las obras de Sor Juana Inés de la Cruz y de títulos de autores que fueron negados por los propios cánones literarios nacionales, como es el caso de la obra de Roberto Arlt. Además, de temáticas que implican una inmersión en temas ligados a la homosexualidad como es el caso de la novela Hombres sin mujer de Carlos Montenegro.

En comparación con los títulos hallados en soporte impreso, destacamos especialmente que los títulos de algunos autores canónicos que comparten la élite en los resultados de las búsquedas en ambos soportes no coinciden en ambos hallazgos (en ambas tablas):

- En el caso de Julio Cortázar, los títulos más hallados en papel son Bestiario, Las armas secretas y Octaedro. Y para el mismo autor en soporte digital el título más hallado en las búsquedas es Los premios.

- Otro tanto sucede con los títulos de Jorge L. Borges. En soporte impreso se destacan El Aleph, Ficciones, Inquisiciones y Obras completas. En digital se destacan El Aleph, El hacedor e Historia universal de la infamia. Solo coincide en ambos soportes el ultracanónico Ficciones.

- En el caso de Pablo Neruda se destaca en soporte impreso su poemario 20 poemas de amor y una canción desesperada, pero en digital el título que forma parte de los resultados más altos de las búsquedas es Canto general.

- Y en el caso de los títulos de Miguel Ángel Asturias, en soporte impreso se relevan Leyendas de Guatemala, Hombres de maíz y Weekend en Guatemala y en digital El Señor Presidente.

- Además, tampoco coinciden los autores bloomianos más presentes en los resultados de las búsquedas: 
- En soporte impreso Mario Vargas Llosa, Reinaldo Arenas, José Donoso y Alejo Carpentier forman parte del lote superior. En digital no aparece ninguno de ellos entre los resultados más altos.

- Pero sí se destaca en digital la presencia de la obra de Rubén Darío y de Gabriel García Márquez.

- En los resultados de las búsquedas en soporte impreso no se destacan títulos de la Sección de Crónicas de Indias, primeras historias de los futuros países latinoamericanos y primero escritos de mujeres y de costumbres que detallamos en los resultados más destacados de las búsquedas en soporte digital.

- En los resultados de las búsquedas en soporte digital no se destaca una sección de títulos de escritores de la generación McOndo y de las ediciones cartoneras latinoamericanas.

- Tampoco,en los resultados de las búsquedas, en ambos soportes, se destaca la presencia de autores caribeños del CLLyC en los segmentos de mayor relevancia.

- Finalmente y, en especial, los cincuenta títulos del CLLyC que más aparecen en digital funcionan como un canon de hecho, un canon oculto, articulado por la combinación de estrategias de puesta en digital y por la disposición de los títulos de los autores que mencionamos mediante el agrupamiento en las secciones que describimos previamente.

\subsubsection{Los primeros cincuenta autores que aparecen en impreso}

\begin{tabular}{|c|c|c|}
\hline Autor & Fuentes & Pape \\
\hline Allende, Isabel & 3 & 13 \\
\hline \begin{tabular}{|l|} 
Arlt, Roberto \\
\end{tabular} & 2,14 & 13 \\
\hline Borges, Jorge Luis & $1,2,3,14$ & 13 \\
\hline Roncagliolo, Santiago & $3,8,12$ & \\
\hline Altamirano, Ignacio Manuel & 2,14 & 12 \\
\hline Asturias, Miguel Ángel & $1,2,14$ & 12 \\
\hline Conti, Haroldo & 2,14 & 12 \\
\hline Neruda, Pablo & $1,2,14$ & 12 \\
\hline Palma, Ricardo & 2,14 & 12 \\
\hline Velasco, Xavier & 3 & 12 \\
\hline Adán, Martín & $2,12,14$ & 11 \\
\hline Balboa, Silvestre de & 2 & 11 \\
\hline Bayly, Jaime & 6 & 11 \\
\hline Bellatin, Mario & 12 & 111 \\
\hline Bolaño, Roberto & 6 & 11 \\
\hline Bombal, María Luisa & 2,14 & 11 \\
\hline Cabrera, Lydia & $2,13,14$ & 11 \\
\hline Cané, Miguel & 2,14 & 11 \\
\hline Cortázar, Julio & $1,2,3,14$ & 11 \\
\hline 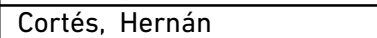 & 2 & $\mid 11$ \\
\hline Darío, Rubén & $1,2,14,3$ & 11 \\
\hline Di Benedetto, Antonio & 2,14 & 11 \\
\hline Díaz del Castillo, Bernal & 2 & 11 \\
\hline Juarroz, Roberto & 2,14 & 11 \\
\hline Piglia, Ricardo & $3,14,12$ & 11 \\
\hline
\end{tabular}

\begin{tabular}{|l|l|l|}
\hline Autor & Fuentes & Papel \\
\hline Rulfo, Juan & $2,3,14$ & 11 \\
\hline Acevedo Díaz, Eduardo & 2,14 & 10 \\
\hline Aguirre, Nataniel & 2,14 & 10 \\
\hline Alegría, Ciro & 2,14 & 10 \\
\hline Amado, Jorge & 2,14 & 10 \\
\hline Arturo, Aurelio & 14 & 10 \\
\hline Balbuena, Bernardo de & 2 & 10 \\
\hline Cabrera Infante, Guillermo & $1,13,14,2$ & 10 \\
\hline Cambaceres, Eugenio & 2,14 & 10 \\
\hline Carriego, Evaristo & 2,14 & 10 \\
\hline Celorio, Gonzalo & 3 & 10 \\
\hline Corcuera, Arturo & 2,14 & 10 \\
\hline Dononoso, José & $1,2,3,14,11$ & 10 \\
\hline Freyre, Gilberto & 2,14 & 10 \\
\hline Frías, Heriberto & 2,14 & 10 \\
\hline Glantz, Margo & 3,12 & 10 \\
\hline Gutiérrez, Pedro Juan & 13 & 10 \\
\hline Ingenieros, José & 2,14 & 10 \\
\hline López de Gómara, Francisco & 2 & 10 \\
\hline López, Alejandro & 12 & 10 \\
\hline Padilla, Ignacio & 3,9 & 10 \\
\hline Parra, Teresa de la & 2,14 & 10 \\
\hline Porchia, Antonio & 2 & 10 \\
\hline Rejtman, Martín & 6 & 10 \\
\hline Sarduy, Severo & $1,2,13,14$ & 10 \\
\hline
\end{tabular}

Tabla 25. Los cincuenta autores que más aparecen en soporte impreso. ${ }^{20}$ Elaboración propia. 
En el nivel de autores, la oferta de las plataformas y bibliotecas de los títulos relevados en soporte impreso estaría estructurada de la siguiente manera:

a) En los niveles más altos de la oferta conviven autores del canon de Bloom como Alejo Carpentier, Mario Vargas Llosa, Jorge Luis Borges, Julio Cortázar, Rubén Darío, Gabrie García Márquez, Miguel Ángel Asturias, José Donoso, Carlos Fuentes, César Vallejo, Vargas Llosa, Pablo Neruda, Severo Sarduy, Reinaldo Arenas, con autores cuyas obras se encuentran en dominio público, como Ricardo Palma, Horacio Quiroga, Eugenio Cambaceres, Miguel Cané, Evaristo Carriego, Roberto Arlt, Mariano Azuela, Alcides Arguedas, López de Gómara, José Ingenieros.

b) Se destaca la presencia de Santiago Roncagliolo (un autor de la matriz de la Generación McOndo y autor de ediciones cartoneras) entre los autores destacados en las búsquedas en impreso y de Ignacio Padilla, un escritor del Crack.

c) Completa la élite de autores hallados en soporte impreso en las búsquedas la escritora Isabel Allende, ligada por la crítica al aparato de superventas y la industria bestseller, incorporada al CLLyC diseñado para esta investigación por el segmento de $\mathrm{La}$ gran novela latinoamericana, de Carlos Fuentes.

d) Adolfo Bioy Casares, Mario Benedetti, Manuel Puig, Sergio Pitol, Juan Filloy, Rosario Castellanos, Salvador Elizondo y Haroldo Conti son autores que componen una muestra de la oferta más destacada en soporte impreso en las plataformas y bibliotecas requeridas y que representarían un estadio medio-alto de la oferta.
4.1.6. Un recorte más amplio: un análisis de la disposición en soporte digital sobre los 193 títulos que más aparecen (de diez a siete veces sobre trece plataformas) sobre los resultados en las búsquedas en plataformas comerciales internacionales y servicios de intercambio de documentos ${ }^{21}$

\begin{tabular}{|c|c|c|c|c|}
\hline Autor & Obra & Fuentes & (;) & 를 \\
\hline Altamirano, Ignacio Manuel & Clemencia & 2 & 11 & 06 \\
\hline Nervo, Amado & Los jardines interiores & 2,14 & 11 & 05 \\
\hline Aguinis, Marcos & La gesta del marrano & 14 & 10 & 05 \\
\hline Alberdi, Juan Bautista & Bases y puntos de partida para la organización polititca.. & 2,14 & 10 & 03 \\
\hline Benedetti, Mario & La tregua & 2,14 & 10 & 06 \\
\hline Borges, Jorge Luis & El Aleph & $1,2,3,14$ & 10 & 06 \\
\hline Darío, Rubén & Prosas profanas & 2,3 & 10 & 04 \\
\hline Lillo, Baldomero & Sub Terra & 2,14 & 10 & 05 \\
\hline Lugones, Leopoldo & Cuentos fatales & 2,14 & 10 & 05 \\
\hline Mármol, José & Amalia & 2 & 10 & 07 \\
\hline Nervo, Amado & Místicas & 2 & 10 & 04 \\
\hline Palma, Ricardo & Tradiciones & 2 & 10 & 07 \\
\hline Quiroga, Horacio & Cuentos de amor, de locura y de muerte & 2 & 10 & 05 \\
\hline Rodó, José Enrique & Ariel & 2,14 & 10 & 06 \\
\hline $\begin{array}{l}\text { Villaverde, Cirilo } \\
\end{array}$ & Cecilia Valdés & 2,14 & 10 & 06 \\
\hline Acevedo Díaz, Eduardo & Brenda & 14 & 09 & 03 \\
\hline Aguinis, Marcos & La cruz invertida & 14 & 09 & 06 \\
\hline Alberdi, Juan Bautista & El crimen de la guerra & 2,14 & 09 & 05 \\
\hline Allende, Isabel & La casa de los espíritus & 3 & 09 & 07 \\
\hline Asturias, Miguel Ángel & El señor Presidente & 2,14 & 09 & 06 \\
\hline Barros Arana, Diego & Historia general de Chile & 2,14 & 09 & 04 \\
\hline Blest Gana, Alberto & Martín Rivas & 14 & 09 & 05 \\
\hline Borges, Jorge Luis & El Hacedor & $1,2,14$ & 09 & 05 \\
\hline Borges, Jorge Luis & Ficciones & $1,2,3,14$ & 09 & 06 \\
\hline Borges, Jorge Luis & Historia universal de la infamia & $2,3,14$ & 09 & 06 \\
\hline Cieza de León, Pedro & Crónica del Perú & 2 & 09 & 04 \\
\hline Cortázar, Julio & Final del juego & 2 & 09 & 05 \\
\hline Cortázar, Julio & Historias de cronopios y de famas & 2,14 & 09 & 06 \\
\hline Cortázar, Julio & Los premios & 2,14 & 09 & 04 \\
\hline Cortázar, Julio & Rayuela & $1,2,3,14$ & 09 & 05 \\
\hline Cruz, Sor Juana Inés de la & Obras & 2 & 09 & 06 \\
\hline Darío, Rubén & Canto errante & 2 & 09 & 02 \\
\hline $\begin{array}{l}\text { Dario, Rubén } \\
\end{array}$ & Cantos de vida y de esperanza & $2,3,14$ & 09 & 05 \\
\hline Darío, Rubén & Tierras solares & 2,14 & 09 & 02 \\
\hline Edwards, Jorge & Persona non grata & 2,14 & 09 & 06 \\
\hline Fuentes, Carlos & Aura & 2 & 09 & 07 \\
\hline García Márquez, Gabriel & Cien años de soledad & $1,2,3,14$ & 09 & 06 \\
\hline García Márquez, Gabriel & La hojarasca & 2,14 & 09 & 05 \\
\hline García Márquez, Gabriel & La Mala Hora & 2,14 & 09 & 06 \\
\hline García Márquez, Gabriel & Relato de un náufrago & 2,14 & 09 & 06 \\
\hline $\begin{array}{l}\text { Garcilaso de la Vega } \\
\end{array}$ & Comentarios reales & 2 & 09 & 07 \\
\hline Gómez de Avellaneda, Gertrudis & Espatolino & 2 & 09 & 02 \\
\hline Ingenieros, José & El hombre mediocre & 2,14 & 09 & 06 \\
\hline Las Casas, Bartolomé de & Historia de las Indias & 2 & 09 & 03 \\
\hline Lillo, Baldomero & Sub sole & 2 & 09 & 05 \\
\hline López de Gómara, Francisco & Historia general de las Indias & 2 & 09 & 05 \\
\hline Lugones, Leopoldo & Las fuerza & 2,14 & 09 & 06 \\
\hline Montenegro, Carlosdiecio & 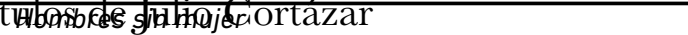 & 2,13 & 09 & 04 \\
\hline
\end{tabular}

${ }^{21}$ Se recorta el universo de títulos disponibles en digital en plataformas y en servicios de intercambio de documentos. 


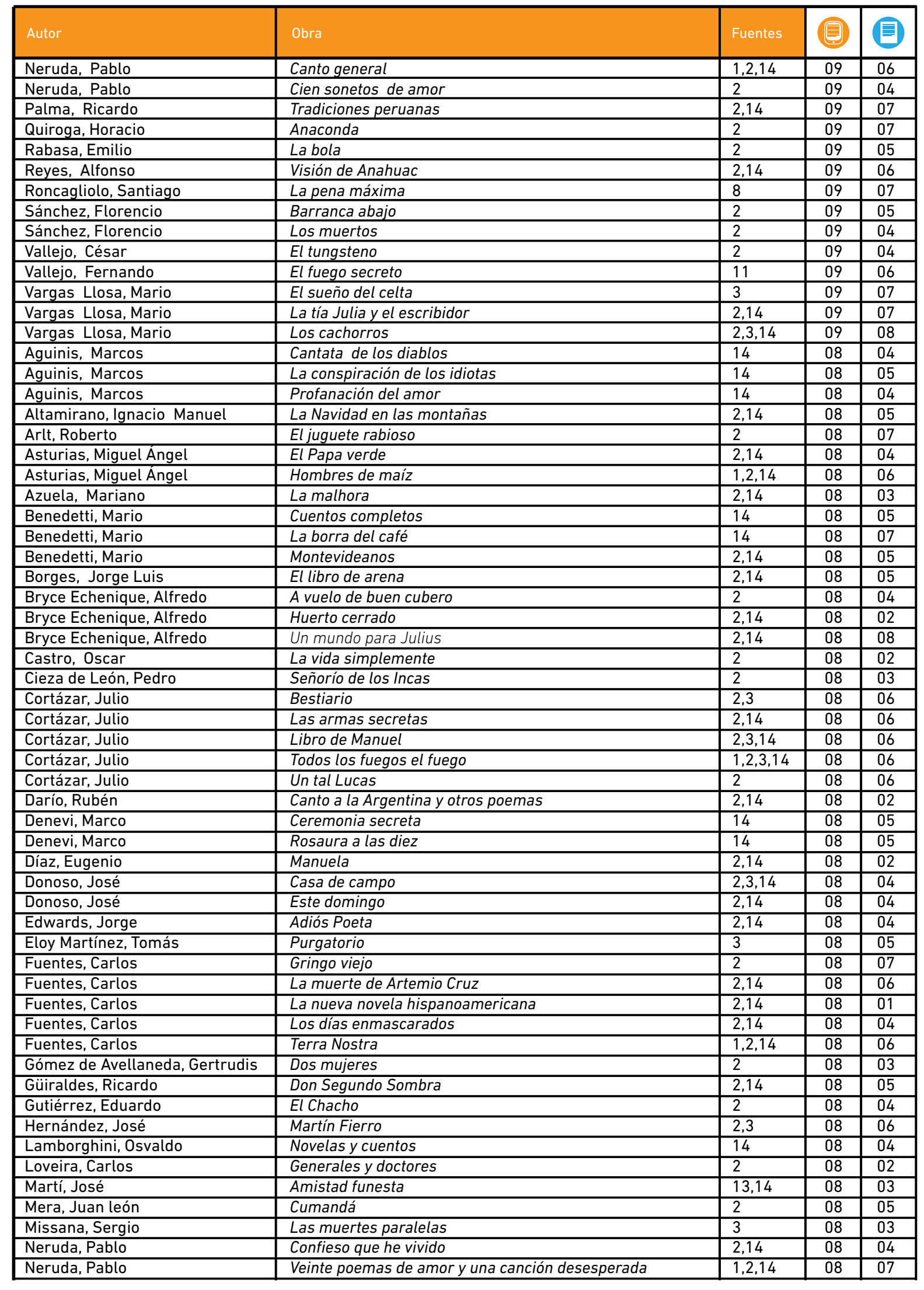

\begin{tabular}{|c|c|c|c|c|}
\hline Autor & Obra & Fuentes & (:) & 言 \\
\hline Ocampo, Silvina & Autobiografía de Irene & 2,14 & 08 & 04 \\
\hline Padilla, Ignacio & Amphitryon & 3 & 08 & 06 \\
\hline Palma, Ricardo & Neologismos y americanismos & 2,14 & 08 & 04 \\
\hline Puig, Manuel & Boquitas pintadas & 2,14 & 08 & 06 \\
\hline Puig, Manuel & El beso de la mujer araña & 2,14 & 08 & 06 \\
\hline Puig, Manuel & La traición de Rita Hayworth & 2,14 & 08 & 04 \\
\hline Ramírez Mercado, Sergio & Adiós muchachos & 3 & 08 & 04 \\
\hline Ramírez Mercado, Sergio & Catalina y Catalina & 3 & 08 & \\
\hline Rejtman, Martín & Velcro y yo & 6 & 08 & 05 \\
\hline Rivera Garza, Cristina & Nadie me verá llorar & 3 & 08 & \\
\hline Roncagliolo, Santiago & Pudor & $\begin{array}{r}8 \\
8\end{array}$ & 08 & \begin{tabular}{|l|l|}
07 \\
07
\end{tabular} \\
\hline Sabato, Ernesto & El túnel & 2,14 & 08 & 06 \\
\hline Sánchez, Florencio & Lagringa & 2 & 08 & 04 \\
\hline Santiago, Esmeralda & Conquistadora & 13 & 08 & 05 \\
\hline Sarmiento, Domingo Faustino & El Chacho & 2 & 08 & 04 \\
\hline Sarmiento, Domingo Faustino & Recuerdos de provincia & 2,14 & 08 & 04 \\
\hline Solares, Ignacio & Columbus & 3 & 08 & 03 \\
\hline Solares, Ignacio & La invasión & 3 & 08 & 05 \\
\hline Valdelomar, Abraham & El caballero Carmelo & 2 & 08 & 04 \\
\hline Vargas Llosa, Mario & Conversación en la catedral & $2,3,14$ & 08 & 07 \\
\hline Vargas Llosa, Mario & La casa verde & 3,14 & 08 & 06 \\
\hline Vargas Llosa, Mario & La fiesta del chivo & 3 & 08 & 06 \\
\hline Vargas Llosa, Mario & Lituma de los Andes & & 08 & 05 \\
\hline Vargas Llosa, Mario & Los jefes & 2,14 & 08 & 07 \\
\hline Villoro, Juan & El testigo & 3 & 08 & 05 \\
\hline Volpi, Jorge & La tejedora de sombras & 9 & 08 & 07 \\
\hline Zaid, Gabriel & Cómo leer en bicicleta & 2,14 & 08 & 06 \\
\hline Zaid, Gabriel & La poesía & 2,14 & 08 & 04 \\
\hline Zaid, Gabriel & Los demasiados libros & 2,14 & 08 & 07 \\
\hline Agustín, José & La tumba & 3 & 07 & 04 \\
\hline Alberto, Eliseo & Caracol Beach & 13 & 07 & 06 \\
\hline Benedetti, Mario & Primavera con una esquina rota & 2 & 07 & 07 \\
\hline Bolívar, Simón & Carta de Jamaica & 14 & 07 & 04 \\
\hline Bryce Echenique, Alfredo & La felicidad ja ja & 2,14 & 07 & 03 \\
\hline Bryce Echenique, Alfredo & Tantas veces Pedro & 2,14 & 07 & 04 \\
\hline Cané, Miguel & El viaje & 2 & 07 & 05 \\
\hline Cané, Miguel & Juvenilia & 2,14 & 07 & 06 \\
\hline Castellanos, Rosario & Ciudad Real & 2 & 07 & 05 \\
\hline Castillo, Abelardo & Cuentos completos & 14 & 07 & 04 \\
\hline Celorio, Gonzalo & Tres lindas cubanas & 3 & 07 & 06 \\
\hline Cortázar, Julio & 62 modelo para armar & $2,3,14$ & 07 & 06 \\
\hline Cortázar, Julio & Alguien que anda por ahí & 2,14 & 07 & 05 \\
\hline Cortázar, Julio & Deshoras & 14 & 07 & 04 \\
\hline Cortázar, Julio & Divertimento & 14 & 07 & 05 \\
\hline Cortázar, Julio & El examen & 14 & 07 & 02 \\
\hline Cortázar, Julio & La vuelta al día en ochenta mundos & 2,14 & 07 & 06 \\
\hline Cortázar, Julio & Los reyes & 2,14 & 07 & 04 \\
\hline Cortázar, Julio & Octaedro & 2,14 & 07 & 06 \\
\hline Cortázar, Julio & Queremos tanto a Glenda & 2,14 & 07 & 06 \\
\hline Cruz, Sor Juana Inés de la & Carta Athenagórica & 2 & 07 & 03 \\
\hline Cruz, Sor Juana Inés de la & Los empeños de una casa & 2 & 07 & 04 \\
\hline Cruz, Sor Juana Inés de la & Respuesta a sor filotea de la Cruz & 2 & 07 & 03 \\
\hline Darío, Rubén & Azul & 2 & 07 & 03 \\
\hline Delgado, Rafael & Angelina & 2,14 & 07 & 04 \\
\hline Díaz del Castillo, Bernal & Historia verdadera de la conquista de la Nueva España & & 07 & 06 \\
\hline Donoso, José & El lugar sin límites & $2,3,11,14$ & 07 & 05 \\
\hline Donoso, José & El Mocho & 2,14 & 07 & \\
\hline Donoso, José & La misteriosa desaparición de la m & 2,14 & 07 & \\
\hline Donoso, José & Poemas de un novelista & 14 & 07 & 03 \\
\hline Eloy Martínez, Tomás & Santa Evita & 3,14 & 07 & 04 \\
\hline
\end{tabular}




\begin{tabular}{|c|c|c|c|c|}
\hline Autor & Obra & Fuentes & (:) & 를 \\
\hline Emar, Juan & Miltin & 2 & 07 & 04 \\
\hline Ercilla y Zúñiga, Alonso de & La araucana & 2 & 07 & 03 \\
\hline Estrada, Genaro & Pero Galín & 2 & 07 & 02 \\
\hline Fuentes, Carlos & Cambio de piel & 1,2 & 07 & 06 \\
\hline Fuentes, Carlos & Casa con dos puertas & & 07 & 01 \\
\hline Fuentes, Carlos & Cristóbal Nonato & 2,14 & 07 & 06 \\
\hline Fuentes, Carlos & Diana o la cazadora solitaria & 2,14 & 07 & 06 \\
\hline Fuentes, Carlos & El espejo enterrado & 2,14 & 07 & 05 \\
\hline Fuentes, Carlos & La cabeza de la Hidra & & 07 & 03 \\
\hline Fuentes, Carlos & La frontera de cristal & 2,14 & 07 & 07 \\
\hline Galeano, Eduardo & Memoria del fuego & 14 & 07 & 05 \\
\hline Gamboa, Federico & Santa & $2,3,14$ & 07 & 06 \\
\hline Garro, Elena & Los recuerdos del porvenir & 2 & 07 & \\
\hline Gómez de Avellaneda, Gertrudis & Guatimozín & 2 & 07 & 03 \\
\hline Gómez de Avellaneda, Gertrudis & La hija de las flores & 2 & 07 & 02 \\
\hline Gorostiza, Manuel Eduardo & Contigo pan y cebolla & 2 & 07 & 05 \\
\hline Gutiérrez, Eduardo & Juan Moreira & 2,14 & 07 & 05 \\
\hline Halfón, Eduardo & El ángel literario & 8 & 07 & 03 \\
\hline Huidobro, Vicente & Sátiro o el poder de las palabras & 2,14 & 07 & 01 \\
\hline Ibargüengoitia, Jorge & Estas ruinas que ves & 2,14 & 07 & 04 \\
\hline Ingenieros, José & Las fuerzas morales & 2 & 07 & 04 \\
\hline Iparraguirre, Sylvia & El muchacho de los senos de goma & 3 & 07 & 03 \\
\hline Ixtlilxochitl, Fernando de Alva & Historia chichimeca & 2 & 07 & 03 \\
\hline Lamborghini, Osvaldo & Poemas & 14 & 07 & 03 \\
\hline Las Casas, Bartolomé de & Brevísima relación de la destrucción de las Indias & & 07 & 05 \\
\hline Martí, José & Amor con amor se paga & 13 & 07 & 03 \\
\hline Martí, José & Ismaelillo & $2,13,14$ & 07 & 05 \\
\hline Martí, José & Versos sencillos & $2,13,14$ & 07 & 05 \\
\hline Mitre, Bartolomé & Rimas & 2,14 & 07 & 02 \\
\hline Montero, Mayra & Púrpura profundo & 13 & 07 & 04 \\
\hline Neruda, Pablo & Para nacer he nacido & 2 & 07 & 04 \\
\hline Nettel, Guadalupe & El cuerpo en que nací & 8 & 07 & 05 \\
\hline
\end{tabular}

Tabla 26. Los 193 títulos que más aparecen en ofertas en digital en plataformas comerciales y servicios de lectura en streaming y descarga de los titulos y autores del CLLyC. Elaboración propia

- catorce títulos de Carlos Fuentes

- nueve títulos de José Donoso

- ocho títulos de Mario Vargas Llosa

- seis títulos de Rubén Darío

- cinco títulos de Jorge Luis Borges

- cinco títulos de Mario Benedetti

- cinco títulos de Marcos Aguinis

- cinco títulos de Sor Juana Inés de la Cruz
- cuatro títulos de Pablo Neruda

- cuatro títulos de Gabriel García Márquez

- cuatro títulos de Gabriel Zaid

- cuatro títulos de Manuel Puig

- tres títulos de,Florencio Sánchez

- tres títulos de Ricardo Palma

- tres títulos de Ricardo Güiraldes

- tres títulos de Gertrudis Gómez de Avellaneda

- tres títulos de Alfredo Bryce Echenique

- tres títulos de Miguel Ángel Asturias

- dos títulos de Ignacio Solares

- dos títulos de Domingo Faustino Sarmiento

- dos títulos de Horacio Quiroga

- dos títulos de Amado Nervo

- dos títulos de Leopoldo Lugones

- dos títulos de Baldomero Lillo

- dos títulos de José Ingenieros

- dos títulos de José Hernández

- dos títulos de Elena Garro

- dos títulos de Jorge Edwards

- dos títulos de Marco Denevi

- dos títulos de Pedro Cieza de León

- dos títulos de Ignacio Manuel Altamirano

- dos títulos de Juan Bautista Alberdi 
- dos títulos de José Agustín

- dos títulos de Santiago Roncagliolo

- un título de Juan José Arreola

- un título de Agustín Yáñez

- un título de Jorge Volpi

- un título de Juan Villoro

- un título de Cirilo Villaverde

- un título de Xavier Velasco

- un título de Fernando Vallejo

- un título de César Vallejo

- un título de Abraham Valdelomar

- un título de Osvaldo Soriano

- un título de Esmeralda Santiago

- un título de José Enrique Rodó

- un título de Cristina Rivera Garza

- un título de Alfonso Reyes

- un título de Efrén Rebolledo

- un título de Sergio Ramírez

- un título de Emilio Rabasa

- un título de Ignacio Padilla

- un título de Silvina Ocampo

- un título de Guadalupe Nettel

- un título de Carlos Montenegro

- un título de Sergio Missana
- un título de Juan león Mera

- un título de Tomas Eloy Martínez

- un título de José Pedro Mármol

- un título de Francisco López de Gómara

- un título de Bartolomé de Las Casas

- un título de Osvaldo Lamborghini

- un título de Sylvia Iparraguirre

- un título de Jorge Ibargüengoitia

- un título de Eduardo Gutiérrez

- un título de Garcilaso de la Vega

- un título de Federico Gamboa

- un título de Eduardo Galeano

- un título de Genaro Estrada

- un título de Alonso de Ercilla y Zúñiga

- un título de Juan Emar

- un título de Eugenio Díaz

- un título de Bernal Díaz del Castillo

- un título de Rafael Delgado

- un título de Gonzalo Celorio

- un título de Oscar Castro

- un título de Abelardo Castillo

- un título de Rosario Castellanos

- un título de Miguel Cané

- un título de Simón Bolívar 
- un título de Alberto Blest Gana

- un título de Diego Barros Arana

- un título de Mariano Azuela

- un título de Roberto Arlt

- un título de Eduardo Anguita

- un título de Isabel Allende

- un título de Mayra Montero

- un título de Bartolomé Mitre

- un título de Fernando de Alva Cortés Ixtlilxóchitl

- un título de Vicente Huidobro

- un título de Eduardo Acevedo Díaz

Analizando este recorte más amplio de la oferta de los títulos del CLLyC elaborado, podemos destacar que se sostiene la tendencia a construir la oferta desde estrategias que incluyen primero los títulos de los autores del canon bloomiano: Julio Cortázar, Carlos Fuentes, Mario Vargas Llosa, José Donoso, Jorge L. Borges y Rubén Darío constituyen la élite por cantidad de títulos dispuestos en digital. Luego, Gabriel García Márquez, Pablo Neruda y Miguel Ángel Asturias también se encuentran en el lote superior.

Posteriormente, marcamos una "clase media" de la oferta con la presencia de Sor Juana Inés de la Cruz, Mario Benedetti, Marcos Aguinis, Gabriel Zaid y Manuel Puig, José Agustín, Santiago Roncagliolo, Marco Denevi, etc.

La sección de obras del canon escolar, folklore latinoamericano y "obras morales" sigue en la zona media/media alta de la oferta con títulos de Florencio Sánchez, Ricardo Palma, Ricardo Güiraldes, Gertrudis Gómez de Avellaneda.

Luego viene un lote que incluye tanto autores de la sección de Crónicas de Indias, primeras historias de los futuros países latinoamericanos y primeros escritos de mujeres y de costumbres como de la sección de obra del canon escolar, folklore y "obras morales": Pedro Cieza de León, Ercilla y Zúñiga, Bernal Díaz del Castillo, Ignacio Solares, Inca Garcilaso de la Vega, Domingo F. Sarmiento, Horacio Quiroga, Amado Nervo, Leopoldo
Lugones, Baldomero Lillo Figueroa, José Ingenieros, José Hernández, Jorge Edwards, Juan B. Alberdi.

Dentro de los 200 títulos más presentes en digital, la sección de obras escritas por mujeres está repartida entre los cinco títulos de Sor Juana Inés de la Cruz, tres títulos de Gertrudis Gómez de Avellaneda, dos títulos de Elena Garro, un título de Sylvia Iparraguirre, un título de Silvina Ocampo, un título de Cristina Rivera Garza, un título de Guadalupe Nettel, un título de Isabel Allende.

Las secciones de narrativas de crítica social y "realismo" latinoamericano y de de títulos de autores que recién ingresan en dominio público no tienen una presencia destacable en este recorte. 
4.1.6.2. Un análisis de la disposición en soporte digital sobre los 18 títulos que más aparecen (de cuatro a cinco veces sobre ocho

bibliotecas) en los resultados en las búsquedas en bibliotecas ${ }^{21}$

\begin{tabular}{|c|c|c|c|}
\hline Autor & Obra & Fuentes & (- \\
\hline Cieza de León, Pedro & Crónica del Perú & 2 & 05 \\
\hline Ercilla y Zúñinga, Alonso de & La araucana & 2 & 05 \\
\hline Agustini, Delmira & Los cálices vacíos & $\frac{2}{2}$ & 04 \\
\hline Alberdi, Juan Bautista & El crimen de la guerra & 2,14 & 04 \\
\hline Alberdi, Juan Bautista & $\begin{array}{l}\text { Peregrinación de luz del día, o Viaje y aventuras de la } \\
\text { verdad en el Nuevo Mundo }\end{array}$ & 2 & 04 \\
\hline Altamirano, Ignacio Manuel & El Zarco & 2,14 & 04 \\
\hline Ascasubi, Hilario & Santos Vega & 2 & 04 \\
\hline Bobadilla, Emilio & A fuego lento & 2 & 04 \\
\hline Bobadilla, Emilio & Sintiéndome vivir & 2 & 04 \\
\hline Cambaceres, Eugenio & En la sangre & 2,14 & 04 \\
\hline Cambaceres, Eugenio & Música sentimental & 2,14 & 04 \\
\hline Cané, Miguel & Juvenilia & $\frac{2,14}{2,14}$ & 04 \\
\hline Carpio, Manuel & $\frac{1 \text { Juvinida }}{\text { Poesías }}$ & $\frac{2,14}{2}$ & $\frac{04}{04}$ \\
\hline Carriego, Evaristo & Misas herejes & 2,14 & 04 \\
\hline Cervantes de Salazar, Francisco & Crónica de Nueva España & 2 & 04 \\
\hline Cortés, Hernán & Cartas de relación & $\frac{2}{2}$ & 04 \\
\hline Díaz del Castillo, Bernal & Historia verdadera de la conquista de la Nueva España & 2 & 04 \\
\hline Mármol, José & Amalia & $\frac{2}{2}$ & 04 \\
\hline
\end{tabular}

Tabla 27. Los

dieciocho títulos En el nivel de la oferta de títulos en digital en bibliotecas se destaca que más aparecen que, de los primeros dieciocho títulos más presentes en digital (aquellos que en ofertas en digital están en más del $50 \%$ de las bibliotecas), el total de las obras pertenece a en bibliotecas de los obras que están en dominio público. Sobre 4.842 títulos en digital, solo los títulos y autores del 18 títulos de la Tabla 27 aparecen en más del 50\% de las bibliotecas (en este $C L L y C$. Elabora- caso, en cuatro o cinco bibliotecas). Y, de esa élite, son dos títulos aparecen

ción propia en las búsquedas en digital en cinco bibliotecas: Crónica del Perú, de Pedro Cieza de León y La araucana de Alonso de Ercilla y Zúñiga. Remarcamos que la Crónica del Perú, de Pedro Cieza de León y Amalia de José Mármol son los dos títulos más presentes en impreso (en 14 bibliotecas y plataformas). Esta última obra de José Mármol también es una de las dieciocho que componen la lista de obras más presentes en digital.

La preeminencia en la oferta de títulos más presentes en bibliotecas en digital parece ser la de obras en dominio público pertenecientes a la sección de Crónicas de Indias y primeras historias de los futuros países latinoamericanos (en este caso, no se encuentran presentes los primeros escritos de mujeres y de costumbres, tales como los títulos de Sor Juana Inés de la Cruz). A la Crónica de Perú de Pedro Cieza de León y el poema épico culto La araucana de Alonso Ercilla y Zúñiga, ya mencionadas, se suman Historia verdadera de la Conquista de la Nueva España de Bernal Díaz del Castillo, Cartas de relación de Hernán Cortés y la Crónica de Nueva España de Francisco Cervantes de Salazar.

${ }^{21}$ Se recorta el universo de títulos disponibles en digital en bibliotecas a aquellos que aparecen en más del $50 \%$ de ellas.
Además, componen este segmento obras ligadas al canon escolar, como Juvenilia de Miguel Cané, En la sangre de Eugenio Cambaceres, o títulos relativos al folklore como el poema gauchesco Santos Vega, de Hilario Ascasubi, El Zarco de Ignacio Altamirano. Se destaca Los cálices vacios de Delmira Agustini, el único título de una escritora latinoamericana del segmento más alto de las búsquedas en bibliotecas: un poema moderno fundante de la escritura femenina latinoamericana.

Destacamos, asimismo, que en esta élite de títulos en digital hallados en las ocho bibliotecas de esta investigación no se encuentran títulos bloomianos ni de autores bloomianos, ni ligados al realismo mágico latinoamericano, ni a las propuestas de $\mathrm{McOndo}$ o del Crack, ni títulos ligados al aparato de superventas. 


\subsubsection{Los primeros cincuenta autores que aparecen en digita}

\begin{tabular}{|l|l|c|}
\hline Autor & Fuentes & Digital \\
\hline Cieza de León, Pedro & 2 & 14 \\
\hline Altamirano, Ignacio Manuel & 2,14 & 13 \\
\hline Lillo, Baldomero & 2,14 & 13 \\
\hline Barros Arana, Diego & 2,14 & 12 \\
\hline Borges, Jorge Luis & $1,2,3,14$ & 12 \\
\hline Ercilla y Zuñiga, , Alonso de & 2 & 12 \\
\hline Ingenieros, José & 2,14 & 12 \\
\hline López de Gómara, Francisco & 2 & 12 \\
\hline Díaz del Castilllo, Bernal & 2 & 11 \\
\hline Las Casas, Bartolomé de & 2 & 11 \\
\hline Neruda, Pablo & $1,2,14$ & 11 \\
\hline Palma, Ricardo & 2,14 & 11 \\
\hline Rabasa, Emilio & 2 & 11 \\
\hline Arlt, Roberto & 2,14 & 10 \\
\hline Cané, Miguel & 2,14 & 10 \\
\hline Carriego, Evaristo & 2,14 & 10 \\
\hline Cervantes de Salazar, Fco. & 2 & 10 \\
\hline Cortázzar, Jullio & $1,2,3,14$ & 10 \\
\hline Cortés, Hernán & 2 & 10 \\
\hline Cruz, Sor Juana Inés de la & 2,14 & 10 \\
\hline Garciá Márquez, Gabriel & $1,2,3,14$ & 10 \\
\hline Allende, Isabel & 3 & 09 \\
\hline Asturias, Miguel Ángel & $1,2,14$ & 09 \\
\hline Vallejo, Fernando & 11 & 09 \\
\hline Villoro, Juan & 3,12 & 09 \\
\hline
\end{tabular}

\begin{tabular}{|l|l|c|}
\hline Autor & Fuentes & Digitial \\
\hline Acevedo Díaz, Eduardo & 2,14 & 08 \\
\hline Balboa, Silvestre de & 2 & 08 \\
\hline Bobadilla, Emilio & 2 & 08 \\
\hline Bryce Echenique, Alfredo & 2,14 & 08 \\
\hline Celorio, Gonzalo & 3 & 08 \\
\hline Denevi, Marco & 14 & 08 \\
\hline Eloy Martínez, Tomás & $3,14,12$ & 08 \\
\hline Fuentes, Carlos & $1,2,14$ & 08 \\
\hline Garro, Elena & 2,14 & 08 \\
\hline Padilla, Innacio & 3,9 & 08 \\
\hline Puig, Manuel & 2,14 & 08 \\
\hline Rejman, Martín & 6 & 08 \\
\hline Rivera Garza, Cristina & 3 & 08 \\
\hline Solares, Ignacio & 3 & 08 \\
\hline Alberto, Eliseo & 13 & 07 \\
\hline Ascasubi, Hilario & 2,14 & 07 \\
\hline Cambaceres, Eugenio & 2,14 & 07 \\
\hline Carpio, Manuel & 2 & 07 \\
\hline Díaz Mirón, Salvador & 2,14 & 07 \\
\hline Donoso, José & $1,2,3,14,11$ & 07 \\
\hline Emar, Juan & 2,12 & 07 \\
\hline Estrada, Genaro & 2 & 07 \\
\hline Iparraguirre, Sylvia & 3 & 07 \\
\hline Meza, Ramón & 2 & 07 \\
\hline Ortega, Francisco & 2 & 07 \\
\hline
\end{tabular}

Tabla 28. Los cincuenta autores del corpus que más aparecen en soporte digital. ${ }^{22}$ Elaboración propia.

A nivel de los autores, la oferta de las plataformas y bibliotecas de los títulos relevados en soporte digital estaría estructurada de la siguiente manera:

a) Se destaca sobre el total de las búsquedas la presencia de títulos de autores cuyos derechos de autor pertenecen al dominio público:

Sor Juana Inés de la Cruz, Hernán Cortés, López de Gómara, Bernal Díaz del Castillo, Pedro Cieza de León, Inca Garcilaso de la Vega, Alonso de Ercilla y Zúñiga, Fray Bartolomé de Las Casas, Fernando de Alva Cortés Ixtlilxóchitl, Francisco Cervantes de Salazar, José Joaquín Fernández de Lizardi, Carlos Loveira y Chirino, Joaquim Maria Machado de Assis, Alejandro Magariños Cervantes, José Mármol, José Ingenieros, Baldomero Lillo, Miguel Cané, Leopoldo Lugones, Ricardo Güiraldes, Rubén Darío, Ricardo Palma, Juan Bautista Alberdi, Bartolomé Mitre, Diego Barros Arana, Cirilo Villaverde, José
Enrique Rodó, Ignacio Manuel Altamirano, Carlos Montenegro Quiroga, José Eugenio Díaz Castro, Domingo Faustino Sarmiento, Amado Nervo, Florencio Sánchez, Mariano Azuela, Evaristo Carriego, Eugenio Cambaceres, Miguel de Carrión, Julián de Casal, Juan Mera, Emilio Rabasa, Rafael Delgado, Federico Gamboa Iglesias, Horacio Quiroga, José Hernández.

b) Se subraya que también poseen una mayor representación en digital algunos autores del canon de Bloom como Jorge Luis Borges, Julio Cortázar, Rubén Darío, Gabriel García Márquez, Miguel Ángel Asturias, José Donoso, Carlos Fuentes, César Vallejo, Vargas Llosa, Pablo Neruda.

c) Poseen una alta oferta en soporte digital autores que provienen del Manifiesto del Crack, como Ignacio Padilla, de la generación del 72 como Tomás Eloy Martínez o del "post-boom" como Jorge Edwards. Santiago Roncagliolo, un autor aportado por McOndo y que es, a su vez, autor de ediciones cartoneras latinoamericanas también tiene un alto nivel de oferta en digital.

d) Isabel Allende, ligada por la crítica académica (Mizraje, 2007; Arróspide, 2002) al aparato de superventas y la industria bestseller, incorporada al CLLyC diseñado para esta investigación por los segmentos de La gran novela latinoamericana, de Carlos Fuentes y de Latin American Women Writers: An Enyclopedia de André y Bueno (2008) compone la élite de la oferta en digital en las plataformas y bibliotecas requeridas.

e) Completan esta élite los siguientes autores cuyos títulos en digital han sido hallados en las búsquedas: Mario Benedetti, Roberto Arlt, Fernando Vallejo, Gonzalo Celorio, Juan Villoro y Carlos Montenegro, Silvina Ocampo, Ignacio Padilla, Elena Garro, Sergio Ramírez, Alfredo Bryce Echenique, Oscar Castro, Elena Garro, Jorge Ibargüengoitia, Sergio Missana, Guadalupe Nettel.

f) Pese a la relación directa de la literatura caribeña con la industria editorial de las respectivas metrópolis y exmetrópolis -Londres, París, Ámsterdam-, no se subraya una presencia marcada dentro de los títulos más destacados en soporte digital, excepto en el caso de algunos de los escritores cubanos cuyos derechos de autor se encuentran en dominio público y ya mencionados: Martí, Villaverde, de Carrión, de Casal, Gertrudis Gómez de Avellaneda, Carlos Loveira y Chirino. ${ }^{23}$ 
g) De los cuarenta títulos que aparecen en los primeros puestos de las búsquedas realizadas (las obras que aparecen 13, 12 y 11 veces en las respectivas plataformas y bibliotecas), veintisiete son títulos de autores cuyas obras están en dominio público, nueve títulos son de autores del canon de Bloom y un título es un bestseller de Isabel Allende. Tres de ellos son títulos del canon de Bloom.

\subsubsection{Los primeros cincuenta títulos que aparecen en plataformas} latinoamericanas (ambos soportes)

\begin{tabular}{|c|c|c|c|c|}
\hline Autor & Obra & Fuentes & (-) & 룰 \\
\hline Acevedo Díaz, Eduardo & Brenda & 14 & 04 & 01 \\
\hline Alberdi, Juan Bautista & Bases y puntos de partida para la organización política. & 2,14 & 04 & \\
\hline Allende, Isabel & La casa de los espíritus & 3 & 04 & 03 \\
\hline Altamirano, Ignacio Manuel & Clemencia & 2 & 04 & 02 \\
\hline & & 2,14 & 04 & 03 \\
\hline Blest Gana, Alberto & Martín Rivas & 14 & 04 & 02 \\
\hline Cortázar, Julio & Bestiario & 2,3 & 04 & \\
\hline Cortázar, Julio & Final del juego & 2 & 04 & 02 \\
\hline Cortázar, Julio & Historias de cronopios y de famas & 2,14 & 04 & 03 \\
\hline Cortázar, Julio & Las armas secretas & 2,14 & 04 & 03 \\
\hline Cortázar, Julio & Los premios & 2,14 & 04 & 01 \\
\hline Cortázar, Julio & Queremos tanto a Glenda & & 04 & 03 \\
\hline Cortázar, Julio & Rayuela & $1,2,3,14$ & 04 & 02 \\
\hline Cortázar, Julio & Todos los fuegos el fuego & $1,2,3,14$ & 04 & 03 \\
\hline Darío, Rubén & Prosas profanas & 2,3 & 04 & 02 \\
\hline Darío, Rubén & Tierras solares & 2,14 & 04 & 00 \\
\hline Díaz, Eugenio & Manuela & 2,14 & 04 & 00 \\
\hline García Márquez, Gabriel & Cien años de soledad & $1,2,3,14$ & 04 & 03 \\
\hline García Márquez, Gabriel & La hojarasca & 2,14 & 04 & 03 \\
\hline Garcia Márquez, Gabriel & La Mala Hora & 2,14 & 04 & \\
\hline Garcia Márquez, Gabriel & Noticias de un secuestro & 2,14 & 04 & \\
\hline García Márquez, Gabriel & Relato de un náufrago & 2,14 & 04 & 03 \\
\hline Gómez de Avellaneda, Gertrudis & Dos mujeres & 2 & 04 & 00 \\
\hline Güiraldes, Ricardo & Don Segundo Sombra & 2,14 & 04 & 02 \\
\hline Lillo, Baldomero & Sub sole & 2 & 04 & 02 \\
\hline Lillo, Baldomero & Sub Terra & 2,14 & 04 & 02 \\
\hline Lugones, Leopoldo & Cuentos fatales & 2,14 & 04 & 02 \\
\hline Lugones, Leopoldo & Las fuerzas extrañas & 2,14 & 04 & 02 \\
\hline Mera, Juan león & Cumandá & & 04 & 02 \\
\hline Neruda, Pablo & Canto general & $1,2,14$ & 04 & 03 \\
\hline Neruda, Pablo & Cien sonetos de amor & 2 & 04 & \\
\hline Neruda, Pablo & Confieso que he vivido & 2,14 & 04 & 02 \\
\hline Nervo, Amado & Los jardines interiores & 2,14 & 04 & 01 \\
\hline Nervo, Amado & Misticas & 2 & 04 & 01 \\
\hline Quiroga, Horacio & Cuentos de amor, de locura y de muerte & 2 & 04 & 02 \\
\hline Rodó, José Enrique & Ariel & 2,14 & 04 & 03 \\
\hline Sánchez, Florencio & Barranca abajo & 2 & 04 & \\
\hline Sánchez, Florencio & La gringa & 2 & 04 & 02 \\
\hline Sánchez, Florencio & Los muertos & 2 & 04 & 02 \\
\hline Vallejo, César & El tungsteno & 2 & 04 & 02 \\
\hline Abreu Gómez, Ermilo & Canek & 2 & 03 & 02 \\
\hline Aguinis, Marcos & Cantata de los diablos & 14 & 03 & 02 \\
\hline Aguinis, Marcos & nde los idiotas & 14 & 03 & 02 \\
\hline Aguinis, Marcos & La cruz invertida & 14 & 03 & 03 \\
\hline Aguinis, Marcos & La gesta del marrano & 14 & 03 & 02 \\
\hline Aguinis, Marcos & Profanación del amor & 14 & 03 & 02 \\
\hline Alarcón, Daniel & Guerra a la luz de las velas & 8 & 03 & 02 \\
\hline Alarcón, Daniel & Radio Ciudad Perdida & 8 & 03 & 03 \\
\hline Alberdi, Juan Bautista & El crimen de la guerra & 2,14 & 03 & 01 \\
\hline Asturias, Miguel Angel & El Papa verde & 2,14 & 03 & 管 \\
\hline
\end{tabular}

Tabla 29. Los primeros cincuenta títulos que aparecen en plataformas comerciales latinoamericanas (ambos soportes): Gandhi - Librería Santa Fe - Livraria Cultura Perubookstore.com. Elaboración propia. 
En relación con la oferta de títulos en impreso, ninguno de los títulos está en todas las plataformas de los países emergentes.

Las plataformas de los países emergentes ofrecen los títulos de los autores bloomianos García Márquez, Rubén Darío, Miguel Ángel Asturias, Pablo Neruda, César Vallejo y Julio Cortázar entre los más encontrados en la élite. Livraria Cultura ofrece 26 títulos en impreso de los 42 del total de segmento latinoamericano y caribeño del canon bloomiano.

Isabel Allende y Gertrudis Gómez de Avellaneda poseen un título cada una entre los más relevados.

Se resalta la presencia de obras del canon escolar, folklore latinoamericano y "obras morales" como las de Ignacio Altamirano, Amado Nervo, Baldomero Lillo Figueroa, Florencio Sánchez, Ricardo Güiraldes y Leopoldo Lugones.

También se destaca la presencia de autores como Marcos Aguinis, Daniel Alarcón y Alberto Blest Gana.

En relación con la oferta en digital, podemos acotar que, de las primeras cincuenta obras, cuarenta de ellas están en todas las plataformas.
4.1.9. Los primeros cincuenta títulos que aparecen en bibliotecas latinoamericanas (ambos soportes)

\begin{tabular}{|c|c|c|c|c|}
\hline Autor & Obra & Fuentes & + & 를 \\
\hline Cieza de León, Pedro & Crónica del Perú & 2 & 01 & 100 \\
\hline Cordero, Luis & Enumeración de las plantas de la provincia de Azuay & 2 & 01 & 100 \\
\hline González Prada, Manuel & & 2,14 & 01 & \\
\hline González Prada, Manuel & Trozos de vida & & 01 & \\
\hline Guillén Pinto, Alfredo & Lágrimas indias & 2 & 01 & 00 \\
\hline León Pinelo, Antonio de & Epítome de una biblioteca oriental y occidental, geográfica & 2 & 01 & 00 \\
\hline López Albújar, Enrique & Cuentos andinos & 14 & 01 & 01 \\
\hline Medina, José Toribio & Biblioteca Hispano-americana (1493-1907) & 2 & 01 & 00 \\
\hline Mitre, Bartolomé & Catálogo razonado de las lenguas americanas & 2 & 01 & 00 \\
\hline Aarons, Rudolph L. C. & The Cow that Laughed and Other Stories & 13 & 00 & 100 \\
\hline Abalos, Jorge W. & Animales, leyendas y coplas & 2 & 00 & \\
\hline Abalos, Jorge W. & Cuentos con y sin viboras & 2 & 00 & \\
\hline Abalos, Jorge W. & Don Agamenón y don Velmiro & 2 & 00 & 100 \\
\hline Abalos, Jorge W. & La viuda negra & 2 & 00 & 100 \\
\hline Abalos, Jorge W. & Lapachos & 2 & 00 & 100 \\
\hline Abalos, Jorge W. & Noroeste & $\frac{2}{2}$ & 00 & 100 \\
\hline Abalos, Jorge W. & Norte pencoso & 2 & 00 & 01 \\
\hline Abalos, Jorge W. & Shalacos & & 00 & \\
\hline Abalos, Jorge W. & Shunko & 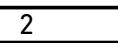 & 00 & 00 \\
\hline Abalos, Jorge W. & Terciopelo, la cazadora negra & 2 & 00 & 100 \\
\hline Abalos, Jorge W. & ¿Qué sabe usted de viboras? & 2 & 00 & 00 \\
\hline Abbenhuis, Richard & Science Fiction Villains & 13 & 00 & 100 \\
\hline Aboud, James & The Stone Rose & 13 & 00 & 100 \\
\hline Abreu Gómez, Ermilo & A un joven novelista mexicano & 14 & 00 & ${ }_{100}$ \\
\hline Abreu Gómez, Ermilo & Canek & 2 & 00 & 01 \\
\hline Abreu Gómez, Ermilo & Clásicos, románticos, modernos & 14 & 00 & 00 \\
\hline Abreu Gómez, Ermilo & El corcovado & 2 & 00 & 00 \\
\hline Abreu Gómez, Ermilo & Héroes mayas & $\frac{2}{2}$ & 00 & \\
\hline Abreu Gómez, Ermilo & Juan pirulero & $\frac{2}{2}$ & 00 & $\frac{10}{00}$ \\
\hline Abreu Gómez, Ermilo & $\begin{array}{l}\text { La vida milagrosa del venerable siervo de Dios } \\
\text { Gredario ónez }\end{array}$ & 2 & 00 & 00 \\
\hline Abreu Gómez, Ermilo & Leyendas y consejos del antiguo Yucatán & $\frac{2}{14}$ & 00 & 00 \\
\hline Abreu Gómez, Ermilo & Naufragio de indios & 14 & 00 & 00 \\
\hline Abreu Gómez, Ermilo & Páginas escogidas: creación critica & 14 & 00 & 00 \\
\hline Abreu Gómez, Ermilo & Quetzalcóatl, sueño y vigilia & & 00 & \\
\hline Abreu Gómez, Ermilo & Romance de reyes & 14 & 00 & \\
\hline Abreu Gómez, Ermilo & Viva el Rey & 14 & $\overline{00}$ & 00 \\
\hline Abreu, Capistrano de & A língua dos Caxinauás & 2 & 00 & \\
\hline Abreu, Capistrano de & Caminhos antigos epovoamento do Brasil & 2 & 00 & 00 \\
\hline Abreu, Capistrano de & Capitulos de historia colonial & $\frac{2}{2}$ & 00 & 00 \\
\hline Abreu, Capistrano de & Ensaios e estudos & $\frac{2}{2}$ & 00 & 00 \\
\hline Abreu, Capistrano de & Fr. Vicente do Salvador & 2 & 00 & 00 \\
\hline Abreu, Capistrano de & O descobrimento do Brasil e seu desenvolvimento & 2 & & lno \\
\hline Ahrou Cacimirodo & $\frac{\text { no século XVI }}{\text { As Primaveras }}$ & $\frac{2}{2}$ & 00 & 00 \\
\hline Abreu, Casimiro de & Camoes eo Jau & $\frac{2}{2}$ & 00 & 00 \\
\hline Abreu, José Vicente & Guasima, donde el rio perdió las siete estrellas & 2 & 00 & 00 \\
\hline Abreu, José Vicente & Las cuatro letras & $\frac{2}{2}$ & 00 & 00 \\
\hline
\end{tabular}

Tabla 30. Los primeros cincuenta títulos que aparecen en bibliotecas latinoamericanas (ambos soportes): Biblioteca Nacional de Perú - Biblioteca de São Paulo. Elaboración propia. 
Escasísima y casi nula la presencia de los títulos y autores del CLLyC diseñado en digital en Biblioteca Nacional de Perú y Biblioteca de São Paulo: solo nueve títulos sobre 4.842 títulos hallados en digital (el 0,18\% del total). En soporte papel, la Biblioteca Nacional de Perú dispone de 2.855 títulos (el 19,24\% de los títulos existentes en soporte papel) y la Biblioteca de São Paulo ofrece 218 títulos en impreso (1,46\%).

\subsubsection{Resultados destacados de las búsquedas por segmento} del CLLyC ${ }^{24}$

1. De El canon occidental, de Harold Bloom

- La oferta en soporte impreso de los títulos de esta sección del CLLyC es alta: Amazon ofrece 39 (92\%) sobre 43 títulos en total. Google Books ofrece 34 títulos sobre 43. Public Library of New York ofrece 27 títulos en soporte impreso y la Biblioteca Nacional de España ofrece 24 títulos sobre 43.

- En las principales plataformas comercializadoras en digital, la frecuencia de oferta de los títulos del segmento latinoamericano del canon de Bloom disponibles en formato digital va desde los 19 títulos que ofrece Livraria Cultura, de San Pablo (dato muy destacable), pasando por los 20 títulos disponibles en Scribd y los 12 títulos disponibles en IBookstore y Nubico. Se marca que Gandhi ofrece 14 títulos en digital de canon bloomiano y que ninguno de los títulos bloomianos fue creado especialmente para formato iBooks.

- De la disponibilidad de las obras canónicas en soporte digital se destacan los 16 títulos sobre 43 que ofrece la Biblioteca Nacional de España.

2. Del Diccionario de literatura latinoamericana de César Aira

- Google Books ofrece en soporte impreso 6.771 títulos (cerca del 60\%) de los 11.155 títulos que componen el total.

${ }^{24}$ En ciertos casos, algunos de los autores solo publican en versiones en digital sin a soporte impreso: tal es el caso de la escritora ar-

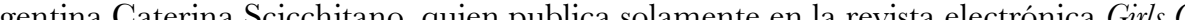
Busy \#20 y en su blog de Tumblr http:/ / yournaughtybits.tumblr.com/; el escritor español Óscar García Sierra (incorporado por el carácter iberoamericano de la antología) quie publica sus textos en su blog de Tumblr I WANNA MEET KRISTLE COLE: http:/ oscargsierra.tumblr.com/ y de la escritora colombiana Alexandra Espinosa, quien publica sus textos en su blog Efervescer. http://efervesciendoymesiendo.blogspot.com.ar/.
- Livraria Cultura ofrece 1.308 títulos en soporte impreso (el $11 \%$ del total) y 701 títulos en digital (el 6\%). Además, se destaca que Livraria Cultura ofrece toda la obra de Jorge Amado en soporte digital y casi el 60\% de la obra de Carlos Drummond de Andrade.

- Scribd ofrece 1.032 títulos del Diccionario de literatura latinoamericana de César Aira, es decir, el 9,29\% de los títulos. Además, la Web de intercambios Scribd ofrece un porcentaje cercano al 50\% de los títulos de la obra que componen este segmento del CLLyC de los siguientes autores: Nicanor Parra, Roberto Payró, Octavio Paz, Severo Sarduy, Domingo F. Sarmiento, Alfonsina Storni, Cruz Sousa, Héctor Tizón, Joaquín V. González, Abraham Valdelomar, Artemio de Valle Arizpe, Rosamel De Valle, César Vallejo, Mario Vargas Llosa, David Viñas y Rodolfo Walsh.

- Destacadísima oferta en digital de la Biblioteca Nacional de España: 1.734 títulos (el 15\% del total).

3. De La gran novela latinoamericana de Carlos Fuentes

- Amazon cubre 116 títulos (el 93\%) de los 124 títulos en total que componen esta fuente del CLLyC. La Public Library of New York ofrece 105 títulos (84\%) en soporte papel sobre 124.

- La Web de intercambios Scribd ofrece 58 títulos (47,58\%) en digital sobre 124 títulos del total de obras. La plataforma Amazon ofrece en digital 55 títulos (el 44,35\%) sobre 124 títulos incorporados por Carlos Fuentes en su ensayo y Barnes\&Noble 32 títulos en digital $(25,80 \%)$

4. De Saraus. Movimiento - Literatura - Periferia - São Paulo. Antología, compilada por Lucía Tennina

- La oferta en soporte impreso es muy baja: solo Google Books ofrece ocho títulos y Livraria Cultura siete títulos sobre un total de 58 obras.

- La oferta en digital es nula.

5. De De la Tricolor a la Wiphala. Narrativa contemporánea de Bolivia, de Sergio Di Nucci, Nicolás Recoaro y Alfredo Grieco y Bavio (selección, edición y notas) 
- Google Books ofrece en soporte papel 38 títulos de un total de 67 títulos de esta fuente (el 56,71\%). La Public Library of New York ofrece en soporte impreso 33 títulos sobre un total de 67 (el 49,25\% de los títulos).

- La oferta en digital de títulos de esta fuente es prácticamente inexistente: solo Amazon dispone de seis títulos en digital (8,95\% de los títulos) y dos títulos de Wilmer Urrelo Zárate en Amazon, Nubico, Librería Santa Fe y Livraria Cultura.

6. De McOndo (una antología de nueva literatura hispanoamericana) de Alberto Fuguet y Alberto Gómez

- Google Books ofrece en soporte impreso todos los títulos sobre 17 obras que componen el total.

- Public Library of New York dispone de 16 obras en impreso (excepto Amores imperfectos de Edmundo Paz Soldán).

- En digital, el nivel de oferta de este segmento es medio: siete títulos sobre 17 del total de este segmento están disponibles en digital en la Web de intercambios Scribd y cinco títulos en la plataforma Nubico.

7. De 1.000 millones: poesía en lengua española del siglo XXI, editada por Daniel Helder, Daiana Henderson y Bernardo Orge

- Google Books ofrece en soporte impreso 27 títulos sobre 97 obras que componen el total.

- Solo cinco títulos sobre 97 del total de este segmento están disponibles en digital, todos en la Web de intercambios Scribd.

8. De Bogotá39, una selección realizada por los escritores colombianos Piedad Bonnet, Héctor Abad Faciolince y Oscar Collazos

- La plataforma Google Books ofrece 74 títulos en soporte impreso sobre 133 obras que componen el total de 36 autores (el 56,33\% de los títulos del segmento).

- La Biblioteca del Instituto Latinoamericano de Berlín ofrece 42 títulos en impreso (el 31,57\%).

- Amazon y Livraria Cultura ofrecen 25 títulos en digital, sobre 133 que componen el total (el 18,79\% del total). Lo cinco títulos del autor Santiago Roncagliolo están disponibles en su mayoría en Amazon, Barnes\&Noble, Gandhi, Nubico, Livraria Cultura y Librería Santa Fe.

9. Del Manifiesto del Crack, de Pedro A. Palou; Eloy Urroz; Ignacio Padilla; Ricardo Chávez Castañeda y Jorge Volpi

- Google Books ofrece en soporte impreso nueve títulos sobre 22 obras que componen el total. Tanto Columbia University Libraries, Public Library of New York como la Biblioteca del Instituto de Estudios Latinoamericanos de Berlín disponen de siete títulos en impreso.

- En digital, todos los títulos de Jorge Volpi están disponibles en Scribd.

10. De Los chongos de Roa Bastos. Narrativa contemporánea de Paraguay, selección y edición de Sergio Di Nucci, Nicolás Recoaro y Alfredo Grieco y Bavio

- Google Books dispone 17 títulos en soporte impreso sobre 33 títulos en total del segmento (el 51,51\% del total).

- Solo cuatro títulos están en soporte impreso y en digital: de Javier Viveros, Dulce y doliente ayer y En una baldosa y de Domingo Aguilera, El Rubio.

- En bibliotecas, solo la Biblioteca Nacional de España, ofrece en soporte impreso y en digital, Paraguayología para extranjeros de Domingo Aguilera.

11. De Latin American Writers on Gay and Lesbian Themes: A Bio-Critical Sourcebook de David William Foster

- Se destacan El lugar sin límites, de José Donoso y El fuego secreto, de Fernando Vallejo. El primero está disponible en soporte impreso y en digital en Amazon, Casa del Libro, Livraria Cultura y en la Biblioteca Nacional de España. Y en digital solamente en Scribd, Nubico, Perubookstore y en Europeana, Biblioteca de la Unión Europea. El título de Fernando Vallejo está disponible en soporte impreso y en digital en Amazon, Casa del Libro, Livraria Cultura y LSF, y solo en formato digital en Barnes \& Noble, Scribd, Nubico, iBookstore.

- Public Library of New York posee una oferta media de los títulos de este segmento del CLLyC en soporte papel: catorce títulos.

- Se apunta que Google Books dispone de casi todos los títulos de este repertorio en soporte impreso. Pero no ofrece ningún título en digital. 
- Scribd dispone de cinco títulos en digital

12. Del catálogo de títulos de autores latinoamericanos y caribeños de la Base de Datos de Editoriales Cartoneras de University of Wisconsin

- La plataforma Google Books dispone de 300 títulos de los títulos de este segmento de 487 títulos en total (el $61 \%$ de los títulos hallados).

- Se destaca especialmente que la Biblioteca del Instituto de Estudios Latinoamericanos de Berlín es la que más títulos del catálogo de ediciones cartoneras dispone en impreso: 156 títulos (el 32\%) de 487 del total.

- Se encuentran en las búsquedas en digital 75 títulos de 48 autores. Es decir, se obtiene el $15,4^{\circ} \%$ de los títulos de las ediciones cartoneras en digital y el $12,73 \%$ de los autores.

- Scribd ofrece dieciséis títulos transpuestos a digital. Se subraya que existe transposición de editoriales cartoneras a digital. En este punto, se destaca que el proceso de transposición pudo efectuarse primero de impreso "industrial tradicional" a digital o se transpuso de impreso "industrial tradicional" a cartonera, y de ese soporte a digital de manera paralela.

\section{A]}

Atarraya Cartonera

27 de febrero a la(s) 17:38 - e

Ya están disponibles para leer en línea la mayoría de nuestros libros publicados entre el 2009 y el 2014. Disfruta:

http://atarrayacartonera.blogspot.com/p/lee-en-linea.html

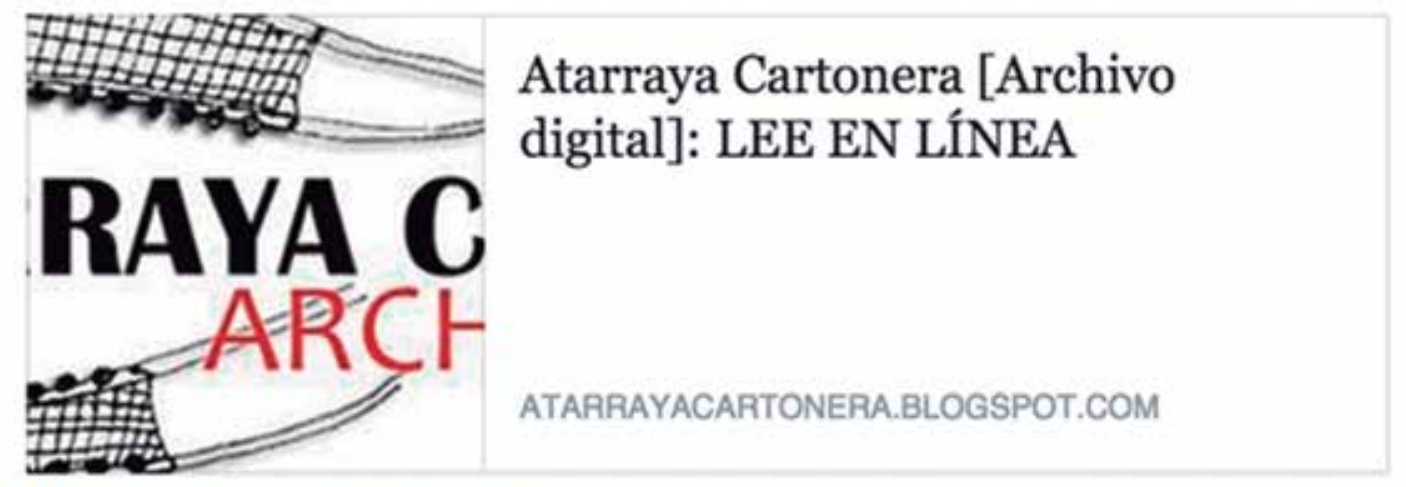

Me gusta $\cdot$ Comentar $\cdot$ Compartir

Figura 20. Cartoneras en digital. Atarraya Cartonera (Puerto Rico) publicita el acceso libre en digital a la mayoría de sus títulos en su página de Facebook.
13. De la sección del CLLyC conformada por títulos de escritores caribeños, antillanos y de las Guayanas

- Se destaca el escaso nivel de transposición a digital de sus títulos, aunque se destaca la oferta de títulos en impreso de dicho segmento.

- En soporte impreso, las plataformas que más títulos disponen son Amazon y Google Books, ambas con cerca del $40 \%$ de los títulos del segmento. Columbia University Libraries dispone de cerca del $20 \%$ de los títulos en soporte papel.

- Scribd ofrece en digital 152 títulos (no llega al 10\% del total de los títulos del segmento). El jamaiquino Kincaid posee casi toda su obra en Amazon en ambos soportes, así como V. S. Naipaul. Marcamos la presencia de las obras de José Martí y Jean Rhys en Scribd (casi el 50\% en digital) y de Caryl Phillips en Amazon y Barnes\&Noble, y Edwige Danticat en Livraria Cultura. Esmeralda Santiago también posee una alta oferta digital de sus títulos del CLLyC en Amazon y Barnes\&Noble y Scribd. También destacamos que Livraria Cultura posee una oferta media de títulos de la sección caribeña, antillana y de Guayana del CLLyC: John Agard, Aimé Cesaire, Michael Anthony, Franz Fanon, Jamaica Kincaid, V. S. Naipaul, José Martí, Jean Rhys, Caryl Phillips y Edwige Danticat. Livraria Gultura dispone de 127 títulos en digital (7\%).

- La presencia de obras de este segmento es muy bajo en bibliotecas, excepto la oferta en soporte impreso de autores cubanos en la Biblioteca Nacional de España.

14. Del Diccionario de la literatura latinoamericana de Susana Cella

- Google Books ofrece en soporte impreso cerca del 80\% de los 4.757 títulos que componen el total del segmento. Asimismo, Amazon dispone de cerca del 50\% de los títulos en impreso: 2.357.

- Es significativa la oferta en soporte impreso de la Biblioteca del Instituto de Estudios Latinoamericanos de Berlín: cerca del $20 \%$ de las obras del segmento. También la Biblioteca Nacional de Francia dispone de cerca del 20\% de los títulos del segmento y Columbia University Libraries dispone de cerca del 10\% de los títulos en soporte impreso.

- Las bibliotecas relevadas no se destacan por una oferta significativa en soporte digital. Solo la Biblioteca Nacional de 
España ofrece cerca del 15\% de los títulos del segmento, principalmente escritores latinoamericanos consagrados: Cortázar, Bioy Casares, Borges, Di Benedetto, Diego, Donoso, Durand, Elizondo, Filloy, Gerbassi, González Prada, Mallea, Mejía Vallejo, Mujica Láinez, Monterroso, Onetti.

- Livraria Cultura ofrece en soporte impreso toda la obra de los escritores brasileños Oswald de Andrade, de João Cabral de Melo Neto, de Antonio Calado, de Antonio Cándido, de Clarice Lispector, de Nelson Rodríguez, José Mauro de Vasconcelos y de Érico Veríssimo. Y de algunos escritores del boom, como es el caso de la obra de Gabriel García Márquez. Se destaca la oferta por parte de Livraria Cultura de toda la obra de Jorge Amado en soporte digital, y casi el $60 \%$ de la obra de Carlos Drummond de Andrade.

- Además, la Web de intercambios Scribd ofrece en soporte digital cerca de 600 títulos (cerca del 12\% de los títulos de este segmento). Scribd ofrece un alto porcentaje de los títulos que componen este segmento del CLLyC de los siguientes autores: Adolfo Bioy Casares, Manuel Bandeira, Nicanor Parra, Nicolás Olivari, Roberto Payró, Afranio Peixoto, José Pedroni, Octavio Paz, Manuel Peyrou, Juan de Dios Peza, Virgilio Piñeira, Severo Sarduy, Domingo F. Sarmiento, Alfonsina Storni, Cruz Sousa, Franz Tamayo, Franklin Távora, Lygia Telles, César Tiempo, Héctor Tizón, Jaime Torres Bodet, Dalton Trevisan, Froylán Turcios, Luis Urbinas, Francisco Urquizo, Rodolfo Usigli, Joaquín V. González, Abraham Valdelomar, Artemio de Valle Arizpe, Rosamel De Valle, César Vallejo, Mario Vargas Llosa, José María Vargas Vila, José Mauro de Vasconcelos, Carlos Vaz Ferreira, Érico Veríssimo, David Viñas, Ida Vitale, Cintio Vitier, Rodolfo Walsh, Emilio Westphalen, Eduardo Wilde, Manuel Olivela Zapata y Agustín Yáñez.

15. De la sección del CLLyC conformada por títulos de escritoras relevado del repertorio Latin American Women Writers: An Encyclopedia, editado por María André y Eva Bueno

- En soporte impreso, Google Books dispone de 269 títulos (el 9,11\% del total). Columbia University Library dispone de 146 títulos y Public Library of New York 153 títulos, ambos en soporte impreso.

- En digital, Scribd dispone de 196 títulos (el 6,64\% del tota de los títulos del segmento). Dispone de casi toda la obra de Diamela Eltit, Amparo Dávila, María Rosa Lojo, Elena Garro, Alejandra Pizarnik, Laura Restrepo, Gioconda Belli, Ma- ría Luisa Bombal, Sor Juana Inés de la Cruz, Marta Traba y Marcela Serrano.

- La Biblioteca Nacional de España ofrece cincuenta y cinco títulos del segmento en digital.

- La novela de Isabel Allende La casa de los espiritus está disponible (en alguno de los soportes) en todas las bibliotecas y plataformas, excepto en Free-ebooks, la Biblioteca Nacional de España y Europeana.

16. De la sección de literatura precolombina

- La presencia de títulos de este segmento es muy baja en ambos soportes.

- Ollantay, Popol Vuh y Rabinal Achí poseen una buena oferta en impreso y en digital en plataformas: Amazon, Barnes\&Noble, Livraria Cultura y en Columbia University Libraries, Biblioteca Nacional de Francia y Biblioteca Nacional de Perú (en este caso, solo en impreso).

- Poemas de Nezahualcóyotl posee una mavor oferta en digital que en soporte papel: Amazon, Barnes\&Noble, Livraria Cultura, iBookstore y la Biblioteca del Instituto de Estudios Lationamericanos de Berlín.

17. De Encyclopedia of Latin American and Caribbean Literature 1900-2003, editado por Daniel Balderston y Mike Gonzalez

- Google Books ofrece en soporte impreso cerca del 80\% de los 2.672 títulos que componen el total del segmento. Asimismo, Amazon dispone de cerca del 40\% de los títulos en impre-

- Es significativa la oferta en soporte impreso de la Biblioteca del Instituto de Estudios Latinoamericanos de Berlín: cerca del 30\% de las obras del segmento. También la Biblioteca Nacional de Francia y Columbia University Libraries disponen de cerca del 20\% de los títulos en soporte impreso. La Biblioteca Nacional de Perú ofrece cerca del 10\% del total en impreso.

- Las bibliotecas relevadas no se destacan por una oferta significativa en soporte digital. Solo la Biblioteca Nacional de España ofrece cerca del 15\% de los títulos del segmento, principalmente escritores latinoamericanos consagrados: Julio Cortázar, Miguel Ángel Asturias, Adolfo Bioy Casares, Jorge Luis 
Borges, Antonio Di Benedetto, Gabriel Casaccia, Rosario Castellanos, Haroldo Conti, José Donoso, Elena Garro, Ricardo Güiraldes, González Prada, Jorge Ibarbengoitía, Roberto Juarroz, Jesús Lara, Enrique Lihn, Marta Lynch, Leopoldo Marechal, Rafael Maya, Pablo Neruda, Juan Carlos Onetti.

- Livraria Cultura ofrece en soporte digital una parte la obra de los escritores brasileños Jorge Amado, Joaquín Machado de Assis, Aluizio Azevedo, Oswald de Andrade, José Monteiro Lobato, Antonio Calado, Antonio Cándido, Clarice Lispector, Nelson Rodríguez, José Mauro de Vasconcelos y de Érico Veríssimo. Y se destaca la oferta en digital en Livraria Cultura de toda la obra del segmento de Jaime Bayly, Mario Benedetti, Julio Cortázar, José Donoso, Carlos Fuentes, Eduardo Galeano, Gabriel García Márquez y Manuel Puig.

- Además, la Web de intercambios Scribd ofrece en soporte digital cerca de 507 títulos (cerca del 18,97\% de los 2.672 títulos de este segmento). Scribd ofrece un alto porcentaje de los títulos que componen este segmento del CLLyC de los siguientes autores: Marcos Aguinis, Raúl Andrade, Oswald de Andrade, José María Arguedas, Roberto Arlt, Miguel Angel Asturias, Mario Benedetti, Diana Bellessi, Jorge Luis Borges, Paulo Coelho, Julio Cortázar, Diamela Eltit, Carlos Fuentes, Eduardo Galeano, Gabriel García Márquez, Mauricio Kartún, Osvaldo Lamborghini, José Monteiro Lobato, Raduan Nassar, Eduardo Pavlovsky, Alejandra Pizarnik, Graciliano Ramos, Andrés Rivera, Gonzalo Rojas, Antonio Skármeta y Mario Vargas Llosa.

\subsection{Algunos aspectos destacables de los}

resultados de las búsquedas

- En la mayoría de las plataformas comercializadoras, autores y títulos del corpus propuesto gozan de visibilidad y oferta en soporte papel, pero el proceso de transposición a digital es lento y se estaría realizando con criterios distintos a los sostenidos en relación con la actividad canónica. Así, también deseamos destacar la disparidad en la oferta en digital: la oferta de títulos del segmento latinoamericano y caribeño del canon propuesto por Bloom es reducida y no supera el $50 \%$ de las obras tal es el caso de Barnes \& Noble). ${ }^{25}$ De los resultados de las búsquedas se deduce que la Web de intercambios Scribd es la plataforma que más títulos ofrece en digital: 1.718 títulos sobre 4.842 títulos hallados en digital, es decir, el 35,48\% de los títulos existentes en digital para las búsquedas efectuadas. Amazon ofrece 1.101 títulos, es decir, una oferta media en relación con el universo de búsquedas en digital (el 22,73\% del total de los títulos). Barnes \& Noble, 600 títulos en digital. Se apunta que la oferta de literatura latinoamericana y caribeña en digital en los idiomas originales de las obras es muy baja por parte de la plataforma Kobo: 262 títulos (menos del 5,41\% de la oferta relevada). Casa del Libro y Nubico (ambas de España) forman parte de la "clase media" de la oferta de títulos de literatura latinoamericana y caribeña, en idiomas originales, en digital: 512 y 496 títulos respectivamente, así como los títulos disponibles en iBook Store de Apple: 368 títulos en digital. De las plataformas comerciales latinoamericanas, Livraria Cultura (Brasil)es la que ofrece más títulos en digital: 1.035. Esta última, se destaca por poseer una buena oferta de títulos de autores brasileños (y de algunos escritores del boom, como García Márquez) y también posee una oferta media de títulos en digital de autores brasileños. 
- En relación con la oferta en digital en bibliotecas, se visualiza que el proceso de transposición a digital de las colecciones de literatura latinoamericana y caribeña es más lento en la mayoría de las bibliotecas todavía que en plataformas comercializadoras. Aunque, destacamos que la Biblioteca Nacional de España es el sitio donde se relevaron más título en digital de las búsquedas efectuadas en esta investigación: 1.749. También remarcamos que en las bibliotecas las obras en dominio público tienen mayor peso que en plataformas comercializadoras a nivel de la oferta. En cuanto a los resultados de las búsquedas, además de los 1.749 títulos relevados en la oferta de la Biblioteca Nacional de España (es decir, casi el $36,12 \%$ de la oferta relevada de títulos existentes en digital), remarcamos la oferta de la Biblioteca Europeana de la Unión Europea, con 582 títulos y Columbia University Libraries con 572 títulos. Se apunta la muy baja oferta en digital de la Public Library of New York y la Biblioteca Nacional de Francia -Gallica- con 21 y 23 títulos respectivamente. Biblioteca Nacional de Perú dispone de diez títulos y Biblioteca de São Paulo no ofrece ningún título en digital.

- En soporte impreso, la plataforma que más obras dispone es Google Books: 11.140 títulos sobre una búsqueda total de 14.835 (casi el 75,09\% de los títulos del CLLyC disponibles en soporte impreso). Además, Google Books dispone 1.575 autores en soporte impreso (el 63,58\% del 2.477 del total de autores relevados en soporte papel). Luego siguen Amazon, con 7.144 títulos (el 48,15\% de la oferta existente en impreso). De las plataformas de los países emergentes, la que más títulos impresos dispone es Livraria Cultura, de São Paulo, con 1.785 (el 12,03\%).

- En relación con la oferta en bibliotecas en soporte impreso, la biblioteca que más títulos de literatura latinoamericana y caribeña dispone es la Public Library of New York, con 5.760, es decir, casi el 38,82\% de los títulos del CLLyC disponibles en soporte impreso. Luego la sigue la Biblioteca del Instituto Latinoamericano de Berlín dispone de 4865 títulos (32,79\% del total de los títulos de la búsqueda). Columbia University Libraries con 4.663 títulos en soporte papel (el 31,43\%).

- La política de oferta de los fondos bibliográficos de las bibliotecas en soporte digital se caracterizaría por tener un desarrollo más relacionado con la disposición de los títulos en digital por parte de las editoriales proveedoras y por criterios de construcción de la oferta bibliotecológica que por criterios de autoimposición de las obras por sublimidad estética que nutren el centro de la teoría del canon que sostiene el mencionado
Bloom y por criterios de construcción de la oferta por parte de la crítica tradicional especializada. ${ }^{26}$

- Alonso Arévalo y Cordón García (2010: 67) enfatizan que las bibliotecas se articulan como elementos dinámicos del ámbito cultural que siempre se constituyeron como vanguardia en la incorporación de las tecnologías de la información y que desarrollan cada vez con mayor intensidad la oferta de libros electrónicos a sus usuarios. Asimismo, Alonso Arévalo y Martín Rodero (2012: 376-377) resaltan que una parte importante de los editores y agregadores de libros electrónicos orienta en la actualidad sus modelos de negocio hacia las bibliotecas. Es decir, podríamos tomar el estado actual del catálogo en digital de las bibliotecas analizadas ligado al CLLyC construido como un estadio intermedio de la transposición a digital de los títulos. Además, en el nivel de las bibliotecas se destaca que el proceso de transposición a digital es más lento todavía que en el caso de las plataformas comercializadoras y también se estaría realizando con criterios estratégicos distintos al sostenido por Bloom en relación con la actividad canónica.

\section{Composición de la oferta relevada}

\section{Títulos en dominio público}

Se destaca sobre el total de las búsquedas la presencia de títulos de autores cuyos derechos de autor pertenecen al dominio público. En todos los recortes se relevan como los títulos con mayor oferta en digital aquellos que pertenecen al dominio público.

\section{Títulos bloomianos}

Marcamos que la puesta en oferta en digital por parte de la industria (plataformas) de títulos de literatura latinoamericana y caribeña transpuestos de soporte impreso combina con títulos de dominio público la adición de títulos bloomianos: las obras canónicas disponen de una alta visibilidad consolidada estructural dada su legitimación proveniente del campo académico (Cordón García, 2004: 23) y, asimismo, de las ventas y recepción permanentes. Además, como la noción de canon se opone a la de mercado, dado que las obras canónicas no deben su existencia a una demanda real de mercado, sino al sistema de tradiciones que las sostiene y que el canon mismo retroalimenta. Esto nos permite establecer una comparación entre

\footnotetext{
${ }^{26}$ Ver Tabla 3.4. y Figura 15.
} 
disponibles en soporte impreso y digital, es decir, habilita la obtención de un estado del arte de la transposición a digital de los títulos del segmento latinoamericano y caribeño del canon de Bloom.

\section{Bestseller y títulos de los escritores de las editoriales cartoneras}

Señalamos la presencia en los segmentos de mayor oferta en digital de títulos bestseller de la escritora chilena Isabel Allende, así como de Santiago Roncagliolo, un escritor de la matriz de Generación McOndo y escritor de ediciones cartoneras latinoamericanas.

\section{Una "clase media" de la oferta}

Sobresale la oferta de títulos de un grupo de escritores provenientes de Manifiesto del Crack (tal es el caso de Ignacio Padilla), de la generación del 72 como Tomás Eloy Martínez, o del "post-boom" como Jorge Edwards, que componen una oferta medio-alta en digital. A nivel de los títulos con mayor cantidad de resultados, destacamos Hombres sin mujer, de Carlos Montenegro y La tregua, de Mario Benedetti, ambos títulos relacionados con lo que denominamos Sección de narrativas de crítica socialy "realismo" latinoamericano.

\section{Las ventanas por las que ingresa el gusto de los lectore}

De los 4.842 títulos hallados en digital, Scribd ofrece 1.718 títulos, es decir, el $35,48 \%$ de los títulos existentes en digital para las búsquedas efectuadas. Además, Scribd ofrece 715 autores sobre 1353 autores hallados en digital: el 52,84\% de los autores relevados en las búsquedas. En este punto, la intervención de los usuarios en Scribd funciona como ventana por la cual los criterios poéticos, estéticos, artísticos sobre la literatura latinoamericana y caribeña ingresan en las formas de construcción del catálogo general en digital.

Entonces, se deduce de los resultados de las búsquedas que la oferta general en digital de literatura latinoamericana y caribeña se construye mediante la combinación de las siguientes estrategias:

1) Estrategias de puestas en digital por parte de la industria editorial "demanda real de mercado" (Cordón García, 2004: 23) + estrategias relacionadas a los derechos de autor + estrategias de marketing relacionadas con los costos + estrategias que provienen de la circulación de criterios estéticos y poéticas.

2) La acción del usuario lector mediante la incorporación de títulos ligados a su "gusto".
3) Títulos autopublicados por los autores (mediante $K D P$, iBooks Author, Smashwords, LULU, etc... ${ }^{27}$

Finalmente y, en especial, se detectaron las secciones mediante las cuales se articula la oferta del CLLyC en soporte digital y se resaltan, especialmente, las que proponen los títulos que mayor representatividad tienen, como se observa en Tabla 24. Los autores de los títulos del CLLyC que más aparecen en digital funcionan como un canon de hecho, un canon oculto, articulado por la combinación de estrategias de puesta en digital y por la disposición de los títulos de los autores que mencionamos mediante el agrupamiento en las secciones que describimos previamente. 
Acción

de la

industria

editorial

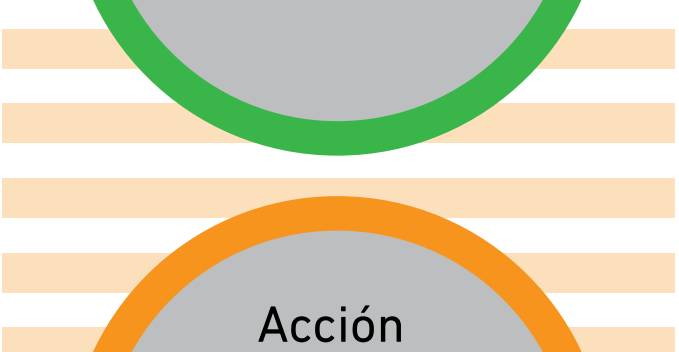

Acción

de los usuarios:

plataformas de

intercambio

Scribd

Títulos

autopublicados

Figura 21. Compo-

sición de la oferta en

digital. Elabora-

ción propia.

\subsection{Conclusiones relacionadas con el corpus literario latinoamericano y caribeño propuesto para las búsquedas en plataformas comerciales y bibliotecas}

El objetivo de esta Tesis es la descripción del estado de la transposición a soporte digital de literatura latinoamericana y caribeña editada en impreso. Colocando especial atención a la oferta de las principales plataformas comercializadoras y bibliotecas digitales internacionales y las especializadas en títulos de la literatura latinoamericana y caribeña. Para el análisis de ese estado, se diseñó un corpus literario latinoamericano y caribeño (CLLyC) basado en la incorporación de la mayor amplitud de perspectivas posible sobre estas literaturas: obras y autores que desde América Latina proponen teorías y corrientes que se posicionan desde una mirada crítica con el enfoque clásico de Harold Bloom. Es decir, se propone ampliar la muestra a aquellos autores y títulos a relevar de distintos repertorios críticos, diccionarios, historias y antologías de literatura latinoamericana y que pueden integrar el corpus desde una perspectiva teórica que comprende a la crítica feminista, los estudios queer, los cultural studies, a los llamados estudios de la subalternidad y del giro poscolonial y que subsume la versión canónica tradicional. Mencionábamos anteriormente que para Ana Pizarro (1987: 190-191), al formar parte la literatura de la formalización estético-cultural, permitiría ampliarse la propia noción de literatura "hasta incluir en su ámbito discursos como la oratoria, los sermones, el discurso histórico, político, filosófico, etc.”. Así, en este registro, formas de la literatura no percibidas como tales por una perspectiva moderna clásica ingresarían en el CLLyG. Si la idea de Lotman-Uspenski (1971: 77) es la de hablar de "la cultura como mecanismo que crea un conjunto de textos y hablar de los textos como realización de la cultura" esto implica que la cultura funciona como mecanismo generativo y estructurador que basa sus fronteras en su propia autoconciencia y autoorganización. Así, el CLLyC diseñado se propone como resultado de formas de autoconcepción sobre la literatura latinoamericana y caribeña. Y de algunas de las formas de su propia organización. Es decir: el corpus propuesto surge, entonces, tanto del relevamiento de repertorios y fuentes literarios latinoamericanos y caribeños heterogéneos, disímiles, distantes entre sí tanto en los periodos temporales como en las perspectivas y criterios de selección como de algunas de las propuestas de inclusión de formas textuales en la literatura latinoamericana y caribeña. E incorpora tanto la versión canónica tradicional de la literatura latinoamericana y caribeña como a cánones alternativos sumados a repertorios que trasciendan el castellano y el portugués y que expresen las distintas formas 
de la lengua y hablas de las distintas regiones. Y las distintas poéticas que van desde la literatura nacida en el boom de los 60, pasando por la llamada Generación McOndo y la literatura del Crack mexicano (ambas de los 90), las literaturas de las periferias de las grandes ciudades (marginalia de São Paulo, literaturas de "edición cartonera" de Buenos Aires, Asunción, Lima, La Paz, Santiago, São Paulo, San Salvador, Quito, Guayaquil, México DF etc.) hasta las distintas transposiciones en el sentido de soporte impreso tradicional a las ediciones cartoneras. Este corpus propuesto dispuso en su inicio de 20.409 títulos, de los cuales fueron hallados en impreso 14.835 (casi el 75\% del corpus buscado). De ese total de libros impresos hallados, el 50,62\% ha sido transpuesto a digital: 4.842 títulos (casi el 24\% del corpus inicial buscado), pero existen 10.190 títulos, es decir, casi el 50\% de lo hallados en algún soporte en alguna plataforma o biblioteca que solamente se encuentra en soporte papel..$^{2}$

\subsection{El canon oculto. Conclusiones relacionadas \\ con la transposición a digital de literatura \\ latinoamericana y caribeña en plataformas \\ comerciales y en bibliotecas}

- Si las ideas mismas de canon y corpus sugieren un cierto recorte de las posibilidades de tratamiento de "lo literario", es decir, la de cierta preeminencia del hecho académico y su lectura del catálogo general de la edición literaria, también sabemos que la capacidad de influencia de la tradición académica no es precisamente un recurso único a la hora de la construcción del catálogo por parte de las editoriales. Muchos de los textos relevados fueron títulos de alta rotación y de alto impacto al nivel de la conformación del campo de la literatura latinoamericana y caribeña antes de la construcción de un canon literario latinoamericano (y/o caribeño). Es decir, que muchos de los títulos relevados se destacan por haber organizado parte del debate contextual estético, politico y cultural (Zanetti, 1998: 105-106) para la conformación de los cánones nacionales de la región. Estos textos aparecen, mayoritariamente, como títulos en dominio público de la oferta relevada, principamente en Tabla 24, en lo que definimos como Secciones de la oferta (especialmente las secciones obras del canon escolar, folklore latinoamericano y "obras morales"; de Crónicas de Indias, primeras historias de los futuros países latinoamericanos y primeros escritos de mujeres y de costumbres; y de títulos de autores que recién ingresan en dominio público).

- Además de lo que podemos denominar "problemática propia del campo literario latinoamericano y caribeño", la acción de la industria editorial en la transposición de libros impresos a soporte digital también puede configurar su acción estratégica con criterios que ingresarían en tensión con una autonomía del campo académico en la fijación de títulos y autores. La intervención de formas editoriales vinculadas a disciplinas del marketing en el marco de procesos de concentración del mercado internacional del libro, así como las estrategias propias de las plataformas comercializadoras (sobre todo: Amazon, Barnes \& Noble, Google Books, Kobo y Apple/iBooks) componen una batería de acciones que descolocarían la estrategias de construcción de catálogos basados en la autoridad estética del canon (Bloom, 1995: 47). 
- En un recorte amplio, sobre los 200 títulos que más aparecen en ofertas en digital en plataformas también se destaca la presencia de títulos de autores cuyos derechos de autor pertenecen al dominio público; autores bloomianos; autores provistos tanto por el Manifiesto del Crack (como Ignacio Padilla) de la generación del 72 (como Tomás Eloy Martínez) o del llamado "post-boom" (Jorge Edwards) y autores aportados por el dispositivo de $\mathrm{McOndo}$, como Santiago Roncagliolo y Roberto Bolaño; autoras como Isabel Allende, ligada al aparato de superventas y, finalmente, una clase media de la oferta, compuesta por un colectivo de autores como Mario Benedetti, Sergio Ramírez, Fernando Vallejo o Guadalupe Nettel.

- Ahora bien: en una orientación de los resultados más destacados de las búsquedas de las obras y autores del CLLyC diseñado efectuadas, destacamos especialmente que los resultados exhiben que los títulos cuyos derechos de autor están en dominio público encabezan la transposición a digital de la literatura latinoamericana y caribeña en impreso. En las búsquedas de títulos en soporte impreso, entre los primeros cincuenta título en este soporte los títulos de autores en dominio público no tienen demasiado peso en la composición de la élite la oferta. Sin embargo, de los primeros cincuenta títulos que aparecen en soporte digital en las búsquedas realizadas (aquellos que aparecen 14, 13, 12 y 11 veces en la misma cantidad de plataforma y bibliotecas), cuarenta y uno son títulos de autores cuyas obras están en dominio público. Esto ratifica uno de los criterios de transposición por parte de la industria: se transpone con mayor frecuencia aquello por lo cual no se cotizan derechos de autor. ${ }^{29}$ A su vez, aparece un lote de algunos de los títulos bloomianos en la élite de la oferta. De los primeros cincuenta títulos, doce títulos son de autores bloomianos y tres de ellos son títulos bloomianos.

- Este listado superior, es decir, el segmento que aparece con mayor recurrencia en las tablas de resultados de las búsqueda de la investigación funciona de hecho como el canon literario latinoamericano y caribeño oculto, aportado desde estrategias editoriales y bibliotecológicas acompañadas por las acciones relacionadas con la inclusión de títulos mediante ventanas al gusto de los lectores. Este canon oculto destaca una organización de los títulos en seis secciones:
1) Sección de obras y autores bloomianos.

2) Sección de obras del canon escolar, folklore latinoamericano y "obras morales".

3) Sección de Crónicas de Indias, primeras historias de los futuros países latinoamericanos y primeros escritos de mujeres y de costumbres.

4) Sección de narrativas de crítica social y "realismo" latinoamericano.

5) Sección de títulos de autores que recién ingresan en dominio público.

6) Sección de escritura de mujeres.

- Como observamos en la Figura 22, del desarrollo de esta investigación se desprende un esquema de autores y categorías de formas literarias latinoamericanas y caribeñas que permanecen como un canon oculto en soporte digital, detrás de la transposición de soporte impreso del CLLyC.

- En este punto, también destacamos que algunos de los títulos de autores en dominio público son, a la vez, títulos de autores del canon de Bloom (como es el caso de Rubén Darío). Además, se destaca que existen títulos que corresponden a más de una sección como es el caso de los autores que componen la sección de Crónicas de Indias, primeras historias de los futuros países latinoamericanos y primeros escritos de mujeres y de costumbres, cuyas obras están todas en dominio público. Y como es el caso de las obras de Sor Juana Inés de la Cruz, cuyos títulos también pertenecen al dominio público, a la sección de Crónicas de Indias, primeras historias de los futuros países latinoamericanos y primeros escritos de mujeres y de costumbres, y a la sección de escritura de mujeres. También existen autores que se incorporan al canon oculto tanto por su pertenencia a una sección de títulos de autores que recién ingresan en domino público como a la sección de narrativas de crítica social y "realismo" latinoamericano, como sería el caso de Roberto Arlt. 


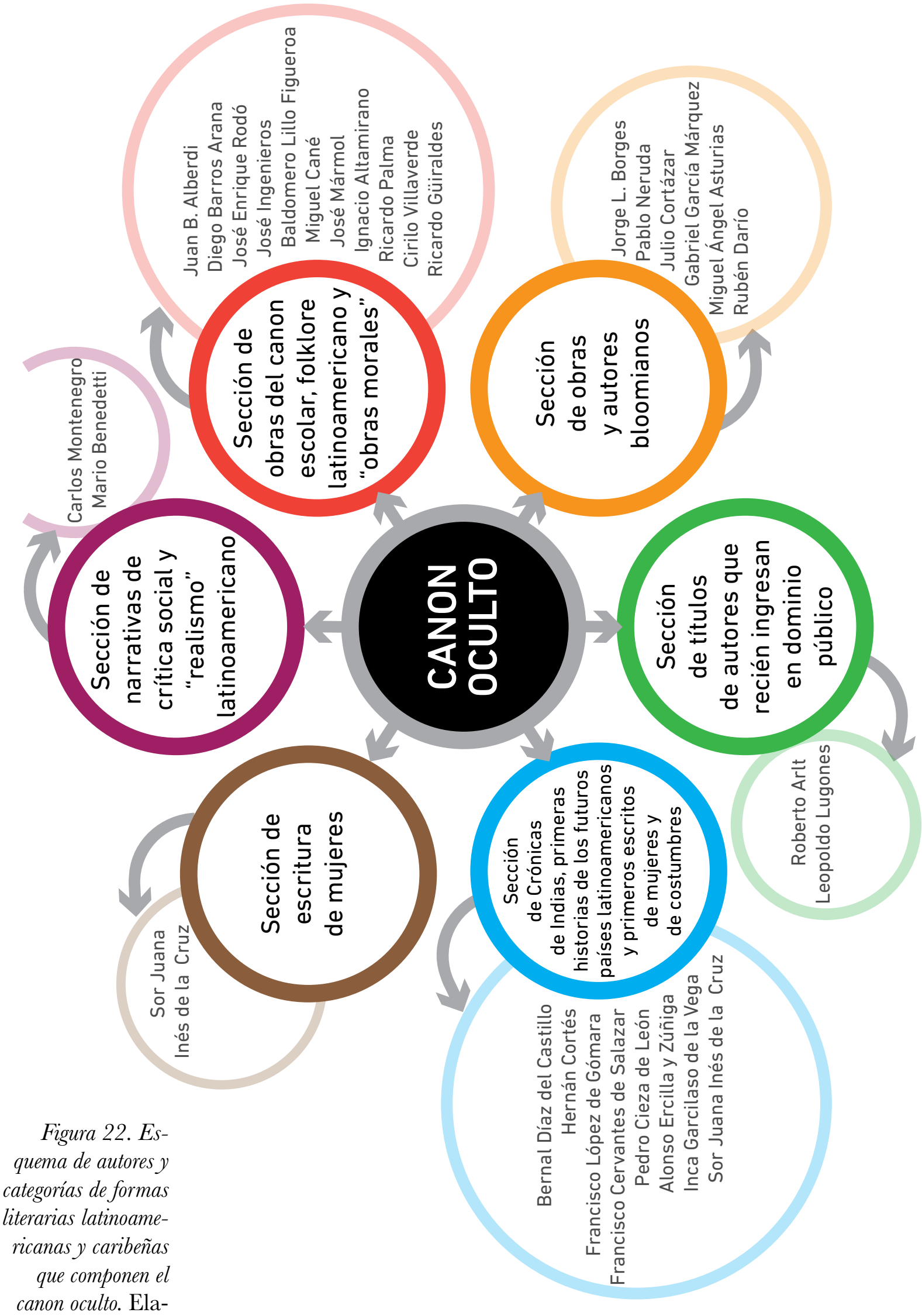

- El debilitamiento de la crítica especializada y de la acción de las formas académicas (cátedras, programas de investigación, crítica literaria, intelectualado, revistas culturales, recensiones, revistas científicas) que intervinieron tradicionalmente en la construcción del catálogo en impreso dificultaría, asimismo, tanto la construcción canónica de este como la concreción en soporte digital de un CLLyC que incorporase prácticas discursivas y autores y tópicos invisibilizados por los mecanismos de construcción académica especializada. Aunque, como destacamos previamente, hay títulos que comparten más de una sección literaria. Esto es: hay obras que componen el canon oculto y que forman parte de la oferta en digital porque, entre otras cosas, son incorporadas desde criterios de sublimidad estética y las formas de legitimación tradicional. Estas obras forman parte del canon oculto detectado en la investigación al ser incorporadas por la industria editorial desde un vector de "visibilidad consolidada" de obras que poseen alto reconocimiento, entre otras razones porque son obras o que aparecen en listas de más vendidos, o porque poseen un alto valor simbólico. En este nivel, este canon oculto detectado se desempeñaría como una desagregación entre el prestigio cultural que otorga a los catálogos la incorporación de las obras que lo componen y las lógicas del comercio editorial y la lectura.

- Entonces, se subraya que la corriente ligada al boom de la literatura latinoamericana de la década del '60 se incorporó a la corriente principal de la literatura en castellano de una manera anticipada, a la que luego se dio con el llamado giro poscolonial, es decir, la inclusión al mainstream de las formas artísticas latinoamericanas y del Tercer Mundo. Ya en los 90 Hall 1991: 37) sintetizaba:

La revolución cultural más profunda ha sido una consecuencia de los márgenes entrando a la representación: en el arte, en la pintura, en el cine, en la música, en la literatura, en las artes modernas de todos lados, en política y, en términos generales, en la totalidad de la vida social. Y estos márgenes no lo hacen para ser situadas por otro régimen, por el ojo del imperio, sino que lo hacen para reclamar para sí mismas alguna de las formas posibles de representación. En nuestro mundo, de manera paradójica, la marginalidad se ha convertido en un espacio poderoso. Se trata de un espacio de poder débil, pero es, al fin y al cabo, un espacio de poder.

Esta incorporación a escala global de una corriente artística "poscolonial" - determinada por "valores locales, nacionales, anticoloniales, independientes y antiglobalización"- circula hoy por los circuitos comerciales del mainstream internacional. 
En este tópico, con las reservas correspondientes, tal vez se pueda establecer un paralelismo con lo que sucede en el mundo de las artes visuales. Terry Smith, en ¿Qué es el Arte Contemporáneo? (2012: 22, 23, 331$)^{29}$ señala que el llamado giro poscolonial ha hecho que el arte de la periferia "se vuelva predominante en los circuitos de arte internacional" y, para nosotros, puede constituirse en una perspectiva de interpretación de la construcción de la oferta bibliotecológica tanto en impreso como en soporte digital de literatura latinoamericana y caribeña a escala global. Siguiendo la descripción de Smith (2012: 330), hoy se destaca la presencia del "arte del sur mundial" - los denominados "segundo, tercer y cuartos mundos"en el nivel de difusión y comercialización potenciadas por los nuevos mercados y bienales de arte.

El auge del boom de la década del 60 permitió concretar alrededor de la literatura latinoamericana una política editorial centrada en avances de mercado ligados a estrategias de marketing propias de las industrias culturales de los países centrales. Antes del boom, la literatura latinoamericana no registraba ventas masivas y ahora ingresaba en el mercado de bienes simbólicos de la mano de la masividad de sus autores, que ganaron los medios de comunicación de la época.

La primera edición de Cien años de soledad de Gabriel García Márquez, en 1967, por la editorial Sudamericana tuvo una edición total de 8.000 ejemplares; a los pocos días, otra edición de 8.000 ejemplares, luego varias reimpresiones de 100.000 ejemplares (Mora, 1997). Hasta la fecha lleva vendidos más de 30 millones de ejemplares y ha sido traducida a 35 idiomas. La primera edición de Rayuela, de Julio Cortázar, también por la editorial Sudamericana, en 1965, tuvo una tirada de 3.000 ejemplares; en 1973 ya llevaba vendidas 500.000 copias.

${ }^{30}$ Por supuesto, no se pretenden dilucidar en el marco de esta investigación -ni es su objeto investigativo- los mecanismos de producción artística latinoamericana ni como se incorporarían las formas, valores, estéticas, ideologías y razones del arte latinoamericano al nivel de la producción artística mundial. Tampoco se procuran dilucidar (ni es objeto de esta investigación) las causas geoestéticas/geoepistémicas de la incorporación del llamado arte poscolonial a los circuitos de comercialización del arte internacional (incluidos los centros metropolitanos más prominentes). Se subraya, también, que no es intención estratégica de esta investigación la de establecer paralelismos entre las causas (ideológicas, comerciales, estéticas, poéticas) de la incorporación de un segmento la literatura latinoamericana -boom mediante- a la gran industria cultural con la incorporación - giro poscolonial de por mediodel arte latinoamericano a los principales mercados del arte.
La primera edición rusa de Rayuela, en 2013, fue de 100.000 ejemplares (Tverítina, 2013). Estas cifras mencionadas expresan que algunos de los autores canónicos bloomianos (Julio Cortázar, Jorge Luis Borges, Gabriel García Márquez, José Donoso, Mario Vargas Llosa, Miguel Ángel Asturias, Alejo Carpentier) ya formaban parte del mainstream literario internacional. A posteriori, también se incluye en esa corriente principal una propuesta literaria encuadrada por un segmento de la crítica que concibe la literatura de algunos de estos autores como la corriente del llamado "realismo mágico" (Miguel Ángel Asturias, Carlos Fuentes, Julio Cortázar, Alejo Carpentier y, sobre todo, Gabriel García Márquez). En este punto, debemos remarcar que una de las secciones del canon oculto se solapa con una parte importante del segmento latinoamericano y del Caribe del canon bloomiano.

- En relación con la oferta de títulos en digital, se destacan principalmente la Biblioteca Nacional de España (1.749 títulos y 522 autores) y la Web de intercambios Scribd (1.718 títulos y 715 autores). A su vez, ambos sitios tienen una superposición de oferta de 269 títulos y 157 autores, representando para la Biblioteca Nacional de España el 15,38\% de su oferta de obras y el $30,07 \%$ de su oferta de autores. Es decir que en la Biblioteca Nacional de España el 84,62\% de su oferta de obras y el 69,93\% de su oferta de autores no está disponible en Scribd. Por su parte, en Scribd, esta superposición con la Biblioteca Nacional de España representa un 15.65\% de su oferta de obras y el $21.95 \%$ de su oferta de autores. Es decir que el $84,35 \%$ de la oferta de obras y el 78,05\% de la disposición de autores de Scribd no está disponible en la Biblioteca Nacional de España. Los criterios de construcción de la oferta de títulos transpuestos a digital en cuanto a la elaboración del catálogo en bibliotecas públicas y de contenidos en una Web de intercambio priman sobre la disposición de títulos y autores: los datos exponen que tanto la Biblioteca Nacional de España como Scribd poseen una oferta que apunta a dos conjuntos literarios latinoamericanos y caribeños diversos y diferentes, constituyéndose en ofertas exclusivas en tres cuartas partes en cuanto a los títulos y en dos tercios en cuanto a los autores. ${ }^{31}$ 


\subsection{Conclusiones relacionadas con el ingreso de criterios de gusto en la construcción de la oferta} en digital de literatura latinoamericana y caribeña

- La industria editorial figuraría yuxtaponiendo distintas estrategias comerciales relacionadas con las estadísticas de ventas de los títulos en soporte impreso consideradas "demanda real de mercado" (Cordón García, 2004) para asumir el riesgo empresario de transposición a digital con aquellas estrategias ligadas a la necesidad de recuperación de retornos financieros dadas las inversiones efectuadas en términos de compra de lo derechos de autor, sumados a los costos de las estrategias de marketing relacionadas con esos mismos títulos y sus autores. Pero, asimismo, la acción estratégica general pareciera sumar procedimientos que devienen también de la circulación de criterios que priman para la elección de estilos, poéticas, estéticas, autores y obras de la literatura latinoamericana y caribeña. Esto último, quizá, como resultado también de la incorporación al mainstream de la comercialización de arte internacional de ciertas estéticas del arte latinoamericano como sección de la corriente artística poscolonial (Smith, 2012: 22, 23) y que Cristina Civale (2014) califica como "una automatización del mercado que indica qué es lo legítimo como arte" que estaría dada por el trabajo conjunto de curadores de museos y coleccionistas. Es la era transestética del "triunfo del capitalismo artístico" donde los fenómenos estéticos no reflejan pequeños mundos periféricos, sino que han sido "integrados en inmensos mercados organizados por gigantes económicos internacionales" (Lipovetsky Serroy, 2015: 20-21). Según Lipovetsky y Serroy (2015), el mundo atravesó tres etapas de estetización: la artistización ritual, la estetización aristocrática (desde fines de la Edad Media) y la estetización moderna (desde el siglo XVIII). Hoy estaríamos viviendo la era transestética, en la que "el complejo económico-estético", "la economía estética" del capitalismo artístico (2015: 354) articularía cuatro lógicas:

a) Integración y generalización del orden del estilo, la seducción y la emoción en los bienes destinados al consumo comerción

b) Generalización de la dimensión empresarial de las industrias culturales y creativas.

c) Nueva empresas que combinan un polo económico y un polo creativo, es decir, grupos dedicados a las producciones dotadas de un componente estético (Lipovetsky y Serroy, 2015: 56) d) Un sistema en el que desestabilizan las antiguas jerarquías y se imbrican las esferas artísticas, económicas y financieras en el que el estilo se constituye en imperativo económico.Don Thompson (2015: 29) detecta 3.000 salas de subastas (1.600 de las cuales están en China), unas 425 ferias de arte, 17.000 galerías comerciales $(60 \%$ en Norteamérica y Europa), con una facturación por ventas en galerías de U $\$ \$ 15.000$ millones anuales. Las ferias de arte venderían U\$S3.000 millones anuales. Sumadas las ventas privadas serían de cerca de U\$S12.000 millones (Thompson, 2015: 29-30). En la Feria Internacional ARCO Madrid 2015, de 218 galerías de 29 países, 47 son de 10 países latinoamericanos en las que se presentan más de 300 grandes coleccionistas y profesionales de 42 países. En ese marco, se ofrecen obras de valor millonario como Nature morte, de Picasso (tasada en $€ 1,4$ millón); obras de David Hockney, Allen Jones, Andy Warhol, Salvador Dalí, Paul Klee y Joaquín Torres García y la costosísima Quij, de Jean Michel Basquiat (valuada en $€ 2,5$ millones). La Feria pretende recuperar el espacio perdido frente al Art Basel Miami Beach como vidriera de la vanguardia latinoamericana: "Es inevitable mirar hacia América. La escena latinoamericana es una de las más creativas e innovadoras del arte actual", plantea Carlos Urroz, director de ARCO, que además, esperaba la presencia de los grandes compradores de la escena internacional del arte, como la baronesa Thyssen y la pareja Juan Abelló-Anna Gamazo (Rodríguez Yebra, 2015). Para de Diego (2015), el arte latinoamericano ha ganado autonomía sin poseer ya dependencia de los museos tradicionales como MOMA, Tate Modern o el Centro Pompidou, en un mundo donde "lo que presagiaba la teoría poscolonial se ha hecho realidad", pasando ciertas antiguas periferias a ser centros en un mundo globalizado. Vattimo (2014), entrevistado para esta investigación, recomendó "no despreciar la calidad cosmopolita y 'global' de ciudades como Buenos Aires, que también construyen el 'gusto global' sobre lo latinoamericano".

- Groys (2014) analiza que el tiempo en que las élites culturales definían el gusto de su tiempo ya ha pasado. Las personas interesadas seriamente en el arte y la literatura han perdido influencia en la sociedad, aunque sustenten algo de la influencia perdida en su campo de acción sostenido (todavía) en universidades y museos. etc. Pero en el tiempo presente "las masas y el gusto de las masas se volvieron más importantes, y esas masas, al mismo tiempo, también están muy fragmentadas". Si "sociedad del conocimiento" es otra "forma de describir la dinámica del sistema capitalista que incluye el conocimiento y otras formas de trabajo no remunerado (desde las habladurías hasta la producción de sentido) en su lógica de rédito" (Graw, 2013: 319), las nuevas formas de intervención 
de los lectores sobre las obras, tanto en el plano de la lectura social como en el nivel de la crítica y de la construcción de la colección bibliotecaria constituyen un giro que incorpora criterios de gusto en el mercado de bienes simbólicos.

- La idea de lo global como "interpretación o perspectiva desde donde se ven los hechos" (Schettini, 2014) está presente en la constitución de las ofertas editorial y bibliotecológica tanto en impreso como en soporte digital de literatura latinoamericana y caribeña a escala global. En este plano, aportamos con una ampliación del campo de estudios de la "construcción del gusto" en los nuevos soportes digitales y como aporte al sostenimiento de una conciencia crítica de la relación entre "gusto" (Bourdieu, 1988) e industria, y como fuente de testimonio de algunas de las formas que componen el gusto global que articula la elección de los títulos de la literatura latinoamericana y caribeña en el plano de la oferta de bibliotecas y plataformas comercializadoras en digital. Todo esto en un contexto donde la globalización nos confrontaría "con la posibilidad de aprehender fragmentos, nunca la totalidad, de otras culturas, y reelaborar lo que veníamos imaginando como propio en interacciones y acuerdos con otros, nunca con todos" (García Canclini, 1999: 123). Si cada campo regula sus prácticas y representaciones y "ofrece a los agentes una forma legítima de realización de sus deseos basada en una forma particular de illusio" (Bourdieu, 1995: 338) destacamos que esta illusio es una precondición y un resultado del juego social, es decir que "no es posible esquivarla por completo". En este punto, también se nos presentan las figuras tanto del decisor en la estructura de las editoriales en relación con la transposición de obras a digital y la de los bibliotecarios encargados de construir la oferta de títulos en digital, en el mismo plano en que el crítico artístico ingresa en ese juego social aludido previamente al seleccionar ciertas obras y declararlas "merecedoras de discusión pública" (Graw, 2013: 24).

- Las estrategias de compras de títulos digitales basadas en el modelo de adquisición impulsada por el usuario (Patron Drven Acquisition-PDA) (Vicente García, 2013; Esposito et al., 2012; Cordón García, Gómez Díaz, Alonso Arévalo y Alonso Berrocal, 2014; Gammon y O'Neill, 2011; Walters, 2012) dejan espacio a una participación directa del usuario en la construcción de la colección y se constituye en una zona de negociación y competencia entre los usuarios y los bibliotecarios decisores. La mayoría de los agregadores ofrece acceso tanto a todos los títulos de libros electrónicos como a un grupo de títulos seleccionados por la biblioteca de acuerdo con el perfil o interés de la biblioteca. Si la industria editorial configura su modelo de transposición a digital sobre la base de combinación de estrate- gias basadas tanto en vectores comerciales ligados a la demanda de mercado como en procedimientos que devienen de criterios ligados al gusto, la construcción de la oferta bibliotecológica en digital mediante el modelo de adquisición de libros digitales impulsada por el usuario (Patron Driven Acquisition-PDA), es una de las ventanas por las cuales el gusto, los criterios poéticos, estéticos, artísticos sobre la literatura ingresan en las formas de construcción del catálogo general de la biblioteca. ${ }^{32}$

- En relación con estas formas de inclusión del gusto de los usuarios en la transposición a digital, parte del análisis de los resultados de las búsquedas de esta investigación confirman que la plataforma que más títulos ofrece en digital es la Web de intercambios Scribd. Esto ratifica que la participación del usuario en la oferta produce un incremento de las posibilidades de acceso de los títulos de literatura latinoamericana y caribeña en soporte digital. De los 4.842 títulos hallados en total en todas las búsquedas en digital, Scribd ofrece 1.718 títulos, es decir, el $35,48 \%$ de los títulos existentes en ese soporte. De esos títulos, 864 son títulos únicos aportados por Scribd. Y ofrece 715 autores, el 52,84\% \% de los 1.353 autores relevados en digital en las búsquedas realizadas, de los cuales 209 son autores únicos contribuidos por la mencionada Web de intercambio. Es decir que Scribd provee el $15,44 \%$ de los autores del total de autores hallados en las búsquedas en digital (sin contar los títulos superpuestos con otras plataformas, que se manifiesta en alto grado en las búsquedas). ${ }^{33}$ En este punto, la intervención de los usuarios en Scribd funciona como otra ventana por la cual los criterios poéticos, estéticos, artísticos sobre la literatura latinoamericana y caribeña ingresan en las formas de construcción del catálogo general en digital. Es decir: si la industria editorial desarrolla estrategias para la circulación de criterios ligados al gusto mediante la construcción de una oferta de títulos de literatura latinoamericana y caribeña en digital, el esquema se complementa con el ingreso de criterios ligados al gusto mediante la intervención de los usuarios en la Web de intercambios Scribd con su aporte de títulos de esas literaturas y la ampliación de la oferta en el mismo movimiento. ${ }^{34}$
${ }^{32}$ Ver Figura 23.

${ }^{33}$ Ver Tabla 21.

${ }^{34}$ Ver Figura 21. 
- En contexto de nuevas formas de escritura, nuevas ideas de lo que es una obra y de lo que es autoría, las respuestas a los interrogantes acerca de cómo se construye la oferta en soporte digital quedan también en manos de nuevos agentes y de nuevas formas de legitimación, tales como la influencia de un "gusto global" en relación con la literatura latinoamericana que orienta la oferta bibliotecológica de autores y títulos pertenecientes al dominio de esta literatura en el marco de un proceso transnacional de reconfiguración del negocio editorial. En este punto debemos destacar que, aunque esta investigación puede describirse como un análisis parcial, también puede considerarse como un aporte al estudio y descripción de lo que llamamos "gusto global". De esta investigación se puede desprender una nueva hipótesis interpretativa, a partir del análisis de los datos relevados y construidos, es decir que surge una nueva hipótesis, construida inductivamente y por analogía con la teoría incorporada en el marco teórico de esta tesis: los trabajos de Robert Fleck (2014), Frédéric Martel (2014), Terry Smith (2012), Giles Lipovetsky y Jean Serroy (2015), y Don Thompson (2015) sobre el mundo del arte contemporáneo y de la recurrencia a los criterios relacionados con el gusto por parte de informantes clave entrevistados. Específicamente, en lo que hace a los criterios sobre "lo latinoamericano" que funcionan como componentes de las estrategias decisionales para la oferta de títulos y obras de la literatura latinoamericana tanto en los circuitos que constituyen el mainstream comercial como al nivel de la oferta bibliotecológica. Para Fleck (2014: 17), uno de los planos de la globalización se articula en la "globalización del arte moderno". La detección de tradiciones propias de la modernidad clásica ("de las que hace veinte o treinta años no sabíamos nada") están presentes (y actuales) en la "vía principal" (mainstream) del arte moderno del siglo XX proveniente de Europa y EE.UU. $\mathrm{Y}$, entre otras tradiciones modernas, se han vuelto presentes "los desarrollos en Latinoamérica entre 1920 y hoy".

- Graw (2013: 199-205, 321) propone modificar el modelo de "autonomía relativa del arte" de Pierre Bourdieu (1995: 248) para plantear un modelo de "heteronomía relativa", es decir que "las restricciones externas prevalecen pero de manera relativa" en el mundo del arte. Las restricciones externas (económicas, de mercado) se ubican en primer plano en el campo artístico, de la mano del "predominio del sistema económico en la sociedad" y como consecuencia de constituirse en la forma de pensar predominante dentro del mundo del arte (Graw: 
200-201). Si en el modelo de autonomía relativa primaba la idea de diferenciación del arte "hacia un mundo propio", en el modelo de heteronomía relativa propuesto con cierta efectividad conceptual por Graw los acontecimientos económicos "externos" poseen un poder que se acentúa, pero no como un absoluto, sino de manera limitada. En algunos segmentos de CLLyC elaborado, en algunos de las fuentes relevadas, como es el caso De la Tricolor a la Wiphala. Narrativa contemporánea de Bolivia; en 1.000 millones: poesía en lengua española del siglo XXI; en Los chongos de Roa Bastos. Narrativa contemporánea de Paraguay; en Saraus. Movimiento - Literatura - Periferia - São Paulo y, muy especialmente en las ediciones cartoneras latinoamericanas, se destaca lo que Isabelle Graw (2013) plantea para el mundo de las artes plásticas: muchos artistas (así como numerosos escritores) buscan la libertad total en relación con cualquier intervención a lo percibido como "externo" al campo del arte. Si la tensión en el arte moderno fue por la independencia absoluta del campo literario de lo económico, es decir, finalizar con la autonomía relativa de la literatura para pasar a la autonomía absoluta, relevamos autores de los segmentos mencionados que establecen como estrategia propia o bien no publicar en soporte papel o bien solo publicar en ediciones cartoneras. Y, en algunos casos, solo publicar en versiones en digital sin transposición en el sentido inverso a soporte impreso. ${ }^{35}$

- Una de las tensiones que atravesaron el arte moderno desde el siglo XIX se articuló alrededor de la búsqueda de la independencia absoluta del campo literario de lo económico, es decir, finalizar con la autonomía relativa de la literatura para pasar a la autonomía absoluta. En la acción de la industria editorial digital en el marco de la globalización se está corriendo el eje de una autonomía relativa a una heteronomía relativa (Graw, 2013) donde, quizá lo "exterior" al campo artístico tenga mayor preeminencia que antes. A lo largo de la historia, los libros y el contenido que portan se han distribuido como un bien escaso y como fuente de adquisición de conocimiento y entretenimiento de las élites. Al acoplarse los libros de manera versátil a los flujos mundiales de contenidos digitales, de manera sencilla de acceso, en cualquier lugar y momento, esto permitiría un cambio notable en la distribución de entrenamientos educativos/culturales (Wischenbart et al., 2013: 153). Aunque destacamos en este punto que las formas materiales mediante las cuales accedemos a las literaturas latinoamerica-

${ }^{35}$ Tal es el caso de la escritora argentina Caterina Scicchitano, del escritor español Óscar García Sierra (incorporado por el carácter iberoamericano de la antología) y de la escritora colombiana Alexandra Espinosa. Todos publican sus textos solamente en sus blogs y blogs de Tumblr. nas poseen una mayor diversificación y amplitud de escalas, o sea de propuestas, de estilos, de lo editorial tipográfico y de las formas de concebir la escritura mucho más amplias y diversas que antes de la irrupción del fenómeno digital. Esto es, sin desconocer que las tecnologías de la información rompen con una concepción cerrada vinculada a la Galaxia Gutenberg y redimensionan la concepción creativa para dar lugar a la aparición de nociones que rediseñan las funciones de escritura/lectura "hasta extraerlas en muchos casos del propio circuito editorial" (Cordón García y Carbajo Cascón, 2012: 177).

- De la propuesta (poscolonial/decolonial) de las editoriales cartoneras a los títulos en formato AZW3 de Amazon que constituyen "lo último" del ecosistema digital existe una frecuencia de ofertas mayor a las disponibles hace menos de una década a nivel de los dispositivos materiales formales mediante los cuales se accede a la literatura. Muchas de las obras de la literatura latinoamericana y caribeña tienen la opción de ser transpuestas a digital desde el "modo tradicional" de edición en soporte impreso. Pero también pueden ser transpuestas a las formas de edición cartonera por fuera del "modo tradicional" todo esto sin incluir las obras "born-digital" que no son fruto de transposición alguna). En este punto, la irrupción de las llamadas editoriales cartoneras a inicio de la primera década del siglo XXI constituye lo que llamamos "especificidad editorial latinoamericana". ${ }^{36}$ Del segmento de editoriales cartoneras del corpus, se encuentran transpuestos a digital el 11,40\% de los títulos. Es decir, el campo se ha expandido a un mayor número de formas materiales, que van desde fórmulas de edición de las editoriales cartoneras latinoamericanas hasta el formato AZW3 de Kindle. Esto expresa una mayor amplitud en las maneras de concebir la escritura, estas también ligadas a las formas materiales, impresas, "tipográficas" (Chartier, 1992:113-114).

- Ya en los siglos XVII y XVIII las modificaciones "formales", "tipográficas" (Chartier, 1992:113) de los libros que compusieron las colecciones de la Biblioteca Azul se constituyeron como una fórmula editorial que extrajo del repertorio de textos ya publicados aquellos que le resultaron más "convenientes" para alcanzar al gran público. Cordón García (2006: 27) introduce la idea de protocolos de lectura presentes en la forma de cada texto, "confirmados en la actualidad a través de la lectura, redacción y edición de textos electrónicos". Esto es, no disociar "el análisis de las significaciones simbólicas del de las formas materiales que las transmiten” (Chartier, 2006: 10). Es más, si para Chartier (1992: 111) "los autores no escriben libros: escri-

${ }^{36}$ Ver apartado 3.1.1. y Figura 6. 
ben textos que luego se convierten en objetos impresos", para nosotros el libro también es el punto de convergencia de la batería de recursos que un sinnúmero de actores pone a disposición del texto. En nuestro caso de estudio, podríamos hablar de la batería de recursos puestos a disposición de la industria de la edición digital en la transposición de las obras y autores del CLLyC construido en esta investigación, tanto desde la perspectiva de aquellas corrientes críticas al mainstream literario como de la versión canónica de Bloom. Destacaremos, entonces, que en la tensión entre la oferta literaria latinoamericana y caribeña y la construcción del catálogo editorial digital, la transformación al nivel de los dispositivos materiales también ofrece un recorte de la estructura tanto del canon como del CLLyC (en soporte impreso) construido a efectos de esta investigación y exterioriza el canon oculto de la literatura latinoamericana y caribeña.

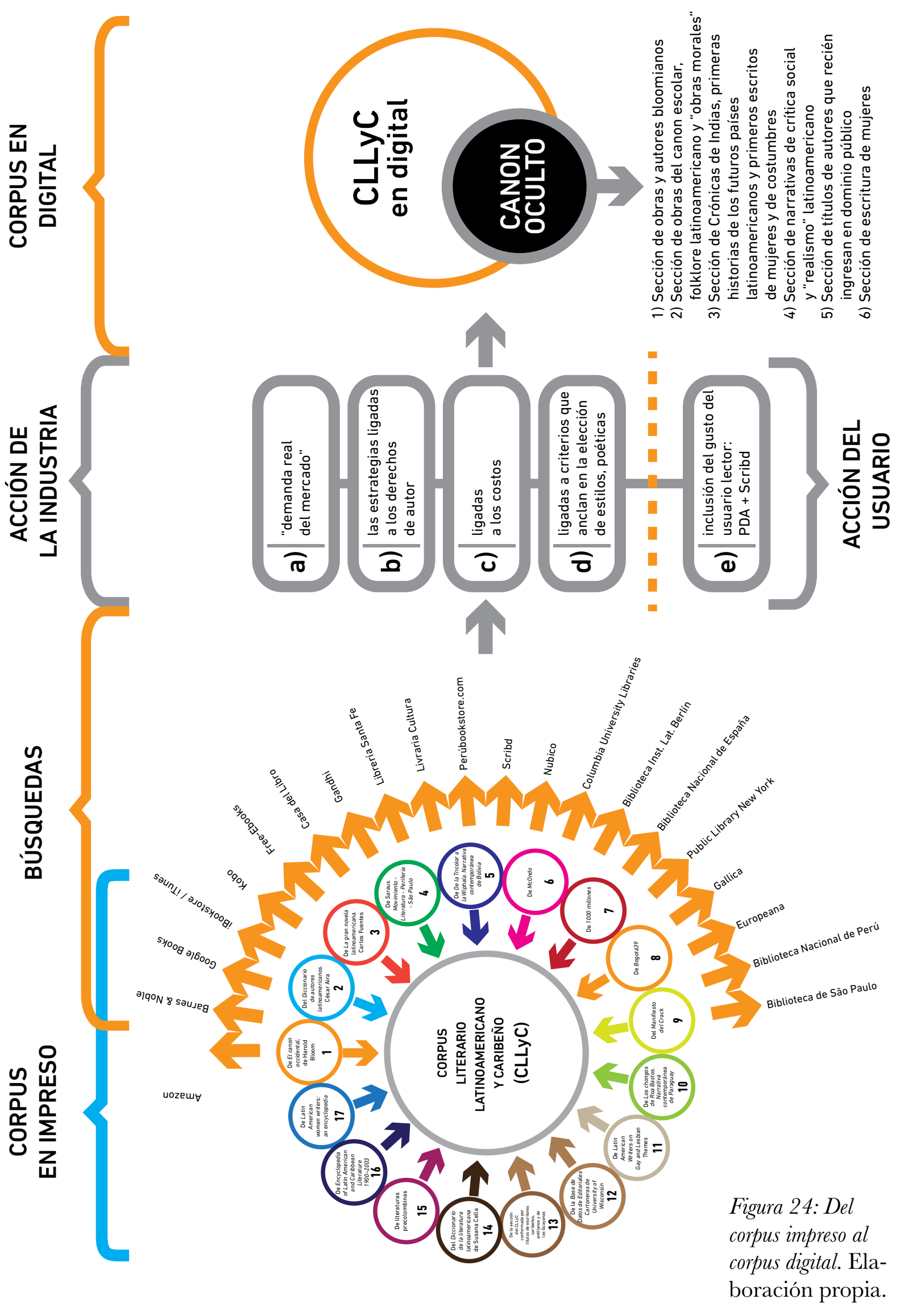




\section{LÍNEAS DE TRABAJO A FUTURO}

Otras líneas de investigación que surgen a partir de algunos de aspectos de esta investigación y que se constituyen como necesarias para una ampliación del conocimiento son:

- Las que surgirían del estudio de la "construcción del gusto" en nuevos repertorios literarios surgidos de la literatura born-digital (Strickland, 2009).

- Las que resultarían a partir de la incorporación en el CLLyC de títulos y autores aportados por perspectivas tales como los estudios judeolatinoamericanos y los estudios afrolatinoamericanos, y las perspectivas relacionadas con manifestaciones culturales latinoamericanas y caribeñas como el bossa, el tango, el candombe, los diversos folklores nacionales y regionales, la murga rioplatense, el reggae y el ska (entre otros).

- También surgiría una línea de investigación acerca de las ormas en que la literatura infantil y juvenil latinoamericana y caribeña se transponen a digital y cómo circula esa literatura, habida cuenta del crecimiento de las obras born-digital infantil y juvenil.

- Asimismo, deseamos marcar la necesidad de ampliar este tipo de investigación a la literatura latinoamericana y caribeña que se está desarrollando en el territorio de EE.UU.

- También se detectan líneas de investigación resultantes del relevamiento de las condiciones editoriales y del aparato paratextual de cada una de las obras que componen el CLLyC: editorial, año, cantidad de ejemplares, cantidad de ediciones y reimpresiones y, también, de la incorporación los géneros de cada una de las obras que componen el CLLyC.

- Se destaca la necesidad de ampliar la investigación a los títulos del CLLyC traducidos a otros idiomas y su transposición a digital. 
- Se subraya la necesidad de ampliar líneas de investigación rios construidos por la acción de los usuarios que incorporan las obras sin atender al estado de derechos de autor (las "zonas marrones" de la oferta).

- Igualmente, se señala la necesidad de establecer líneas de investigación acerca de las formas en que los títulos autopublicados se incorporan al catálogo general de la edición digital latinoamericana y caribeña.

- También se señala que el CLLyC resultante de esta investigación puede constituirse en un punto de partida para la construcción de una biblioteca digital de literatura latinoamericana y caribeña, habida cuenta de la detección de 20.409 títulos distintos de 2.932 autores diferentes y la localización de la presencia de estos títulos en las bibliotecas y plataformas de las búsquedas efectuadas, así como la dispositividad material disponible: impreso, impreso en edición cartonera y las distintas opciones y formatos de edición digital. for Huge Share of Hachette Ebook Sales, Nueva York: Publishing Perspectives, 16/07/2014 [Consulta: 02/01/2015] Disponible en: http://publishingperspectives.com/2014/06/amazonresponsible-for-huge-share-of-hachette-ebook-sales/.

- Abrams, Denis (2014 b). [En línea] Print Continues to Outsell Digital During First Half of 2014, Nueva York: Publishing Perspectives, 15/10/2014 [Consulta: 02/01/2015] Disponible en: http://publishingperspectives.com/2014/10/printcontinues-outsell-digital-first-half-2014/.

- Adorno, Theodor y Horckheimer, Max (1987). Dialéctica del Iluminismo, Buenos Aires: Sudamericana.

- Aira, César (2001). Diccionario de autores latinoamericanos, Buenos Aires: Emecé y Ada Korn.

- Alabarces, Pablo y Añón, Valeria (2008). “¿Popular(es) o subalterno(s)? De la retórica a la pregunta por el poder", en Alabarces, Pablo y Rodríguez, María G. (compiladores), Resistencias y mediaciones. Estudios sobre cultura, popular, Buenos Aires: Paidós.

- Alatriste, Sealtiel (1999). "El mercado editorial en lengua española". En García Canclini, Néstor y Moneta, Carlos (compiladores), Las industrias culturales en la integración latinoamericana, Buenos Aires: Eudeba, pp. 207-226.

- Almunia, Joaquín (2012). Statement on commitments from Apple and four publishing groups for sale of e-books [En línea] Bruselas: Comisión Europea, 13/12/2012 [Consulta: 11/01/2015] Disponible en: http://europa.eu/rapid/press-release_ SPEECH-12-955_en.htm.

- Alonso-Arévalo, Julio (2013). "El Ecosistema del Libro Electrónico Universitario". [En línea] Presentación en Slideshare. 02/10/2013 [Consulta: 02/01/2015] Disponible en: http://es.slideshare.net/jalonsoarevalo/presentacion-dellibros-el-ecosistema. 
- Alonso-Arévalo, Julio y Cordón García, José Antonio (2015). “¿Para qué servirá la Biblioteca Pública en el futuro? Depende de su capacidad de adaptación a los imparables cambios sociales, económicos y tecnológicos". [Web] Málaga: revista Mi biblioteca vol. 11, $\mathrm{n}^{\circ}$ 40, invierno 2015. Disponible en: http://gredos.usal.es/jspui/bitstream/10366/125206/1/ MiBibliotecaNNTT-MB401.pdf.

- Alonso-Arévalo, Julio y Cordón García, José Antonio (2010 a). El Libro electrónico en el ecosistema de información. [En línea]. Ciencias de la Información. 2010, vol. 41, no. 2, pp. 58-68. [Consulta 05/06/2014] Disponible en: http://gredos.usal.es/ jspui/bitstream/10366/83072/1/DBD_AlonsoArevalo_Ellib roelectronicoenelecosistema.pdf.

- Alonso-Arévalo, Julio y Cordón García, José Antonio (2010 b). El libro electrónico ha llegado a las bibliotecas... y viene para quedarse. [En línea]. Mi biblioteca. 2010, vol. 23, p. 74-83 [Consulta 15/04/2014] Disponible en: http://gredos.usal. es/jspui/bitstream/10366/83074/1/DBD_AlonsoArevalo_

Ellibroelectronicohallegado.pdf.

- Alonso-Arévalo, Julio; Cordón García, José Antonio y Gómez Díaz, Raquel (2014 a). Comparación de los hábitos y perfil del lector digital entre Estados Unidos y España. [En línea]. Murcia: Anales de Documentación, vol. 17, n ${ }^{\circ}$ 1, p. 1-16. [Consulta 02/11/2014]. Disponible en: http://revistas.um.es/analesdoc/ article/view/analesdoc.17.1.193111/160851.

- Alonso-Arévalo, Julio; Cordón García, José Antonio y Gómez Díaz, Raquel (2014b). La autopublicación: un nuevo paradigma en la creación digital del libro. [En línea]. La Habana: Acimed, Vol. 25, No 1. [Consulta 27/04/2014]. Disponible en: http://gredos.usal.es/jspui/bitstream/10366/122473/1/ La\%20autopublicaci\%C3\%B3n.pdf.

- Alonso-Arévalo, Julio y Martín Rodero, Helena (2012). "La integración de los libros electrónicos en la biblioteca”, en: Libros electrónicos y contenidos digitales en la sociedad del conocimiento: mercado, servicios y derechos, Madrid: Pirámide.

- Alvite Díez, María Luisa (2009). Interfaces y funcionalidades de bibliotecas digitales. [En línea]. Madrid: Anales de Documentación, $n^{\circ}$ 12. [Consulta 30/04/2014]. Disponible en: http://revistas. um.es/analesdoc/article/view/70221/67691.
- Amat, Nuria (1992). El libro mudo. Las aventuras del escritor entre la pluma y el ordenador, Madrid: Anaya \& Mario Muchnik.

- Anderson, Chris (2010). In the Next Industrial Revolution, Atoms Are the New Bits. [En línea]. San Francisco: Wired. [Consulta 02/05/2014]. Disponible en http://www.wired. com/2010/01/ff_newrevolution/.

- André, María y Bueno, Eva (2008). Latin American women writers: an encyclopedia, Nueva York: Routledge.

- Antelo, Raúl. Latinoamericanismo (Sin fecha), [En línea]. Lima: Blog de Richard Angelo Leonardo Loayza. [Consulta 01/11/2014]. Disponible en http://blog.pucp.edu.pe/ item/45521/latinoamericanismo.

- Apple. Ibooks. [En línea] Cupertino: Apple. [Consulta 21/04/2014]. Disponible en: https://itunes.apple.com/ar/ app/ibooks/id364709193?mt=8.

- Araújo, Rafael (2013). "Kobo entra en España” [En línea] Madrid: Blog Duento: 15/10/2013. [Consulta: 22/01/2015] Disponible en: http://www.duento.com/2013/10/koboentra-en-espana/.

- Ardao, Arturo (1980). Génesis de la idea y el nombre de América Latina, Caracas: Centro de Estudios Latinoamericanos.

- Ardao, Arturo (1996). "Del hispanoamericanismo literario al latinoamericanismo literario", en La inteligencia latinoamericana, Montevideo: Universidad de la República.

- Arróspide, Amparo (2002). "Best seller y paraliteratura: la obra de Isabel Allende". [En línea] Guadalajara: Universidad de Guadalajara, Departamento de Letras, Revista Sincronía no 4, Invierno 2002. [Consulta: 02/02/2015] Disponible en: http://sincronia.cucsh.udg.mx/arrospideinv02.htm.

- Aznar, Luis y De Luca, Miguel (editores) (2007). Política. Cuestiones y problemas, Buenos Aires, Emecé.

- Balderston, Daniel y Gonzalez, Mike (editores) (2004), Encyclopedia of Latin American and Caribbean Literature 1900-2003, LondresNueva York: Routledge. 
- Barnes \& Noble. [En línea] Nueva York: B\&N [Consulta: 12/01/2015] Disponible en: http://www.barnesandnoble com/u/nook-glowlight-ereader/379004122/.

- Bastide, Roger (1967). Les Amériques noires. La civilisation africaine dans le Nouveau Monde, París: Payot.

- Bellis, Rich (2015). "Ebooks Finding Their Place Among Young Readers" [En línea] Nueva York: Digital Book World, 09/01/2015 [Consulta: 14/01/2015] Disponible en: http:// www.digitalbookworld.com/2015/ebooks-finding-their-placeamong-young-readers/.

- Benjamin, Joel; Kallicharan, Lakshmi; McDonald, Ian y Searwar, Lloyd (editores) (1998). They Came in Ships: An Anthology of Indo-Guyanese Writing, Londres: Peepal Tree P.

- Benkler, Yochai (2002). Coase's Penguin, or Linux and the Nature of the Firm, Nueva Haven: The Yale LawJournal, no 112.

- Beverley, John (1996). Una conversación. [En línea] Entrevista de Ortega, Alicia. Kipus, revista andina de letras, $\mathrm{n}^{\circ}$ 5. Quito: Corporación Editora Nacional, 1996. [Consulta 25/4/2014]. Disponible en: http://repositorio.uasb.edu.ec/ bitstream/10644/1891/1/RK-05-Entrevista.pdf.

- Besen, Stanley M. y Kirby, Sheila Nataraj (2012). [En línea] E-books and Libraries: An Economic Perspective. Chicago: American Library Association, 2012. [Consulta: 02/02/2015] Disponible en: http://www.ala.org/transforminglibraries/sites/ala.org transforminglibraries/files/content/final \% 20economic \%20 report $\% 20$ sept2012.pdf

- Beverley, John (2004). Subalternidad y representación: debates en teoría cultural, Madrid: Iberoamericana.

- Beyhaut, Gustavo (1962). Raíces contemporáneas de América Latina, Buenos Aires: Eudeba.

- Bezos, Jeff, Amazon. [En línea]. Seattle: Amazon. [Consulta 01/03/2014]. Disponible en: http://www.amazon.com/ Books $/ \mathrm{b}$ ?node $=301731$

- Biblioteca Nacional (España). Catálogo de la Biblioteca Nacional de España. [Web] Madrid: BNE. [Consulta 31/02/2015]. Disponible en: http://catalogo.bne.es/uhtbin/webcat
- Biblioteca Nacional (Francia). Gallica.[Web] París: BNF. [Consulta 31/02/2015]. Disponible en: http://gallica.bnf.fr/ advancedsearch?lang $=\mathrm{ES}$

- Bilbija, Ksenija (2010). "Borrón y cuento nuevo: las editoriales cartoneras latinoamericanas". [En línea] Caracas: revista Nueva Sociedad, n ${ }^{\circ} 230$, noviembre-diciembre de 2010. [Consulta: 09/02/2015] Disponible en: http://www.nuso.org/ upload/articulos/3744_1.pdf.

- Birbalsingh, Frank (editor) (1988). Jahäi Bhai: An Anthology of Indo-Caribbean Literature,Toronto: TSAR Publications.

- Bloom, Harold (1995). El canon occidental: la escuela y los libros de todas las épocas, Barcelona: Anagrama.

- Bloom, Harold (2011). Le di la espalda a la Academia sin pensar que sería un éxito. Entrevista de Grau, Ana. [En línea]. Madrid: Diario ABC Madrid, 15/10/2011. [Consulta: 26/04/2014]. Disponible en: http://www.abc.es/20111015/cultura/abcpharold-bloom-espalda-academia-20111015.html.

- Bogotá39 (Sin fecha). 39 escritores menores de 39 [En línea] Bogotá: Hay Festival. Secretaría Distrital de Cultura, Recreación y Deporte de Bogotá [Consulta: 10/12/2014]. Disponible en: http://www.hayfestival.com/bogota39/esindex.aspx?skinid $=7$ \&localesetting $=\mathrm{es}-\mathrm{ES} \&$ currencysetting $=\mathrm{E}$ UR\&resetfilters $=$ true

- Bokwer (2013). Self-Publishing in the United States 20072012. [En línea] New Providence: Bokwer ProQuest, 09/10/2013 [Consulta: 03/02/2015] Disponible en: http://www.bowker.com/assets/downloads/products/ selfpublishingpubcounts_2007_2012.pdf.

- Bolaño Sandoval, Adalberto (2011). Cómo leer y por qué el canon occidental de Harold Bloom. [En línea] Barranquilla: Revista Amauta, Universidad del Atlántico, Volumen 9, número 17, Enero-Junio. [Consulta 11/03/2014]. Disponible en: https:// es.scribd.com/doc/178890172/Bolano-Sandoval-AdalbertoComo-leer-y-por-que-El-Canon-Occidental-de-Harold-

Bloom. 
- Bollier, David (2013). En torno a la economía y las relaciones del procomún. [En línea]. Madrid: Por Goteo. [Consulta 01/05/2014]. Disponible en: http://www.eldiario.es/ colaboratorio/procomun-economia-P2P-comunidadrecursos_6_128147189.html.

- Bosman, Julie (2014). "Holiday Sales Slide 60\% at Struggling Barnes \& Noble Nook Unit" [En línea]. Nueva York: The New York Times, 09/01/2014 [Consulta del: 11/01/2015] Disponible en: http://www.nytimes.com/2014/01/10/ business/media/barnes-noble-reports-steep-drop-in-holidaysales.html.

- Bourdieu, Pierre (2002 a) [1966]. Campo de poder, campo intelectual. Itinerario de un concepto, Buenos Aires: Montressor.

- Bourdieu, Pierre (2002 b). "Disposición estética y competencia artística. Lápiz: Revista internacional del arte, $\mathrm{N}^{\circ}$ 187-188 (Ejemplar dedicado a 20 años), Madrid: Moloc Ediciones, 2002, pp. 58-67 [Consulta 11/03/2014] Disponible en: http://gep21.files.wordpress.com/2010/04/2-bourdieudisposicion-estetica-y-competencia-artistica.pdf.

- Bourdieu, Pierre (1995). "El mercado de los bienes simbólicos". En Las reglas del arte. Génesis y estructura del campo literario, Barcelona: Anagrama, pp. 213-261.

- Bourdieu, Pierre (2010). El sentido social del gusto. Elementos para una sociología de la cultura, Buenos Aires: Siglo Veintiuno Editores Argentina.

- Bourdieu, Pierre (1988). La distinción: criterios y bases sociales del gusto, Madrid: Taurus.

- Bourdieu, Pierre (1999). "Una revolución conservadora en la edición”. En Intelectuales, política y poder, Buenos Aires: Eudeba.

- Bourdieu, Pierre (2005) [1985]. ¿Qué significa hablar? Economía de los intercambios lingǘsticos, Madrid: Akal.

- Brown, Stewart y McWatt, Mark (editores) (2004), The Oxford Book of Caribbean Verse, Oxford, Inglaterra: Oxford UP.

- Bueno, Mónica y Taroncher, Miguel Ángel (coordinadores) (2006). Centro Editor de América Latina. Capitulos para una historia, 1 edición, Buenos Aires: Siglo Veintiuno Editores Argentina.
- Buonocuore, Domingo (1968). Libreros, editores e impresores de Buenos Aires, Buenos Aires: CEAL.

- Cámara Argentina del Libro (CAL) (2014). Informe estadístico anual de Producción del libro argentino 2013. [Web] Buenos Aires: CAL.[Consulta: 13/01/2015] Disponible en: http://www. camaradellibro.com.ar/estadisticas/PDF/Estadisticas $\% 20$ 2013.pdf.

- Cadarso, Juan (2015). "El 35\% de los españoles no lee "nunca o casi nunca"” [En línea] Madrid: periódico Mirada 21, 09/01/2015 [Consulta: 09/01/2015] Disponible en: http:// www.mirada21.es/detalle-noticia/el-35-de-los-espanoles-nolee-34nunca34-o-34casi-nunca34-11099.

- Campal, Felicidad (2012), "Alfabetización y libros electrónicos en las bibliotecas electrónicas",en Cordón García, José Antonio; Carbajo Cascón, Fernando, Gómez Díaz, Raquel y Alonso-Arévalo, Julio (Coords.). Libros electrónicos y contenidos digitales en la sociedad del conocimiento. Mercado, servicios y derechos, Madrid: Pirámide, pp. 385-412.

- Carrenho, Carlo (2015). "In Brazil, Amazon Starts Selling Kindles Direct, Books are Next" [En línea]. Nueva York: Publishing Perspectives, 12/01/2015 [Consulta: 12/01/2015] Disponible en: http://publishingperspectives.com/2014/02/ in-brazil-amazon-starts-selling-kindles-direct-books-are-next/.

- Carta de dominio público de Europeana. [En línea]. Europeana, Biblioteca digital de la Unión Europea. [Consulta 18/01/2014]. Disponible en: http://www.publicdomaincharter.eu/.

- Casanova, Pascale (2001). La República mundial de las letras. Barcelona: Anagrama

- Castañeda, María del Carmen (2009). Una propuesta de descanonización de la literatura latinoamericana. [En línea]. Madrid: Espéculo. Revista de estudios literarios, $\mathrm{n}^{\circ} 41$ Universidad Complutense de Madrid. [Consulta 01/03/2014]. Disponible en: http://pendientedemigracion.ucm.es/info/especulo/ numero4l/descanon.html.

- Castells, Manuel (2009). Comunicación y poder, Madrid: Alianza.

- Castells, Manuel (1997). La era de la información: economía, sociedad y cultura. I. La sociedad red, Madrid: Alianza Editorial. 
- Castells, Manuel (2000). La era de la información. Economía, sociedad y cultura, 2. El poder de la identidad, Madrid: Alianza.

- Castro, Jorge (2009). "La importancia de India es obra de su industria de alta tecnología".[En línea] Buenos Aires: diario Clarín, 23/11/2009 [Consulta: 11/01/2015] Disponible en: http://politicasociedad.blogspot.com.ar/2009/11/laimportancia-de-india-es-obra-de-su.html.

- Castro, Jorge (2014). "Alibaba se vuelca a la 'nube' para competir". [En línea]. Buenos Aires: diario Clarín, 10/11/2014 [Consulta: 10/11/2014]. Disponible en: http:// www.ieco.clarin.com/economia/Alibaba-vuelca-lanubecompetir_0_1245475580.html.

- Castro, Jorge (2015). "Las limitaciones de Brasi para exportar". [En línea]. Buenos Aires: diario Clarín, 10/01/2015 [Consulta: 10/01/2015]. Disponible en http://www.ieco.clarin.com/economia/limitaciones-Brasilexportar_0_1283271844.html

- Cavallo, Guglielmo y Chartier, Roger (1998). Historia de la lectura en el mundo occidental, Madrid: Taurus.

- Cavallo, Guglielmo y Chartier, Roger (1998). Historia de la lectura en el mundo occidental, Madrid: Taurus.

- Cella, Susana (1998 a). Acerca del canon, Buenos Aires: Losada

- Cella, Susana (1998 b). Diccionario de literatura latinoamericana Buenos Aires: El Ateneo.

- Certeau, Michel de (1996). La invención de lo cotidiano. Tomos Iy II, México: Universidad Iberoamericana / ITESO / Centro de Estudios Mexicanos yCentroamericanos.

- Chartier, Roger (1992). El mundo como representación. Estudios sobre historia cultural, Barcelona: Editorial Gedisa.

- Chartier, Roger (2006). Inscribir y borrar. Cultura escrita y literatura (siglos XI-XVIII), Buenos Aires: Katz Editores.

- Chartier, Roger (2001). Las revoluciones de la cultura escrita, Barcelona: Gedisa.
- Chartier, Roger (2012). Leer la lectura. Conferencia magistral [En línea]. Santiago de Chile: 2012. [Consulta 18/04/2014] Disponible en: http://www.leechilelee.cl/wp-content/files_ mf/1363098617RogerChartier.pdf

- Chaunu, Pierre (1964), L'Amérique et les Amériques, París: Colin.

- Chowdhury, Gobinda y Foo, Schubert (editores) (2012). Digital libraries and information access: Research perspectives, Londres: Facet Publishing.

- Chowdhury, Gobinda y Foo, Schubert (2012). "Digital libraries and information access: Research trends". En Chowdhury, Gobinda y Foo, Schubert (Eds.), Digital libraries and information access: Research perspectives, Londres: Facet Publishing.

- Cohen, David y Felitti, Guilherme (2015). "A chegada da Amazon ao Brasil". [En línea] San Pablo: Revista Época Negócios, 10/02/2015. [Consulta: 23/02/2015] Disponible en: http://epocanegocios.globo.com/Informacao/Visao/ noticia/2015/02/chegada-da-amazon-ao-brasil.html.

- Colombani, Laurent; Sanderson, David y Videlaine, François (2014). The rise of Generation \#hashtag. [En línea] Boston: Bain \& Company, 06/11/2014. [Consulta: 28/01/2015] Disponible en: http://www.bain.com/Images/BAIN_BRIEF_ Generation_hashtag.pdf

- Columbia University Libraries (USA). Columbia University Libraries Catalogue. [Web] New York: Columbia. [Consulta 30/03/2014]. Disponible en: http://library.columbia.edu/.

- Comunidad Baratz (2015). "La lectura ilimitada es una moda sana... las bibliotecas saben mucho de esto". [En línea] Madrid: 09/03/2015. [Consulta 10/03/2015]. Disponible en: http://www.comunidadbaratz.com/blog/la-lectura-ilimitadaes-una-moda-sana-las-bibliotecas-saben-mucho-de-esto?utm source $=$ HS.

- Cordón García, José Antonio (2004) "La visibilidad en los circuitos de la creación: literatura y traducción". [En línea]. En Gonzalo García, Consuelo y García Yebra, Valentín (eds.), Manual de documentación y terminología para la traducción especializada, Madrid: Arco/Libros. [Consulta 18/01/2014]. Disponible en: http://eprints.rclis.org/8900/1/Cap_Visibilidad.pdf. 
- Cordón García, José Antonio (2006). "Lecturas sobre la lectura: los circuitos de compra y lectura de libros y otro aspectos de recepción actual en Europa". [En línea]. En P. Hernuñez (ed.), Lecturas sobre la lectura, Madrid: Arco Libros, pp. 735-763. [Consulta: 11/12/2014] Disponible en: http:// eprints.rclis.org/8646/1/lecturas_sobre_la_lectura.pdf.

- Cordón García, José Antonio (2006). Traducción: representatividad, presencia y disponibilidad. [En línea]. Salamanca: Pliegos de Yuste $\mathrm{N}^{\circ}$ 4, I, 2006, pp. 25-34. [Consulta22/04/2014]. Disponible en: http://www.pliegosdeyuste.eu/n4pliegos/jacordon. pdf.

- Cordón García, José Antonio (2011). La revolución del libro electrónico, Barcelona: El Profesional de la InformaciónUniversitat Oberta de Catalunya (UOC).

- Cordón García, José Antonio (2013). La edición académica será electrónica o no será. Entrevista de Arjona, Daniel [En línea]. Madrid: Diario El Mundo, suplemento El Cultural, 2013. [Consulta 27/04/2014]. Disponible en: http://www.elcultural es/noticias/LETRAS/5436/Jose_Antonio_Cordon-_La_ edicion_academica_sera_electronica_o_no_sera.

- Cordón García, José Antonio (2014). Los componentes estructurales del nuevo ecosistema del libro: editores y bibliotecas, el camino hacia la convergencia, Madrid: Lectyo. [Consulta30/04/2014]. Disponible en: http://www.lectyo.com/.

- Cordón García, José Antonio; Carbajo Cascón Fernando y Alonso-Arévalo, Julio (2011). El libro electrónico: propiedad intelectual, derechos de autor y bibliotecas, Bilbao: Deusto.

- Cordón García, José Antonio; Carbajo Cascón, Fernando Gómez Díaz, Raquel y Alonso-Arévalo, Julio (coordinadores) 2012). Libros electrónicos y contenidos digitales en la sociedad del conocimiento. Mercado, servicios y derechos, Madrid: Pirámide.

- Cordón García, José Antonio y Alonso-Arévalo, Julio (2011). Mediación y desintermediación en los entornos digitales: nuevos actores y nuevas funciones en la cadena del libro electrónico. [En línea] Anuario ThinkEPI, v. 5, pp. 121-127. [Consulta 27/04/2014]. Disponible en: http://www.thinkepi.net/tag/amazon/page/2
- Cordón García, José Antonio y Alonso-Arévalo, Julio (2012). Mediación y legitimación cultural: la impronta de las redes sociales. [En línea] Anuario ThinkEPI, v. 6, pp. 264-268. [Consulta 27/04/2014]. Disponible en: http://www.thinkepi. net/mediacion-y-legitimacion-cultural-la-impronta-de-lasredes-sociales.

- Cordón García, José Antonio; Gómez Díaz, Raquel y Fernández Gómez, M ${ }^{a}$ José (2014). "Nube de lágrimas: el efecto de la formación en los lectores digitales". [En línea]. En Nube de Lágrimas, club de lectura en la nube. Lectores digitales y lectura social, Peñaranda de Bracamonte, Salamanca: Proyecto Nube de Lágrimas, Programa Territorio E-book, Fundación Germán Sánchez Ruipérez. [Consulta 27/04/2014]. Disponible en: http://www.territorioebook.net/recursos/vozelectores/nube_ lagrimas/Informe_lectores_nube_lagrimas.pdf.

- Cordón García, José Antonio; Gómez Díaz, Raquel; Alonso-Arévalo, Julio (2011 a). Gutenberg 2.0: la revolución de los libros electrónicos, Gijón: Trea.

- Cordón García, José Antonio; Gómez Díaz, Raquel; Alonso-Arévalo, Julio $(2011$ b). Las plataformas de venta de libros electrónicos: modelos de negocio y estrategias de mercado. [En línea]. Barcelona: Revista bid - textos universitaris de biblioteconomia i documentació, número 26, junio de 2011. [Consulta: 18/04/2014]. Disponible en http://bid.ub.edu/26/cordon2. htm.

- Cordón García, José Antonio; Gómez Díaz, Raquel; Alonso-Arévalo, Julio y Alonso Berrocal, José Luis (2014). El ecosistema del libro electrónico universitario, Salamanca: Ediciones Universidad de Salamanca ( $2^{\text {a }}$ edición corregida y aumentada), Salamanca.

- Correa-Díaz, Luis (2013-2014). La poesía cibernética latinoamericana: un recorrido desde los años 50 y 60 hasta finales de la primera década del 2000. [En línea]. Cardiff: New Readings, número 13, 2013-2014, pp. 57-73. [In print] [Consulta 30/04/2014]. Disponible en: http://letras.s5.com/lcor071213.html

- Cornejo Polar, Antonio (1987). "La literatura latinoamericana y sus literaturas regionales y nacionales como totalidades contradictorias". En Pizarro, Ana (Coordinadora), Hacia una historia de la literatura latinoamericana, México: El Colegio de México/Universidad Simón Bolívar. 
- Corroto, Paula (2014 a). "Ebooks en Europa: un mercado tradicional con falta de catálogo y precios altos". [En línea], Madrid: periódico El Diario, 20/10/14 [Consulta: 30/10/2014]. Disponible en: http://www.eldiario.es/turing/ propiedad_intelectual/mercado-tradicional-catalogo-preciosaltos_0_311469836.html.

- Corroto, Paula (2014 b). "Los ebooks después del ‘boom’ de la autopublicación en España". [En línea] Madrid: periódico El Diario, 23712/2014 [Consulta: 2/1/2015 Disponible en: http://www.eldiario.es/turing/industria_editorial/Bajasoufle-autopublicacion_0_337716838.html.

- Cortina, Guadalupe (2005). Conversación con David William Foster. [En línea]. Revista Hipertexto 2, Verano 2005. Edinburg. The University of Texas-Pan American, pp. 85-91. [Consulta 02/11/2014] Disponible en: http://portal.utpa.edu/utpa main/daa_home/coah_home/modern_home/hipertexto_ home/docs/Hiper2Cortina.pdf.

- Costa, Jordi (2003). "Notas sobre lo Trash. Apuntes para la redención de una contracultura mutante". En: Cultura porqueria. Una espeleologia del gust, Barcelona: Centre de Cultura Contemporània de Barcelona, p. 144-153.

- Dedieu, Horace (2013). "Measuring the iBook market" [En línea] Helsinski: 28/02/2013 [Consulta del 14/01/2015] Disponible en: http://www.asymco.com/2013/02/28/ measuring-the-ibook-market/

- De la Campa, Román (2008). "Literatura, neoliberalismo, poscolonia: acotaciones y precisiones". Revista $A$ Contracorriente Vol. 6, n ${ }^{\circ}$. 1, Fall 2008, 93-111. Raleigh: North Carolina State University: Department of Foreign Languages and Literatures [Consulta: 08/01/2015] Disponible en: http://www.ncsu.edu/ acontracorriente/fall_08/r_dela_ca.pdf.

- Del Rey, Jason (2013), How Big Is Amazon's Kindle Business. Morgan Stanley Takes a Crack at It. [Web [En línea] Nueva York: Wall Street Journal, Sección All Things, /08/2013 [Consulta: 08/01/2015] Disponible en: http://allthingsd. com/20130812/amazon-to-sell-4-5-billion-worth-of-kindlesthis-year-morgan-stanley-says/.

- Diccionario de poetas latinoamericanos. [En línea] Revista Libros Ë Letras,
- Bogotá: Fundación Libros \& Letras. [Consulta: 03/11/14] Disponible en: http://www.librosyletras.com/p/diccionariolatinoamericano-de-poetas.html.

- Diego, Estrella de (2015). "Cambio de paradigma" [En línea] Madrid: diario El País, 26/02/2015. [Consulta: 26/02/2015] Disponible en: http://cultura.elpais.com/ cultura/2015/02/19/babelia/1424346537_484701.html.

- Diego, José Luis de (director) (2006). Editores y políticas editoriales en Argentina, 1880-2000, $1^{\mathrm{a}}$ edición, Buenos Aires: Fondo de Cultura Económica.

- Diego, José Luis de (2004). "Políticas editoriales e impacto cultural en Argentina (1940 - 2000)”. [En línea] III Congreso Internacional de la Lengua Española. Rosario, 2004. [Consulta 02/03/2014] Disponible en: http://congresosdelalengua.es/ rosario/ponencias/internacional/diego_j.htm

- Dillworth, Dianna (2015). "HarperCollins eBooks Now in EPUB3". [Web] Nueva York: Adweek Blog Network, 14/01/2015 [Consulta: 14/01/2015] Disponible en: http:// www.adweek.com/galleycat/harpercollins-ebooks-now-inepub3/97539

- Di Nucci, Sergio; Recoaro, Nicolás y Grieco y Bavio, Alfredo (2014 a). De la Tricolor a la Wiphala. Narrativa contemporánea de Bolivia, Buenos Aires: Santiago Arcos Editor.

- Di Nucci, Sergio; Recoaro, Nicolás y Grieco y Bavio, Alfredo (2014 b). Los chongos de Roa Bastos. Narrativa contemporánea de Paraguay, Buenos Aires: Santiago Arcos Editor, 2014

- Di Nucci, Sergio; Recoaro, Nicolás y Grieco y Bavio, Alfredo (2014 c), "Relatos variados como comida boliviana". Entrevista de Sucarrat, Mariana. [En línea] Buenos Aires: diario Tiempo Argentino, 11/10/14. [Consulta 14/11/2014] Disponible en: http://tiempo.infonews.com/edicion/1596/ entrevistas

- Donnell, Alison y Bucknor, Michael (editores) (2011). The Companion to Anglophone Caribbean Literature, Londres: Routledge

- Donnell, Alison y Lawson Welsh, Sara (editoras) (1996). The Routledge Reader in Caribbean Literature, Londres: Routledge. 
- Douglas, Mary e Isherwood, Baron (1979). El mundo de los bienes. Hacia una antropología del consumo, México: Grijalbo.

- Eagleton, Terry (1988). Una introducción a la teoría literaria, México: Fondo de Cultura Económica.

- El espacio iberoamericano del libro 2012. [En línea] Bogotá: CERLALC-UNESCO, 2012. [Consulta: 08/01/2015] Disponible en: file:///Users/editorvilagmailcom/Downloads/ Libro\%20Cerlalc\% 202012.pdf.

- El sector del libro en España 2012-2014 (2014), Madrid: Observatorio de la Lectura y del Libro.

- Encuesta Nacional de Consumos Culturales 2013 (2014) [Web] Buenos Aires: Secretaría de Cultura de la Nación de República Argentina. [En línea] [Consulta 13/01/2015] Disponible en: http://sinca.cultura.gob.ar/sic/encuestas/.

- Engelhardt, Tom (1991)."Bottom Line Dreams", Barcelona: Letra Internacional, núm. 21-22, primavera de 1991, pp. 3-11.

- Escarpit, Robert (1968). La revolución del libro, Madrid: Alianza.

- Escarpit, Robert (1971). Sociología de la literatura, Barcelona: Oikos-Tau

- Esposito, Joseph J.; Walker, Kizer; y Ehling, Terry (2012), PDA and the university press. A report prepared for The Andrew W. Mellon Foundation. [En línea] Baltimore/Ithaca: The Johns Hopkins University Press/Cornell University Library, 26/09/2012. [Consulta: 16/01/2015] Disponible en: https://jscholarship library.jhu.edu/bitstream/handle/1774.2/36210/PDA\%20 and $\% 20$ the $\% 20$ University $\% 20$ Press $\% 20$ FINAL $\% 202012-10$ 15.pdf.

- Esteban, Chiqui y Quirós, Francisco. Mapa de las redes sociales 2014 [En línea] Burgos: iRedes/ BBVA/Telefónica/ Ayuntamiento de Burgos, 20/02/2014 [Consulta: 14/01/2015] Disponible en: http://www.iredes.es/2014/02/mapairedes-2014/.

- Ethnologue. Statistical Summaries [En línea]. [Consulta: 28/01/2015]. Disponible en: http://www.ethnologue.com/ statistics/family.
- Europeana. European Digital Library. The Netherlands: Europeana. [Consulta: 01/03/2014]. Disponible en: http://www.europeana.eu/portal/search. $\mathrm{html}$ ?query $=$ ebooks\&rows $=24 \& q \mathrm{f}=\mathrm{LANGUAGE} \% 3$ Aes .

- Fariza,Ignacio(2015). "La UE cree que las ayudas a Amazon en Luxemburgo pueden ser ilegales" [En línea] Madrid, diario El País, 16/01/2015. [Consulta: 16/07/2015] Disponible en: http://economia.elpais.com/economia/2015/01/16/ actualidad/1421434389_901438.html,

- Federación de Gremios de Editores de España. $2^{a}$ encuesta sobre el libro digital en España: Impacto de la digitalización en el catálogo, canales de distribución y de venta y politica comercial. [En línea]. Madrid: Federación de Gremios de Editores; Fundación Germán Sánchez Ruipérez. [Consulta: 02/05/2014] Disponible en: file:///Users/editorvilagmailcom/Downloads/2a_encuesta_ sobre_el_libro_digital_en_espa\%C3\%B1a-2011.pdf,

- Ferenczi, Imre, y Willcox, Walter F. (1929). International Migrations, Nueva York: National Bureau of Economic Research.

- Fleck, Robert (2014). El sistema del arte en el siglo XXI. Museos, artistas, coleccionistas, galerías, Buenos Aires: Mardulce.

- Forbes Statista (2014). "Revenue from e-book sales in the United States from 2008 to 2018 (in billion U.S. dollars)". [En línea] Nueva York: 30/09/14 [Consulta: 28/10/2014] Disponible en: http://www.statista.com/statistics/190800/ ebook-sales-revenue-forecast-for-the-us-market/.

- Foster, David William (1991). Latin American Writers on Gay and Lesbian Themes: A Bio-Critical Sourcebook, Austin: University of Texas Press

- Foster, David William (2005). En Cortina, Guadalupe (2005), Conversación con David William Foster. [En línea]. Revista Hipertexto 2, Verano 2005. Edinburg: The University of Texas-Pan American, pp. 85-91. [Consulta 02/11/2014] Disponible en: http://portal.utpa.edu/utpa_main/daa home/coah_home/modern_home/hipertexto_home/docs/ Hiper2Cortina.pdf. 
- Fottrell, Quentin (2014). "iPhones could become most popular e-reader. How smartphone screens are changing book Reading". [En línea] Nueva York: Wall Street Journal, 11/05/2014. [Consulta: 11/05/2014] Disponible en: http://www.marketwatch com/story/iphones-could-become-most-popular-ereader-2014-05-09.

- Franco, Jean (1989). Plotting Women. Gender and Representation in México, Nueva York: Columbia.

- Free-Ebooks. Free-eBooks. [Web]. [Consulta: 30/03/2014]. Disponible en: http://espanol.free-ebooks.net/.

- Friedman, Jane (2015). "How E-Books Have Changed the Print Marketplace: Digital Book World, Day 3" [Blog] Charlottesville: Blog,16/01/2015 [Consulta: 16/01/2015] Disponible en: http://janefriedman.com/2015/01/16/ ebooks-print-market/.

- Fuguet, Alberto y Gómez, Sergio (editores) (1996). Mc Ondo (una antología de nueva literatura hispanoamericana), Barcelona: Gijalbo-Mondadori.

- Fundación Copyleft (2014). ¿Qué es Copyleft? [En línea] Madrid: Fundación Copyleft [Consulta: 02/04/2014] Disponible en: http://fundacioncopyleft.org/es/9/que-escopyleft

- Furtado, José Antonio (2012). "Self-publishing: ¿tsunami o "business as usual"? En Cordón García, José Antonio; Carbajo Cascón, Fernando; Gómez Díaz, Raquel y Alonso-Arévalo, Julio (coordinadores), Libros electrónicos y contenidos digitales en la sociedad del conocimiento: mercado, servicios y derechos, Madrid: Pirámide.

- Galán Pérez, José Manuel (1986), Análisis estructural del sector editorial español Salamanca - Madrid: Fundación Germán Sánchez Ruipérez, - Pirámide.

- Gandhi. Librerías Gandhi. [Web] México D.F: Gandhi. [Consulta: 31/03/2014]. Disponible en: http://www.gandhi. com.mx/.
- Gammon, Julia y O'Neill, Edward (2011), OhioLINKOCLC Collection and Circulation Analysis Project 2011. Dublin, Ohio: OCLC Research, septiembre 2011. [Consulta: 16/01/2015] Disponible en: http://www.oclc.org/content/dam/research/ publications/library/2011/2011-06.pdf.

- Gantz, John F. (director) (2008). Diverse and Exploding Digital Universe. An Updated Forecast of Worldwide Information Growth Through 2011. Framingham: IDC White Paper/EMC. [Consulta: 29/03/2014] Disponible en: http://www.emc. com/collateral/analyst-reports/diverse-exploding-idc-execsummary.pdf.

- García, Joaquín (2015). "Los títulos de ficción triunfan en el formato digital". [Web] Madrid: Todoereaders.com, 18/01/2015. [Consulta: 18/01/2015] Disponible en: http:// www.todoereaders.com/los-titulos-de-ficcion-triunfan-en-elformato-digital.html.

- García Canclini, Néstor (1984). Las culturas populares en el capitalismo, México: Nueva Imagen.

- García Canclini, Néstor (coordinador) (1993). El consumo cultural en México, México: CONACULTA.

- García Canclini, Néstor (1995). Consumidores y ciudadanos. Conflictos culturales de la globalización, México: Grijalbo,.

- García Canclini, Néstor (1999). La globalización imaginada, Buenos Aires: Editorial Paidós.

- García Canclini, Néstor (2015) "La cultura global fue una ficción". Entrevista de Oybin, Marina [En línea], Buenos Aires: Revista Ñ, 23/9/13 [Consulta: 29/10/2014] Disponible en: http://www.revistaenie.clarin.com/ideas/filosofia/NestorGarcia-Canclini-cultura-global-ficcion_0_997100309.html

- García Canclini, Néstor; Cruces, Francisco y Urteaga Castro Pozo, Maritza (2012). Fóvenes, culturas urbanas y redes digitales, Buenos Aires: Ariel/Fundación Telefónica.

- García Canclini, Néstor y Moneta, Carlos (compiladores), Las industrias culturales en la integración latinoamericana. Buenos Aires: EUDEBA, 1999. 
- García Pinto, Magdalena (2004). "Isabel Allende". En Balderston, Daniel y Gonzalez, Mike (editores) (2004), Encyclopedia of Latin American and Caribbean Literature 1900-2003, Londres-Nueva York: Routledge, pp. 53.

- Garza, Mercedes de la (1980). Literatura maya. Antología Popol Vuh, Memorial de Sololá, Libro de Chi-lam Balam de Chumavel, Rabinal Achí, Libro de los Cantares de Dzitbalché, Título de los señores de Totonicapán, Las historias de los Xpantzay, Códice de Calkinî), Caracas: Biblioteca Ayacucho.

- Geli, Carles (2008). "Malos tiempos para libreros y distribuidores". [En línea]. Madrid: diario El País, 20/06/2008. [Consulta: 15/04/2014] Disponible en: http://elpais.com/ diario/2008/06/20/cultura/1213912806_850215.html.

- Geli, Carles (2013). La autoedición explota en Fráncfort". [En línea]. Madrid: diario El País, 12/10/2013. [Consulta: 03/02/2015] Disponible en: http://cultura.elpais.com/ 03/02/2015] Disponible en: http://cultura.elpais.com/
cultura/2013/10/11/actualidad/1381522683_036441.html.

- Gil, Manuel (2014) [2013]. "Sin prejuicios ni temores: Un posible modelo de venta digital a Bibliotecas" [Web] Madrid: Blog @ntinomias Libro, 2014 [tomado de la revista Madrid, TRAMA \& texturas, $\mathrm{n}^{\circ}$ 22, 2013] [Consulta: 15/01/2015] Disponible en: https://antinomiaslibro.files. wordpress.com/2015/01/sin_prejuicios_sin_temores.pdf.

- Gilbert,Jonathan (2014). "Latin American 'e' market stalls" [En línea] Londres: The Bookseller. 12/05/14. [Consulta: 23/12/2014]. Disponible en: http://www.thebookseller.com/ news/latin-american-e-market-stalls.

- Giorgi Gabriel "best-sellers". En Balderston, Daniel y Gonzalez, Mike (editores) (2004), Encyclopedia of Latin American and Caribbean Literature 1900-2003, Londres-Nueva York: Routledge, pp. 174

- Giunta, Andrea (1999). "Crítica de arte y Guerra Fría en la América Latina de la Revolución”. Ponencia presentada en la sesión anual del seminario internacional "Los estudios de arte desde América latina: temas y problemas" dirigido por la Mtra. Rita Eder y organizado por la UNAM y The Getty Grant Foundation. Buenos Aires, 8 al 21 de octubre de 1999 Disponible en: http://www.esteticas.unam.mx/edartedal/ PDF/Buenosaires/complets/giunta_buenosaries99.pdf.
- Giunta, Andrea (2001). 'El 'triunfo' de la pintura argentina. Nacionalismo internacionalista en los sesenta". Comunicación presentada en el congreso del año 2001 de LASA (Latin American Studies Association), Washington D.C. Disponible en: http://proa.org/online/file_224_esp.doc.

- Glissant, Édouard (1981). Le Discours antillais, París: Seuil.

- Glissant, Édouard (1990). Poétique de la Relation, París: Gallimard

- Glissant, Édouard (1998). "Nous sommes tous des créoles". Entrevista de Clermont, Thierry y Casamayor, Odette [En línea]. París: revista Regards, $\mathrm{n}^{\circ}$ 31, 01/01/1998. [Consulta: 30/01/2015] Disponible en: http://www.regards.fr/accespayant/archives-web/edouard-glissant, 794 .

- Glissant, Édouard (2008). "Creolization in the Making of the Americas". Caribbean Quaterly, marzo-junio 2008 Vol. 54 Issue 1/2, marzo de 2008.

- Gonzalo García, Consuelo y García Yebra, Valentín (editores) (2004). Manual de documentación y terminología para la traducción especializada, Madrid: Arco/Libros. [Consulta 18/01/2014]. Disponible en: http://eprints.rclis.org/8900/1/ Cap_Visibilidad.pdf.

- Google Books. [Web] Mountain View: Google. [Consulta : 21/03/2014]. Disponible en: http://books.google.es/.

- González de Requena Redondo, Fernando (2012). "Política digital y nuevas prácticas tecnológicas". En García Canclini, Néstor, Cruces, Francisco y Urteaga Castro Pozo, Maritza. Fóvenes, culturas urbanas y redes digitales, Buenos Aires: Ariel/Fundación Telefónica, 2012, pp. 229-251.

- Graw, Isabelle (2013). ¿Cuánto vale el arte?, Buenos Aires: Mardulce.

- Grillo, Rafael (2013). Corpus y Canon: ¿democracia vs. autoritarismo?. [Web] [En línea] La Habana: Isliada, 7/8/13 [Consulta: 2/11/14] Disponible en: http://www.isliada. org/articulos/2013/08/corpus-y-canon-democracia-vsautoritarismo/.

- Grimson, Alejandro (2011). Los límites de la cultura, Buenos Aires: Siglo Veintiuno Editores. 
- Gross, Manuel (2014). Manifiesto del Movimiento Makers: El trabajador del siglo 21 es un artesano. [Blog]. [En línea]. Santiago de Chile: Pensamiento Imaginactivo. [Consulta: 02/05/2014] Disponible en: http://manuelgross.bligoo.com/20140227manifiesto-del-movimiento-makers-el-trabajador-del-siglo-21es-un-artesano

- Gorys, Boris (2014). "Boris Groys: el gran crítico sale a ruedo". [En línea] Entrevista de Prieto, Ana, Buenos Aires: Revista Ñ, 13/11/14 [Consulta: 10/11/2014] Disponible en http://www.revistaenie.clarin.com/arte/Boris-Groys-grancritico-ruedo_0_1244875530.html

- Grupo Planeta. Casa del libro. [Web] Madrid: Casa de Libro. [Consulta: 30/03/2014]. Disponible en: http://www. casadellibro.com/ebooks.

- Hall, Suart (1991). "The local and the Global: Globalization and Ethnicity". En King, Anthony D. (editor), Culture Globalization and the World-System. Contemporary Conditions for the Representation of Identity. Macmillan/State University of New York at Binghamton, Binghamton, pp. 19- 39.

- Hall, Stuart (2008). “¿Cuándo fue lo postcolonial? Pensar al límite”. En Mezzadra, Sandro (compilador), Estudios postcoloniales. Ensayos fundamentales, Madrid: Traficantes de Sueños.

- Halperín Donghi, Tulio (1989). Historia contemporánea de América Latina, Madrid: Alianza.

- Hannerz, UIf (1996). Conexiones transnacionales, Madrid: Cátedra

- Hazard Owen, Laura (2013). Ebooks made up 20\% of the U.S consumerbookindustry in 2012, up from 15\% in 2011. [Web] [En línea] San Francisco: Paid Content.Org. [Consulta: 03/05/2014]. Disponible en: http://gigaom.com/2013/05/14/ebooksmade-up-20-of-the-u-s-consumer-book-industry-in-2012-upfrom-15-in-2011/.

- Helder, Daniel; Henderson, Daiana y Orge, Bernardo (2014). 1.000 millones: poesía en lengua española del siglo XXI, Rosario: Editorial Municipal de Rosario.
- Herbst-Bayliss, Svea y Forgione, Sam. (2015) [En línea] "Top U.S. hedge funds cut Apple stakes ahead of alltime high", Londres: Reuters, 18/02/2015. [Consulta: 22/02/2015] Disponible en: http://www.reuters.com/ article/2015/02/18/investments-funds-highlights-update-3co-idUSL1N0VR24J20150218.

- Henríquez Ureña, Pedro (1978). La Utopía de América, Caracas: Biblioteca Ayacucho.

- Henríquez Ureña, Pedro y Reyes, Alfonso (1983). Epistolario intimo, Santo Domingo: Universidad Nacional Biblioteca Ayacucho.

- Huntington, Samuel. (1994) La tercera ola. La democratización a finales del siglo XX, Madrid: Paidós.

- Ibañez Ridao, José Luis (2014). La guerra digital se encanalla, Iy II. (2014) [Web] [En línea] Madrid: Zoom News, 25/08/2014 [Consulta: 08/01/2015] Disponible en: http:// www.zoomnews.es/371431/letras-y-tretas/guerra-digital-seencanalla-y-ii.

- Infuz Digital Blog (2012). "Digital Ecosystem, infographic". Saint Louis: Integrity Corp. [Consulta: 08/02/2015] Disponible en: http://blog.infuz.com/approach/.

- Invernizzi, Hernán y Gociol, Judith (2002). Un golpe a los libros. Represión a la cultura durante la última dictadura militar, Buenos Aires: Eudeba.

- Jackson, William (1997). "The 80/20 archives: a study of use its implications". [En línea] Palm Beach: Archival Issues. [Consulta: 19/01/2015] Disponible en: http://minds. wisconsin.edu/bitstream/handle/1793/45848/MA22_2_4. pdf? sequence $=3$.

- Jenkins, Henry (2008). Convergence Culture: la cultura de la convergencia de los medios de comunicación, Barcelona: Paidós.

- Jenkins, Henry (2009). Fans, Blogueros y Videojuegos: La cultura de la colaboración, Barcelona: Paidós. 
- Jhonsa, Eric (2013). "U.S. district judge Denise Cole declares Apple (AAPL) guilty of conspiring to fix e-book prices" [En línea] Nueva York: Seeking Alpha, 10/07/2013 [Consulta: 10/01/2015] Disponible en: http://seekingalpha. com/news/1129372.

- Johnson, Steven (2004). Emergence: the conected lives of ants, brains, cities, and software, Nueva York: Scribner.

• Jones, Philip (2015). "Surprise, surprise". [En línea] Londres: The Bookseller. 16/01/15. [Consulta: 21/01/2015]. Disponible en: http://www.thebookseller.com/blogs/surprisesurprise

- Kan, Elianna (2015). "Global Ebook Retailers Race to Beat Amazon into Latin America". [En línea] Nueva York: Publishing Perspectives, 12/01/2015 [Consulta: 12/01/2015] Disponible en: http://publishingperspectives.com/2015/01/ global-ebook-retailers-race-beat-amazon-latin-america/.

- Katz, Alejandro (2003). “¿Qué es el libro hoy?”. En Sagastizábal de Leandro y Esteves Fros, Fernando. El mundo de la edición de libros, Buenos Aires: Paidós, pp. 14-32.

- Keefe, David (2013). "Brand ecosystems" [En línea] San Francisco: Landor Associates. Diciembre de 2013, pp. 1617 [Consulta: 12/02/2015] Disponible en: http://landor $\mathrm{com} / \# ! /$ talk/articles-publications/articles/branding-in-thenew-era-of-ecosystems/.

- King, Anthony D. (editor) (1991). Culture Globalization and the World-System. Contemporary Conditions for the Representation of Identity. Macmillan/State University of New York at Binghamton, Binghamton.

- Klibanski, Mónica (2006). Grandes bibliotecas digitales y virtuales del mundo. [En línea]. Buenos Aires: portal Educ.ar. [Consulta: 10/05/2014] Disponible en: http://portal.educ. ar/debates/educacionytic/super-sitios/grandes-bibliotecasdigitales-y-virtuales-del-mundo.php.

- Krakowiak, Fernando Andrés (2003). Concentración transnacionalización en las industrias culturales, surgimiento y consolidación de los conglomerados transnacionales de medios. Director: Guillermo Mastrini. Tesina de grado, Buenos Aires: Facultad de Ciencias Sociales de la UBA, Carrera de Comunicación, Noviembre 2003
- Krise, Thomas (editor) (1999). Caribbeana: An Anthology of English Literature of the West Indies, 1657-1777,Chicago: University of Chicago Press.

- Kelty, Christopher (2008). Two bits: The Cultural Significance of Free Software, Durham: Duke University Press.

- Lafuente, Esteban (2014). "Los ebooks representan menos del 5 por ciento de las ventas de libros en la Argentina" [Web] [En línea] Buenos Aires: Infotechnology.com 06/08/2014 [Consulta: 12/01/2015] Disponible en: http://www. infotechnology.com/negocios/Los-ebooks-aun-no-lograndespegar-en-la-Argentina-20140806-0003.html.

- Lampert, Cory (2013). Required Reading: A Librarian's 2.0 Manifesto. [En línea]. Las Vegas: University of Las Vegas, Digitization Projects at UNLV Libraries. [Consulta: 30/04/2014]. Disponible en: http://www.library.unlv.edu/ digitization-projects-unlv-libraries/2007/09/requiredreading-librarians-20-manifesto.html.

- Lebovics, Herman (2000). La misión de Malraux; salvar la cultura francesa de las fábricas de sueños, Buenos Aires: Eudeba.

- Leer-e. [Web]. Pamplona: Leer-e. [Consulta 21/11/2014]. Disponible en: http://www.leer-e.es/.

- Lemus, Jorge (2008). "Un modelo de revitalización lingüística: el caso del náhuat/pipil de El Salvador". [En línea] El Salvador: revista Experiencias educativas de publicación $\mathrm{n}^{\circ}$ 2, Universidad Don Bosco, marzo de 2008. [Consulta: 28/01/2015] Disponible en: http://www.unavarra.es/ digitalAssets/172/172558_JLemus-revitalizaci--n-linguisticadel-Nahuat.pdf.

- Leon-Portilla, Miguel (2002). In the Language of Kings: An Anthology of Mesoamerican Literature, Pre-Columbian to the Present, Nueva York: W. W. Norton \& Co.

- Lerner, Fred (1999). Historia de las bibliotecas del mundo, Buenos Aires: Troquel.

- Lessig, Lawrence (2008). REMIX: Making Art Commerce Thrive in the Hybrid Economy, Nueva York: Penguin Press. 
- Librería Santa Fe. [Web]. Santa Fe: Librería Santa Fe. [Consulta: 30/03/2014]. Disponible en: http://www.lsf.com. ar/.

- Linnemann, Maja (2013). "Cloudary: A Chinese online literature platform is using cooperation to conquer the market" [En línea] Frankfurt: Frankfurt Quarterly, 18/07/2013 [Consulta: 14/01/2015] Disponible en: http://blog.book-fair. com/2013/07/18/faq-summer2013-trendingtopics/.

- Lipovetsky, Gilles y Serroy, Jean (2015). La estetización del mundo. Vivir en la época del capitalismo artístico, Barcelona: Anagrama.

- LitRes [Web] Moscú: Rusia [Consulta: 10/01/2015] Disponible en: http://www.litres.ru/.

- Lotman, Iuri (1998). «El fenómeno de la cultura». En La semiósfera. II. Semiótica de la cultura, del texto, de la conducta y del espacio (Selección y traducción Desiderio Navarro), Madrid: Cátedra, págs. 25-41.

- Lotman, Iuriy Uspenski, Boris (1979). «Sobre el mecanismo semiótico de la cultura». En Lotman y Escuela de Tartu: Semiótica de la cultura, Madrid: Cátedra, pp. 67-92.

- Magán Walls, José Antonio y Tardón González, Eugenio (2014). "Google Libros" yla digitalización masiva: La aportación de la Universidad Complutense de Madrid”. [En línea] Madrid: Revista General de Información y Documentación

- Vol. $24 \mathrm{n}^{\mathrm{o}}$ 1, enero-junio de 2014. [Consulta: 22/01/2015] Disponible en: http://revistas.ucm.es/index.php/RGID/ article/view/9-24/42440.

- Malamud, Andrés (2007). "Estado". En Aznar, Luis y De Luca, Miguel (editores), Política. Cuestiones y problemas, Buenos Aires, Emecé.

- Maristany, José Javier (2008). “¿Una teoría queer latinoamericana? Postestructuralismo y políticas de la identidad en Lemebel". [En línea] París: Lectures du genre $n^{\circ} 4$ : Lecturas queer desde el Cono Sur, julio de 2008 [Consulta: 21/12/2014]. Disponible en: http://www.lecturesdugenre.fr/Lectures_du_ genre_4/Maristany_files/MARISTANY.pdf.

- Martel, Frédéric (2014). Cultura mainstream. Cómo nacen los fenómenos de masas, Buenos Aires: Taurus.
- Martín Aceña, Pablo; Meisel, Adolfo y Newland, Carlos (editores) (1999). Madrid: Revista de Historia Económica Año XVII, número especial: "La historia económica en América Latina".

- MartínRodrigo,Inés(2013). "Nubico,elSpotifydeloslibros" [En línea] Madrid: Periódico ABC. [Consulta: 26/04/2014]. Disponible en: http://www.abc.es/cultura/libros/20130926/ abci-nubico-ebooks-libros-circulo-201309261319.html.

- Martínez, Diego (2012). "La influencia de la Unión Europea en las transiciones democráticas sudamericanas. El caso argentino" [En línea]. La Plata: revista Relaciones Internacionales $n^{\circ} 42$, Instituto de Relaciones Internacionales (IRI), Facultad de Ciencias Jurídicas y Sociales, Universidad Nacional de La Plata, noviembre de 2012. [Consulta: 16/03/2015] Disponible en: http://sedici.unlp.edu.ar/ bitstream/handle/10915/24655/Documento_completo. pdf? sequence $=1$.

- Maunás, Delia (1995). Entrevistas a Boris Spivacow. Memoria de un sueño argentino, Buenos Aires: Colihue.

- Medición de la Sociedad de la Información. [En línea] Ginebra: Unión Internacional de Telecomunicaciones (UTI), octubre de 2012. [Consulta: 13/01/2015] Disponible en: http://www.itu.int/ITU-D/ict/publications/idi/ material/2012/MIS2012-ExecSum-S.pdf.

- Mezzadra, Sandro (compilador) (2008). Estudios postcoloniales. Ensayos fundamentales, Madrid: Traficantes de Sueños.

- McLuhan, Marshall (1972) [1962]. La galaxia Gutenberg. Génesis del Homo Typographicus, Madrid: Aguilar.

- McLuhan, Marshall y Nevitt, Barrington (1972). Take Today, the Executive as Dropout, San Diego: Harcourt Brace Jovanovich.

- Merino, Marcos (2014). La salud del español en Internet. [En línea]. Madrid: Ticbeat. [Consulta: 10/05/2014]. Disponible en: http://cyborgcultura.ticbeat.com/salud-espanol-internet/.

- Mignolo, Walter (1998). «Los cánones y (más allá de) las fronteras culturales (o ¿̇de quién es el canon del que hablamos?)». En Sullá, Enric (editor) (1998), El canon literario, Madrid: ArcoLibros pp. 237-270. 
- Mignolo, Walter (1994-1995). «Entre el canon y el corpus. Alternativas para los estudios literarios y culturales en y sobre América latina», Nuevo Texto Crítico, 2, 14-15, págs. 23-36.

- Mignolo, Walter (2003). Historias locales/diseños globales. Colonialidad, conocimientos subalternos y pensamiento fronterizo, Madrid: Akal.

- Miguel de Bustos, Juan Carlos (1993). Los grupos multimedia Estructuras y estrategias en los medios europeos, Barcelona: Bosch.

- Millán, José Antonio (1998). De redes y saberes. Educación y cultura en las nuevas tecnologías, Madrid: Santillana.

- Miilliot, Jim (2011), The Latest E-Book Buying Trends. [En línea]. Publisher's Weekly. [Consulta: 01/05/2014] Disponible en: http://www.publishersweekly.com/pw/by-topic/digital/ content-and-e-books/article/48418-the-latest-e-book-buyingtrends.html.

- MIT Technology Review. [En línea]. The 50 Smartest Companies. Cambridge: Massachusetts Institute of Technology, 2014 [Consulta: 03/01/2015] Disponible en: http://www2 technologyreview.com/tr50/2014/.

- Mizraje, María Gabriela (2003). "La perspectiva de género en la Universidad. Y 'Mariquita Sánchez de Thompson"”. Entrevista de Pfleiderer, Elsa. Venado Tuerto: revista Lote [Consulta: 01/03/2015] Disponible en: http:// fernandopeirone.com.ar/Lote/nro088/perspectiva.htm.

- Mizraje, María Gabriela (2007). "Latinoamérica, un cuento sobre datos ciertos" [En línea]. Minneapolis: Hispanic Issues On Line 01/2007, No. 2, 2007 (Ejemplar dedicado a: Estudios Hispánicos: perspectivas internacionales), págs. 4754 [Consulta: 11/11/14] Disponible en: http://hispanicissues. umn.edu/assets/pdf/5-HIOL-2-3.pdf.

- Monge, Yolanda (2014). "Amazon vs Hachette y el debate sobre los monopolios en la distribución de la cultura". [En línea] Buenos Aires: diario La Nación, 04/06/2014 [Consulta: 11/01/2015] Disponible en: http://www.lanacion.com. ar/1698276-amazon-vs-hachette-y-el-debate-sobre-losmonopolios-en-la-distribucion-de-la-cultura.
- Monroe, Juli (2014). "Sony to shut down Reader store: customers will move to Kobo" [Web] Philadelphia: Teleread, 06/02/2014. [Consulta: 22/01/2015]

- Disponible en: http://www.teleread.com/bookstore/ sony-to-shut-down-reader-store-customers-will-move-tokobo/.

- Mora, Rosa (1997). “30 años de 'Cien años de soledad'“[En línea] Madrid: diario El País, 09/03/1997 [Consulta: 12/02/2015] Disponible en: http://www.udel.edu/leipzig/ texts2/ela09037.htm.

- Moraña, Mabel (2004). "Literatura, subjetividad y estudios culturales". En Walsh, Catherine (editora) (2004), Estudios culturales latinoamericanos, retos desde y sobre la región andina, Quito: Universidad Andina Simón Bolívar y Abya Yala.

- Moraña, Mabel (editora) (2000). Nuevas perspectivas desde /sobre América Latina: El desafio de los estudios culturales, Santiago de Chile: Editorial Cuarto Propio /Instituto Internacional de Literatura Iberoamericana.

- Moreno, Hilario; García, Santiago y Sardi, Valeria (2014). "Los números de la lectura en Argentina. Análisis de los resultados de la $2^{\text {a }}$ Encuesta Nacional de Hábitos de Lectura" en Lectores, libros, lecturas Cambios en las prácticas y hábitos de lectura, Buenos Aires: Ministerio de Cultura de la Nación.

- NASDAQ. [Web] Cloudary Corp. Nueva York: NASDAQ, status del 07/12/2013 [Consulta: 13/12/2015] Disponible en: http://www.nasdaq.com/markets/ipos/company/cloudarycorp-856191-67233.

- Nicholson, Brantley y McClennen, Sophia (editores) (2013). The Generation of '72, Raleigh: Editorial Contracorriente.

- Nubico. [Web]. Barcelona: Nubico. [Consulta: 01/04/2014]. Disponible en: https://www.nubico.es/.

- Ong, Walter (1982). Orality and Literacy: The Technologizing of the Word, Londres: Routledge.

- Orera Orera, Luisa (2011). "La biblioteca. Una revisión del concepto". En López Yepes, José y Osuna Alarcón, Rosario (Coord.), Manual de Ciencias de la Información y Documentación, Madrid: Pirámide, pp. 81-101. 
- Ortega, Enedina (2012). "Aprendices, emprendedores y empresarios". En García Canclini, Néstor; Cruces, Francisco y Urteaga Castro Pozo, Maritza (2012), Jóvenes, culturas urbanas y redes digitales, Buenos Aires: Ariel/Fundación Telefónica, pp. 111-130.

- Oszlak, Oscar; Fontana, Andrés y Gutiérrez, Leandro (1982). La formación del estado argentino, Buenos Aires: Editorial de Belgrano.

- Oszlak, Oscar (1982). "Reflexiones sobre la formación del Estado y la construcción de la sociedad argentina", Buenos Aires: revista Desarrollo Económico, no 21 (84), enero-marzo 1982.

- Oszlak, Oscar (2007). "El Estado democrático en América Latina. Hacia el desarrollo de líneas de investigación" Caracas: revista Nueva Sociedad n 210, julio-agosto de 2007.

- Paredes, Viviana (2014). [En línea] Stealth con Casa del Libro (España), 19/6/2014 [Consulta: 2/1/2015] Disponible en: http://viviana.simplicissimus.it/2014/06/19/stealth-concasa-del-libro-espana/.

- Palmeiro, Cecilia (2011). Desbunde y Felicidad: De la Cartonera a Perlonguer, Buenos Aires: Títuto.

- Palou, Pedro Ángel; Urroz, Eloy; Padilla, Ignacio; ChávezCastañeda, Ricardo y Volpi, Jorge (2000). "Manifiesto Crack I, II, III, IV, V". [En línea] México: Lateral. Revista de Cultura. N. 70 octubre de 2000. [Consulta: 11/11/14] Disponible en https://es.scribd.com/doc/64919561/Manifiesto-Crack.

- Pedrosa, Fernando (2012). La otra izquierda. La socialdemocracia en América Latina, Buenos Aires: Capital Intelectual.

- Pedrosa, Fernando. (2013). "La influencia externa en las transiciones de la 'tercera ola' en América Latina. Debates, definiciones y propuestas teóricas", Mar del Plata, Revista PolHis, n $^{\circ}$ 6, segundo semestre de 2013.

- Peñalosa, Fernando (1957). The Mexican book industry, Nueva York: Scarecrow Press.

- Petrucci, Armando (1998). "Leer por leer: un porvenir para la lectura". En Cavallo, Guglielmo y Chartier, Roger (1998), Historia de la lectura en el mundo occidental, Madrid: Taurus.
- Phaf-Rheinberger, Ineke (editora) (2008). El lenguaje-nación y la poética del acriollamiento. Una conversación entre Kamau Brathwaite y Édouard Glissant, Santiago: Revista Literatura y Lingüística, n ${ }^{\circ}$ 19.

- Phillips, Caryl (Editora) (1997). Extravagant Strangers: A Literature of Belonging, Londres: Faber and Faber.

- Pineda-Botero, Álvaro (1995). El reto de la crítica, Bogotá, Editorial Planeta, Colección Pensamiento.

- Pilleul, Gilbert (1992). De Gaulle en son siécle. Actes des journées internationales tenues à Unesco, Paris, 19-20 noviembre 1990: De Gaulle et la culture, París: Institut Gharles De Gaulle, vol.7.

- Piscitelli, Alejandro (2002). Ciberculturas 2.0. En la era de las máquinas inteligentes, Buenos Aires: Paidós, 2002.

- Piscitelli, Alejandro (2005). Internet, la imprenta del siglo XXI, Barcelona: Gedisa.

- Piscitelli, Alejandro (2010). "Post-Gutenberg es PreGutenberg. Quinientos años de textualidad son suficientes". [En línea] Buenos Aires: Filosofitis, 05/25/10 [Consulta: 23/02/2015] Disponible en: http://www.filosofitis.com. ar/2010/05/24/post-gutenberg-es-pre-gutenberg-quinientosanos-de-textualidad-son-suficientes/.

- Pizarro, Ana (Coordinadora) (1985). La literatura latinoamericana como proceso, Buenos Aires: Centro Editor de América Latina (CEAL).

- Pizarro, Ana (Coordinadora) (1987). Hacia una historia de la literatura latinoamericana, México: El Colegio de México/ Universidad Simón Bolívar.

- Pfanner, Eric (2011). "In France, Publisher and Google Reach Deal" [En línea] New York: The New York Times, 25/08/2011. [Consulta: 20/12/2014] Disponible en: http:// www.nytimes.com/2011/08/26/technology/google-reachesdeal-with-2nd-french-publisher.html?_r=0.

- Pozzi, Sandra (2015). "Los ingresos del iPhone superan todos los de Microsoft y Google juntos". [En línea] Madrid: diario ElPaís, 28/01/2015. [Consulta:28/01/2015]. Disponible en: http://economia.elpais.com/economia/2015/01/28/ actualidad/1422399861_176320.html. 
- Ponte di Pino, Oliviero (2015). "Le quattro grandi guerre dei libri”" [En línea] Milán: Il Libraio, 23/02/2015 [Consulta: 23/02/2015] Disponible en: http://www.illibraio.it/lequattro-grandi-guerre-dei-libri-183131/.

- Pozuelo Yvancos, José Ma . (1995). "El canon en la teoría literaria contemporánea”,. Revista Eutopías, vol. 108, Valencia: Episteme.

- Pozuelo Yvancos (1996). «Canon: ¿estética o pedagogía?», Barcelona: revista Ínsula, no 600.

- Pozuelo Yvancos, José $\mathrm{M}^{\mathrm{a}}$ y Aradra Sánchez, Rosa $\mathrm{M}^{\mathrm{a}}$ (2000). Teoría del canon y literatura española, Madrid: Cátedra.

- Prieto, M. (2014). “Nubico alcanza 100.000 clientes de libros digitales" [En línea] MADRID: ABC, 7/11/2014. [Consulta: 04/01/2015]. Disponible en: http://www.expansion. com/2014/11/07/empresas/tecnologia/1415389264.html.

- Public Library New York. Public Library New York Catalogue. [Web] New York: NYPL. [Consulta: 01/04/2014]. Disponible en: http://www.nypl.org/ebooks.

- Rama, Ángel (1984). La ciudad letrada, Montevideo: Comisión Uruguaya pro Fundación Internacional Ángel Rama.

- Rama, Carlos M. (1978). Historia de América Latina, Barcelona: Editorial Bruguera.

- Rama, Claudio (2003). Economía de las industrias culturales en la globalización, Buenos Aires, Eudeba.

- Rainie, Lee y Smith, Aaron. Tablet and E-reader Owner ship Update (2013). [En línea]. Washington: PewResearch Center. [Consulta: 03/05/2014] Disponible en: http://www. pewinternet.org/files/oldmedia//Files/Reports/2013/PIP

Tablets\%20and\%20e-readers\%20update_101813.pdf.

- Ramchand, Kenneth (Editor) (1966). West Indian Narrative: An Introductory Anthology, Londres: Nelson.

- Ramchand, Kenneth (1987). "Problemas para la historia de la literatura en las Indias Occidentales". En Pizarro, Ana (Coordinadora) (1987), Hacia una historia de la literatura latinoamericana, México: El Colegio de México/Universidad Simón Bolívar.
- Ribeiro, Darcy (1969). Las Américas y la civilización, Buenos Aires: Centro Editor de América Latina.

- Rivera, Jorge B. (1985). "Apogeo y crisis de la industria del libro: 1955-1970". Capitulo 3: cuadernos de literatura argentina: el escritor y la industria cultural, Buenos Aires, Centro Editor de América Latina, t. 3, pp. 625-648.

- Rivera, Jorge B. (1982). "El auge de la industria cultural (1930-1955)". En AA.VV. Historia de la literatura argentina. $2^{a}$ edición, Buenos Aires: Centro Editor de América Latina, Vol. 4, pp. 577-600.

- Rodrigues Dantas, Taísa (2014). "The importance of training for the promotion and development of digital reading literacy: the case of the "Territorio Ebook"'. En TEEM '14. Proceedings of the Second International Conference on Technological Ecosystems for Enhancing Multiculturality, Nueva York: ACM, pp. 531-535.

- Rodríguez Yebra, Martín (2015). "La feria ARCO confirma el fervor por el arte latino en el mundo". [En línea] Buenos Aires: diario La Nación, 25/02/2015. [Consulta: 25/02/2015] Disponible en: http://www.lanacion.com.ar/1771463-la-feriaarco-confirma-el-fervor-por-el-arte-latino-en-el-mundo.

- Romero, José Luis (1976). Latinoamérica: las ciudades y las ideas, México: Siglo XXI.

- Romero, Luis Alberto (2003). Libros baratos y cultura para los sectores populares, Buenos Aires: Centro de Estudiantes de Filosofía y Letras.

- Ros García, Juan (1994). Documentación general (sistemas, redes, centros). Guía del alumno, Madrid: Síntesis.

- Rouquié, Alain (1989). América Latina. Introducción al Extremo Occidente, México: Ed. Siglo Veintiuno.

- Rueda, Nicolás (2012). Amazon estrena 'Fet City', su propio sello de cómics. [Web] [En línea] Bogotá: Revista Enter, 09/07/2012 [Consulta: 03/01/2015] Disponible en: http://www.enter.co/ cultura-digital/entretenimiento/amazon-estrena-jet-city-supropio-sello-de-comics/.

- Sagastizábal de, Leandro y Esteves Fros, Fernando (2003). El mundo de la edición de libros, Buenos Aires: Paidós, pp. 14-32. 
- Sahagún, fray Bernardino (1997). Historia General de las Cosas de la Nueva España, México: Porrúa.

- Said, Edward (1999). Out of Place: A Memoir, Nueva York: A. Knoff.

- Said, Edward (2003) [1978]. Orientalismo, Barcelona: De Bolsillo.

- Said, Edward (2006). Humanismo y crítica democrática Barcelona: Debate.

- Sainz Borgo, Karina (2015). "La industria editorial en España recorta la oferta de libros con respecto a 2013". [En línea] Madrid: diario Vozpópuli Digital, 27/01/2015 [Consulta: 28/01/2015] Disponible en: http://vozpopuli.com/ocio-ycultura/56534-la-industria-editorial-en-espana-recorta-la-

oferta-de-libros-con-respecto-a-2013.

- Sánchez Alonso, Blanca (2007). "The Other Europeans: Immigration into Latin American and the International Labour Market (1870-1930)". [En línea] Madrid: Editorial Universidad Carlos III de Madrid. Instituto Laureano Figuerola. [Consulta: 27/01/2015] Disponible en: http://earchivo.uc3m.es/bitstream/handle/10016/14973/RHE2007-XXV-Blanca \% 20Sanchez.pdf?sequence $=1$.

- Santos, Lidia (2013). "Ni nacional ni cosmopolita: la literatura hispanoamericana contemporánea" . [En línea] Bogotá: cuadernos de literatura VOL. XVII n 33 , enero junio 2013, págs. 282-298 [Consulta: 21/12/2014]. Disponible en: http://revistas.javeriana.edu.co/index.php/cualit/article/ viewFile/5598/4470

- Sarlo, Beatriz (1983). La perspectiva americana en los primero. años de Sur, Buenos Aires: Punto de Vista, año VI, núm. 17, pp. 10-12.

- Sarlo, Beatriz (2007). Hoy las editoriales inventan géneros que no son literarios, Buenos Aires: Clarín.

- Sarlo, Beatriz (2009). "La teoría en tiempos de Google. Sobre Las teorías salvajes, de Pola Oloixarac", Suplemento Cultura, diario Perfil, Buenos Aires: 15/02/2009.
- Sauerberg, Lars Ole (2009). The Encyclopedia and the Gutenberg Parenthesis. [En línea]. Cambridge: Simposio Media in Transition 6: stone and papyrus, storage and transmission, April 24-26. [Consulta: 28/04/2014]. Disponible en: http:// web.mit.edu/comm-forum/mit6/papers/sauerberg.pdf.

- Sayers Peden, Margaret. (1982). A Woman of Genius - The Intelectual Autobiography of Sor Fuana Inés de la Cruz. Connecticut, Lime Rock Press Incorporated.

- Schettini, Ariel (2009). El tesoro de la lengua. Una historia latinoamericana del yo, Buenos Aires: Entropía.

- Schiffrin, André (2000). La edición sin editores, Barcelona: Destino.

- Schiffrin, André (2001). The Business of Books. How International Conglomerates Took Over Publishing and Changed the War we Read, Londres y Nueva York: Verso Books.

- Serra, Giorgio (2012). Naufragios literarios. Colonialismo, poscolonialismo y encuentro entre culturas. [En línea]. Director: Virgilio Tortosa. Tesis doctoral. Alicante: Universidad d'Alacant/ Universidad de Alicante. [Consulta: 14/04/2014]. Disponible en: http://rua.ua.es/dspace/bitstream/10045/24365/1/ Tesis_Giorgio\%20Serra.pdf.

- Sina, news horizons for news [En línea] Kindle now available on Chinese mainland. Shanghai: 06/08/2013 [Consulta: 04/01/2015] Disponible en: http://english.sina.com/ business/2013/0607/597496.html.

- Shatzkin, Michael (2014). The disruption of the disruption is temporary. [En línea]. The Shatzkin Files: The idea logical company. [Consulta: 01/05/2014]. Disponible en: http://www.idealog. $\mathrm{com} / \mathrm{blog} /$.

- Shelf awareness magazine [En línea]. Amazon Now Selling Kindles in India. Seattle: 14/06/2013 [Consulta: 02/01/2015] Disponible en: http://www.shelf-awareness.com/issue. html?issue $=2018 \# \mathrm{~m} 20405$.

- Smith, Terry (2012). ¿Qué es el arte contemporáneo?, Buenos Aires: Siglo Veintiuno Editores Argentina. 
- Sonny Bono Copyright Term Extension Act. [En línea]. En One Hundred Fifth Congress of the United States of America. Washington: 1998. [Consulta: 22/04/2014]. Disponible en http://www.copyright.gov/legislation/s505.pdf.

- Spindler, Tim (2009). Statistical Analysis Models. Applications for Libraries. [Web] Bristol, EE.UU.: Roger Williams University, 01/01/2009 [Consulta: 16/01/2015] Disponible en: http://docs.rwu.edu/cgi/viewcontent cgi?article $=1010 \&$ context $=$ librarypub.

- Stein, Bob (2014). Social reading -an opportunity. [En línea] Londres: The Bookseller. 12/11/14. [Consulta: 23/11/2014]. Disponible en: http://www.thebookseller.com/futurebook/ social-reading-opportunity.

- Strickland, Stephanie (2009). "Born Digital: A Poet in the Forefront of the Field Explores What is - and is notElectronic Literature." [En línea]. En The Poetry Foundation, 2009. [Consulta: 23/04/2014]. Disponible en: http://www. poetryfoundation.org/article/182942.

- Szumruk, Mónica y McKee Irwin, Robert (2009). Diccionario de estudios culturales latinoamericanos, México: Siglo Veintiuno Editores.

- Tappuni, Jane (2015). "What Nielsen Bookscan data tells us about ebook sales cycles \& the ebook plateau". [Web] Oxford: Publishing Techonology, 20/01/2015 [Consulta 22/01/2015] Disponible en: http://www.publishingtechnology. com/2015/01/what-nielsen-bookscan-data-tells-us-about-

ebook-sales-cycles-the-ebook-plateau/.

- Teixeira Stevens, Iona (2013). "Apple iBookstore Leads Brazil's Ebook Market in 2013". [En línea] San Pablo: PublishNews Brazil, 02/05/2013 [Consulta: 13/01/2015] Disponible en: http://publishnewsbrazil.com/2013/05/appleibookstore-leads-brazils-ebook-market-in-2013/.

- Tennina, Lucía (2010). ¡Cuidado con los poetas! Una etnografía sobre el mundo de la literatura marginal de la ciudad de San Pablo. Tesis de Maestría en Antropología Social, Instituto de Desarrollo Económico y Social e Instituto de Altos Estudios Sociales, Universidad Nacional General San Martín, Buenos Aires.
- Tennina, Lucía (compiladora) (2014). Antología Saraus. Movimiento - Literatura - Periferia - São Paulo, Buenos Aires: Tinta Limón.

- The Brooking Institution. Global Cities Initiative a foint Project of Brookings \& FPMorgan Chase. [En línea]. Washington: 26/07/2013 [Consulta: 10/01/2025] Disponible en: http://www.brookings.edu/ /media/Multimedia/

Interactives/2013/tentraits/Bangalore.pdf.

- Thompson, Don (2015). La supermodelo y las cajas de brillo. Los entresijos de la industria del arte contemporáneo, Barcelona: Ariel.

- Toffler, Alvin (1980). La tercera ola, Madrid: Plaza \& Janes.

- Toledo, Aída (2004). "Visiones discursivas a partir de un canon alternativo: Clarice Lispector, Diamela Eltit y Eugenia Gallardo y el cómo narrar desde espacios femeninos". [En línea] Pittsburgh: Universidad de Pittsburgh, Revista Iberoamericana, Vol. LXX, Núm. 206, Enero-Marzo 2004, 237-249 [Consulta: 11/11/14] Disponible en: http://revistaiberoamericana.pitt.edu/ojs/index.php/Iberoamericana/ article/viewFile/5595/5743.

- Torras, Meri (2003). Soy como consiga que me imaginéis. La construcción de la subjetividad en las autobiografias epistolares de Gertrudis Gómez de Avellaneda y Sor Fuana Inés de la Cruz. Cádiz: Servicio de Publicaciones de la Universidad de Cádiz.

- Torres-Rioseco, Arturo (1951). La gran literatura iberoamericana, Buenos Aires: Emecé.

- Tramullas Saz, Jesús (2002). Propuestas de concepto y definición de la biblioteca digital. [En línea] En e-LIS, 2002 [Consulta: 10/05/2014] Disponible en: http://eprints.rclis. org/15118/1/04_2002.pdf.

- Trueswell, Richard L. (1969). "Library Users: The 80/20 Rule", Nueva York: Wilson Library Bulletin, 43(5).

- Tsang, José (2013). Doble personalidad. Entrevista a Alberto Fuguet. [En línea] Lima: Blog Buen Salvaje, 02/05/2013. [Consulta: 11/03/2015]. Disponible en: http://buensalvaje. $\mathrm{com} / \mathrm{tag} / \mathrm{mcondo} /$. 
- Turiel,Josep (2010). Lamanía de las listas: 100 bibliotecas digitales y 'recolectores' de libros electrónicos. [En línea]. Barcelona: Revista bid - textos universitaris de biblioteconomia i documentació, número 24, junio de 2010. [Consulta: 10/05/2014]. Disponible en: http://bid.ub.edu/24/turiel2.htm.

- Tverítina, Aliona (2013). "Rayuela en Rusia: el juego que se convirtió en un clásico" [En línea]. Moscú: Rusia Beyond The Head Lines: 15/08/2013. [Consulta: 14/02/2015] Disponible en: http://es.rbth.com/cultura/2013/08/15/rayuela_en_ rusia_el_juego_que_se_convirtio_en_un_clasico_31133.html.

- United Nations Educational, Scientific \& Cultural Organization. International Flows of Selected Cultural Goods and Services 1994-2003. [En línea]. París: UNESCO, 2005 [Consulta: 09/03/2014]. Disponible en: http://www.uis. unesco.org/template/pdf/cscl, 2005.

- Urbano, Victoria (1990). Sor Fuana Inés de la Cruz: amor, poesía, soledumbre, Potomac: Scripta Humanistica Publishing Company

- Varda, Francesca (2015). "¿Qué es América Latina?”. [En línea] Lima: blog About me, s/f [Consulta: 28/01/2015] Disponible en: http://americalatina.about.com/od/Datosgenerales/a/que-Es-America-Latina.htm.

- Vicente, Alberto y Gozzer, Silvano (2012). "Notas para una estrategia editorial y de contenidos digitales". En Cordón García, José Antonio; Carbajo Cascón, Fernando; Gómez Díaz, Raquel y Alonso-Arévalo, Julio (coordinadores) (2012), Libros electrónicos y contenidos digitales en la sociedad del conocimiento. Mercado, servicios y derechos, Madrid: Pirámide, pp. 93-106.

- Vicente García, Remedios de (2013). «Los libros electrónicos en las colecciones de las bibliotecas públicas». Barcelona: Revista bid - textos universitaris de biblioteconomia i documentació núm. 30, junio de 2013 [Consulta: 16-012015]. Disponible en: http://bid.ub.edu/es/30/devicente. htm\#sthash.UPeloIq8.dpuf.

- Villar, Jorge (2002). Las edades del libro: una crónica de la edición mundial, Madrid: Debate.

- VV.AA. (2014). Disculpe que no me levante, Madrid: Demipage
- Walsh, Catherine (editora) (2004). Estudios culturales latinoamericanos, retos desde y sobre la región andina, Quito: Universidad Andina Simón Bolívar y Abya Yala.

- Walters, William H. (2012). "Patron-Driven Acquisition and the Educational Mission of the Academic Library" [En línea] Piscataway: Rutgers University Libraries, Library Resources \& Technical Services Volumen 56, número 3 /2012 [Consulta: 20/01/2015] Disponible en: http://alcts.metapress. com/content/p3w1m407262111hx/fulltext.pdf.

- Walwyn Michael, Anette (Editora) (2001). Sugar Is All: Caribbean Short Stories and Poems from St. Kitts and Nevis. Kearney, Nebraska: Morris Publisher.

-Whitaker, Arthur P. (1964). Argentina, Nueva Jersy: Prentice Hall, Inc.

- Whitney, Lancey (2011). "Google adds e-books to Android Market” [En línea] Nueva York: CNET, 25/02/2011 [Consulta: 02/01/2015] Disponible en: http://www.cnet.com/news/ virtual-reality-will-be-huge-in-2015-but-it-wont-be-perfect-fora-while/.

- Williamson, Jeffrey G. (1999). "Real Wages Inequality and Globalization in Latin America before 1940” En Martín Aceña, Pablo; Meisel, Adolfo y Newland, Carlos (editores), Madrid: Revista de Historia Económica Año XVII, número especial: "La historia económica en América Latina”, pp. 101-142

- Wilson, Patricia (2004). La Constelación del Sur. Traductores y traducciones en la literatura argentina del siglo XX. $1^{\text {a }}$ edición, Buenos Aires: Siglo Veintiuno Editores Argentina.

- Wischenbart, Rüdiger; Carrenho, Carlo; Licher, Veronika; Kovac, Miha y Vinhuta, Mallya (2013), Global eBook: Current Conditions \& Future Projections, Londres: O'Reillym.

- Wischenbart, Rüdiger; Carrenho, Carlo; Celaya, Javier; Licher, Veronika; Kovac, Miha y Vinhuta, Mallya (2014). Investigación adicional: Coufal, Julia; Krenn, Jennifer y Stalujanis, Sabine. Global eBook: A report on market trends and developments. Update spring 2014, Londres: O'Reillym. 
- Wakabayashi, Daisuke (2015). [En línea] "Apple: $\$ 710$ Billion and Counting". Washington: The Wall Street Journal, 22/02/2015 [Consulta: 22/02/2015] Disponible en: http://www.wsj.com/articles/apple-the-700-billioncompany-1423602877.

- Woods, Gregory (2001). Historia de la literatura gay, Madrid: Ediciones Akal.

- Wylie, Andrew (2014). Los lectores digitales morirán jóvenes, deberian tirar sus kindles a la basura. Entrevista de Páez, Natalia, Buenos Aires: diario Tiempo Argentino.

- University of Wisconsin Digital Collections. The Art Collection. Base de Datos de Editoriales Cartoneras. [Web] Madison: University of Wisconsin. [Consulta: 05/12/2014] Disponible en: http://digicoll.library.wisc.edu/WebZ/

SearchOrBrowse?sessionid=01-53965-684142241.

- Zaid, Gabriel (1996). Los demasiados libros, México: Editorial Océano.

- Zanetti, Susana (1998). "Apuntes acerca del canon latinoamericano". En Cella, Susana. Acerca del canon, Buenos Aires: Losada, pp. 87-105.

- Zúñiga, Fernando (2006). Mapudungun. El habla mapuche, Santiago de Chile: Centro de Estudios Públicos. 


\subsection{Entrevistas}

En este apartado se exponen las desgrabaciones de las entrevistas efectuadas a:

- Dra. Freidenberg, Flavia. Directora del Instituto de Iberoamérica de la Universidad de Salamanca y politóloga especialista en procesos políticos latinoamericanos. Doctora en Ciencia Política por la Universidad de Salamanca. Entrevista realizada el día 17/10/14.

- Lic. Schettini, Ariel. Licenciado en Letras; docente de la Maestría en Literatura Latinoamericana, Universidad de Tres de Febrero, Argentina. Docente de Teoría Literaria en la Universidad de Buenos Aires, Argentina. Entrevista realizada el día 29/10/14.

- Lic. Civale, Cristina. Licenciada en Letras por la Universidad de Buenos Aires. Periodista especializada en Arte. Sus trabajos críticos se publican en las secciones de Artes de los periódicos Página 12 y Clarín, ambos de la Argentina. Es curadora y preside la Fundación Jaque al Arte, Argentina. Entrevista realizada el día $05 / 10 / 14$

- Dr. Vattimo, Gianni. Filósofo italiano. Doctor en Filosofía por la Universidad de Heidelberg (Alemania). Doctor Honoris Causa por la Universidad de Buenos Aires (Argentina), la Universidad de La Plata (Argentina), la Universidad de Palermo (Italia), la UNED (España), la Universidad Inca Garcilaso de la Vega (Perú), la Universidad Nacional Mayor de San Marcos (Perú) y miembro de la Academia Europea de Ciencias y Artes. Entrevista realizada el día 5/11/14.

- Lic. Corvalán, Eugenia. Directora del portal Leedor.com. Licenciada en Letras y en Antropología por la Universidad de Buenos Aires. Es curadora de arte y especialista en arte contemporáneo. Docente de la Carrera de Artes en la Universidad del Museo Social, Argentina. Entrevista realizada el día 29/12/14

- Dr. Andrés Malamud. Politólogo graduado en la Universidad de Buenos Aires. Doctor en Ciencias Sociales y Políticas por el Instituto Universitario Europeo (IUE), Florencia, Italia. Entrevista realizada el día 29/01/15.
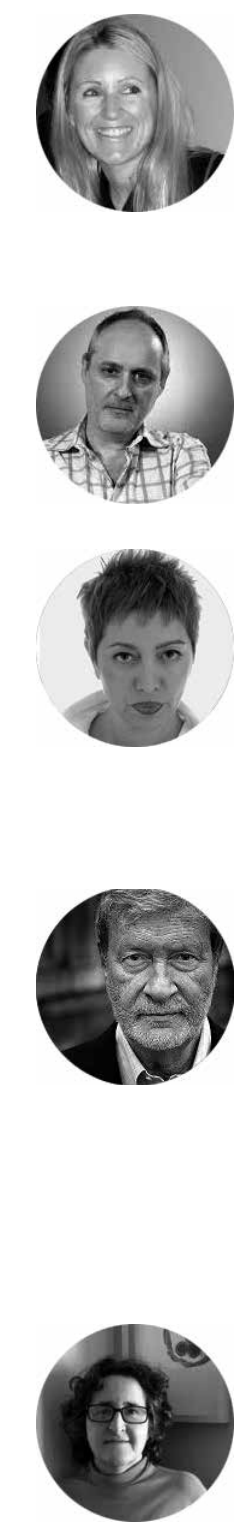
- Dra. Isabel Huizi Castillo. Realizó estudios de historia y cinematografía y de maestría en la Escuela de Altos Estudios en Ciencias Sociales, Universidad de París VII, Sorbona (1976) bajo tutoría del Profesor Marc Ferro. Ha sido Directora Ejecutiva de la Fundación Galería de Arte Nacional (Venezuela); Directora General de Museos del CONAC (Venezuela); Directora de la Biblioteca Isaac J. Pardo del Centro de Altos Estudios Rómulo Gallegos (CELARG - Venezuela); Directora General del Museo de la Estampa y el Diseño Carlos Cruz-Diez (Caracas - Venezuela) y Directora General Editorial de la Universidad Nacional Experimental de las Artes (UNEARTE) de Venezuea. Entrevista realizada el día 19/02/15.

- Lic. Julio Alonso-Arévalo. Licenciado de Geografía e Historia por la Universidad de Salamanca y Diplomado en Biblioteconomía y Documentación por la misma Universidad. Actualmente es Jefe de Biblioteca Universidad de Salamanca. Facultad de Traducción y Documentación. Ha desarrollado varios proyectos: Dathateke, DOIS, Digitalia: Portal de recursos Informativos de la Facultad de Traducción y Documentación, InfoDOC, InfoTRAD. Dirige el influyente blog de la biblioteca de la Facultad de Traducción y Documentación de Salamanca: Universo Abierto. Entrevista realizada el día 22/02/15.

\section{Preguntas para informantes clave}

l) Giro poscolonial mediante, ¿hay un gusto global sobre "lo latinoamericano" en el arte?

2) ¿Ud. considera que existe un gusto, criterio, concepción "global" de/sobre la literatura latinoamericana o "lo atinoamericano"?

Algunas de las preguntas se diseñan en función del aporte del especialista entrevistado:

¿Existe algo así como Latinoamérica?

¿Por qué el arte (o la literatura) caribeña puede formar un corpus de obras con el arte latinoamericano?

¿O Ud. lo ve como una unidad al arte (o la literatura) latinoamericano y caribeño?

¿Qué beneficios traen los PDA (Patron Drivens Adquisitions)? 


\section{Primera entrevista: Dra. Flavia Freidenberg}

¿Existe algo así como Latinoamérica?

\section{Respuesta de la Dra. Flavia Freidenberg}

Latinoamérica es una construcción que necesitamos tener para poder vivir en la diferencia. Es interesante ver cómo se utilizan las categorías. Para mí, nacida del otro lado, yo me sentía argentina. Cuando vengo aquí, me siento latinoamericana. Cuando voy a la Argentina, no hay algo parecido a Latinoamérica.

Para los académicos soy hispanoamericana. No es inocente la elección del término. Tenemos una revista que se llama "América Latina hoy", tenemos un Máster en Estudios Latinoamericanos, el Doctorado, también, pero el Instituto se llama de Iberoamérica. iAh!: antes se llamaba de Iberoamérica y Portugal.

Si le preguntas a los estudiantes acá hablan de Latinoamérica, pero habría que preguntarles como se llaman a sí mismos cuando se van (mexicanos, argentinos, uruguayos), cómo se llaman a sí mismos y cómo se mencionarán cuando se vayan de estudiar en Salamanca.

En Ciencias Políticas, en Ciencias Sociales hay una serie de problema que son propios de Latinoamérica: todo lo que tiene que ver teoría de las transiciones a la democracia, todo lo que tiene que ver con la modernización de sociedades que no siguieron los patrones europeos y todos los estudios sobre el populismo, son problemas científicosociales latinoamericanos. O sea: características de la ciencia social latinoamericana de los que están allá y de los que estamos acá.

\section{Segunda entrevista: Lic. Ariel Schettini}

1) Giro poscolonial mediante, ¿hay un gusto global sobre "lo latinoamericano" en el arte?

2) ¿Ud. considera que existe un gusto, criterio, concepción "global" de/sobre la literatura latinoamericana o "lo latinoamericano"?

\section{Respuesta del Lic. Ariel Schettini}

Obviamente hay criterios, gustos y concepciones globales.

La literatura es un conjunto de hechos que pueden ser experimentados, comprados, constituidos en cosa, mercancía y, por lo tanto, formar parte de cualquier mercado.

El concepto de global no nombra un hecho, sino una interpretación o una perspectiva desde donde se ven los hechos. Para una persona que tiene una mirada "global" obviamente, existe... Pero la literatura no es una ni es algo fijo ni algo que se pueda decidir... es un debate que está en la sociedad. Si esas empresas multinacionales que nombrás y yo, por ejemplo, un profesor de universidades periféricas, subalternas, subordinadas, provincianas o como quieras llamarlas, pensáramos lo mismo de la literatura, tendría que matarme, porque no tengo ninguna capacidad de respuesta a esos conglomerados, de modo que mi aporte al debate sería nulo.

Quiero creer que pienso la literatura con otros propósitos, para otros públicos, que aspira a otro tipo de contacto social y, por lo tanto, es otra literatura, sin dudas antimoderna, antiglobal, provincial y subalterna.

Lo global solo se puede pensar desde el centro; desde la periferia, lo global es "obligaciones". 


\section{Tercera entrevista: Lic. Cristina Civale}

1) Giro poscolonial mediante, ¿hay un gusto global sobre "lo latinoamericano" en el arte?

2) ¿Ud. considera que existe un gusto, criterio, concepción "global" de/sobre la literatura latinoamericana o "lo latinoamericano"?

\section{Respuesta de la Lic. Cristina Civale}

En cuanto a la respuesta sobre si hay un gusto global sobre "lo latinoamericano" en el arte, te respondería que este gusto global, como vos lo llamás, tiene que ver con una automatización del mercado que indica qué es lo legítimo como arte. Esta legitimación está dada por los curadores de museos y coleccionistas trabajando en tandem. Existe, sin embargo, otro arte que se genera por fuera de estos circuitos y que no está en el gusto-mercado pero que tiene valor por su riesgo de producción más allá de esta percepción de lo global. En las artes visuales existe un lobby armado por curadores, coleccionistas, críticos del establishment que indican qué debe gustar y qué debe valer, más allá de que por fuera de este circuito se genere otro no mainstream que va marcando el verdadero valor del arte de vanguardia.

\section{Cuarta entrevista: Dr. Gianni Vattimo}

1) Giro poscolonial mediante, ¿hay un gusto global sobre "lo latinoamericano" en el arte?

2) ¿Ud. considera que existe un gusto, criterio, concepción "global" de/sobre la literatura latinoamericana o "lo latinoamericano"?

\section{Respuesta del Dr. Gianni Vattimo}

No soy un especialista en temas de arte. Y creo, eso sí, que existen formas globales que circulan sobre "lo latino", no se olvide de que soy italiano. Creo, también, que trabajos como los que usted está haciendo no deben caer en el error de despreciar la calidad cosmopolita y 'global' de ciudades como Buenos Aires, que también construyen el 'gusto global' sobre lo latinoamericano. 


\section{Quinta entrevista: Dr. Andrés Malamud}

¿Qué tipo de demarcación permite acuñar la categoría «América latina y el Caribe»?

\section{Respuesta del Dr. Andrés Malamud}

La demarcación de un concepto es la que sirva al objetivo de investigación. Objetivamente, la única manera de justificar la existencia de "América Latina y el Caribe" es "países del hemisferio occidental en vías de desarrollo". No creo que sirva para justificar una investigación literaria. La otra vía es la definición intersubjetiva: cómo se autodefinen ellos mismos. Las organizaciones globales (ONU, BM, FMI) imponen la categoría con fines de simplificación estadística, pero la CELAC muestra que estos países la aceptan. Para mí, esa es la justificación: autorreconocimiento de la etiqueta por los países implicados vía participación en la CELAC, por ejemplo.

\section{Sexta entrevista: Dra. Isabel Huizi Castillo}

1) ¿Por qué el arte (o la literatura) caribeña puede formar un corpus de obras con el arte latinoamericano?

2) ¿O Ud. lo ve como una unidad al arte (o la literatura) atinoamericano y caribeño?

\section{Respuestas de la Dra. Isabel Huizi Castillo}

1) Porque en una clasificación según un criterio de lugar y tiempo de producción de la obra de arte, (criterio geográfico, o en el mejor de los casos geohistórico) ubicamos la región de El Caribe en América Latina. Sin siquiera entrar a analizar la problemática de lo "latinoamericano", pensamos que sería más enriquecedor para los estudios e interpretaciones ir algo más allá de una geohistoria de las artes y partir de criterios estilísticos o estéticos desde enfoques teórico-críticos más amplios, lo que cambiaría completamente tanto los enfoques mismos y métodos como los resultados producto del uso de las clasificaciones canónicas de la teoría, la historia y la crítica de arte tal como las estudiamos hasta hoy.

2) No veo las artes como una "unidad", ni latinoamericana ni caribeña. Cada obra de arte es una realidad única y compleja difícil de relacionar con otras obras de arte. Pienso que el criterio geográfico da cuenta de regiones y "zonas culturales" que requieren caracterizaciones más trabajadas para operar en el campo de las artes. Nunca me he sentido cómoda operando con esas categorías, pues las encuentro, justamente, cómodas, pero de escaso valor teórico, crítico y operativo. Solo sirven para establecer grandes generalizaciones que dificultan en gran medida los análisis más exhaustivos y singulares de las obras de arte. No se trata de no establecer contextos culturales amplios donde situar la obra de arte, pero esto representa grandes dificultades teóricas e incluso geohistóricas que aún no hemos logrado desmontar. Pienso que requerimos revisiones más profundas de nuestros métodos de estudio, crítica y análisis de la obra de arte. Salvo en casos muy puntuales, hasta ahora, solo seguimos teniendo aproximaciones convencionales pero en los casos en los que los estudiosos se separan de estas sendas trilladas siempre la obra de arte gana con nuevos enfoques en riqueza de interpretaciones y lecturas. Pienso que el esfuerzo vale la pena. 


\section{Séptima entrevista: Lic. Eugenia Corvalán}

1) Giro poscolonial mediante, ¿hay un gusto global sobre "lo latinoamericano" en el arte?

2) También giro poscolonial mediante, ¿hay un gusto global (o concepción o criterios globales) sobre la literatura latinoamericana?

\section{Respuestas de la Lic. Eugenia Corvalán}

1) Creo que sí, que hay dos cosas que pasan con el arte latinoamericano. Por un lado, el giro político, donde somos señeros. Desde la antropofagia y el muralismo mexicano, es decir, desde las vanguardias que empiezan a debatir temas comunes con toda la producción artística como pueden ser la profesionalización del escritor o el pintor, la sindicalización (Bern en la Argentina, Siqueiros en México pero también en EE.UU.); Tarsila y Oswald planteando la vuelta de tuerca de la relación con el occidentalismo y la construcción europea del Otro, donde, como dice Gerardo Mosquera, el problema del Otro es que el Otro siempre somos Nosotros. Este giro político vuelve con toda su contundencia con el pop y el conceptual, por tomar dos nodos fundamentales del arte de finales de los 60 tienen en la producción continental un giro político único. El caso paradigmático es el de Antonio Caro, pero también el del brasileño Ruben Gerschman, en Cuba Raúl Martínez y, por supuesto, el Pop Achorado peruano, un ejemplo poco estudiado, en general. En todos los casos estamos hablando de giro político porque son movimientos fuertemente articulados con gobiernos particulares, en el caso de Perú con "populismos" difíciles de comprender y de asimilar al caso de Andy Warhol o Richard Hamilton. El otro giro que focaliza el arte latinoamericano en ese lugar del Otro frente al arte de hegemonías es el giro afectivo. Es decir, una cierta manera de provocar y confrontar relaciones y hacer emerger nuevos modos de ser, una nueva suavidad, una enunciación que por más individual que se quiera es siempre colectiva, polifónica, menor mayoritaria, problemática, afirmativa pero disolvente. En este sentido, creo que hay una fuerte valoración del "desde aquí", gesto que puede verse también en el hecho de que, en plena bienalización de las artes visuales como su principal modo de circulación, la segunda bienal del mundo (en antigüedad, en presupuesto financiero y en cantidad de visitantes) es la Bienal de San Pablo.

2) Creo que hay una herencia del boom que hoy se fragmentó. Habría que pensar cómo se negocian las identidades siempre eventuales, en la literatura. Aquí además se juegan modos de resistencia editorial bien interesantes, prácticas inéditas que negocian los cánones desde estrategias globales, como los soundclouds, las ediciones on demand, los libros para armar que se envían por pdf, los videopoemas en youtube, olas editoriales cartoneras, la liberación de libros y los libros de artista, por enumerar formas de cirulación y consagración que nacen post los 90 . Me parece que hoy no hay canon literario per se, como podría pensarlo Bloom, más apoyado en un gusto personal desde un mandato más o menos académico y decimonónico. Creo que hoy los cánones han estallado y hay trizas de ese estalle por todos lados. 
1) ¿Qué beneficios traen los PDA (Patron Drivens Adquisitions)?

\section{Respuesta del Lic. Julio Alonso Arévalo}

Para mí, PDA es un modelo con mucho futuro.

Tiene importantes ventajas:

- La colección se adecua a la demanda de los usuarios.

- Disponemos de todo el catálogo editorial (al igual que en pago por uso, solo que pago por uso sale muy caro para la biblioteca: $\mathrm{U} \$ \mathrm{~S} 1$ o 2 por préstamo).

El problema es que aún se oferta poco por parte de las editoriales y cuando lo hacen suelen ofrecer una selección muy limitada. 
8.1. Tabla general de comparación de ofertas en papel en plataformas comerciales y servicios de lectura en streaming y descarga de los títulos y autores del corpus literario latinoamericano diseñado.

Amazon - Barnes \& Noble - Google Books -

iBookstore / iTunes - Kobo - Free-Ebooks - Casa del Libro - Gandhi - Librería Santa Fe - Livraria Cultura - Perúbookstore.com - Scribd - Nubico ${ }^{37}$

\begin{tabular}{|c|c|c|c|}
\hline Autor & Obra & Fuentes & 을 \\
\hline Bayly, Jaime & No se lo digas a nadie & 6 & 08 \\
\hline Bryce Echenique, Alfredo & Un mundo para Julius & 2,14 & 08 \\
\hline Roncagliolo, Santiago & Abril rojo & 3,8 & 08 \\
\hline Vargas Llosa, Mario & La ciudad y los perros & 3,14 & 08 \\
\hline Vargas Llosa, Mario & Los cachorros & $2,3,14$ & 08 \\
\hline Vargas Llosa, Mario & Pantaleón y las visitadoras & 2,14 & 08 \\
\hline Allende, Isabel & La casa de los espíritus & & 07 \\
\hline Altamirano, Ignacio Manuel & El Zarco & 2,14 & 07 \\
\hline Arlt, Roberto & El juguete rabioso & & 07 \\
\hline Arlt, Roberto & Los siete locos & 2 & 07 \\
\hline Azuela, Mariano & Los de abajo & $2,3,14$ & 07 \\
\hline Benedetti, Mario & Inventario & 2,14 & 07 \\
\hline Benedetti, Mario & La borra del café & $\frac{2,14}{14}$ & 07 \\
\hline Benedetti, Mario & La muerte y otras sorpresas & 2,14 & 07 \\
\hline Benedetti, Mario & Pedro y el capitán & 14 & 07 \\
\hline Benedetti, Mario & Primavera con una esquina rota & 2 & 07 \\
\hline Bolaño, Roberto & Llamadas telefónicas & 6 & 07 \\
\hline Bolaño, Roberto & Los detectives salvajes & 6 & 07 \\
\hline Bryce Echenique, Alfredo & El hombre que hablaba de Octavia de Cádiz & 2 & 07 \\
\hline Bryce Echenique, Alfredo & La última mudanza de Felipe Carrillo & 2 & 07 \\
\hline Bryce Echenique, Alfredo & No me esperen en abril & 2,14 & 07 \\
\hline Cambaceres, Eugenio & En la sangre & 2,14 & 07 \\
\hline Cambaceres, Eugenio & Sin rumbo & 2,14 & 07 \\
\hline Carpentier, Alejo & Concierto Barroco & $2,13,14$ & 07 \\
\hline Carpentier, Alejo & El recurso del método & $1,2,3,13,14$ & 07 \\
\hline Carpentier, Alejo & El reino de este mundo & $1,2,3,13,14$ & 07 \\
\hline Carpentier, Alejo & Los pasos perdidos & $1,2,3,13,14$ & 07 \\
\hline Castellanos, Rosario & Oficio de tinieblas & 2,14 & 07 \\
\hline Fuentes, Carlos & Aura & 2 & 07 \\
\hline Fuentes, Carlos & Gringo viejo & & 07 \\
\hline Fuentes, Carlos & La frontera de cristal & 2,14 & 07 \\
\hline Fuentes, Carlos & La región más transparente & 2,14 & 07 \\
\hline Garcilaso de la Vega & Comentarios reales & 2 & 07 \\
\hline Girondo, Oliverio & En la masmédula & 2,14 & 07 \\
\hline Glantz, Margo & El rastro & 3 & 07 \\
\hline Glantz, Margo & Las genealogías & 3 & 07 \\
\hline Guerra, Wendy & Todos se van & 8 & 07 \\
\hline Icaza, Jorge & Huasipungo & 2,14 & 07 \\
\hline Mármol, José & Amalia & & 07 \\
\hline Neruda, Pablo & Veinte poemas de amor y una canción desesperada & $1,2,14$ & 07 \\
\hline Nervo, Amado & Plenitud & 2 & 07 \\
\hline Nettel, Guadalupe & $\begin{array}{l}\text { Pétalos } \\
\end{array}$ & 8 & 07 \\
\hline Palma, Ricardo & Tradiciones & 2 & 07 \\
\hline Palma, Ricardo & Tradiciones peruanas & 2,14 & 07 \\
\hline Paz, Octavio & Corriente alterna & $\frac{2,14}{2}$ & 07 \\
\hline Paz, Octavio & El laberinto de la soledad & $1,2,14$ & 07 \\
\hline Paz, Octavio & Libertad bajo palabra & 2,14 & 07 \\
\hline Pitol, Sergio & Juegos florales & 2,14 & 07 \\
\hline Quiroga, Horacio & Anaconda & 2 & 07 \\
\hline Roncagliolo, Santiago & La pena máxima & 8 & 07 \\
\hline Roncagliolo, Santiago & Pudor & 8 & 07 \\
\hline Rulfo, Juan & El llano en llamas & $2,3,14$ & 07 \\
\hline
\end{tabular}

El criterio del recorte de los títulos para ser incorporados es el de que estén presentes en oporte impreso en más del $50 \%$ de las plataformas. 
8.2. Tabla general de comparación de ofertas en papel en bibliotecas globales de los títulos y autores del corpus literario latinoamericano

diseñado

Columbia University Libraries - Biblioteca del

Instituto Latinoamericano de Berlín - Biblioteca

Nacional de España - Public Library New York

- Gallica (Biblioteca Nacional de Francia) -

Europeana (Biblioteca digital de la Unión Europea)

- Biblioteca Nacional de Perú - Biblioteca de São

Paulo 38

\begin{tabular}{|c|c|c|c|}
\hline Autor & Obra & Fuentes & 軎 \\
\hline Arguedas, José María & Los ríos profundos & 2,14 & 07 \\
\hline Borges, Jorge Luis & El Aleph & $1,2,3,14$ & 07 \\
\hline Borges, Jorge Luis & Obras completas & 2,14 & 07 \\
\hline Carpentier, Alejo & Concierto Barroco & $2,13,14$ & 07 \\
\hline Carpentier, Alejo & Los pasos perdidos & $1,2,3,13,14$ & 07 \\
\hline Abreu Gómez, Ermilo & Canek & & 06 \\
\hline Abril, Xavier & Dos estudios & 2 & 06 \\
\hline Acevedo Díaz, Eduardo & Ismael & 2,14 & 06 \\
\hline Acevedo Díaz, Eduardo & Lanza y sable & 2,14 & 06 \\
\hline Acevedo Díaz, Eduardo & Nativa & 2,14 & 06 \\
\hline Acevedo Díaz, Eduardo & Soledad & 2,14 & 06 \\
\hline Acosta, Oscar & Poesía & \begin{tabular}{|l|l|l|l}
2 \\
\end{tabular} & 06 \\
\hline Adán, Martín & De lo Barroco en el Perú & 2,14 & 06 \\
\hline Adán, Martín & La Casa de Cartón & $2,12,14$ & 06 \\
\hline Aguirre, Nataniel & Juan de la Rosa: memorias del último soldado de & 214 & 06 \\
\hline Alberdi, Juan Bautista & Bases y puntos de partida para la organización política. & 2,14 & 06 \\
\hline Alberdi, Juan Bautista & El crimen de la guerra & 2,14 & 06 \\
\hline Alberdi, Juan Bautista & Peregrinación de luz del día, o Viaje y aventuras de & 2 & 06 \\
\hline Alegría, Ciro & $\begin{array}{l}\text { la verdad en el Nuevo Mundo } \\
\text { El mundo es ancho y ajeno }\end{array}$ & $\frac{2}{2,14}$ & 06 \\
\hline Alegría, Ciro & La serpiente de oro & 2,14 & 06 \\
\hline Alegría, Ciro & Lázaro & 2 & 06 \\
\hline Alegriá, Fernando & Caballo de copas & 2,14 & 06 \\
\hline Allende, Isabel & La casa de los espíritus & & 06 \\
\hline Almeida, José Américo & A bagaceira & $\frac{2}{2}$ & 06 \\
\hline Altamirano, Ignacio Manuel & Clemencia & 2 & 06 \\
\hline Altamirano, Ignacio Manuel & La Navidad en las montañas & 2,14 & 06 \\
\hline Amado, Jorge & Cacao & 2 & 06 \\
\hline Amado, Jorge & Gabriela, cravo e canela & 2,14 & 06 \\
\hline Amado, Jorge & Jubiabá & 2,14 & 06 \\
\hline Amado, Jorge & O sumico da Santa & 2,14 & 06 \\
\hline Amado, Jorge & Os pastores da noite & 2 & 06 \\
\hline Amado, Jorge & Sudor & $\frac{2}{2}$ & 06 \\
\hline Ambrogi, Arturo & Crónicas marchitas & 2 & 06 \\
\hline Amorim, Enrique & La carreta & 2,14 & 06 \\
\hline Anderson Imbert, Enrique & Crítica interna & 2,14 & 06 \\
\hline Anderson Imbert, Enrique & La flecha en el aire & 2 & 06 \\
\hline Anderson Imbert, Enrique & Los domingos del profesor & 2 & 06 \\
\hline Araujo, Orlando & Lengua y creación en la obra de Rómulo Gallegos & $\frac{2}{2}$ & 06 \\
\hline Arciniegas, Germán & Amerigo y el Nuevo Mundo & 2 & 06 \\
\hline Arciniegas, Germán & Biografía del Caribe & 2,14 & 06 \\
\hline Arciniegas, Germán & El caballero de EI Dorado & 2 & 06 \\
\hline Arciniegas, Germán & El estudiante de la mesa redonda & 2,14 & 06 \\
\hline Arciniegas, Germán & En medio del camino de la vida & 2 & 06 \\
\hline Arciniegas, Germán & Entre la libertad y el miedo & 2,14 & 06 \\
\hline Arciniegas, Germán & Los comuneros & 2 & 06 \\
\hline Arenas, Reinaldo & Otra vez el mar & 13 & 06 \\
\hline Arévalo Martínez, Rafael & El hombre que parecía un caballo & 11 & 06 \\
\hline Arévalo Martinez, Rafael & Las rosas de Engaddi & 2 & 06 \\
\hline Arguedas, Alcides & Pueblo enfermo & \begin{tabular}{|l|l|}
2,14 \\
\end{tabular} & 06 \\
\hline
\end{tabular}

${ }^{38}$ El criterio del recorte de los títulos para ser incorporados es el de que estén presentes en soporte impreso en más del 50\% de las bibliotecas. 
8.3. Tabla general de comparación de ofertas en digital en plataformas comerciales y servicios de lectura en streaming y descarga de los títulos y autores del corpus literario latínoamericano diseñado.

Amazon - Barnes \& Noble - Google Books iBookstore / iTunes - Kobo - Free-Ebooks - Casa del Libro - Gandhi - Librería Santa Fe - Livraria Cultura - Perúbookstore.com - Scribd - Nubico ${ }^{39}$

\begin{tabular}{|c|c|c|c|}
\hline Autor & Obra & Fuentes & (2) \\
\hline Altamirano, Ignacio Manuel & Clemencia & 2 & 11 \\
\hline Nervo, Amado & Los jardines interiores & 2,14 & \\
\hline Aguinis, Marcos & La gesta del marrano & 14 & 10 \\
\hline Alberdi, Juan Bautista & Bases y puntos de partida para la organización política. & 2,14 & 10 \\
\hline Benedetti, Mario & La tregua & 2,14 & 10 \\
\hline Borges, Jorge Luis & El Aleph & $1,2,3,14$ & 10 \\
\hline Darío, Rubén & Prosas profanas & 2,3 & 10 \\
\hline Lillo, Baldomero & Sub Terra & 2,14 & 10 \\
\hline Lugones, Leopoldo & Cuentos fatales & 2,14 & 10 \\
\hline Mármol, José & Amalia & & 10 \\
\hline Nervo, Amado & Misticas & $\frac{2}{2}$ & 10 \\
\hline Palma, Ricardo & Tristlicis & $\frac{2}{2}$ & $\frac{10}{10}$ \\
\hline $\begin{array}{l}\text { Palma, Kicarao } \\
\text { Quiroga, Horacio }\end{array}$ & Iraentons de amor, de locura y de muerte & $\frac{2}{2}$ & $\frac{10}{10}$ \\
\hline Rodó, José Enrique & Ariel & 2,14 & $\frac{10}{10}$ \\
\hline Villaverde, Cirilo & Cecilia Valdés & 2,14 & $\frac{10}{10}$ \\
\hline Acevedo Díaz, Eduardo & Brenda & 14 & 09 \\
\hline Aguinis, Marcos & $\begin{array}{l}\text { Lielind invertida } \\
\text { La cruz }\end{array}$ & $\frac{14}{14}$ & 09 \\
\hline Alberdi, Juan Bautista & El crimen de la guerra & 2,14 & 09 \\
\hline Allende, Isabel & La casa de los espíritus & 3 & 09 \\
\hline Asturias, Miguel Angel & El señor Presidente & 2,14 & 09 \\
\hline Barros Arana, Diego & Historia general de Chile & 2,14 & 09 \\
\hline Blest Gana, Alberto & Martín Rivas & 14 & 09 \\
\hline Borges, Jorge Luis & El Hacedor & $1,2,14$ & 09 \\
\hline$\frac{\text { Borges, Jorge Luis }}{\text { Borges, Jorge Luis }}$ & $\begin{array}{l}\text { Ll Hacedor } \\
\text { Ficciones }\end{array}$ & $\frac{1,2,14}{1,2,3,14}$ & 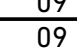 \\
\hline Borges, Jorge Luis & Historia universal de la infamia & $\frac{2,2,3,1,14}{2,3,14}$ & 09 \\
\hline Cieza de León, Pedro & Crónica del Perú & $\frac{2,0,14}{2}$ & 09 \\
\hline Cortázar, Julio & Final del juego & $\frac{4}{2}$ & 09 \\
\hline Cortázar, Julio & Historias de cronopios y de famas & 2,14 & 09 \\
\hline Cortázar, Julio & Los premios & 2,14 & 09 \\
\hline Cortázar, Julio & Rayuela & $1,2,3,14$ & 09 \\
\hline Cruz, Sor Juana Inés de la & Obras & 2 & 09 \\
\hline Darío, Rubén & Canto errante & $\frac{2}{2}$ & 09 \\
\hline Darío, Rubén & Cantos de vida y de esperanza & $2,3,14$ & 09 \\
\hline $\begin{array}{l}\text { Dario, Ruen } \\
\text { Darío, Rubén }\end{array}$ & $\begin{array}{l}\text { Tamos de viod y de esperanzad } \\
\text { Tierras solar }\end{array}$ & $\frac{2,3,14}{2,14}$ & $\frac{09}{09}$ \\
\hline $\begin{array}{l}\text { Larlio, Kuben } \\
\text { Edwards, Jorge }\end{array}$ & $\frac{\text { Tlerras solares }}{\text { Persona non grata }}$ & $\frac{2,14}{2,14}$ & $\frac{09}{09}$ \\
\hline Fuentes, Carlos & Aura & $\frac{21}{2}$ & 09 \\
\hline García Márquez, Gabriel & Cien años de soledad & $\begin{array}{l}2,2,3,14 \\
\end{array}$ & 09 \\
\hline García Márquez, Gabriel & La hojarasca & 2,14 & 09 \\
\hline García Márquez, Gabriel & La Mala Hora & 2,14 & 09 \\
\hline García Márquez, Gabriel & Relato de un náufrago & $\frac{2,14}{2,14}$ & 09 \\
\hline Garcilaso de la Vega & Comentarios reales & 2 & 09 \\
\hline Gómez de Avellaneda, Gertrudis & Espatolino & & 09 \\
\hline Ingenieros, José & El hombre mediocre & 2,14 & 09 \\
\hline Las Casas, Bartolomé de & Historia de las Indias & $\frac{21}{2}$ & 09 \\
\hline Lillo, Baldomero & Sub sole & $\frac{2}{2}$ & 09 \\
\hline $\begin{array}{l}\text { Lillo, Babaomero } \\
\text { López de Gómara, Francisco }\end{array}$ & $\begin{array}{l}\text { Hub sole } \\
\text { Historia general de las Indias }\end{array}$ & $\frac{2}{2}$ & 09 \\
\hline Lugones, Leopoldo & Las fuerzas extrañas & 2,14 & 09 \\
\hline Montenegro, Carlos & Hombres sin mujer & 2,13 & 09 \\
\hline Neruda, Pablo & Canto general & $1,2,14$ & 09 \\
\hline Neruda, Pablo & Cien sonetos de amor & & 09 \\
\hline$\frac{\text { Neruda, rablo }}{\text { Palma, Ricardo }}$ & $\begin{array}{l}\text { Len sonetos se amoro } \\
\text { Tradiciones peruanas }\end{array}$ & 2,14 & 09 \\
\hline
\end{tabular}


8.4. Tabla general de comparación de ofertas

en digital en bibliotecas globales de los títulos

y autores del corpus literario latinoamericano

diseñado

Columbia University Libraries - Biblioteca del

Instituto Latinoamericano de Berlín - Biblioteca

Nacional de España - Public Library New York

- Gallica (Biblioteca Nacional de Francia) -

Europeana (Biblioteca digital de la Unión Europea)

- Biblioteca Nacional de Perú - Biblioteca de São

Paulo ${ }^{40}$

\begin{tabular}{|c|c|c|c|}
\hline Autor & Obra & Fuentes & (-) \\
\hline Cieza de León, Pedro & Crónica del Perú & 2 & 05 \\
\hline Ercilla y Zúñiga, Alonso de & La araucana & 2 & 05 \\
\hline Agustini, Delmira & Los cálices vacíos & 2 & 04 \\
\hline Alberdi, Juan Bautista & El crimen de la guerra & 2,14 & 04 \\
\hline Alberdi, Juan Bautista & $\begin{array}{l}\text { Peregrinación de luz del día, o Viaje y aventuras } \\
\text { de la verdad en el Nuevo Mundo }\end{array}$ & 2 & 04 \\
\hline Altamirano, Ignacio Manuel & El Zarco & 2,14 & 04 \\
\hline Ascasubi, Hilario & Santos Vega & 2 & 04 \\
\hline Bobadilla, Emilio & A fuego lento & 2 & 04 \\
\hline Bobadilla, Emilio & Sintiéndome vivir & 2 & 04 \\
\hline Cambaceres, Eugenio & En la sangre & 2,14 & 04 \\
\hline Cambaceres, Eugenio & Música sentimental & 2,14 & 04 \\
\hline Cané, Miguel & Juvenilia & 2,14 & 04 \\
\hline Carpio, Manuel & Poesías & 7 & 04 \\
\hline Carriego, Evaristo & Misas herejes & 2,14 & 04 \\
\hline Cervantes de Salazar, Francisco & Crónica de Nueva España & 2 & 04 \\
\hline Cortés, Hernán & Cartas de relación & 2 & 04 \\
\hline Díaz del Castillo, Bernal & Historia verdadera de la conquista de la Nueva España & 2 & 04 \\
\hline Mármol, José & Amalia & 2 & 04 \\
\hline
\end{tabular}

